\title{
Climate-smart livestock production at landscape level in Kenya
}




\section{Thesis committee}

\section{Promotor}

Prof. Dr M. Herold

Professor of Geo-information Science and Remote Sensing

Wageningen University \& Research

\section{Co-promotors}

Prof. Dr M.C. Rufino

Professor of Agricultural Systems

Lancaster University, UK

Prof. Dr J.P. Verbesselt

Associate professor, Laboratory of Geo-information Science and Remote Sensing Wageningen University \& Research

\section{Other members}

Prof. Dr K.E. Giller, Wageningen University \& Research

Prof. Dr P.J. Gerber, Wageningen University \& Research

Dr L. Verchot, International Center for Tropical Agriculture (CIAT)

Prof. Dr A.F. Bouwman, Utrecht University

This research was conducted under the auspices of the C.T. de Wit Graduate School of Production Ecology \& Resource Conservation (PE\&RC) 


\title{
Climate-smart livestock production at landscape level in Kenya
}

\author{
Patric Brandt
}

Thesis

submitted in fulfilment of the requirements for the degree of doctor at Wageningen University by the authority of the Rector Magnificus

Prof. Dr A.P.J. Mol, in the presence of the Thesis Committee appointed by the Academic Board to be defended in public on Friday 30 November 2018 at 11 a.m. in the Aula. 
Patric Brandt

Climate-smart livestock production at landscape level in Kenya, 198 pages.

PhD thesis, Wageningen University, Wageningen, the Netherlands (2018) With references, with summaries in English and German

ISBN: 978-94-6343-525-3

DOI: $10.18174 / 462407$ 


\section{Summary}

Greenhouse gas (GHG) emissions from unsustainable land-use practices around the world contribute significantly to anthropogenic climate change. Growing population pressure and low efficiency of agricultural production systems in Sub-Saharan Africa (SSA) trigger the expansion of agricultural land into natural ecosystems, which leads to deforestation and land degradation, and causes GHG emissions. At the same time, prolonged droughts and increasingly erratic weather patterns due to climate change jeopardise food security in SSA countries such as Kenya.

The concept of 'Climate-Smart Agriculture' (CSA) as a global development goal was introduced to guide the transformation of agricultural systems towards sustainable food production systems by integrating measures of climate change adaptation, mitigation and food security. To achieve this goal in SSA, the largely smallholder-driven food production has to be intensified on existing agricultural land. The sustainable intensification of smallholder production systems is crucial to avoid compromising environmental goals such as safeguarding the carbon (C) sink capacity of forest ecosystems.

Kenya's agricultural sector is the largest contributor of the country's total GHG emissions, while $90 \%$ of the agricultural emissions stem from livestock production alone. To curb the increase of GHG emissions, Kenya as a member state of the UN Framework Convention on Climate Change (UNFCCC) has been developing national and sectoral policies that aim to mitigate GHG emissions from agriculture, while increasing agricultural productivity. As part of its ambitious economic development plan, Kenya seeks to boost its dairy sector in order to meet the increasing demand for milk, which results from the fast growing population.

Prior to the implementation of interventions that aim to realise CSA policy objectives, candidate interventions (e.g. climate-smart livestock feeds) have to be evaluated, prioritised and targeted. Decisions must be made by policy makers and planning institutions about the specific practices that are targeted at certain locations. To do so, quantitative information is required that shows whether the interventions at hand can realise 'win-win' potentials for smallholder farmers and climate change mitigation. However, the necessary approaches to obtain this information are often missing. The objectives of this $\mathrm{PhD}$ thesis are i) to improve the support of decision-making processes that aim to prioritise and target 
CSA practices robustly at national scale and ii) to elucidate the potential of intensified smallholder dairy production in Kenya to increase milk yields and to reduce direct and indirect GHG emissions effectively through feed improvements.

Chapter 2 - CSA-targeting and decision-making: "targetCSA", a spatially-explicit framework to target CSA practices was developed and applied in Kenya. The framework strengthens evidence-based decision-making by integrating i) knowledge and opinions on the prioritisation of CSA practices obtained from cross-sectoral stakeholders and ii) spatially-explicit data on climate change vulnerability and CSA suitability. Vulnerability and suitability indices were calculated and weighed by the various preferences of involved stakeholder groups. A multi-criteria optimisation model was used to find consensual preferences, which were then mapped to explore the potential effects of various decision-making outcomes based on group-specific preferences and the approached consensus among stakeholder groups. The integration of quantitative information and stakeholder views to explore and find consensus solutions enables more informed and transparent decisions on targeting CSA interventions.

Chapter 3 - Dairy feed improvements and land availability: The improvement of dairy cattle feeds can lead to synergies between increased farm production and climate change mitigation. However, land-use change (LUC) resulting from the cultivation of improved feeds and the shortage of arable land required to grow the additional feed alternatives can result in GHG emissions that outbalance mitigation or render the implementation of certain feed alternatives unfeasible. By applying a spatially-explicit livestock model, 'win-win' potentials to increase milk yields and to mitigate agricultural GHG emissions, including emissions from LUC, for the entire dairy production region in Kenya were assessed. Moreover, potential productivity gains and GHG emission reduction potentials were linked to related quantitative targets at national scale. The results indicate that Kenya's dairy sector can reduce GHG emission intensities by up to $31 \%$ through feed improvements that increase the forage quality through Napier grass and increase the supplementation of dairy concentrate. In addition, these feed improvements are promising options to meet Kenya's national climate change mitigation target, while the milk yield target could be achieved partially by up to $41 \%$. In contrast, LUC emissions from feed conservation based on maize increase the risk to compromise Kenya's mitigation target at national level. The shortage of land that would be required to cultivate additional fodder maize renders the implementation of related feed improvement options largely unfeasible.

Chapter 4 - Sustainable intensification and forest disturbance: Negative spillover effects such as $\mathrm{C}$ leakage may result from fragmented mitigation approaches that fail to link agricultural and forest land uses. Assessing the impact of agricultural production beyond farm boundaries is therefore crucial to target CSA practices that result in effective mitigation outcomes. The effects of farm practices and characteristics such as cattle management 
and fuelwood consumption on forest disturbance were quantified based on empirical farm data and a forest change detection algorithm using Landsat time-series data. The results show that the intensification of smallholder dairy farming in Kenya can alleviate the pressure on local forests. Improved dairy cattle and feeds, and more trees on farms located closely to forests lower the need to use these forests for cattle grazing and as source for fuelwood, reducing the risk of forest disturbance.

Chapter 5 - Mitigating emissions from agriculture and forests: The combined agricultural and forest mitigation potentials of on-farm CSA practices such as the improvement of dairy feeds, including closing the yield gaps of fodder maize was quantified for the entire dairy production region in Kenya. Forest $\mathrm{C}$ loss due to dairy cattle was quantified by using remote-sensing time-series data on aboveground $\mathrm{C}$ change. The results indicate that GHG emission intensities on agricultural land can be reduced by up to $20 \%$ through closing the maize yield gap. The effect of reduced GHG emissions from avoided LUC was up to five times higher than the increase of GHG emissions from fertiliser application required to close the yield gap. The lowered demand for arable land to cultivate alternative dairy feeds close to forests could reduce forest $\mathrm{C}$ loss due to avoided grazing of dairy cattle inside forests by up to $94 \%$. However, improved forage quality through Napier grass and the increased supplementation of dairy concentrates showed i) the highest potential to reduce emission intensity (29\%), ii) the lowest demand for arable land and iii) the highest reduction of forest C loss $(270 \%)$. These feed improvements could reduce combined total GHG emissions by $2.5 \%$ and, therefore, lead to a net mitigation of direct and indirect GHG emissions from dairy production. Dairy feed improvements may turn mountain forests in Kenya into $\mathrm{C}$ sinks.

Overall, the results of this $\mathrm{PhD}$ thesis show that context-specific and detailed ex-ante impact assessments are essential to inform integrated CSA policies that target effective climate change mitigation across land use sectors and agricultural development. This thesis provides novel approaches and information that contribute to the evidence-based prioritisation and targeting of CSA interventions. These approaches allowed to study interactions between the agricultural and forestry sectors based on empirical data and enabled to identify and quantify synergies and trade-offs that were not known before. 



\section{Zusammenfassung}

Treibhausgasemissionen (THG) aus nicht nachhaltigen Landnutzungspraktiken tragen weltweit erheblich zum anthropogenen Klimawandel bei. Wachsender Bevölkerungsdruck und geringe Effizienz landwirtschaftlicher Produktionssysteme in SubsaharaAfrika (SSA) bewirken die Ausdehnung landwirtschaftlicher Flächen hinein in natürliche Ökosysteme. Derartige Expansionsprozesse führen zu Entwaldung und Landdegradation und verursachen THG-Emissionen. Gleichzeitig gefährden die aufgrund des Klimawandels zunehmenden Dürreperioden und unberechenbarer werdende Wetterlagen die Ernährungssicherheit in SSA-Ländern wie Kenia.

Das Konzept der „Climate-Smart Agriculture” (CSA, klima-intelligente Landwirtschaft) wurde als globales Entwicklungsziel eingeführt, um die Transformation landwirtschaftlicher Produktionssysteme hin zu einer nachhaltigen Nahrungsmittelproduktion durch die Integration von Maßnahmen zur Anpassung an den Klimawandel, zur Eindämmung des Klimawandels und zur Ernährungssicherheit zu steuern. Um diese Ziele in SSA zu erreichen, muss die weitgehend kleinbäuerliche Nahrungsmittelproduktion auf bereits bestehenden landwirtschaftlichen Flächen intensiviert werden. Die nachhaltige Intensivierung von kleinbäuerlichen Produktionssystemen ist von entscheidender Bedeutung, um Umweltziele wie die Sicherung der Kohlenstoff-Senkenfunktion von Waldökosystemen nicht zu gefährden.

Kenias Landwirtschaftssektor hat den größten Anteil an den THG-Emissionen des Landes. Allein $90 \%$ der landwirtschaftlichen Emissionen stammen aus der Tierproduktion. Um den Anstieg der Treibhausgasemissionen einzudämmen, hat Kenia als Mitgliedsstaat der UN-Klimarahmenkonvention (UNFCCC) nationale und sektorale Strategien und Richtlinien entwickelt, die darauf abzielen, die THG-Emissionen aus der Landwirtschaft zu verringern und gleichzeitig die landwirtschaftliche Produktivität zu steigern. Im Rahmen des ambitionierten Plans zur ökonomischen Entwicklung des Landes will Kenia den Aufbau seines Milchsektors fördern, um der steigenden Nachfrage nach Milch, die sich aus der rasant wachsenden Bevölkerung ergibt, gerecht zu werden.

Vor der Implementierung von Interventionen, die darauf abzielen, die gesteckten CSAZiele zu erreichen, müssen potenzielle Optionen wie z. B. klimafreundliche Tierfuttermittel evaluiert, priorisiert und deren Umsetzung gezielt geplant werden. Politische Entschei- 
dungsträger und Planungsinstitutionen müssen Entscheidungen über den Einsatz bestimmter CSA-Praktiken und deren Auswirkungen an den Orten ihrer Umsetzung treffen. Dazu sind quantitative Informationen erforderlich, die zeigen, ob die zur Verfügung stehenden Interventionen „win-win”-Potenziale für Kleinbauern und den Klimaschutz realisieren können. Die notwendigen Ansätze, um diese Informationen zu erhalten, fehlen jedoch oft. Die Ziele dieser Dissertation sind i) die Verbesserung der Unterstützung von Entscheidungsfindungsprozessen, die darauf abzielen, CSA-Praktiken auf nationaler Ebene zu priorisieren sowie deren Umsetzung zu planen, und ii) das Potenzial einer nachhaltig intensivierten, kleinbäuerlichen Milchproduktion in Kenia aufzuzeigen, die Milchleistung zu steigern sowie direkte und indirekte THG-Emissionen durch Futterverbesserungen effektiv zu reduzieren.

Kapitel 2 - CSA-Priorisierung und Entscheidungsfindung: „targetCSA”, ein räumlichexplizites Konzept zur multi-kriteriellen Unterstützung von Entscheidungsprozessen für die Planung von CSA-Praktiken wurde entwickelt und in Kenia angewendet. Das Konzept stärkt evidenzbasierte Entscheidungsfindung durch die Integration von i) Wissen und Präferenzen der einbezogenen, sektorübergreifenden Interessengruppen im Hinblick auf die Priorisierung von CSA-Praktiken und ii) durch die Einbindung räumlich-expliziter Daten zur Anfälligkeit für den Klimawandel und der CSA-Eignung. Anfälligkeits- und Eignungsindizes wurden mit Hilfe der verschiedenen Präferenzen der involvierten Interessengruppen berechnet und gewichtet. Ein multi-kriterielles Optimierungsmodell wurde verwendet, um konsensuale Präferenzen zu finden, die dann kartiert wurden, um die möglichen Auswirkungen verschiedener Entscheidungsergebnisse auf der Grundlage von gruppenspezifischen Präferenzen und dem angenährten Konsens zwischen Interessengruppen zu untersuchen. Die Integration von sowohl quantitativen Informationen als auch qualitativer Informationen bezüglich der Ansichten von Interessengruppen, unterstützt die Suche nach Konsenslösungen und ermöglicht informierte und transparentere Entscheidungen im Hinblick auf die Planung von CSA-Interventionen.

Kapitel 3 - Verbessertes Futter für Milchvieh und Flächenverfügbarkeit: Die Verbesserung von Milchviehfutter kann zu Synergien zwischen der Steigerung landwirtschaftlicher Produktion und der Reduktion von Treibhausgasemissionen führen. Landnutzungsänderungen, die sich aus dem Anbau verbesserter Futtermittel ergeben, und der Mangel an Ackerland, das für den Anbau der zusätzlichen Futteralternativen erforderlich ist, können jedoch Treibhausgasemissionen zur Folge haben, die letztlich zu einer Nettoerhöhung der Treibhausgasemissionen führen oder die Potentiale zur Umsetzung bestimmter Futteralternativen gravierend einschränken. Durch die Anwendung eines räumlich-expliziten Simulationsmodells wurden ,win-win”-Potenziale zur Steigerung der Milchleistung und zur Minderung der landwirtschaftlichen THG-Emissionen, einschließlich der Emissionen von Landnutzungsänderungen, für die gesamte Milchproduktionsregion in Kenia berechnet. Darüber hinaus wurden potenzielle Produktivitätszuwächse und Minderungen der Treibhausgasemissionen mit entsprechenden quantitativen Zielen auf nationaler Ebene 
verknüpft. Die Ergebnisse zeigen, dass Kenias Milchsektor die Intensität der Treibhausgasemissionen um bis zu 31 \% reduzieren kann, indem die Futterqualität durch Napiergras erhöht und das Viehfutter mit Konzentraten ergänzt wird. Darüber hinaus sind diese Futterverbesserungen vielversprechende Optionen die dazu beitragen können, Kenias nationales Klimaschutzziel zu erreichen, während das Milchertragsziel um bis zu $41 \%$ erreicht werden kann. Im Gegensatz dazu erhöhen Emissionen als Folge von Landnutzungsänderungen, die nötig wären um den zusätzlichen Mais zur Futterkonservierung anzubauen das Risiko, Kenias Klimaziel auf nationaler Ebene zu gefährden. Der Mangel landwirtschaftlicher Flächen, die für den Anbau von zusätzlichem Futtermais benötigt würden, reduziert ferner die Machbarkeit der Umsetzung entsprechender Futterverbesserungsoptionen drastisch.

Kapitel 4 - Nachhaltige Intensivierung und Degradation von Wäldern: Negative Übertragungseffekte wie die bloße geografische Verdrängung, anstatt der effektiven Minderung, von THG-Emissionen können durch fragmentierte Maßnahmen politischer Steuerung entstehen, die die Verknüpfungen zwischen der Nutzung von Landwirtschafts- und Waldflächen nicht berücksichtigen. Die Analyse der Auswirkungen landwirtschaftlicher Produktion über die Grenzen kleinbäuerlicher Höfe hinaus ist daher von entscheidender Bedeutung für die Planung und Umsetzung von CSA-Praktiken, die zu wirksamen THG-Reduktionseffekten führen sollen. Die Auswirkungen der landwirtschaftlichen Praktiken und Charakteristiken im Hinblick auf Viehwirtschaft und Brennholznutzung auf die Degradation von Wäldern wurden auf der Grundlage von empirischen Befragungen und eines Algorithmus zur Erkennung von Waldveränderungen unter Verwendung von Landsat-Zeitreihendaten quantifiziert. Die Ergebnisse zeigen, dass die Intensivierung der kleinbäuerlichen Milchviehhaltung in Kenia den Druck auf die örtlichen Wälder verringern kann. Produktivere Milchkühe und verbessertes Futtermittel sowie mehr Bäume auf Höfen in der Nähe von Wäldern verringern die Notwendigkeit, diese Wälder als Weidegrund und als Brennholzquelle zu nutzen, wodurch das Risiko von Waldschäden verringert wird.

Kapitel 5 - Minderung von Emissionen aus Landwirtschaft und Wäldern: Die kombinierten Potenziale von CSA-Praktiken, wie der Verbesserung von Milchviehfutter, einschließlich der Erhöhung von Futtermaiserträgen, THG-Emissionen aus Landwirtschaft und Wäldern zu reduzieren wurden für die gesamte Milchproduktionsregion in Kenia quantifiziert. Der Verlust von Kohlenstoff aus Wäldern durch Beweidung von Milchvieh wurde mit Hilfe von Zeitreihendaten über die von Satelliten beobachtete Veränderung oberirdischer Biomasse in Wäldern ermittelt. Die Ergebnisse zeigen auf, dass die Intensität von THG-Emissionen auf landwirtschaftlichen Flächen durch Schließung der Ertragslücken für Mais um bis zu $20 \%$ reduziert werden kann. Der Effekt reduzierter THG-Emissionen durch vermiedene Landnutzungsänderungen ist bis zu fünf Mal höher als der Anstieg von THG-Emissionen durch den erhöhten Eintrag von Düngemitteln, der erforderlich wäre um die Ertragslücken zu schließen. Der dadurch sinkende Bedarf an Ackerland für den Anbau von alternativen Milchviehfutter auf landwirtschaftlichen 
Flächen in der Nähe von Wäldern könnte den Verlust von Kohlenstoff aus Wäldern um bis zu 94 \% reduzieren, da die Notwendigkeit Wälder als Weidegrund zu nutzen verringert wird. Eine verbesserte Futterqualität durch Napiergras und die Ergänzung des Futters mit Konzentraten zeigten jedoch i) das höchste Potenzial zur Verringerung der Emissionsintensität (29\%), ii) den niedrigsten Bedarf an Ackerland und iii) damit die größte Verringerung des Kohlenstoffverlusts aus Wäldern (270 \%). Verbessertes Milchviehfutter basierend auf den letztgenannten Optionen könnte die Gesamtemissionen von Treibhausgasen um 2,5\% verringern und somit zu einer Nettoverminderung direkter und indirekter THG-Emissionen aus der Milchproduktion führen. Klima-intelligente Milchviehhaltung kann somit die kenianischen Bergwälder in Kohlenstoffsenken verwandeln.

Insgesamt zeigen die Ergebnisse dieser Dissertation, dass kontextspezifische und detaillierte ex-ante Folgeabschätzungen wesentlich sind, um integrierte CSA-Maßnahmen zu planen, die auf eine wirksame Reduktion von THG-Emissionen aus Landnutzungssektoren und der landwirtschaftlichen Entwicklung abzielen. Diese Arbeit liefert neue Ansätze und Informationen, die zur evidenzbasierten Priorisierung und Planung von CSA-Interventionen beitragen. Diese Ansätze erlaubten es, Interaktionen zwischen Landwirtschaft und Wäldern basierend auf empirischen Daten zu untersuchen und Synergien sowie Zielkonflikte, die bisher nicht bekannt waren, zu identifizieren und zu quantifizieren. 


\section{Contents}

Page

Summary $\quad$ v

Zusammenfassung $\quad$ ix

Contents $\quad$ xiii

$\begin{array}{lll}\text { Chapter } 1 & \text { Introduction } & 1\end{array}$

Chapter 2 How to target climate-smart agriculture? Concept and application of the consensus-driven decision support framework "targetCSA" 11

Chapter 3 The contribution of sectoral climate change mitigation options to national targets: a quantitative assessment of dairy production in Kenya

Chapter 4 Sustainable intensification of dairy production can reduce forest disturbance in Kenyan montane forests

Chapter 5 Intensification of dairy feeds increases GHG mitigation potential across the land use sectors of agriculture and forestry in Kenya $\quad 93$

Chapter 6 Synthesis

References

Appendices

Acknowledgements

About the author

PE\&RC Training and Education Statement 

Chapter 1

\section{Introduction}




\subsection{Background}

Negative impacts of climate change on food production are observed already and will become more evident in the near future, especially in regions that are vulnerable to climate shocks such as droughts and floods (Niles \& Salerno, 2018). In the tropics, these extreme weather events are shown to detrimentally affect crop yields and to increase livestock mortality and are expected to cause large-scale failures of food production systems, including rapid increases of food prices with more frequent and widespread occurrences (IPCC, 2014). Consequently, climate change affects food security, which is defined as the sufficient access to healthy and nutritious food supplied through domestic production or imports (Wheeler \& von Braun, 2013). One of the most food insecure continents is Africa, where currently about 1.3 billion people live. Africa's population is projected to increase up to 2.5 billion by 2050 (UN, 2017b). The fast growing population will further rise the continent's demand for food, which is produced predominantly by smallholder farmers (van Ittersum et al., 2016).

The global sustainable development is targeted by the United Nations (UN). With 'Sustainable Development Goal 2' (SDG 2), the UN seeks to "end hunger, achieve food security and improved nutrition, and promote sustainable agriculture" (UN, 2017a, p. 4). Particularly in Sub-Saharan Africa (SSA), where about $30 \%$ of the undernourished people worldwide live (FAO et al., 2017), research and development efforts must be strengthened to achieve this goal. Many SSA countries are lacking food self-sufficiency, which is defined as the ratio between domestic food production and consumption (van Ittersum et al., 2016). The shortage of food produced domestically makes these countries dependent on food imports and renders them highly vulnerable to climate change, particularly given the expected, drastic population increases. Growing population pressure and low efficiency of agricultural production systems in SSA trigger the conversion of natural ecosystems into agricultural land, which leads to deforestation and land degradation, and causes greenhouse gas (GHG) emissions (Fisher, 2010; Hosonuma et al., 2012), thus, contributing to further climate change.

In Kenya, East Africa, the expansion of mostly smallholder-driven agriculture has dwindled the original extent of Afromontane forests to fragmented patches of isolated mountain forests that suffer from anthropogenic disturbance due to high intensity of forest use (Government of Kenya, 2009b; Kinyanjui, 2011). These remaining forest systems, called 'water towers', however, offer valuable ecosystem services such as the supply of water, the sequestration of carbon (C), and erosion control (Jacobs et al., 2017). The forest cover in Kenya amounts to about $7 \%$, while land allocated to largely rain-fed agriculture accounts for about $49 \%$ of the country's land surface (Government of Kenya, 2015b). Nutrientdepleted agricultural soils, stagnating and even declining crop yields, scarcity of arable land and decreasing farm sizes represent significant constraints of the Kenyan food pro- 
duction systems that have to feed a growing population (Tittonell et al., 2009; Vanlauwe et al., 2014; Zhou et al., 2014; van Ittersum et al., 2016). At the same time, Kenya faces increasingly prolonged drought spells and a higher frequency of erratic weather patterns, which have led to crop harvest failures and livestock loss (Molua et al., 2010; Gachathi \& Eriksen, 2011).

Kenya has recently committed to the UN Framework Convention on Climate Change (UNFCCC) to combat climate change (Government of Kenya, 2015a). All member states of the framework agreed to limit the impact of climate change by halting the ongoing global temperature rise by the end of this century, known as the '2 degrees Celsius target of the Paris agreement' (UN, 2015). To curb the global temperature increase below two degrees Celsius above pre-industrial levels, Kenya as a UNFCCC member state must contribute by developing and putting in place policies and planning schemes that mitigate GHG emissions throughout economic sectors.

\subsection{Agricultural and forestry land use sectors: the livestock focus}

GHG emissions from 'Agriculture, Forestry and Other Land Uses' (AFOLU) account

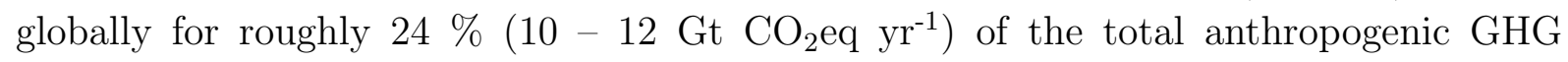
emissions (IPCC, 2014). GHG emissions from agriculture, including related land use changes (LUC) and forestry have with $5.0-5.8 \mathrm{Gt} \mathrm{CO}_{2} \mathrm{eq} \mathrm{yr}^{-1}$ and $4.3-5.5{\mathrm{Gt} \mathrm{CO}_{2} \mathrm{eq}}$ $\mathrm{yr}^{-1}$ respectively the largest shares of GHG emissions from the AFOLU sector (IPCC, 2014). GHG emissions from global livestock production represent the dominant part of agricultural emissions. Livestock emissions are responsible for about $10-14.5 \%$ of all human-induced GHG emissions (Westhoek et al., 2011; Gerber et al., 2013). Large ruminants such as cattle used in the beef and milk production sectors contribute $66 \%$ to the total livestock emissions (Gerber et al., 2013). Beef is responsible for $2.9 \mathrm{Gt} \mathrm{CO}_{2} \mathrm{eq}$ $\mathrm{yr}^{-1}$ while the production of milk from cattle emits $1.4 \mathrm{Gt} \mathrm{CO}_{2} \mathrm{eq} \mathrm{yr}^{-1}$. Disaggregating livestock-related emissions into sources shows that methane $\left(\mathrm{CH}_{4}\right)$ emissions from enteric fermentation and nitrous oxide $\left(\mathrm{N}_{2} \mathrm{O}\right)$, carbon dioxide $\left(\mathrm{CO}_{2}\right)$, and $\mathrm{CH}_{4}$ emissions from feed production and processing account for about $39 \%$ and $45 \%$ respectively, which are by far the largest proportions of the total livestock emissions (Gerber et al., 2013). The intensity of emissions, i.e. the rate of emission per unit output (e.g. $\mathrm{kg}$ milk or protein produced), varies across regions. The highest emission intensity of milk production is shown for SSA where on average $9.0 \mathrm{~kg} \mathrm{CO} \mathrm{CO}_{2} \mathrm{eq}$ fat and protein corrected milk $(\mathrm{FPCM})^{-1}$ are emitted, compared to less than $1.7 \mathrm{~kg} \mathrm{CO}_{2} \mathrm{eq} \mathrm{kg} \mathrm{FPCM}^{-1}$ from intensified production systems in North America and Europe (Gerber et al., 2013). Such a high emission intensity indicates in general low efficiencies of dairy production in SSA, which 
is largely smallholder-driven.

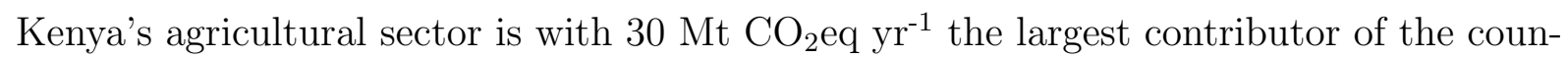
try's total GHG emissions, while $90 \%$ of the agricultural emissions stem from livestock production alone (Government of Kenya, 2015b). At the same time, agricultural production in Kenya is of paramount economic importance. The entire sector contributes directly and indirectly about $51 \%$ of the country's gross domestic product (GDP) and assures the livelihood of $80 \%$ of the rural population (Government of Kenya, 2010). Livestock production contributes $12 \%$ to the GDP in Kenya. Dairy production accounts for about $4 \%$ of the GDP and represents the largest agricultural sub-sector (Government of Kenya, 2010). Milk is predominantly produced (roughly $70-80 \%$ ) by about two million smallholder farmers, which represent $35 \%$ of the rural population in Kenya (Udo et al., 2016; Government of Kenya, 2017b). Nevertheless, low feed quality and the fluctuating availability of cattle feeds, increasing herd sizes, and overgrazed and degraded pastures are determinants for the relatively low productivity of smallholder dairy farms and the high environmental burden of dairy production in Kenya (Bosire et al., 2016).

The global loss of forests contributes about $6-17 \%$ of the total anthropogenic GHG emissions (Baccini et al., 2012). Roughly $80 \%$ of the deforestation worldwide is caused by agricultural expansion. Smallholder agriculture is with about $40 \%$ the predominant reason for the loss of forests in SSA (Hosonuma et al., 2012). Forests are vital ecosystems, which offer a wide array of goods and services that people depend on (Foley et al., 2005). The unsustainable use of forests, however, leads to forest disturbance, which causes GHG emissions through the net removal of biomass or the suppression of vegetation regrowth. Timber harvest, fuelwood extraction and livestock grazing are named as common drivers of forest disturbance in SSA. In SSA countries that passed the peak of deforestation, such as Kenya, fuelwood extraction (58 \%), timber harvest (33\%) and livestock grazing inside forests $(8 \%)$ represent the most important drivers of forest disturbance (Hosonuma et al., 2012). The role of fuelwood extraction was assessed by several studies for SSA in general and for Kenya in particular (e.g. Bailis et al., 2015; Pearson et al., 2017). However, estimates of the extent and impact of the presence of domestic livestock in forests are missing yet. Remote-sensing data such as satellite imagery over longer time periods, obtained from the Landsat archive offer promising opportunities to study the effects of livestock management on forests. This knowledge is important to improve the understanding of the interactions between agricultural production and the state of forests. Moreover, the knowledge is needed to quantify the agricultural GHG emissions that result directly from farm operations and occur indirectly beyond the farm gates. 


\subsection{Climate-Smart Agriculture}

Feeding a growing population sufficiently while reducing the environmental footprint of food production requires the transformation of current agriculture towards sustainable food production systems. The umbrella concept of 'Climate-Smart Agriculture' (CSA) was brought forward to guide this transformation (FAO, 2013). CSA integrates the three pillars of food security, climate change adaptation and mitigation to ensure the availability of healthy food world-wide, produced from agricultural systems that are well adapted and resilient to the various effects of climate change while releasing the lowest levels of GHG emissions or even removing them, if possible (Lipper et al., 2014). To achieve this goal, especially in regions that are characterised by smallholder farming systems such as SSA, the efficiency of food production on existing agricultural land has to be increased. Higher yields per unit land must be attained through sustainable intensification (Smith et al., 2013). Closing the yield gap, i.e. the difference between the actual yield and the yield that can be potentially achieved for a certain crop or livestock product at a given location is shown to contribute to the intensification of smallholder farming without compromising environmental goals (Foley et al., 2011; Mueller et al., 2012). Yield gaps are estimated to be high across SSA, e.g. about $58 \%$ for maize (Hillocks, 2014). There is great potential to increase actual yields in SSA, for instance, though improved resource management such as the appropriate use of organic and synthetic fertilisers for crops and through improvements in the quality of livestock feeds to increase milk yields from dairy production (Lukuyu et al., 2012; van Ittersum et al., 2016).

The climate-smartness of agricultural production has to be studied beyond the level of single farms to assess whether interventions are likely to be effective in achieving CSA objectives. Farms as units of agricultural production are embedded in landscapes, which consist of different land use types such as cropland, pastures and natural ecosystems (e.g. forests) that interact with each other (Scherr et al., 2012). The way how farms are managed has implications for other parts of the landscape. Thus, the landscape level offers a suitable scale at which the effects of CSA practices on different parts of the landscape can be studied. Landscape approaches enable inter and transdisciplinary assessments that integrate several land use sectors and stakeholders to explore the potential impact of targeted CSA practices on the landscape, including synergies and trade-offs between CSA objectives and constraints that limit the feasibility of their implementation (Reed et al., 2016). Hence, direct and indirect emissions can be analysed to assess whether intensification is sustainable throughout the broader landscape. Focusing on synergies between CSA objectives such as the increase of agricultural productivity and the reduction of GHG emissions is important (i) to increase the likelihood that farmers adopt targeted CSA practices and (ii) to concentrate the financial investment on promising interventions that realise 'win-win' potentials for farmers and climate change mitigation (FAO, 2013). 


\subsection{Research gaps}

Following from the commitments to the UNFCCC, countries in SSA have to build capacity to achieve their national targets to reduce the impact of agricultural production on the climate system. Kenya targets to curb the increase of its total GHG emissions by $30 \%$ during the period of 2010 - 2030, as defined in the country's 'Nationally Determined Contribution' (NDC) (Government of Kenya, 2015a). Frameworks and approaches are required urgently, which aid the data-driven and evidence-based integration of climate change mitigation into policy instruments that promote the sustainable development of the agricultural sector and aim to ensure food security. Kenya has developed a national CSA strategy to guide and foster the implementation of measures that increase agricultural productivity sustainably, improve resilience of food production and minimise its GHG emissions by 2026 (Government of Kenya, 2017a). The strategy includes (i) the mitigation of GHG emissions from livestock production through improved feeds and manure management, (ii) the reduction of emissions from deforestation and forest disturbance, and (iii) the development of 'Measurement, Reporting and Verification Systems' (MRVs) to improve the reporting of mitigation actions (Government of Kenya, 2017a). Furthermore, policies that facilitate the development of Kenya's dairy sector are put in place such as the national dairy master plan, which targets the sustainable increase of productivity in the sector by 2030 to meet higher demands for dairy products due to the growing population (Government of Kenya, 2010). Kenya's dairy 'Nationally Appropriate Mitigation Action' (NAMA) seeks to develop a low-emission and climate resilient dairy sector by focusing on synergies between the mitigation of GHG emissions, the increase of milk yields and farmers' incomes (Government of Kenya, 2017b).

Prior to the implementation of interventions that aim to realise CSA-related policy objectives, candidate sets of CSA practices have to be evaluated, prioritised and targeted. Decisions must be made by policy makers and planning institutions about the specific practices that are targeted at certain locations. These decisions should be based on evidence and require, therefore, information that shows the urgency to intervene in specific areas due to their high vulnerability to climate change and the suitability of candidate practices at hand (Notenbaert et al., 2017). However, integrated frameworks that are able to couple spatially-explicit information on climate change vulnerability and CSA suitability with the heterogeneous stakeholder knowledge and opinions to support the decision-making on targeting CSA are missing.

Spatially-explicit information that indicates the 'win-win' potentials to increase the productivity of livestock production and to mitigate GHG emissions of specific CSA options such as feed improvements is missing. The knowledge on ex-ante impacts of candidate interventions is crucial to target CSA effectively. The scarcity of arable land in agricultural landscapes with high population density, such as in Central and Western Kenya 
(Vanlauwe et al., 2014), is often neglected in CSA assessments. In order to assess the feasibility of implementing candidate practices and to avoid negative spillovers such as $\mathrm{C}$ leakage, it is important to include information about constraints such as the availability of arable land into landscape-level approaches that are used to analyse livestock feed improvements. The leakage of $\mathrm{C}$ results from the unintended displacement of GHG emissions that may occur outside the geographical scope of mitigation interventions (Minang \& van Noordwijk, 2013). Approaches that are being developed and applied in this context have to integrate various data on livestock production such as feed intake, feed quality, yields of included feed types, and cattle breeds as well as emission-related parameters such as emission factors. Livestock and spatial modelling techniques need to be coupled to estimate baseline and scenario-related livestock productivity, GHG emission levels, and to upscale this information based on agro-ecological information and production systems.

The intensification of smallholder farming is shown to increase productivity, e.g. milk yields, while mitigating GHG emissions on farms by reducing emission intensities (Campbell et al., 2014; Descheemaeker et al., 2016). Knowledge on the quantitative effects of smallholder intensification on local forests is, however, missing. Answering questions such as to what extent can GHG emissions from forests be avoided due to sustainable intensification of livestock production is crucial to inform CSA policies about the effectiveness of candidate interventions across land use sectors prior to their implementation. In addition, this information is required to evaluate targeted CSA practices regarding their achievement of sectoral and national mitigation targets. Kenya does not have a specific legal framework of 'Reducing Emissions from Deforestation and Forest Degradation' $(\mathrm{REDD}+)$ yet. Quantitative information on the potential reduction of GHG emissions from forests due to the improved management on farms could contribute, therefore, to the design of policy instruments that integrate CSA and REDD+.

\subsection{Research objectives}

The main objectives of this thesis are i) to improve the support of decision-making processes that aim to prioritise and target CSA practices robustly at national scale and ii) to elucidate the potential of intensified smallholder dairy production in Kenya to increase milk yields and to reduce direct and indirect GHG emissions effectively through feed improvements. Based on these objectives, four research questions (RQ) are addressed:

A. How can 'multi-criteria decision-making' support national climate change adaptation and mitigation planning to target CSA practices?

B. Which climate change mitigation options in the Kenyan dairy sector contribute to climate mitigation and food production targets defined at national level?

C. How does the intensification of smallholder dairy farming affect forest disturbance? 
D. What is the potential of livestock intensification options to reduce GHG emissions from agriculture and forests?

\subsection{Thesis outline}

This thesis is structured into four chapters that address the RQs outlined in Section 1.5 (Figure 1.1) and finishes with a concluding synthesis chapter.

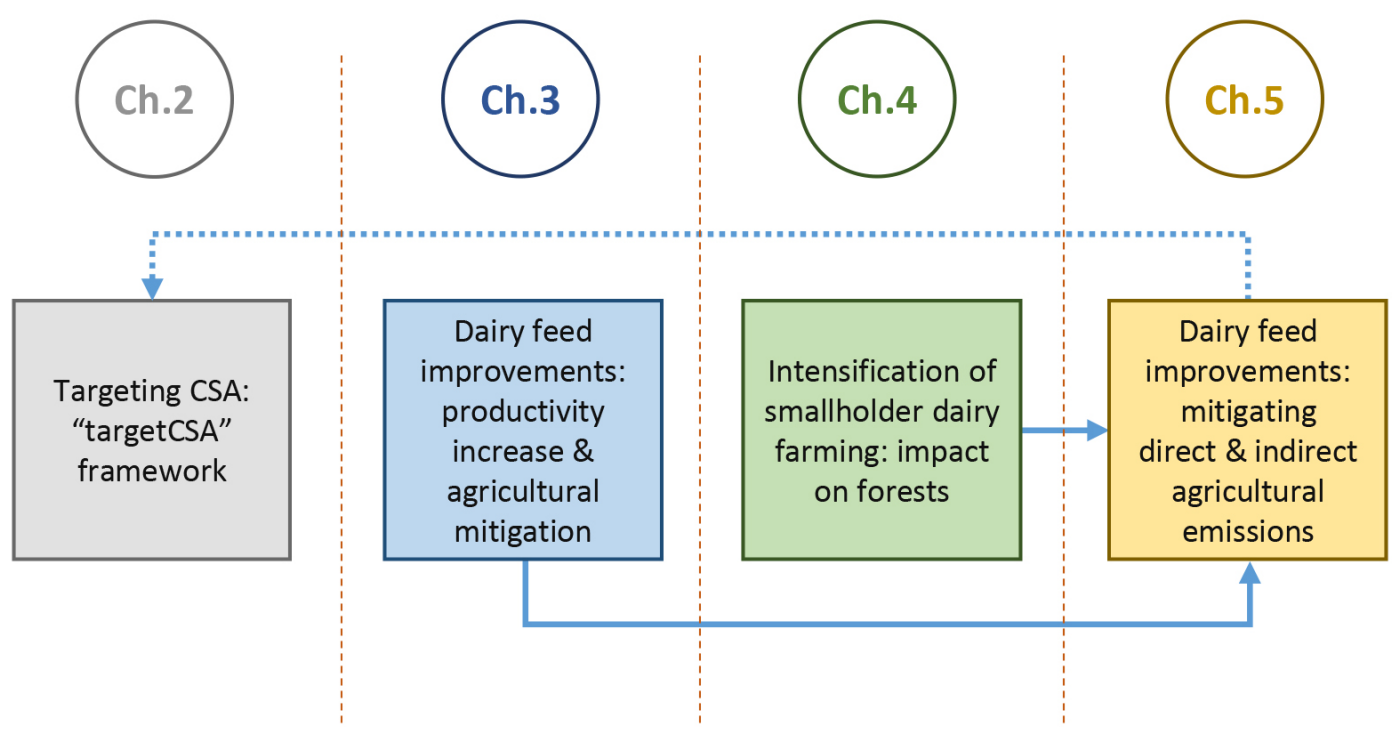

Figure 1.1: Overview of chapters that address the four research questions outlined in Section 1.5

Chapter 2 presents the decision-support framework "targetCSA", which was developed to aid the targeting of CSA practices (RQ A). The framework uses spatially-explicit data on climate change vulnerability and CSA suitability and integrates related stakeholder knowledge and opinions. An optimisation technique is applied to find the most consensual stakeholder preferences regarding the prioritisation of CSA practices. Stakeholder preferences, vulnerability and CSA suitability are coupled to derive an index of CSA potential, which is mapped to explore consensus-driven CSA targeting scenarios and the potential effects of differences in stakeholder opinions. The applicability of the framework is demonstrated in Kenya.

Chapter 3 assesses dairy feed improvements regarding their synergistic potentials to increase milk yields and to mitigate agricultural GHG emissions for the entire dairy production region in Kenya, including emissions from LUC (RQ B). Livestock and spatial 
modelling techniques are used to estimate and upscale productivity and GHG emissions. The demand for land and the availability of potentially arable land are analysed to evaluate the feasibility to implement the feed improvement scenarios. In addition, the scenarios are linked to national mitigation and productivity targets to assess to what extent these targets can be achieved.

Chapter 4 quantitatively relates farm indicators and farm types to forest disturbance across an agriculture-forest landscape located in the Kenyan highlands to analyse the effects of the intensification of smallholder farms on forest disturbance (RQ C). Farm information is obtained from empirical ground data. Forest disturbance data is derived by applying a novel forest change detection algorithm based on time-series data from satellite imagery.

Chapter 5 capitalises on the approaches and findings from Chapters 3 and 4 to assess the potential of dairy feed improvements to reduce direct and indirect GHG emissions from the agricultural land and from forests by avoiding the forest $\mathrm{C}$ loss that results from the presence of dairy cattle (RQ D). A subset of feed improvement scenarios from Chapter 3 is complemented by scenarios that increase the yields of maize used as silage to explore the effects on the demand for arable land of feed improvement scenarios that turned out to require most land in Chapter 3. Data on forest $\mathrm{C}$ change were derived from satellite-based time-series products.

Chapter 6 synthesises and highlights the main findings of this thesis and reflects on the relevance and implications for the CSA policy arena. In addition, an outlook is given outlining further research. The chapter concludes by giving key recommendations inferred from this thesis to policy-makers. 



\section{Chapter 2}

\section{How to target climate-smart agriculture? Concept and application of the consensus-driven decision support framework "targetCSA"}

Brandt, P., Kvakić, M., Butterbach-Bahl, K., Rufino, M.C., 2017. How to target climate-smart agriculture? Concept and application of the consensus-driven decision support framework "targetCSA." Agricultural Systems 151, 234-245. 


\section{Abstract}

Planning for agricultural adaptation and mitigation has to lean on informed decisionmaking processes. Stakeholder involvement, consensus building and the integration of comprehensive and reliable information represent crucial, yet challenging, pillars for successful outcomes. The spatially-explicit multi-criteria decision support framework "targetCSA" presented here aims to aid the targeting of climate-smart agriculture (CSA) at the national level. This framework integrates quantitative, spatially-explicit information such as vulnerability indicators (e.g. soil organic matter, literacy rate and market access) and proxies for CSA practices (e.g. soil fertility improvement, water harvesting and agroforestry) as well as qualitative opinions on these targeting criteria from a broad range of stakeholders. The analytic hierarchy process and a goal optimisation approach are utilised to quantify collective, consensus-oriented stakeholder preferences on vulnerability indicators and CSA practices. Spatially-explicit vulnerability and CSA data are aggregated and coupled with stakeholder preferences deriving vulnerability and CSA suitability indices. Based on these indices, relevant regions with the potential to implement CSA practices are identified. "targetCSA" was applied in Kenya exploring group-specific and overall consensus-based solutions of stakeholder opinions on vulnerability and CSA under different consensus scenarios. In this example, 32 experts from four stakeholder groups who participated in two surveys were included. The subsequent analyses revealed consistently regions with high CSA potential but also highlighted different high potential areas depending on the applied consensus scenario. Thus, this framework allows stakeholders to explore the consequences of scenarios that reflect opinions of the majority, minority or are based on a balance between them. "targetCSA" and the application example contribute valuable insights to the development of policy and planning tools to consensually target and implement CSA. 


\section{$2.1 \quad$ Introduction}

Addressing climate change is crucial to safeguard food provisioning from agricultural systems. Hence, planning efforts are urgently needed to target and implement agricultural adaptation and mitigation options in line with governmental strategies, such as national climate change action plans (Preston et al., 2011; Conway \& Mustelin, 2014). Climatesmart agriculture (CSA) as a global development goal was introduced to guide the transformation of agricultural systems integrating adaptation, mitigation and food security (FAO, 2013). Alleviating vulnerability and fostering resilience of agricultural systems to climate change to secure the sustainable provisioning of food while reducing greenhouse gas (GHG) emissions are the major objectives of CSA (Harvey et al., 2014a).

The targeting of CSA at the national level is fraught with several challenges that, if not properly dealt with, potentially hamper the legitimacy and outcome quality of made decisions. First, relevant stakeholder groups have to be involved in the decision-making process that contribute their valuable expert knowledge but also might disagree due to conflicting interests and views (Nordström et al., 2010). Second, high complexity and uncertainty may arise from the multitude of criteria that need to be considered for the selection and prioritisation of CSA practices at specific locations (Greene et al., 2011). Third, reliable quantitative and spatially-explicit data are required to identify regions suitable for targeting certain CSA practices. Such a database should include biophysical, social and economic determinants on agricultural vulnerability to climate change, consequently, offering a demand-based perspective on CSA (Fellmann, 2012; FAO, 2013). A framework that integrates knowledge and opinions from a broad range of expert stakeholders, weighs those opinions based upon consensus and couples them with spatially-explicit datasets on vulnerability and CSA practices is of paramount interest to support robustly the decision-making on targeting CSA. To the authors' knowledge, such a framework has not been published so far.

The aim of this study was to develop a decision support framework for the spatiallyexplicit targeting of CSA, named "targetCSA", which includes multiple stakeholders, vulnerability indicators and suitable CSA practices. The applicability of this framework is demonstrated through an example from Kenya. Large parts of the country are characterised by arid or semi-arid climate with agricultural production dominated by smallholder farming. Erratic weather patterns, frequent droughts and reduced growing seasons are threats that will increase the vulnerability of the agricultural sector in Kenya (Molua et al., 2010; Gachathi \& Eriksen, 2011). The national climate change action plan recently passed by the Kenyan government calls for urgent implementation of CSA practices, thus, rendering "targetCSA" highly relevant for the development of policy and planning instruments (Government of Kenya, 2012). 


\section{$2.2 \quad$ Material and methods}

\subsubsection{Conception of the decision support framework "targetCSA"}

\section{Background}

Supporting decision makers in their assessment of options based on several criteria can be achieved through multi-criteria decision-making (MCDM) analyses (Romero \& Rehman, 2003). MCDM aims to elicit transparently individual and subjective stakeholder judgements, aggregate them to collective preferences and help to explore their implications for decision-making processes (Greene et al., 2011). Spatial information has to be integrated into MCDM since implementing CSA involves landscape planning. Geographic information systems (GIS) can be applied to link the spatial attributes of criteria to stakeholder preferences (Boroushaki \& Malczewski, 2008). MCDM is based on a well-established set of methods that have been frequently applied to different planning contexts such as the targeting of projects on the mitigation of GHG-emissions or the design of ecological reserves and corridors (cf. Ferretti \& Pomarico, 2013; Lin et al., 2014; Tammi \& Kalliola, 2014).

Adaptation and mitigation planning is the centrepiece of coping strategies for climate change such as action plans passed by national governments (Preston et al., 2011). The decision support framework proposed here is designed to aid planners and decision makers that aim to implement CSA at the regional or national level. Such a planning process involves several sectors such as governmental institutions, civil society, science and the private sector making it mandatory to involve respective stakeholder organisations (FAO, 2013). Therefore, the framework integrates multi-sectoral stakeholder groups to contribute expert knowledge on the selection and importance of vulnerability indicators as well as CSA practices that fit into a country's or regional profile due to prevailing environmental and socio-economic conditions. However, stakeholder perceptions on what is important might differ and result in conflicting judgements and trade-offs among decision options (Nordström et al., 2012). Hence, an adequate decision support framework should allow the exploration of trade-offs and minimise dissent. Integrating expert knowledge and spatial information into MCDM is crucial for informed and robust decisions based on evidence and acceptance (Preston et al., 2011). "targetCSA" uses an optimisationbased approach developed by González-Pachón \& Romero (2007) that applies distance minimisation algorithms to reduce disagreement among the stakeholders' opinions and to facilitate the exploration of different consensus scenarios. Moreover, consensus-oriented opinions from stakeholders are coupled with quantitative and spatially-explicit vulnerability and CSA data building the factual foundation for decisions on where to target CSA. "targetCSA" is structured into three main stages (Figure 2.1). 


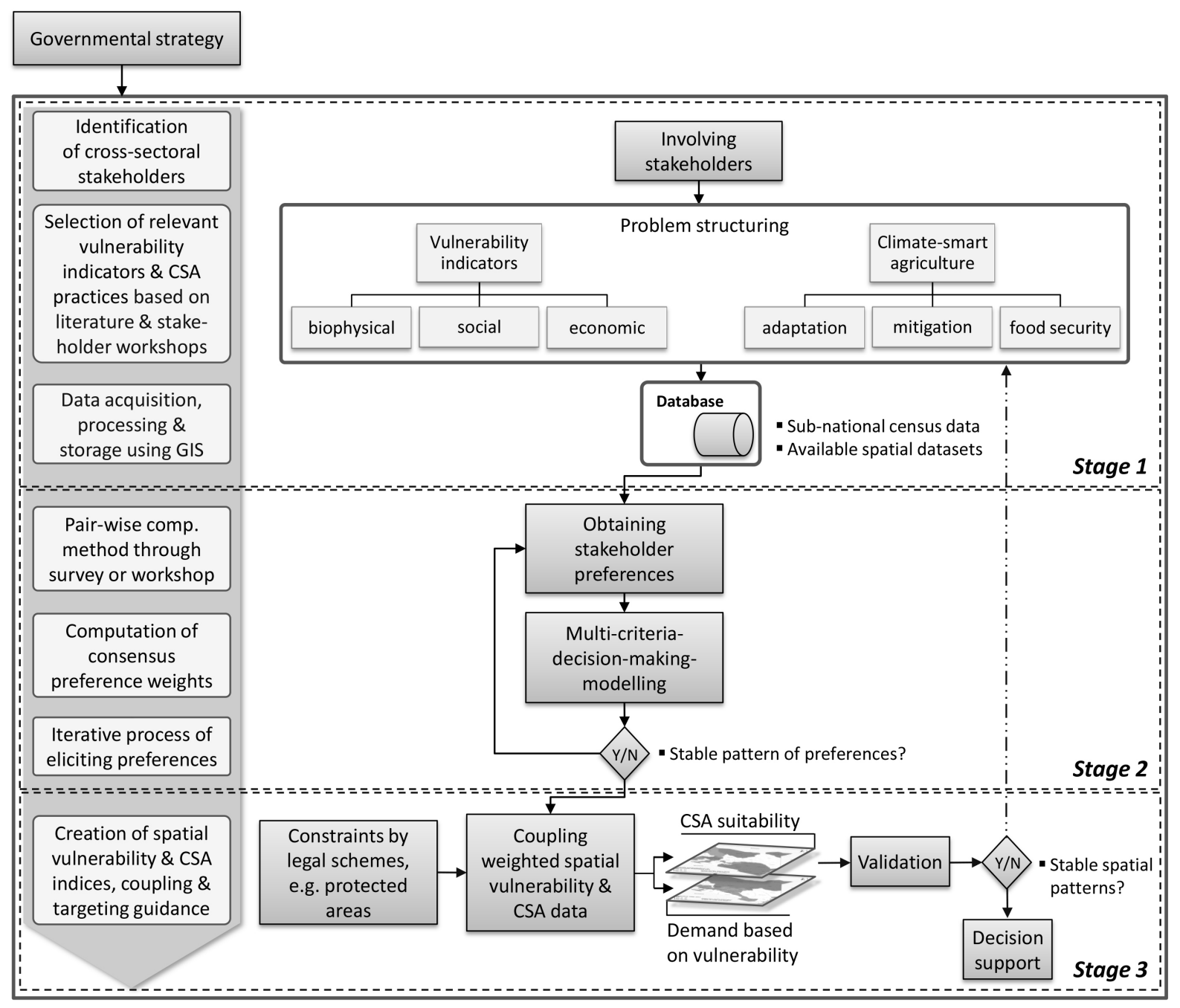

Figure 2.1: Conceptual overview of the decision support framework "targetCSA".

\section{Climate change vulnerability and climate-smart agriculture}

The vulnerability of a system to stressors such as droughts or floods depends on its sensitivity to perturbations, the degree of exposure, and its capacity to adapt on the impact (Challinor et al., 2007; Abson et al., 2012). Climate change is expected to increase the vulnerability of farmers by threatening their livelihood strategies as well as entire food productions systems (Challinor et al., 2007; Harvey et al., 2014b; Thornton et al., 2014). The concept of CSA couples climate change and food security through the integration of adaptation and mitigation measures. It aims to reduce vulnerability by improving the adaptive capacity of agricultural systems to climate stress and, hence, secures the provision of food while reducing GHG-emissions from agricultural practices and land uses contributing to climate change (Scherr et al., 2012; Campbell et al., 2014; Harvey et al., 2014a). Thus, a short (adaptation) and long term (mitigation) perspective are 
integrated into the CSA concept which should be considered in proper targeting and planning processes.

By explicitly including the vulnerability concept into CSA-targeting, a demand-based perspective is taken, meaning that regions with higher climate change vulnerability require more urgently interventions that strengthen their adaptive capacity. The vulnerability of the agricultural sector to climate change is influenced by environmental and socioeconomic factors (Abson et al., 2012; Fellmann, 2012). Thus, information about relevant biophysical (e.g. climate), social (e.g. education) and economic (e.g. market access) dimensions should be taken into account to inform an assessment of where specific CSA practices are suitable.

\section{Stage 1: Structuring the decision-making problem}

Stakeholder involvement and data collection. Relevant stakeholders should be identified at the beginning of the planning process (Nordström et al., 2010). During the first stage (Figure 2.1), meetings with cross-sectoral stakeholders are conducted, e.g. from governments, civil societies, science and private sectors to develop a structured catalogue of context-specific vulnerability indicators and CSA practices (cf. Patt et al., 2010; Fellmann, 2012; Scherr et al., 2012). Related datasets can be obtained from publicly available geo-databases such as the FAO GeoNetwork, HarvestChoice and GEO-Wiki branches or compiled and made spatially-explicit based on sub-national census data using GIS.

The analytic hierarchy process. The analytic hierarchy process (AHP) is widely used in MCDM with numerous applications (Wind \& Saaty, 1980; Saaty, 1994; Nordström et al., 2012). A complex problem is decomposed into pairs of criteria (decision options) through pair-wise comparisons (PC), where two criteria are compared with each other at a time (Wind \& Saaty, 1980). Stakeholders assign numerical preference weights as expression of their opinion to one of the paired criteria that are compared on a measurable scale known as the Saaty scale (Saaty, 1977). It orders the importance of potential judgements from 1 = equal preference to 9 = extreme preference towards one of the paired criteria. Finally, the individual stakeholder preferences are aggregated deriving a normalised vector of overall preferences for considered criteria (Saaty, 1977).

Stage 2: Eliciting stakeholder preferences and consensus building

Multi-criteria decision-making model. The second stage integrates and aggregates formalised stakeholder opinions (Figure 2.1). Individual preference weights are queried through PC questionnaires that are administered through workshops, expert surveys or interviews (cf. Diaz-Balteiro et al., 2009; Sae-Lim et al., 2012). A commonly used 
technique to aggregate individual stakeholder preferences in group decision-making processes is to calculate overall priority vectors (Eigenvectors) through geometric or arithmetic mean methods (Ishizaka \& Labib, 2011; Nordström et al., 2012). "targetCSA", however, utilises a goal programming (GP) approach by implementing a set of MCDM models that are based on linear optimisation. These models were developed by GonzálezPachón \& Romero (2007) and applied by Diaz-Balteiro et al. (2009) as well as Gebrezgabher et al. (2014). The GP approach has two advantages compared to the conventional Eigenvector-based aggregation methods: i) stakeholder preferences do not have to be consistent throughout the PC questionnaire (González-Pachón et al., 2003; González-Pachón \& Romero, 2007) and ii) the MCDM models are designed to minimise distances among obtained PC questionnaires enabling the search for a collective consensus. Hence, this approach offers integrated support for participatory management and planning processes that rely on consensus (Sae-Lim et al., 2012; Gebrezgabher et al., 2014).

The GP approach computes a consensus matrix, which shows minimised differences to the input PC matrices derived from the questionnaires and infers the consensus preferences from this matrix by using a distance minimisation algorithm (González-Pachón \& Romero, 2007). In this context, consensus is specifically defined as a mathematical optimisation goal achieved by minimising matrix distances using certain boundary constraints to find a solution that represents the minimum disagreement between individual preferences. The meaning of consensus from an optimisation point of view does not coincide with the general meaning of the term consensus used in group decision-making processes, where consensus refers to reaching decisions that all stakeholders willingly agree on (Bressen, 2007).

The optimisation process can be controlled by following different consensus scenarios moving along a trade-off curve between majority and minority consensus (González-Pachón \& Romero, 2011). The majority consensus represents the closest solution to all stakeholder preferences whereas the solution based on the minority consensus seeks to satisfy preferences of the stakeholder far apart from the majority. The MCDM models were numerically programmed in $\mathrm{R}$ (v. 3.1.1) using the linear programming library 'lpsolve' (v. 5.6.10). A detailed description of the models can be found in Appendix (S1).

Eliciting stakeholder preferences. Stakeholder preferences represent a source of uncertainty in the decision making process (Mosadeghi et al., 2013). Therefore, it is recommended to elicit preferences iteratively (Nordström et al., 2010). The iterations allow to capture, assess and to reduce the variability of preferences which result from adjusted stakeholder opinions that might affect the targeting outcome (Mosadeghi et al., 2013). Evaluating the robustness of preferences is important to obtain a transparent measure of how reliable the included expert knowledge is for final decision-making (Xu \& Zhang, 2013). 


\section{Stage 3: Spatial aggregation and coupling of vulnerability and CSA indices}

Deriving vulnerability and CSA suitability indices. The third stage combines elicited preferences with spatial data representing quantitative vulnerability indicators and data reflecting CSA practices (Figure 2.1). Weighed linear combination (WLC) is a widely applied aggregation rule where high values of one criterion can be offset by low values of another criterion (Eastman et al., 1995; Greene et al., 2011; Lin et al., 2014). In "targetCSA", values of standardised spatially-explicit criteria are multiplied with related stakeholder preferences and finally summed up deriving combined vulnerability and CSA suitability scores using WLC. Spatial information of constraints, such as regions with legal restrictions or a lacking relevance are masked and excluded from the decision-making process.

Finally, two standardised and spatially-explicit indices depicting climate change vulnerability and CSA suitability are generated. Subsequently, a re-scaling of both indices into low, mid and high vulnerability as well as CSA suitability allows to superimpose them and to assess overlaying classes for the identification of areas with high potential for selected CSA practices. Maps showing these indices can be used to explore the consequences of different consensus scenarios on the CSA targeting and guide decision-making.

Validation. If stakeholder preferences are elicited at several occasions they can be used to validate the robustness of the calculated spatial indices (Figure 2.1). This is crucial to assess how reliable and, hence, how useful the vulnerability and CSA suitability indices are as source of information in a decision-making process (Delgado \& Sendra, 2004). Several sets of aggregated and coupled indices can be spatially compared. Large differences in areas of CSA potential could point to high uncertainties associated to blurred stakeholder opinions and knowledge gaps which have to be addressed (Nordström et al., 2010; Mosadeghi et al., 2013).

\subsubsection{Application example from Kenya}

\section{Study area}

Kenya covers a total area of $581,881 \mathrm{~km}^{2}$ and has a population of about 38 million people (Figure 2.2) (Wiesmann et al., 2014). While the most productive land is situated in the Central and Western, sub-humid parts of Kenya, about $80 \%$ of Kenya is characterised as semi-arid or arid lands with erratic rainfall, droughts and sporadic floods (Molua et al., 2010; Gachathi \& Eriksen, 2011). The agricultural sector plays a pivotal role for food provisioning and the country's economy. However, it suffers from recurring crop failure, livestock mortality and food insecurity (Grace et al., 2014). A large part of Kenya's labour force works in the agricultural sector, which makes about $75 \%$ of the national gross domestic product (Odera et al., 2013). The vulnerability of the mainly rainfed 
agricultural sector to climate change is marked by its exposure and sensitivity to harsh biophysical factors relating to climate and soil as well as low adaptive capacity determined by the socio-economic context, e.g. poverty, poor access to education and health facilities as well as to markets (Eriksen \& O'Brien, 2007).

Selection of stakeholders, vulnerability indicators and CSA practices

The CSA targeting process started in 2013 through discussions between the Kenyan Ministry of Environment, Water \& Natural Resources and the Research Program on Climate Change, Agriculture and Food Security (CCAFS). Stakeholders were selected from four groups representing governmental organisations (GOs), civil society (NGOs), scientific institutions and the private sector (Appendix S2, Table S2.1). A stakeholder workshop was held in early 2014 to select vulnerability indicators and CSA practices. Subsequently, related quantitative data were collected, compiled and processed in ArcGIS (v. 10.1). All datasets were derived from publicly accessible databases or censuses conducted by governmental institutions in Kenya. Resulting grid data were resampled to match a consistent resolution of approximately $10 \times 10 \mathrm{~km}$. A subset of six vulnerability indicators and CSA practices was selected, suitable to test the applicability of "targetCSA" (Table 2.1).

Table 2.1: Overview of the stakeholder-based selection of climate change vulnerability indicators and CSA practices for the application example in Kenya, including descriptions as well as linkages between indicators and practices.

\begin{tabular}{llll}
\hline $\begin{array}{l}\text { Indicators of climate } \\
\text { change vulnerability }\end{array}$ & $\begin{array}{l}\text { Data description and } \\
\text { sources }\end{array}$ & $\begin{array}{l}\text { Linkages climate change } \\
\text { vulnerability - CSA }\end{array}$ \\
\hline
\end{tabular}

\section{Biophysical}

Annual precipitation:

Annual precipitation based 'Annual precipitation' was seon the period: 1950-2000 (Hi- lected as indicator for wajmans et al., 2005). ter availability and ecosystem productivity. The availability of water largely determines agricultural productivity. The improvement of water harvesting and management and the introduction of drought tolerant crop varieties represent viable CSA practices to deal with vulnerability to water shortages (Harvey et al., 2014a). 
Table 2.1: continued

Soil organic matter:

\section{Social}

Percentage of households with access to safe water sources:
Organic carbon content in 'Soil organic matter' is an inthe top soil layer, up to dicator of soil fertility and, $30 \mathrm{~cm}$ depth, contained in thus, ecosystem productiv(decomposed) plant and ani- ity. Regions with low soil ormal residues, tissues and cells ganic carbon need CSA prac(Nachtergaele et al., 2012). tices that alleviate nutrient depletion such as measures to stop erosion to build up soil carbon through organic fertilisers and integrated practices such as agroforestry (Lal et al., 2011).

Proportion of households per county with access to safe water sources such as: boreholes, protected wells and springs, piped water and collected rainwater (Government of Kenya, 2009a; Wiesmann et al., 2014).
'Percentage of households with access to safe water sources' was selected as an indicator of household well-being. Required CSA practices should, thus, improve the management of water that is used for agricultural purposes as well as drinking water and thereby safeguard its availability (Wiesmann et al., 2014). 
Table 2.1: continued

Literacy rate:

\section{Economic}

Female participation in economic activities:
Proportion of the population (aged 15+) per county that is able to read and write (Government of Kenya, 2013).

Active female labour force divided by the total female labour force per county (Government of Kenya, 2009a; Wiesmann et al., 2014).
'Literacy rate' is an education indicator. High illiteracy reflects reduced capabilities (adaptive capacity) of making informed decisions regarding viable coping strategies under climate change (Atela et al., 2014). Thus, it reflects obstacles for implementing CSA due to lack of knowledge and information. CSA practices in turn have to contribute necessary knowledge, thus, help to reduce information gaps as well as facilitate relevant practical skills.

'Female participation in economic activities' is understood as an indicator for women empowerment and economic development. Gender inequality increases the susceptibility to sudden changes and threats as such climate change. Integrated CSA practices such as conservation agriculture and agroforestry have the potential to promote gender equality and improve livelihoods for women and men while supporting mitigation and adaptation (Beuchelt \& Badstue, 2013). 
Table 2.1: continued

Connectivity through transport infrastructure:
Degree of connection between places across Kenya, based on time needed for travelling to the next city $>50000$ inhabitants (Uchida \& Nelson, 2009).
'Connectivity through transport infrastructure' indicates farmers' accessibility to markets for selling farm produces and buying inputs as well as accessing extension services such as vaccination. A reduced access adds additional risks for farmers under climate change (Abson et al., 2012). CSA practices are supposed to support farmers to deal with the impacts of climate shocks such as losses of livestock or crop failures. CSA examples are insurance schemes and drought tolerant varieties/breeds, improved soil and water management (Harvey et al., 2014a; Vrieling et al., 2014).

\begin{tabular}{lll}
\hline CSA practices & $\begin{array}{l}\text { Examples, proxy datasets } \\
\text { and assumption of use }\end{array}$ & $\begin{array}{l}\text { Link to indicators of cli- } \\
\text { mate change vulnerabil- } \\
\text { ity }\end{array}$ \\
\hline
\end{tabular}

Improvement of soil fertility and soil management:
Example: low-cost soil fertility enhancement options, such as green manures, legumes, composting, animal manure management, improved fallows and conservation agriculture; Proxy dataset: low nutrient capital reserves (Sanchez et al., 2003); Assumption: Depleted nutrient stocks in soils call for improved soil fertility management through CSA.
Biophysical: 'Soil organic matter'; Social: 'Literacy rate' 
Table 2.1: continued

Identification and distribu- Example: sorghum, millet tion of drought tolerant cereal crops:

Reduction of greenhouse gas emissions from the livestock sector: and maize; Proxy dataset: suitability of rainfed cereal crops assuming an improved management scenario in terms of labour, fertiliser use, pest control and conservation measures (van Velthuizen et al., 2007); Assumption: The biophysical suitability for cereals under region-specific farm management reflects the potential to grow drought tolerant cereal varieties.

Example: manure management, more efficient breeds, species, feeds and biogas technologies; Proxy dataset: Methane and nitrous oxide emissions from livestock per $\mathrm{kg}$ protein, including cattle, sheep, goats, pigs and poultry (Herrero et al., 2013); Assumption: High livestock-based emission intensities show high demand for GHG mitigation practices.
Biophysical: 'Annual precipitation'; Social: 'Literacy rate'

This is a mitigation practice that, in a long-term perspective, reduces the vulnerability to climate change in general. Therefore, it links to all vulnerability indicators included here. 
Table 2.1: continued

Improvement of water har- Example: community water vesting and water management:

Identification and establishment of agroforestry practices:

pans, micro-catchments and dams constructed to harvest, store and distribute water for crop irrigation and livestock; Proxy dataset: aridity index (Zomer et al., 2008); Assumption: Agricultural practices in drylands, such as pastoralism, are prone to water deficits. Hence, these regions reflect high demands to improve the harvesting and management of water.

Agroforestry integrates trees into croplands and pastures. Example: identifying agroforestry practices (based on surveys etc.), establishing community agroforestry, tree nurseries; Proxy dataset: percentage of cropland area (Fritz et al., 2015) restricted to regions with a tree cover $<10 \%$ (Hansen et al., 2013). Assumption: Regions with higher proportions of cropland show potential for integrating trees into agricultural landscapes that lack a minimum tree cover aligning this CSA practice with the national policy target in Kenya to achieve a tree cover of at least $10 \%$ (Government of Kenya, 2007).
Biophysical: 'Annual precipitation'; Social: 'Percentage of households with access to safe water sources', 'Literacy rate'; Economic: 'Connectivity through transport infrastructure'

Biophysical: 'Soil organic matter'; Economic: 'Female participation in economic activities' 
Table 2.1: continued

Implementation of livestock insurances:
Example: monetary subsidies for farmers in cases of severe climate mediated livestock mortality; Proxy dataset: Insurance premium rates for livestock mortality based on remote-sensing time-series data (normalised difference vegetation index, NDVI) from 1981 - 2012 (Vrieling et al., 2014). Assumption: Regions with increased drought risks and water shortages have a higher demand for livestock insurance schemes.
Biophysical: 'Annual precipitation'; Social: 'Percentage of households with access to safe water sources', 'Literacy rate'; Economic: 'Connectivity through transport infrastructure'

This choice was based on three criteria. First, the selection of vulnerability indicators was based on the scientific vulnerability literature dealing with climate change in Africa (cf. Challinor et al., 2007; Abson et al., 2012; Atela et al., 2014). Selected CSA practices are also listed in a catalogue that is part of the Kenyan National Climate Change Action Plan (Government of Kenya, 2012). Second, the data quality was ensured through peer-reviewed published datasets and consultation of experts. Third, there was no high collinearity among vulnerability and CSA datasets (Spearman's rho < 0.75).

There was no information about the effectiveness of selected CSA practices on alleviating vulnerability of the agricultural sector in Kenya. Therefore, this application example represents a spatially-explicit ex-ante assessment that explores the potential to target CSA practices consensually by focusing on regions that are shown to be vulnerable and suitable.

\subsubsection{Expert survey}

The designed questionnaire comprised two parts. The first part dealt with the pairwise comparison of six selected vulnerability indicators, while the second part focused on comparing the six selected CSA practices. The number of PC items was restricted to six avoiding potential reductions in consistency and quality of the answers (Saaty, 1977). The leading questions in both parts were formulated to elicit preference weights according to the relative importance of the items compared to each other. For this application example, a slightly reduced rating scale was used compared to the original Saaty scale, 
ranging from 1 to 7 , based on results from a pre-test. In order to separate the different intensities of possible preferences more clearly, they were defined as: $1=$ equal preference, $3=$ slight preference, $5=$ moderate preference and $7=$ strong preference. Five different versions of the questionnaire were created differing in their sequence of comparisons based on randomisation to prevent a possible bias resulting from a fixed order of comparisons (Podsakoff et al., 2003).

The survey took place between September and November 2014 interviewing eight experts from each of the four stakeholder groups $(\mathrm{n}=32)$. Each interview took approximately 20 minutes. Before an interview started, the questionnaire was explained and put into the CSA targeting context to avoid misguided judgements due to potential misconception of queried items (Keeney, 2002). During a stakeholder workshop conducted in November of 2014, the survey results were presented, discussed and preferences were re-elicited using the identical PC questionnaire for the validation of spatial indices. Furthermore, the questionnaire was sent to stakeholders that could not attend, including supplementary information about the workshop results. Finally, 16 validation questionnaires were filled covering $50 \%$ of each originally sampled stakeholder group.

\subsubsection{Multi-criteria decision-making model}

Applying the GP optimisation approach developed by González-Pachón \& Romero (2007) allowed us to explore both conflicting group interests and consensus solutions regarding stakeholder preferences for vulnerability indicators and CSA practices. The MCDM models were fitted i) to aggregate group specific preferences separately keeping the experts in each group as individuals and ii) to search a consensus based on the entire set of included expert opinions, referred to as the overall consensus, assuming a collective interest in striving for consensus in a decision-making process. The ability of the MCDM models to move towards mutually exclusive majority or minority oriented consensus scenarios was tested by González-Pachón \& Romero (2007). In this example, three scenarios were applied to explore results that reflect the preferences of the i) majority, ii) minority, and iii) the optimal trade-off indicating the consensus solution that is most balanced in representing the stakeholder opinions (González-Pachón \& Romero, 2011). The latter scenario characterises a compromise, which is especially interesting in a decision-making context where no information is available about the socially desired outcome of the negotiation process. A detailed description of the applied optimisation model used to find the consensus with the most balanced trade-off (i.e. compromise scenario) can be found in Appendix (S1). The modelling procedure was applied on stakeholder preferences obtained from both expert surveys enabling the assessment of changes in opinions among stakeholders. 


\subsubsection{Spatial aggregation and coupling of weighted vulnerability and CSA suitability indices}

The WLC rule was used to combine linearly each of the two sets of spatial data (Table 2.1), excluding constraints such as protected areas, forests, lakes and settlements, with preferences inferred from the overall consensus, deriving combined vulnerability and CSA suitability indices (Eastman et al., 1995). Spatial datasets reflecting these constraints were obtained during the initial data collection process. A detailed description of the WLC rule can be found in the Appendix (S1).

By overlaying the indices of vulnerability and CSA suitability, it was possible to assess the targeting potential of selected CSA practices based on their suitability in regions that bear high vulnerability. The indices were computed for three different consensus scenarios (majority, minority, and the most balanced trade-off) to explore differences in regions with high CSA potential. For validation, the CSA potential was computed based on stakeholder preferences derived from both surveys applying the consensus scenario with the most balanced trade-off. Through comparison of CSA potentials, areas where the survey results (dis)agree were investigated.

\section{$2.3 \quad$ Results}

\subsubsection{Vulnerability indicators and CSA practices}

Both biophysical indicators, 'annual precipitation' and 'soil organic matter' show relatively high vulnerability in Northern and Eastern parts of Kenya (Figure 2.2A). The social indicator 'households with access to safe water sources' reveals a more heterogeneous pattern of vulnerability than the indicator 'literacy rate' which shows higher illiteracy in the North and, thus, elevated vulnerability compared to the rest of the country. The two economic indicators depict a contrasting pattern. Whereas 'female participation in economic activities' highlights the South-Eastern regions as more vulnerable, the indicator 'connectivity through transport infrastructure' emphasises the North and partially the East as more remote and, hence, potentially more vulnerable. 
A

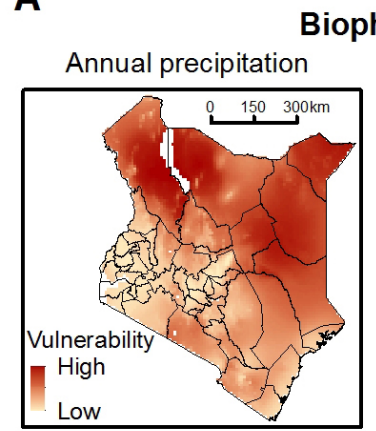

Biophysical

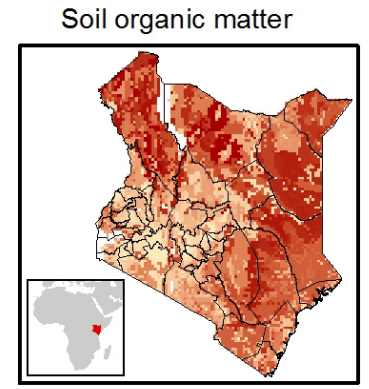

Households with access Social to safe water sources
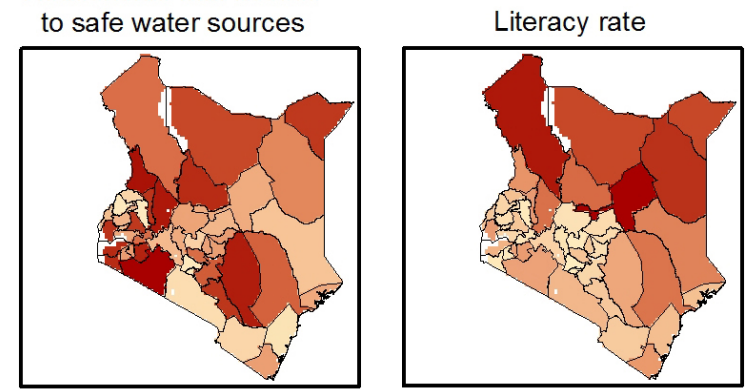

Female participation Ecc in economic activities

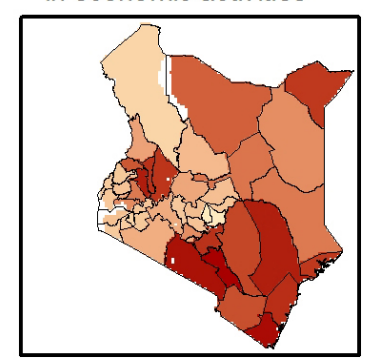

Economic

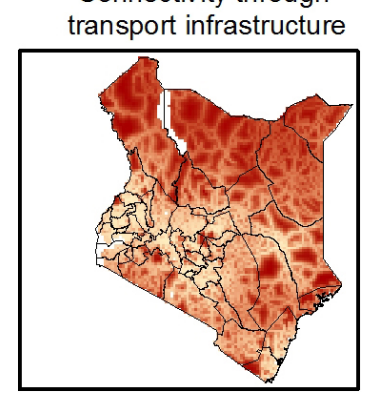

B

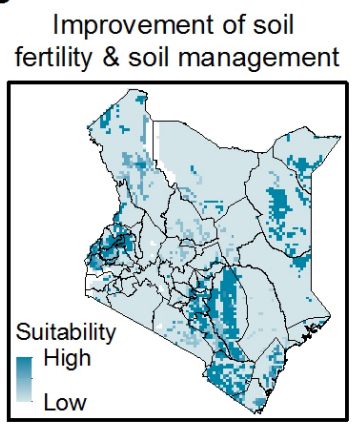

Reduction of GHG-emissions from the livestock sector

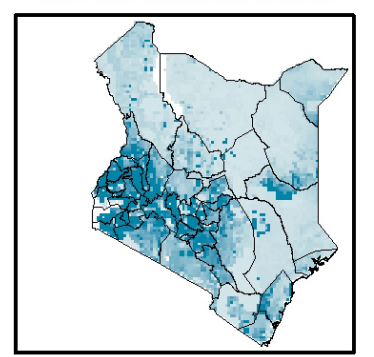

Identification \& establishment of agroforestry practices

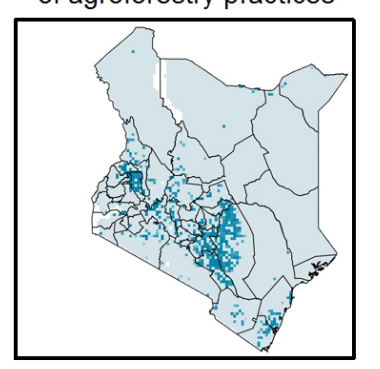

Identification \& distribution of drought tolerant cereal crops

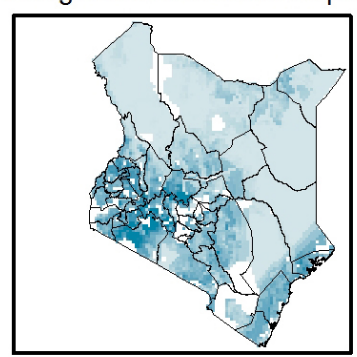

provement of water harvesting \& water management

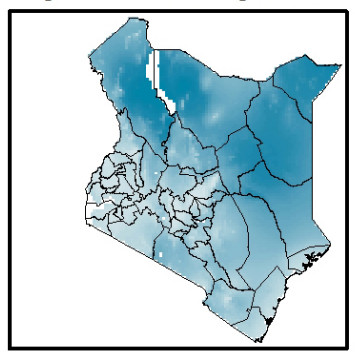

Implementation of livestock insurances

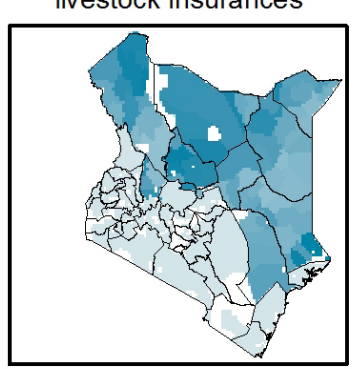

Figure 2.2: Maps show the spatial distribution of consistently re-scaled datasets used to represent (A) vulnerability indicators and (B) CSA practices ranging from $0-1$. For the vulnerability maps, dark red colour means highly vulnerable, for the CSA suitability, dark blue colour means highly suitable for the selected CSA practice. Included CSA practices are reflected by proxy datasets explained in Table 2.1.

Focusing on CSA practices, the dataset on soil nutrients shows a scattered pattern of areas in the North-East, West and South of Kenya where CSA practices relating to the 'improvement of soil fertility and soil management' are potentially suitable (Figure 2.2B). For the 'identification and distribution of drought tolerant cereal crops' regions in Western, Central and coastal Kenya indicate favourable conditions using the dataset on suitability for cereal crops. The arid areas in the North and East are shown as not or marginally suitable for cereals due to prevailing biophysical conditions rendering crop-based agriculture impossible in general, except for the narrow belts along rivers that are not captured by this dataset due to its grid cell resolution of $10 \times 10 \mathrm{~km}$. Relatively high methane and nitrous oxide emissions due to livestock production identify Western, Central and 
partially Eastern as well as Southern regions as suitable for mitigation interventions focusing on the 'reduction of GHG-emissions from the livestock sector'. Increased aridity in the entire North and North-East of Kenya compared to its Western and Central regions reveal areas for the 'improvement of water harvesting and water management'. The percentage of croplands, constrained by low tree cover, used as proxy for the 'identification and establishment of agroforestry practices' delineates Western and Central regions from the rest of the country emphasising them as suitable for related interventions. Insurance premium rates for livestock mortality as proxy for the 'implementation of livestock insurances' reveals Northern and Eastern areas as prone to higher risks offering eligible conditions for implementing this practice.

\subsubsection{Aggregated group-specific and overall consensus-based prefer- ences}

The distribution of preference weights inferred from each stakeholder group separately and based on the overall consensus, including all experts, are shown for vulnerability indicators (Figure 2.3A) and CSA practices (Figure 2.3B). Illustrated preferences result from the consensus scenario that shows the most balanced trade-off between majority and minority. The results for majority and minority scenarios can be found in the Appendix (S2, Figure S2.1 and S2.2). Stakeholder groups differed in their preferences for each of the vulnerability indicators and CSA-practices indicated by across group standard deviation (SD) ranging from 0.02 - 0.09 for vulnerability indicators and from 0.00 0.12 for CSA practices. However, the vulnerability indicator and CSA practice that were weighed low across all groups, namely 'connectivity through transport infrastructure' and 'implementation of livestock insurances', show a relatively homogenous pattern of preferences with the lowest across group SD. Highly preferred vulnerability indicators across stakeholder groups are 'annual precipitation' and 'households with access to safe water sources'. These indicators relate to the biophysical and social dimensions of vulnerability to climate change. The economic vulnerability indicator 'connectivity through transport infrastructure' and the social indicator 'literacy rate' were weighed low throughout the stakeholder groups except for the science group, which assigned slightly lower preferences to 'female participation in economic activities'. For CSA-practices, high preferences were assigned to 'improvement of water harvesting and water management' and 'identification and distribution of drought tolerant cereal crops'. Yet, NGOs deviated from this pattern giving higher importance to 'identification and establishment of agroforestry practices'. Low weighed CSA practices across stakeholder groups are 'implementation of livestock insurances' and 'reduction of GHG-emissions from the livestock sector'. 

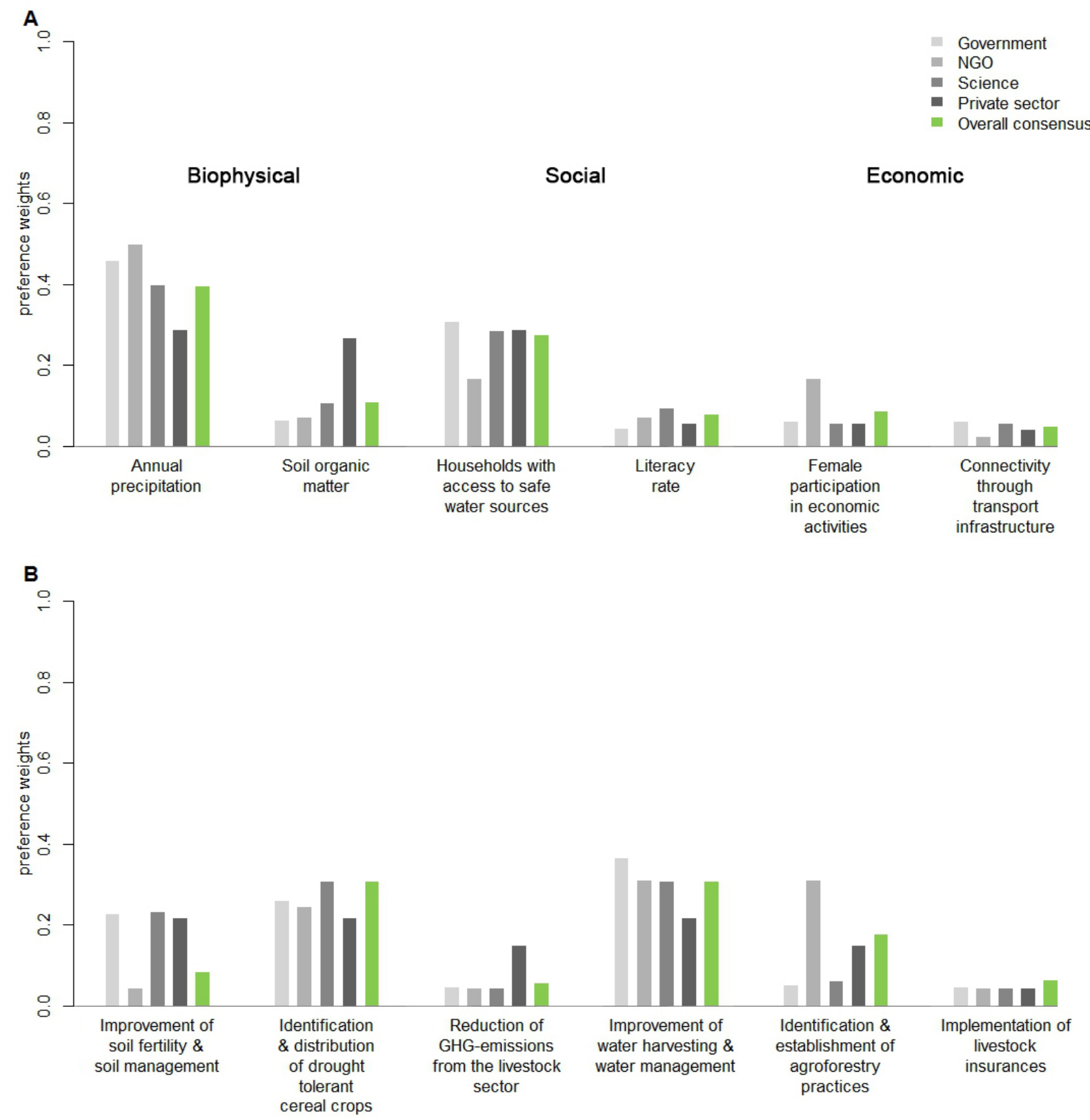

Figure 2.3: Preference weights for each stakeholder group and the overall consensus, including all experts, resulting from the consensus scenario showing the most balanced trade-off between majority and minority for (A) vulnerability indicators and (B) CSA practices.

The preferences based on the overall consensus largely resemble the distribution of groupspecific preferences. However, they rank within the ranges of group preferences for each of the indicators and CSA practices except for 'implementation of livestock insurances' indicating minimised distances among stakeholder opinions by using consensus matrices to infer the overall consensus. 


\subsubsection{CSA potential: coupling spatial indices of vulnerability and CSA suit- ability under different consensus scenarios}

The combined indices for vulnerability and CSA suitability derived from the overall consensus preferences, including all experts, as well as CSA potential maps that resulted from coupling the indices are shown for the majority (Figure 2.4A), minority (Figure 2.4B) and the most balanced trade-off (Figure 2.4C) consensus scenarios. In general, high vulnerability to climate change based on the included indicators is shown for the North and to some degree in Eastern parts of Kenya whereas high CSA suitability is indicated for Western, Central, coastal and partly in Northern parts throughout applied consensus scenarios. However, there are differences in vulnerability among the consensus scenarios at county level. The majority consensus led to higher vulnerability for Turkana and Kitui counties than the minority consensus, which identified the same counties as medium or marginally vulnerable. In contrast, the minority consensus indicated higher vulnerability for Wajir and Tana River counties. The consensus scenario with the most-balanced trade-off shows a pattern of vulnerability intensities that lays between those indicated by majority and minority for these counties. Differences in CSA suitability between the consensus scenarios are less pronounced, yet obvious in several parts of Kenya.

Overlaying CSA suitability on top of high vulnerability regions reveals areas with high CSA potential in Baringo, Mandera and Wajir counties in agreement with all three consensus scenarios. The consensus scenarios disagree on areas of high CSA potential in Turkana, Kitui and Marsabit counties. Comparing majority and minority consensus scenarios, these differences become most obvious for Turkana and Kitui counties. The mostbalanced trade-off consensus reflects areas with high CSA potential whose extents rank between those indicated in the majority and minority consensus scenarios. 
A
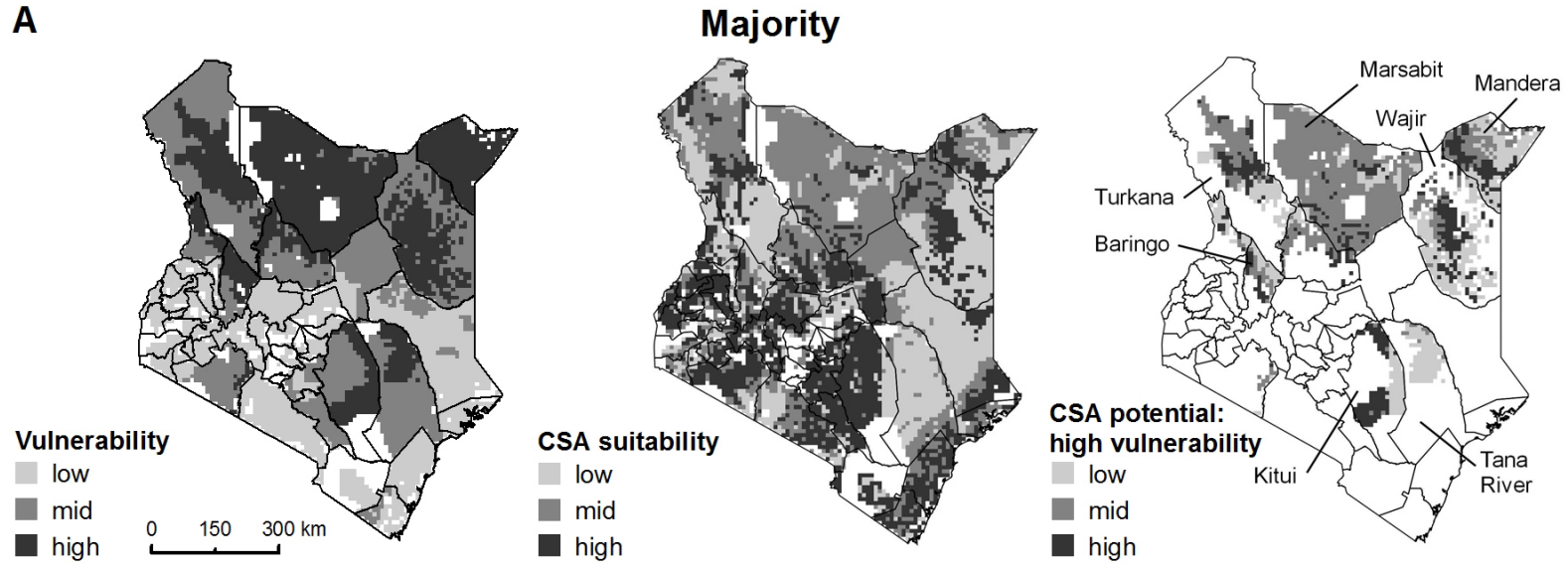

B
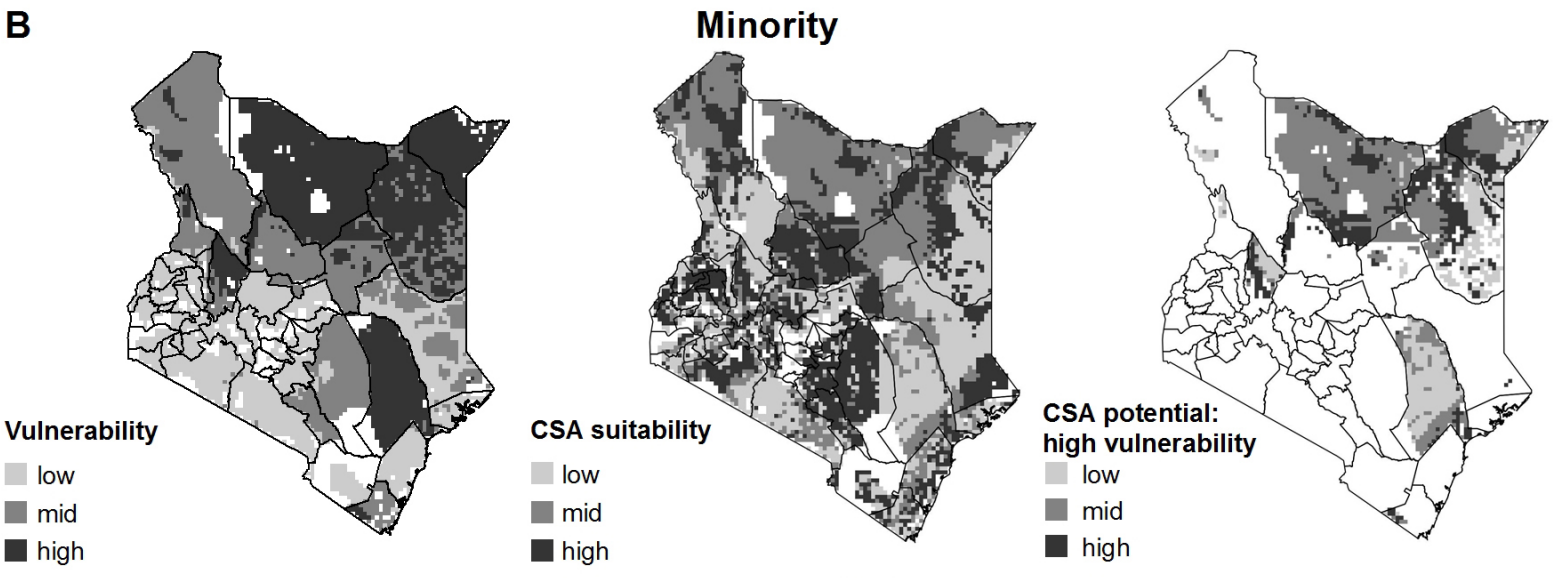

C

Most balanced trade-off

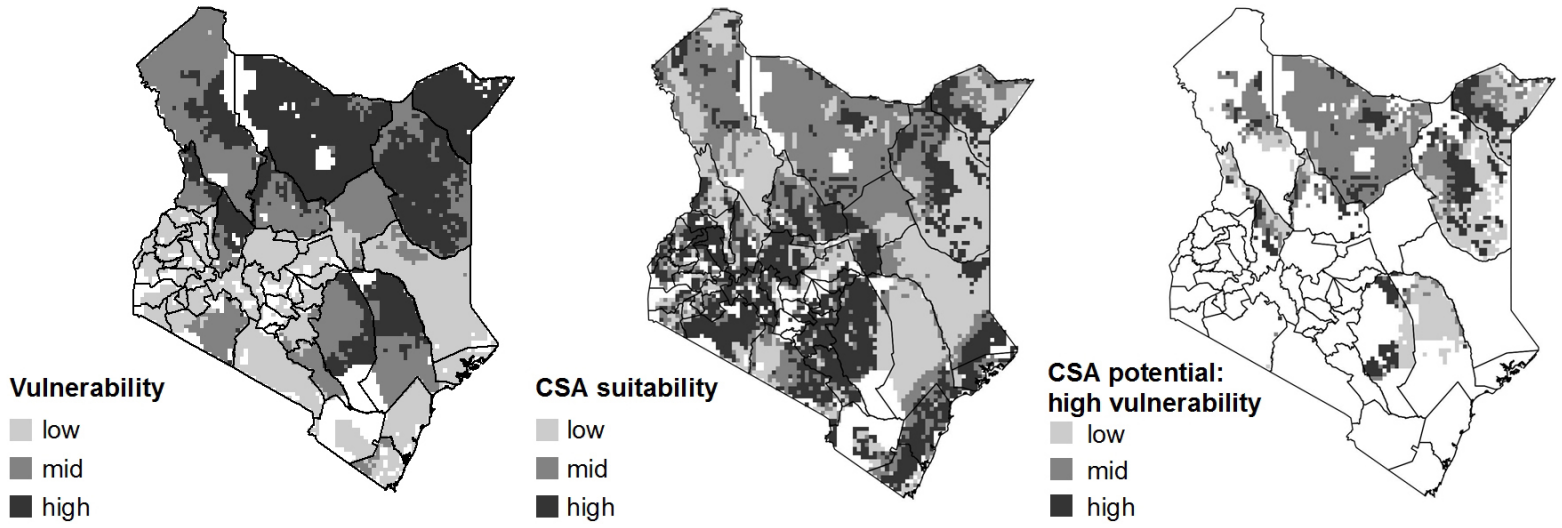

Figure 2.4: Maps show the spatially-explicit indices of vulnerability and CSA suitability as well as the CSA potential for high vulnerability regions based on consensus scenarios of the (A) majority, (B) minority and (C) most-balanced trade-off. Underlying stakeholder preferences were inferred from the overall consensus, including all experts. Classes of vulnerability and CSA suitability indices (low, mid and high) resulted from quantile splits to preserve equal $\mathrm{n}$ sizes per class. 


\subsubsection{Validation}

The preferences inferred from the overall consensus based on two expert surveys differed as shown for vulnerability indicators (Figure 2.5A) and CSA practices (Figure 2.5B) under the consensus scenario with the most-balanced trade-off between majority and minority. These differences are less pronounced for vulnerability indicators than for CSA practices indicated by mean differences between the preferences from the two surveys of 0.08 and 0.13 respectively. However, Wilcoxon signed-rank tests did not reveal significant median difference among the two sets of vulnerability indicators and CSA practices $(\mathrm{p}>$ $0.05)$. 


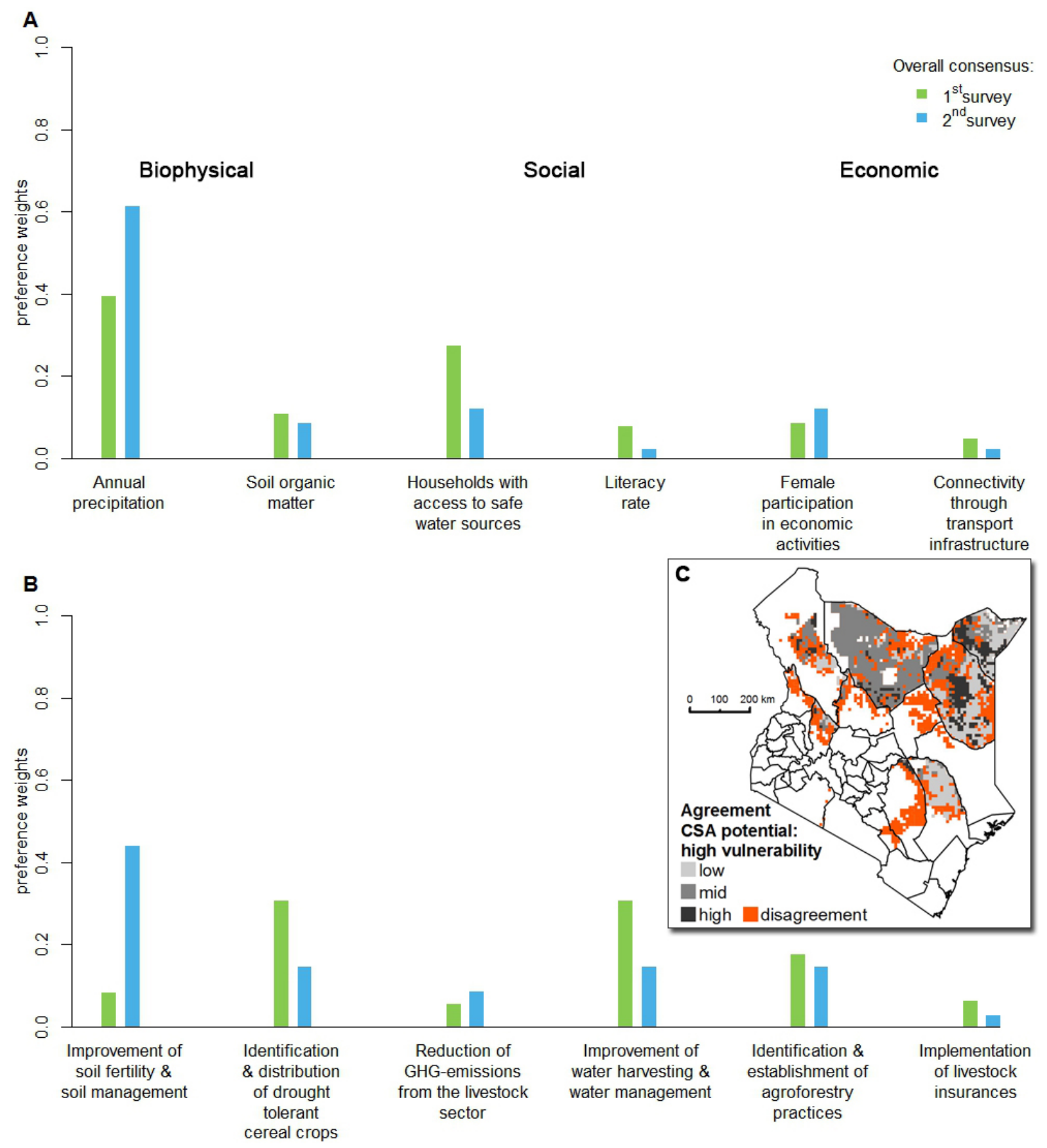

Figure 2.5: Comparison of preferences inferred from the overall consensus (including all experts) based on two expert surveys for (A) vulnerability indicators and (B) CSA practices under the consensus scenario with the most-balanced trade-off. Inset map (C) illustrates agreement on low, mid and high CSA potential in areas with high vulnerability among the two expert surveys under the same consensus scenario. Regions where the surveys disagreed on CSA potential are coloured in orange.

Mapping the CSA potential based on the two sets of vulnerability and CSA suitability indices under the consensus scenario with the most-balanced trade-off depicts agreement 
among surveys on areas with high CSA potential in the North and North-East of Kenya mainly located in Wajir and Mandera counties (Figure 2.5C). Areas of disagreement due to differing stakeholder preferences derived from the two surveys are distributed across the North and Central-East of Kenya.

\subsection{Discussion}

\subsubsection{Informing decisions with "targetCSA" using spatially-explicit vulner- ability and CSA suitability indices}

The combined and spatially-explicit indices reveal a picture of where to target stakeholder selected CSA practices to reduce agricultural vulnerability to climate change at the national level. For Kenya, areas of high vulnerability contrast with areas potentially suitable for implementing CSA practices based on the empirical information included here. This study showed that regions of high vulnerability in Kenya mainly coincide with semi-arid and arid climate resulting in harsh biophysical conditions, confounded by low availability of education and health infrastructure as well as reduced access to markets (Odera et al., 2013; Wiesmann et al., 2014). High vulnerability to climate change for arid and semi-arid areas was also reported at the global scale (Allen et al., 2007). In contrast, high suitability for selected CSA practices concentrated around sub-humid, to some degree semi-arid areas, and is discontinuously spread across arid climate (Grace et al., 2014). Nevertheless, areas of high CSA potential were identified and could be targeted for CSA pilot projects. The Western and Southern parts of Mandera county in the North-West of Kenya represent an example of high CSA potential consistently shown for specific areas across different consensus scenarios as well as expert surveys. The introduction of drought tolerant cereals on moderately suitable lands, the improvement of water management in areas of high aridity, or the implementation of livestock insurances addressing high mortality risk may represent promising CSA measures (Figure 2.4). By coupling the computed spatial indices, the originally unrestricted space could be narrowed to specific regions of high CSA potential enabling a targeted exploration of areas of interest, potentially leading to decisions that are informed by quantitative data and expert opinions.

\subsubsection{CSA-targeting as a consensus-driven approach}

Climate change adaptation planning calls for stakeholder participation integrating perceptions and opinions from a broad range of stakeholders to strive for legitimate decisions and sustainable planning solutions (Conway \& Mustelin, 2014; Krellenberg \& Barth, 2014). However, stakeholder integration may lead to dissent about the importance of planning objectives reflected by measurable preferences on multiple AHP-criteria as shown in this 
example (Figure 2.3). This has also been reported for group decision processes in forest planning (Linares \& Romero, 2002; Kangas et al., 2010). Different interests, highly complex problems and resulting uncertainties are common causes of dissent in multi-criteria decision-making applications (Nordström et al., 2010). Approaching consensus solutions by finding a PC matrix that shares the highest degree of similarity with the stakeholderderived PC matrices reduces discrepancy and hence dissent inherent to group-specific preferences.

The question of what is the appropriate consensus scenario should be asked in a certain decision-making context though. Following different consensus scenarios, changes the patterns of inferred preferences, which determine the location of regions with high potential for targeting selected CSA practices (Figure 2.4). Other studies have shown similar effects on the distribution of stakeholder preferences (Diaz-Balteiro et al., 2009; Nordström et al., 2012). The ability to choose between consensus scenarios and to explore their potential impact on decisions grants higher flexibility and legitimacy to the democratic modes that shape group decision-making processes. Relying on the majority could be a proper principle when all stakeholders possess similar influence on decisions. Instead, giving more weight to the minority might be suitable when marginalised stakeholders such as indigenous people are involved who usually have low influence on decision-making. If no agreement on opting for the majority or minority principle is achievable, a compromise solution, such as the one adopted here, is to select the most balanced trade-off between these two mutually exclusive alternatives (González-Pachón \& Romero, 2011). Hence, the explicit role of "targetCSA" is to structure decision-making problems and to facilitate the exploration as well as the discussion of discrepancies among stakeholder opinions to eventually achieve consensual solutions that aid decision-making processes where a broad range of stakeholders are involved.

\subsubsection{Sticking points of a decision support framework for targeting CSA}

\section{Capturing and reducing uncertainty from stakeholder preferences}

Stakeholder opinions may vary over time, as shown here (Figure 2.5) and represent a source of uncertainty for decision-making processes (Xu \& Zhang, 2013). The detected discrepancies regarding the preferences for some of the CSA practices are most likely an effect of shifts in stakeholder opinions due to changes of knowledge or interests. A reduction of this uncertainty is attainable through an iterative mode of preference elicitation, e.g. by following the Delphi method (Chung et al., 2014). Yet, this might be unfeasible in very conflict prone decision-making situations that are not consensually manageable or due to time and budget constraints (Nordström et al., 2010). Alternatively, additional experts may be involved in case of controversial situations to integrate specific knowledge that was missing but has the potential to mitigate such situations. An approach to analyse and un- 
derstand social dynamics behind preference changes and their effects on decision-making systems is the use of agent-based models (Bousquet \& Le Page, 2004).

\section{Applicability of "targetCSA"}

This example demonstrated the applicability of the presented decision support framework for targeting selected CSA practices. For instance, "targetCSA" could be used in different CSA related planning initiatives at national level such as Kenya's national CSA framework or the Nationally Appropriate Mitigation Action (NAMA) that is currently developed for the dairy production sector in Kenya to support the decision-making on the prioritisation of adaptation and mitigation options. The framework is applicable on a stratified, regional scale, capturing the heterogeneous characteristics within a given country by involving region-specific stakeholders, vulnerability indicators and CSA practices. Furthermore, the restricted sets of vulnerability indicators and CSA practices that were chosen for this application example are easily extendable and adoptable to other countries differing in their biophysical, social and economic conditions. This includes vulnerability indicators that reflect projected changes of temperature and precipitation, e.g. trends of decreasing precipitation and increasing temperature would translate into higher vulnerability and vice versa.

The main objective of "targetCSA" is to support decisions for adaptation and mitigation planning at the national and regional level by structuring decision-making problems as well as exploring and building consensus among different stakeholder groups. However, several scales have to be integrated eventually into a comprehensive planning for adaptation and mitigation (FAO, 2013; Conway \& Mustelin, 2014). Hence, this framework could be coupled with bottom-up approaches to properly deal with local realities and to allow for fine-scale planning (Chaudhury et al., 2014; Rosenstock et al., 2014).

\subsubsection{Further research}

Research efforts should be invested into elucidating the impact of CSA practices on vulnerability alleviation and analyses of synergies and trade-offs among adaptation and mitigation options in specific areas, including assessments of implementation costs and benefits for farmers (Harvey et al., 2014a). Information that links the implementation of CSA practices to their local effects could be derived from household surveys and exhaustive meta-analyses of CSA case studies relating costs and profitability to biophysical and social conditions prevailing in regions of interest. The resulting spatially upscaled indices of CSA costs and benefits would represent further layers of information supporting the decision-making on CSA prioritisation together with the aggregated vulnerability and CSA suitability indices. Moreover, vulnerability indicators need to be further elaborated 
to meet the needs of the planning process and to allow for quantitative analyses of interactions and feedback mechanisms between biophysical indicators mostly pointing to exposure and sensitivity as well as social and economic indicators mainly determining the adaptive capacity of agricultural systems (Fellmann, 2012). Shedding light on how to couple the national top-down approach of CSA-targeting with bottom-up initiatives is necessary to synchronise local and broad scale adaptation planning (Conway \& Mustelin, 2014).

\subsection{Conclusions}

Climate change adaptation and mitigation efforts need to be coordinated through national planning processes that implement properly climate change action plans. Related decisions should be made in accordance with relevant stakeholders and guided by quantitative information including biophysical, social and economic conditions. Especially the latter point might be challenging in data-deficient regions, yet, the exemplary application of "targetCSA" in Kenya showed that it is potentially feasible.

The main benefits of "targetCSA" for decision-makers are:

1. Problem structuring and complexity reduction by using AHP and pair wise comparison methods.

2. Spatially-explicit indices are built upon consensual preferences from cross-sectoral stakeholders on multiple criteria reflected by included vulnerability indicators and CSA practices.

3. The ability to choose between different consensus scenarios and to explore their potential effects on decisions may lead to more sustainable planning outcomes due to higher acceptance.

4. By using a three-dimensional concept of vulnerability, including biophysical, social and economic factors a demand-based assessment of CSA potential becomes possible.

5. Its transferability to other countries makes the applicability of the framework highly flexible.

\section{Acknowledgments}

This work was funded by the 'Climate Change Agriculture, and Food security' (CCAFS) program of the 'Consultative Group on International Agricultural Research' (CGIAR). 
We are very grateful for the cooperation of the 32 participating experts and their institutions. We sincerely thank Catherine Mungai and James Kinyangi for their support in this project. 



\section{Chapter 3}

\section{The contribution of sectoral climate change mitigation options to national targets: a quantitative assessment of dairy production in Kenya}

Brandt, P., Herold, M., Rufino, M.C., 2018. The contribution of sectoral climate change mitigation options to national targets: a quantitative assessment of dairy production in Kenya. Environmental Research Letters 13, 034016. 


\section{Abstract}

Reducing greenhouse gas (GHG) emissions from agriculture has become a critical target in national climate change policies. More than $80 \%$ of the countries in Sub-Saharan Africa (SSA) refer to the reduction of agricultural emissions, including livestock, in their 'Nationally Determined Contributions' (NDC) to mitigate climate change. The livestock sector in Kenya contributes largely to the gross domestic product and to GHG emissions from the land use sector. The government has recently pledged in its NDC to curb total GHG emissions by $30 \%$ by 2030. Quantifying and linking the mitigation potential of farm practices to national targets is required to support realistically the implementation of NDCs. Improvements in feed and manure management represent promising mitigation options for dairy production. This study aimed (i) to assess mitigation and food production benefits of feed and manure management scenarios, including land use changes covering Kenya's entire dairy production region and (ii) to analyse the contribution of these practices to national targets on milk production and mitigation, and their biophysical feasibility given the availability of arable land. The results indicate that improving forage quality by increasing the use of Napier grass and supplementing dairy concentrates supports Kenya's NDC target, reduces emission intensities by $26-31 \%$, partially achieves the national milk productivity target for 2030 by $38-41 \%$, and shows high feasibility given the availability of arable land. Covering manure heaps may reduce emissions from manure management by $68 \%$. In contrast, including maize silage in cattle diets would not reduce emission intensities due to the risk of 10 -fold higher emissions from the conversion of land required to grow additional maize. The shortage of arable land may render the implementation of these improved feed practices largely infeasible. This assessment provides the first quantitative estimates of the potential of feed intensification and manure management to mitigate GHG emissions and to increase milk yields at sectoral-level and at a high spatial resolution for an SSA country. The scientific evidence is tailored to support actual policy and decision-making processes at the national level, such as 'Nationally Appropriate Mitigation Actions' (NAMAs). Linking feed intensification and manure management strategies with spatially-explicit estimates of mitigation and food production to national targets may help the sector to access climate financing while contributing to food security. 


\subsection{Introduction}

Greenhouse gas (GHG) emissions from 'Agriculture, Forestry and Other Land Uses' (AFOLU) are estimated to contribute $24 \%$ to the total anthropogenic GHG emissions (Smith et al., 2014). The global livestock production as a sub-sector of AFOLU emits between $10-14.5 \%$ of total GHG emissions, of which $4 \%$ are due to dairy production (Gerber et al., 2010; Westhoek et al., 2011). Total GHG emissions from dairy production are projected to increase by $82 \%$ under 'business as usual' (BAU) trajectories until 2050 compared to 2000, as production expands to keep up with the milk demand of a growing human population (O’Mara, 2011).

Current food insecurity in many low-income countries, especially in Sub-Saharan Africa (SSA), and sustained population growth call for assessments that contribute to both the mitigation of AFOLU emissions and the improvement of food provisioning from agricultural systems (Smith et al., 2013). The development of schemes that mitigate AFOLU emissions such as 'Nationally Appropriate Mitigation Actions' (NAMAs) have recently gained attention from governments that ratified the Paris climate agreement under the 'United Nations Framework Convention on Climate Change' (UNFCCC, 2011; Grassi et al., 2017). Countries express their mitigation targets in the 'Nationally Determined Contributions' (NDCs). Kenya's NDC targets to limit the increase in total GHG emissions projected in the national BAU scenario by $30 \%$ between the base year of 2010 and 2030 (Government of Kenya, 2015b). Reliable estimates of sectoral baseline emissions and effective mitigation options are still missing and required urgently to develop NAMAs that help achieve the NDC targets. Focussing on livestock production in Kenya is highly relevant since it is responsible for about $30 \%$ of its total GHG emissions and contributes about $45 \%$ to the agricultural gross domestic product (McDermott et al., 2010; Government of Kenya, 2015a).

The dairy sector in Kenya sustains the livelihood of about two million smallholder households, who contribute approximately $80 \%$ to the $3.4 \mathrm{M}$ t of milk produced in the country (Udo et al., 2016). In addition, dairy products supply a range of valuable nutrients and therefore contribute to the human population health. Culturally, milk is a vital component of agro-pastoralists diets in East Africa (Rufino et al., 2013). The population of dairy cattle has increased by about $31 \%$ to 4.3 M heads from 1998 to 2014 (Muriuki, 2011; Government of Kenya, 2014), whereas feed inputs for dairy cattle have increased by about $32 \%$ from 1998 to 2006 (Muriuki, 2011). Increased animal numbers and the additional demand for feeds contribute largely to emissions of non-carbon dioxide GHGs, namely methane $\left(\mathrm{CH}_{4}\right)$ and nitrous oxide $\left(\mathrm{N}_{2} \mathrm{O}\right)$ through enteric fermentation, manure and soil management. In addition, the trend of increasing livestock numbers leads to emissions from degraded rangelands and forests (Kumar et al., 2009; O’Mara, 2011; Bosire et al., 2016). 
The dairy sector has to increase production sustainably by 2030 to be able to meet the projected milk demand estimated in the national policy framework for the development of the dairy sector, called Kenya's national dairy master plan (Government of Kenya, 2010). Several initiatives such as the 'East Africa Dairy Development' (EADD) program, the 'Smallholder Dairy Commercialization Programme' (SDCP) supported by the 'International Fund for Agricultural Development' (IFAD) and the 'Kenya Dairy Sector Competitiveness Program' (KDSCP) supported by the 'United States Agency for International Development' (USAID) are actively engaged in the development of the dairy sector in East Africa. These initiatives are increasingly looking for development outcomes that realise climate change mitigation benefits at the same time. A challenge to realise the projected growth of the dairy sector is that to date, a large share of cattle diets consists of low quality roughage from overstocked grazing land and crop residues (McDermott et al., 2010). Improving feed quality is needed to increase milk yields (Lukuyu et al., 2012). However, the conversion of land to grow higher quality fodder and the GHG emissions resulting from land use change (LUC) may compromise expected reductions from changes in feeding practices advocated in national policies (Valin et al., 2013). In addition, the shortage of arable land may constrain the implementation of feeding practices that increase the demand for cropland.

This study aimed to answer the question: to what extent the improvement of feed quality and manure management may contribute to the milk productivity target of Kenya's national dairy master plan and to the national mitigation target (NDC) given the availability of arable land. The objectives were: i) to quantify total GHG emissions and GHG emission intensities under current feed and manure management conditions, and alternative feed intensification scenarios, including manure management, ii) to assess the potential of these scenarios to meet the national targets and the biophysical feasibility to implement the practices, and iii) to map total baseline GHG emissions, milk production, and the potential changes for the dairy sector. Such analyses are relevant to inform the development of climate mitigation policies.

\subsection{Material and methods}

\subsubsection{Study area}

The main dairy region of Kenya is characterised by rainfed (71\%) and irrigated (29\%) mixed crop-livestock production systems covering the Central and Western highlands as well as humid areas in the West of Kenya with an area of approximately $65,000 \mathrm{~km}^{2}$ and 24 counties (Appendix S3, Figure S3.1). The delineation of the study area was based on (Herrero et al., 2014) who assessed smallholder development trajectories in mixed crop-dairy production systems. Dairy production takes place in a region with high 
agricultural potential, where about $68 \%$ of the total human population lives (Herrero et al., 2014). Typical smallholder farms are small with an average size of 0.47 ha (Lowder et al., 2014).

\subsubsection{Calculating GHG emissions and milk production}

The emission source categories (IPCC, 2006) included in this analysis are: $\mathrm{CH}_{4}$ emissions from enteric fermentation, $\mathrm{CH}_{4}$ emissions from manure management, direct and indirect $\mathrm{N}_{2} \mathrm{O}$ emissions from manure management, direct and indirect $\mathrm{N}_{2} \mathrm{O}$ emissions from managed soils, and $\mathrm{N}_{2} \mathrm{O}$ and carbon dioxide $\left(\mathrm{CO}_{2}\right)$ emissions from LUC converting grazing land to cropland using data from Don et al. (2011) and Hengl et al. (2015). This study followed the IPCC tier 2 approach for most categories. For a detailed description of emission parameters see (Appendix S3, Table S3.1). All emission source categories were quantified separately for dairy cattle using a classification of livestock production systems (LPS) (Appendix S3, Figure S3.2): mixed rainfed system in arid areas (MRA), mixed rainfed system in humid areas (MRH), mixed rainfed system in tropical highlands (MRH), mixed irrigated system in arid areas (MIA), mixed irrigated system in humid areas (MIH) and the mixed irrigated system in tropical highlands (MIT). This LPS classification, developed by Robinson et al. (2011), has been used to analyse different environmental and economic aspects of livestock production (Thornton \& Herrero, 2010; Herrero et al., 2013; Rufino et al., 2014). GHG emissions that result from dairy concentrate supplementation, including the cultivation of feed ingredients were calculated using an emission factor from Weiler et al. (2014). This factor was used in a dairy life cycle assessment at farm level in the Kenyan highlands, assuming that the concentrate ingredients originate from Kenya and Uganda (Appendix S3, Table S3.1).

Conversion factors (expressed as $\mathrm{CO}_{2}$ equivalents) for $\mathrm{CH}_{4}$ and $\mathrm{N}_{2} \mathrm{O}$ were applied according to the most recent global warming potentials (GWP) from the fifth assessment report of the 'Intergovernmental panel on climate change' (IPCC, 2014). GHG emissions are reported as total GHG emissions and emission intensities. The later notion is expressed on product basis and converted into $\mathrm{kg} \mathrm{CO}_{2} \mathrm{eq}$ per $\mathrm{kg}$ fat and protein corrected milk (FPCM). Both notions were selected to relate the mitigation potential of the scenarios to the NDC target (total emissions) and to communicate efficiency gains for each scenario, relevant for a NAMA (emission intensity).

\subsubsection{The Livestock Simulator: LivSim}

The dynamic production model 'LivSim' was used to simulate milk yields, and faecal and urine excretion for individual dairy cattle on a monthly basis (Rufino et al., 2009). The 'HeapSim' model, coupled with LivSim, was used to integrate the dynamics of manure decomposition during storage, including the nutrient losses, and manure application 
(Rufino et al., 2007). LivSim was extended with a GHG emission module to compute GHG emissions from the different source categories (Appendix S3, Table S3.1) following (IPCC, 2006). The models were run using the open source language for numerical computations GNU Octave (v.4.0) (Eaton et al., 2015). Each run simulated a dairy cow over the maximum lifetime of 13 years and was replicated 100 times for each LPS to account for stochasticity in calving and mortality.

LivSim was calibrated with information derived from literature and feed datasets (Anindo et al., 1994; Rufino et al., 2009; Katiku et al., 2011; Herrero et al., 2013; Weiler et al., 2014; Castellanos-Navarrete et al., 2015), cattle breeds and emission parameters (Kategile et al., 1987; Stares et al., 1991; IPCC, 2006; Monfreda et al., 2008; Rufino et al., 2009; Potter et al., 2010; Herrero et al., 2013) representing the baseline conditions for each LPS in Central and Western Kenya (Appendix S3, Table S3.1). Emission uncertainties were estimated using a twofold approach. First, Latin hypercube sampling (LHS) (Xu et al., 2005) was applied to the baseline simulations sampling the ranges of 23 emission parameters. One parameter at a time was sampled through LHS while keeping all others constant at the mean of their ranges (ten Broeke et al., 2016) (Appendix S3, Table S3.1). Second, the emission uncertainties of the modelled scenarios were calculated one parameter at a time sampling at the minimum and the maximum of the parameter ranges.

\subsubsection{Spatial upscaling of GHG emissions and milk production}

Spatially-explicit datasets on LPS and cattle density, at a spatial resolution of $1 \mathrm{x} 1 \mathrm{~km}$ per grid cell (Robinson et al., 2011, 2014), were used to upscale and to map output tables of GHG emissions and milk production derived from LivSim (Figure 3.1). Since this study focused on GHG emissions from dairy production, the density of dairy cattle was calculated using sub-national county level data on cattle types excluding cattle used for beef production (Government of Kenya, 2014). Moreover, herd composition data were applied to reflect the proportion of productive and non-productive animals in dairy herds according to Bebe et al. (2002). The spatial upscaling procedure was implemented using the statistical computing language R (v. 3.2.3), including the R library 'raster' (v. 2.5) (Hijmans, 2016; R Core Team, 2016). Feeds were assumed to be grown locally within one grid cell. Therefore, no transport emissions were included. 


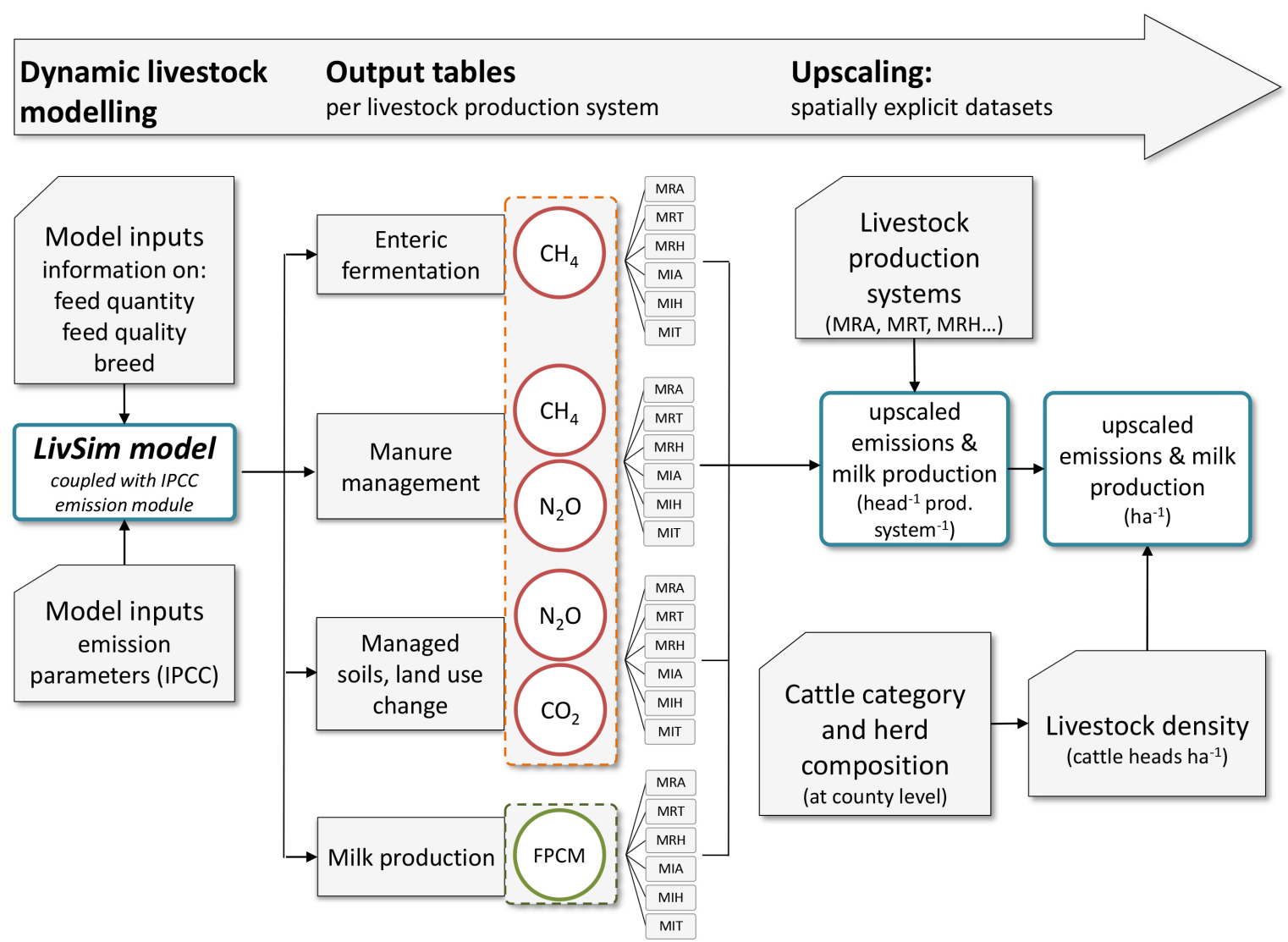

Figure 3.1: Flowchart shows the model framework applied in this study consisting of a dynamic livestock modelling approach to compute output tables of GHG emissions and milk production. Subsequently, these tables were upscaled based on livestock production systems and mapped using data on herd composition, cattle category and density.

\subsubsection{Feed and manure management}

\section{Baseline feeds}

Feed composition and quantity data used to model the baseline reflected typical diets for dairy cattle kept by smallholders across the Kenyan highlands. Feed data were obtained from Rufino et al. (2009), Katiku et al. (2011), Herrero et al. (2013), Weiler et al. (2014), and Castellanos-Navarrete et al. (2015). Agro-climatic conditions present in the various LPS used were taken into account leading to differences in dry matter intake (DMI). Annual DMI ranged between 2,414 - 2,475 kg per tropical livestock unit (TLU). The baseline diet was composed of native grass from grazing land (36-52\%), Napier grass (Pennisetum purpureum) (24 - $42 \%$ ), maize stover $(21-27 \%)$, and dairy concentrate (1\%) (Appendix S3, Table S3.2). Feed quality data, including quality differences due 
to seasonal variation were derived from Rufino et al. (2009) and from the 'Sub-Saharan Africa feed composition database' (Anindo et al., 1994).

\section{Feed intensification scenarios}

Feeds with high energy and protein density increase feed digestibility and milk yields (Hristov et al., 2013a). Thus, using these feeds would reduce the demand for feeds from the low productivity and low quality natural pastures. Dairy farming in Kenya relies primarily on these natural pastures as main source of feed. Different regional estimates show that 41 - $90 \%$ of the dairy farmers use native grass as main feed resource (Katiku et al., 2011; Lukuyu et al., 2011; Njarui et al., 2011). Feeds of high quality pass the rumen faster, which reduces anaerobic fermentation and methanogenesis due to post ruminal digestion and, thus, results in lower production of $\mathrm{CH}_{4}$ (Eckard et al., 2010; Knapp et al., 2014). Highly degradable feedstuffs with high protein and starch contents reduce ruminal $\mathrm{pH}$ and shift the fermentation process from acetate to propionate formation increasing the consumption of $\mathrm{H}_{2}$, which is consequently unavailable for $\mathrm{CH}_{4}$ production (Dijkstra et al., 2011; Soren et al., 2015). However, increased protein content in diets may cause higher N excretion leading to potential trade-offs between $\mathrm{CH}_{4}$ and $\mathrm{N}_{2} \mathrm{O}$ emissions (Dijkstra et al., 2011). Feed intensification scenarios developed in this study were based on plausible strategies that can improve milk yields and reduce GHG emission intensities:

Improved forage quality $\left(F_{0}\right)$ : Increasing forage digestibility improves the efficiency of milk production and can reduce $\mathrm{CH}_{4}$ emissions per unit FPCM ranging from $2.5-21 \%$ (Boadi et al., 2004; Knapp et al., 2014; Trupa et al., 2015). Napier grass is a perennial fodder crop with higher quality than native grass and is widely grown as fodder crop by dairy farmers in Kenya (Kariuki et al., 1999; Muia et al., 2001). It is estimated, that 21 $93 \%$ of the farmers plant Napier grass in the region (Katiku et al., 2011; Lukuyu et al., 2011; Njarui et al., 2011). Hence, there is potential to increase the proportion of Napier grass in the dairy diet (Lukuyu et al., 2012; Owen et al., 2012).

Feed conservation and increased grain content $(\mathrm{Fe})$ : Ensiling fresh fodder such as whole maize plants is proposed as feed conservation strategy for dairy farmers to reduce feed scarcity during the dry season (Lukuyu et al., 2012). $\mathrm{CH}_{4}$ emissions can be reduced by up to $33 \%$ per unit FPCM replacing grasses with maize silage (Boadi et al., 2004; Chagunda et al., 2010; Brask et al., 2013). Increasing the proportion of grain in the diet leads to higher starch concentration, lower fibre content and decreased ruminal $\mathrm{pH}$, which reduces methanogenesis and $\mathrm{CH}_{4}$ emissions per unit feed (Beauchemin et al., 2008; Dijkstra et al., 2011). Crop residues such as maize stover are also commonly fed to dairy cattle by 33 $100 \%$ of the Kenyan dairy farmers (Katiku et al., 2011; Njarui et al., 2011). Since maize is an important food crop, additional maize and arable land are required to produce silage and to avoid compromising food security. The conversion of grazing land to cropland 
causes $\mathrm{N}_{2} \mathrm{O}$ and $\mathrm{CO}_{2}$ emissions, which are henceforth defined as emissions from LUC (de Boer et al., 2011; Don et al., 2011).

Dairy concentrates supplementation (Co): Higher proportion of concentrates in the diet especially during the first half of the lactation can increase milk productivity by $8-37 \%$ (Agle et al., 2010; Richards et al., 2016). Higher concentrate proportion in the diet, replacing roughage can decrease $\mathrm{CH}_{4}$ emissions by 15 - $39 \%$ (Chagunda et al., 2010; Hristov et al., 2013b; Knapp et al., 2014). About 10 - $88 \%$ of dairy farmers in Kenya supplement dairy concentrates, although at very low rates (Katiku et al., 2011; Lukuyu et al., 2011; Njarui et al., 2011).

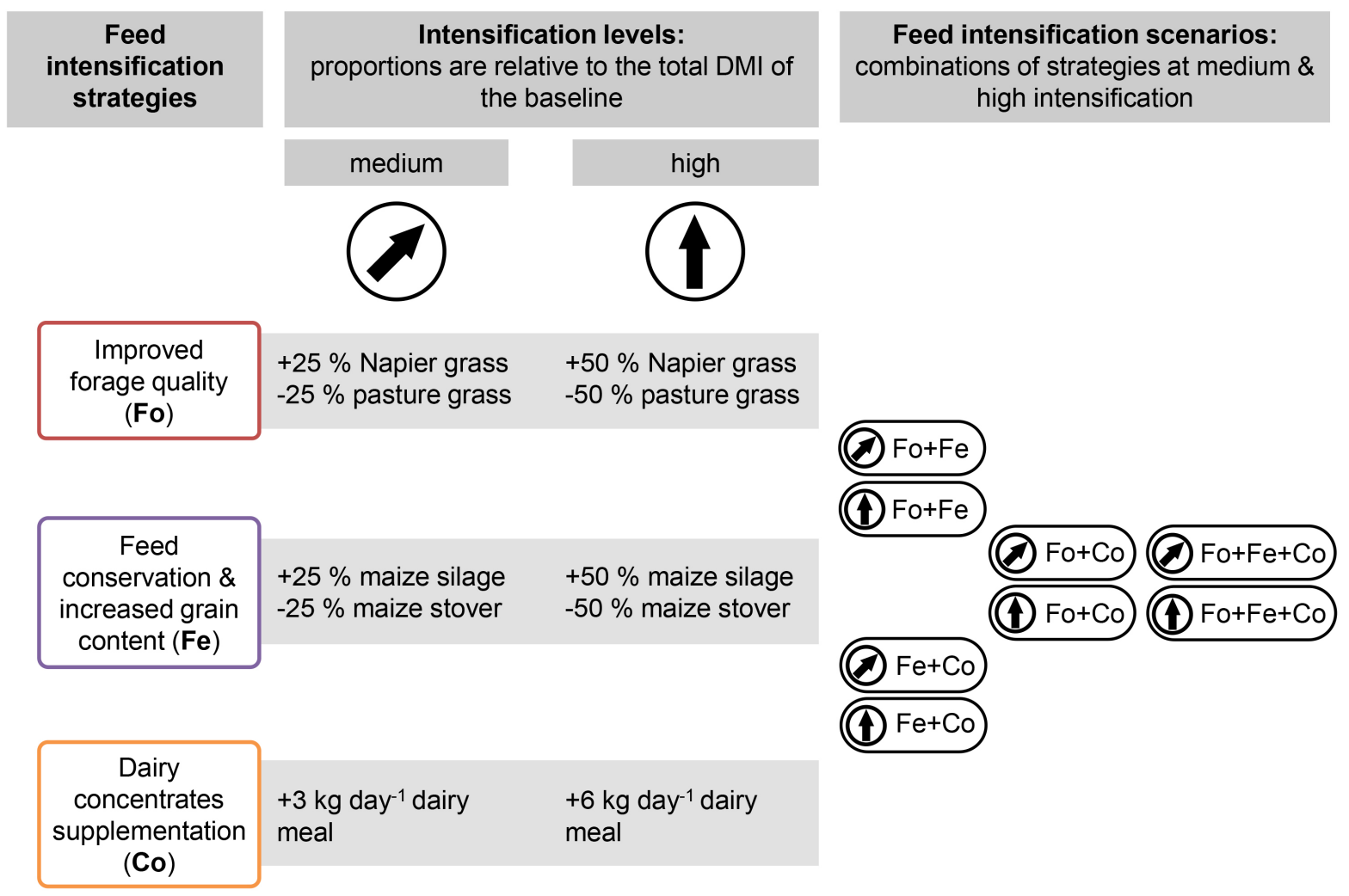

Figure 3.2: Feed intensification scenarios based on combinations of three feed intensification strategies at medium and high level of intensification (DMI $=$ dry matter intake). Dairy concentrates supplementation was increased during the first 150 days of lactation. For details on the baseline diet, see Appendix (S3, Table S3.2)

The scenarios were derived through combinations of the three feed intensification strategies (Figure 3.2) and are henceforth called: 'forage quality and concentrate supplementation' (FoCo), 'feed conservation and concentrate supplementation' (FeCo), 'forage quality and feed conservation' (FoFe), and 'forage quality, feed conservation and concentrate supplementation' (FoFeCo). Each scenario was developed at medium and high level of intensification (Figure 3.2). For the Fo and Fe strategies, baseline feeds were replaced by 
$25 \%$ and $50 \%$ with higher quality alternatives. The supplementation of dairy concentrates was increased for the Co strategy by $3 \mathrm{~kg}^{\text {day }}{ }^{-1}$ and $6 \mathrm{~kg}$ day- 1 during the first 150 days of lactation.

\section{Manure management}

Direct and indirect $\mathrm{N}_{2} \mathrm{O}$ emissions result from nitrification and denitrification of ammonium and nitrate contained in manure, the leaching of nitrate, and the volatilisation of ammonia $\left(\mathrm{NH}_{3}\right)$ (IPCC, 2006). Manure management can prevent the loss of $\mathrm{N}$ during the storage. Manure that is rich in nutrients can be used to improve soil fertility and farm productivity (Tittonell et al., 2009, 2010). Covering manure heaps can reduce leaching and volatilisation and, thus, $\mathrm{N}_{2} \mathrm{O}$ and $\mathrm{NH}_{3}$ emissions by about $30 \%$ and $90 \%$ respectively compared to uncovered heaps (Chadwick, 2005; Hou et al., 2015). However, $\mathrm{CH}_{4}$ emissions can be increased due to anaerobic conditions (Montes et al., 2014). Covering heaps is considered a feasible practice for smallholders in SSA compared to other options such as the separation and cooling of slurry or anaerobic digestion (de Boer et al., 2011). It is uncommon for smallholders to cover manure heaps (Tittonell et al., 2010), thus uncovered heaps were assumed for the baseline (Appendix S3, Table S3.1). For all scenarios, the covering of heaps reduced the baseline factor for direct $\mathrm{N}_{2} \mathrm{O}$ emissions by about $1 \%$ for arid LPS and by about $0.25 \%$ in the humid and highland LPS. The volatilisation and leaching fractions were lowered by $5 \%$ and $10 \%$ respectively, across LPS in relation to the baseline (IPCC, 2006).

\subsubsection{Scenarios, national targets and their biophysical feasibility}

Feed intensification and manure management scenarios were analysed in terms of: i) milk yield increases in relation to the dairy master plan target, ii) total GHG emission increases and the NDC target, and iii) the demand for arable land. Scenario increases in milk yield $\left(\mathrm{X}_{\mathrm{i}}\right)$ were re-scaled $(0-100 \%)$ to the baseline milk yields $\left(\mathrm{X}_{\min }\right)$ and the projected relative increase in milk yield per dairy cow between 2010 - 2030 ( $\mathrm{X}_{\max }=$ dairy master plan target) using equation (3.1). Scenario increases in total GHG emissions $\left(\mathrm{X}_{\mathrm{i}}\right)$ were re-scaled $(0-$ $100 \%)$ to the baseline total GHG emissions $\left(\mathrm{X}_{\min }\right)$ and the projected relative increase in total GHG emissions between $2010-2030$ ( $\mathrm{X}_{\max }=$ national BAU scenario). The relative GHG emission increase of the BAU scenario and the tolerable increase according to the NDC target, which reduces the increase in total GHG emissions by $30 \%$ in relation to the BAU scenario, were calculated by following steps $(1-5)$ in Appendix (S3).

$$
V_{\text {res }}=\frac{\left(X_{\mathrm{i}}-X_{\min }\right)}{\left(X_{\max }-X_{\min }\right)} \times 100
$$


$\mathrm{V}_{\text {res }}=$ re-scaled scenario values of increases in milk yield (\%) and total GHG emissions $(\%)$

$\mathrm{X}_{\mathrm{i}}=$ original scenario values of increases in milk yield (\%) and total GHG emissions $(\%)$

$\mathrm{X}_{\min }=$ minimum values derived from the baseline model for milk yield and total GHG emissions representing $0 \%$

$\mathrm{X}_{\max }=$ maximum values derived from the dairy master plan and Kenya's national BAU scenario representing $124.1 \%$ of milk yield increase and $95.9 \%$ of total emission increase between 2010 - 2030 .

The biophysical feasibility of the scenarios was assessed comparing their demand for arable land and its availability. Only current grazing land was considered suitable for the conversion to grow Napier grass and maize, as the remaining forests in Kenya are protected and the expected GHG emissions from deforestation would be high (Don et al., 2011; Carter et al., 2015). A spatially-explicit dataset on current grazing land was used to analyse the availability of arable land for dairy cattle (van Velthuizen et al., 2007). The demand for cropland was calculated for each scenario based on the crop-specific feed intake per cow, density of dairy cattle, and expected yields per feed type (Appendix S3, Table S3.3, equations S3.1 \& S3.2). The shortage of arable land was calculated for each scenario based on the proportion of grid cells, throughout the study area, where the demand for land exceeds the amount of grazing land available $($ minimum $=0 \%$, maximum $=100 \%$ ). The multivariate measure of Euclidean distances was calculated (Crawley, 2007) to quantify how close each scenario approaches the theoretical optimum for the three dimensions included. The optimum is hereby defined as $100 \%$ milk yield increase, $0 \%$ total emission increase and $0 \%$ shortage of arable land.

\subsection{Results}

\subsubsection{Effects of feed intensification and manure management on total GHG emissions and emission intensities}

Across all scenarios, the simulations showed an average increase in total GHG emissions of $39.5 \pm 23.0 \%$ (standard deviation, SD) per TLU compared to the baseline. The lowest increase was shown for the FoCo scenario at medium level of intensification and the highest increase was indicated for the FoFeCo scenario at high level of intensification. The increase in total emissions throughout the scenarios was largely caused by higher emissions from manure management $(35.6 \pm 32.9 \%)$, emissions from soils due to the cultivation of feeds including concentrates (206.1 $\pm 163.4 \%)$, and LUC emissions resulting from the conversion of grazing land to cropland (Figure 3.3A). The increase in emissions 
from these sources outweighed the reduction of $\mathrm{CH}_{4}$ emissions from enteric fermentation $(9.5 \pm 6.7 \%)$ achieved through substituting low quality feed ingredients by higher quality alternatives. This effect was most pronounced for scenarios that included maize silage at high level of intensification. The reduction of $\mathrm{CH}_{4}$ emissions from enteric fermentation achieved in these scenarios was $11.2 \pm 8.6 \%$, whereas the increase of $\mathrm{N}_{2} \mathrm{O}$ emissions from feed cultivation (mainly dairy concentrates) was on average four times higher compared to the baseline. Feed conservation caused on average three times higher $\mathrm{CO}_{2}$ emissions from LUC compared to scenarios that did not include this strategy at high intensification level. Throughout the scenarios, the covering of manure heaps reduced the increase of related direct $\mathrm{N}_{2} \mathrm{O}$ emissions due to elevated $\mathrm{N}$ excretion on average by $77.0 \pm 1.0 \%$ when compared scenarios without this management option. Indirect $\mathrm{N}_{2} \mathrm{O}$ emissions from $\mathrm{N}$ leaching and volatilisation $\left(\mathrm{NH}_{3}\right)$ were on average reduced by $15.3 \pm 3.0 \%$.

Variability in emissions (shown by SD) among LPS for the baseline and scenarios ranges between $1.6-5.1 \%$ for $\mathrm{CH}_{4}$ emissions from enteric fermentation, $6.5-20.3 \%$ for $\mathrm{CH}_{4}$ and $\mathrm{N}_{2} \mathrm{O}$ emissions from manure management, $2.1-23.8 \%$ for soil emissions from feed cultivation, and $6.2-13.7 \%$ for LUC emissions. This variability resulted from differences in feed quality across LPS (1 - $2 \%$ ) leading to variation in N excretion rates $(2.3-28.3 \%)$. Differences between the yields for Napier and maize $(6.6-12.9 \%)$ also influenced the demand for additional cropland among the LPS.

Four scenarios showed a decrease in emission intensities in relation to the baseline, namely FoCo at medium (27.2\%) and high intensification $(20.4 \%)$, FoFeCo at medium intensification (11.2\%), and FeCo at medium intensification (9.1\%) (Figure 3.3B). Scenarios that included the use of silage, especially at high intensification level, did not reduce emission intensities, largely due to high LUC emissions. Higher milk yields were achieved, yet LUC emissions increased largely due to the conversion of cropland needed to grow additional maize. These emissions were on average ten times higher than those of the high intensification scenario using Napier instead of silage, outweighing the reductions in $\mathrm{CH}_{4}$ emissions from enteric fermentation by $8.4 \% \pm 6.2$. 
A

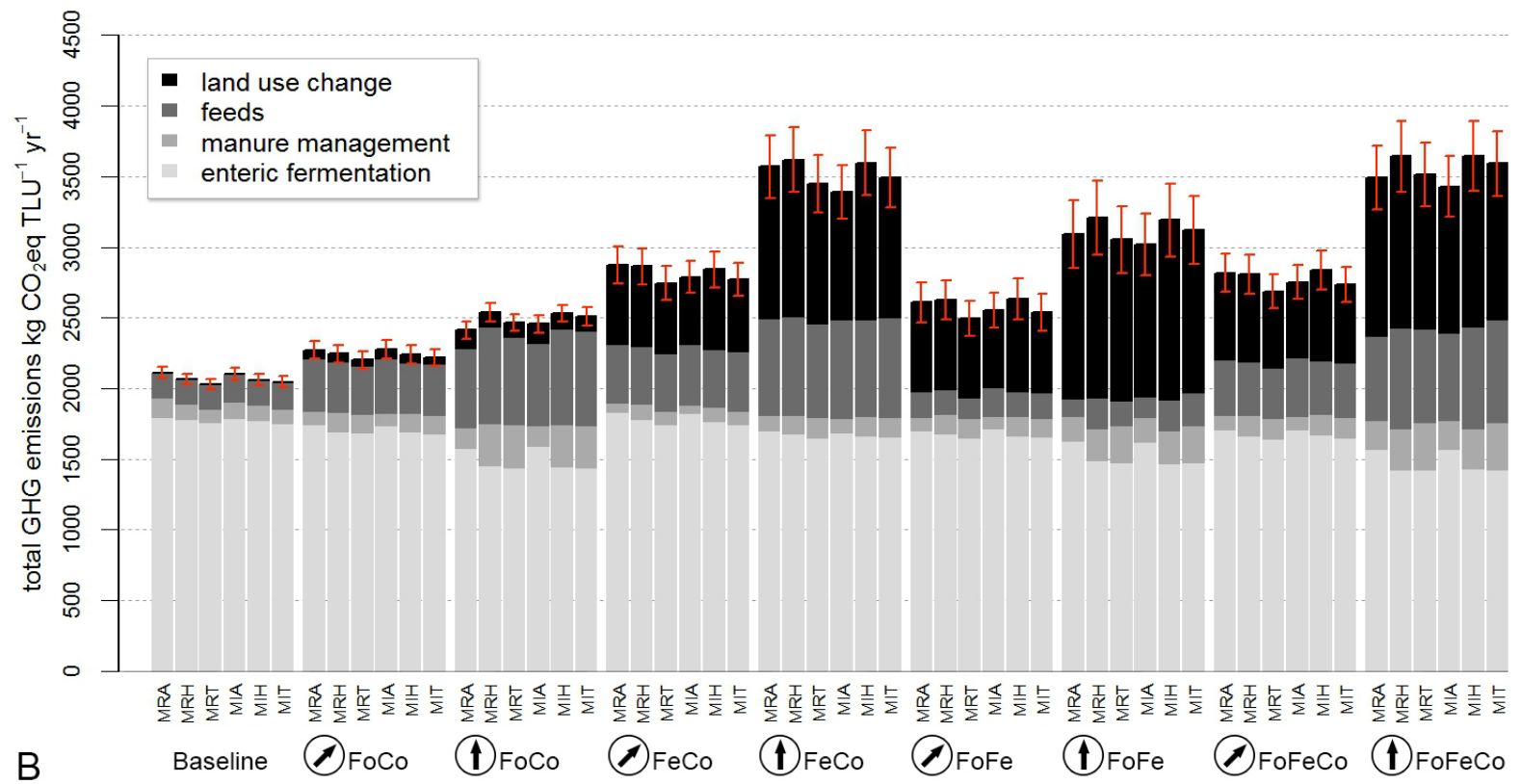

B

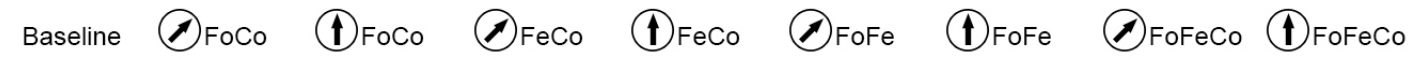

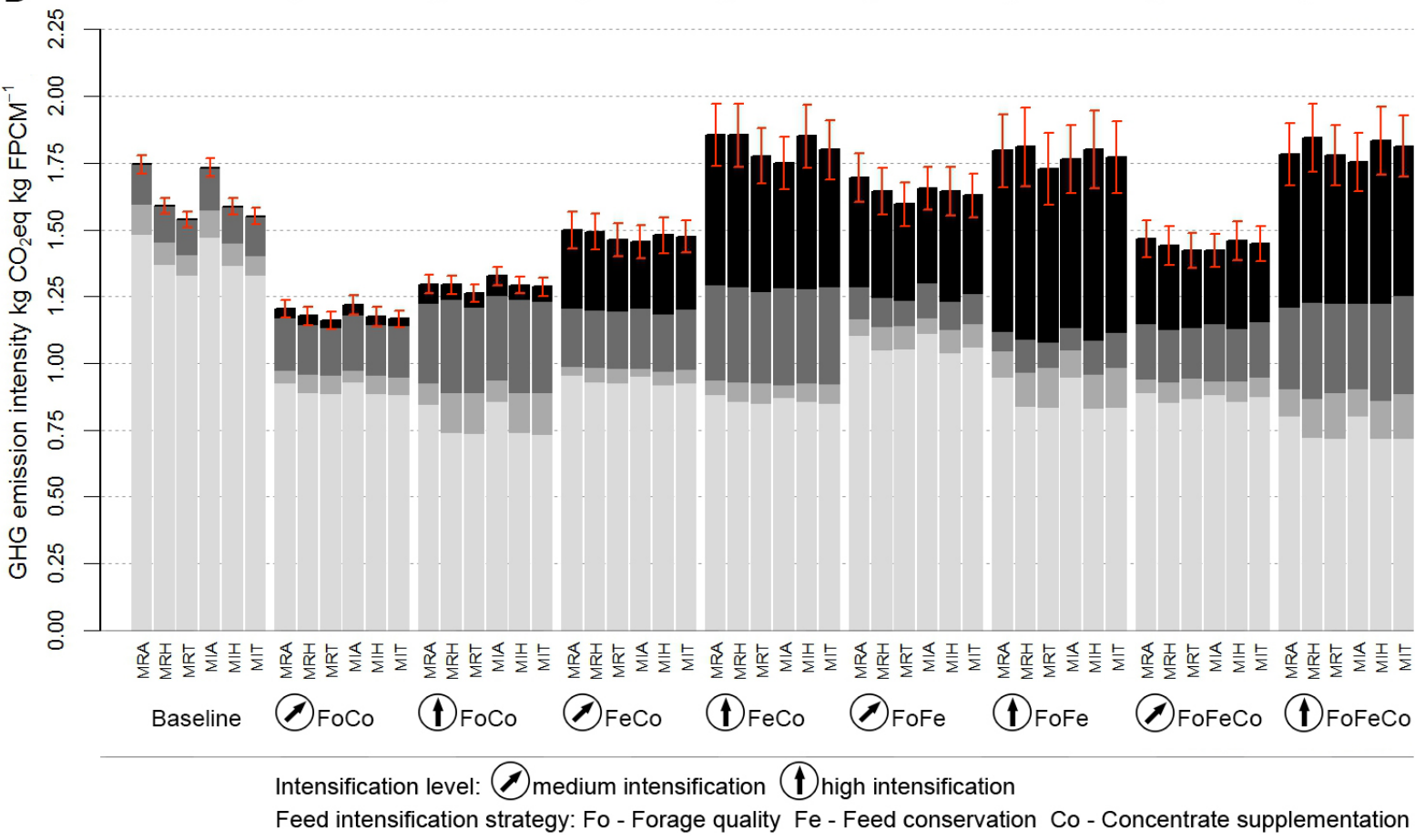

Figure 3.3: For the baseline and scenarios (A) shows total GHG emissions per TLU (tropical livestock unit) for different LPS (livestock production systems, Appendix S3, Figure S3.2) and (B) indicates GHG emission intensities per $\mathrm{kg}$ FPCM (fat and protein corrected milk). $\mathrm{CH}_{4}$ and $\mathrm{N}_{2} \mathrm{O}$ emissions were converted to $\mathrm{kg} \mathrm{CO}_{2}$ eq. Barplots represent i) $\mathrm{CH}_{4}$ emissions from enteric fermentation, ii) $\mathrm{CH}_{4}$ and $\mathrm{N}_{2} \mathrm{O}$ emissions from manure management, iii) $\mathrm{N}_{2} \mathrm{O}$ emissions from soils, including manure deposition on pasture, manure application to fodder crops, crop residues from fodder crops and fertiliser application to fodder crops and emissions from concentrate supplementation, and iv) $\mathrm{N}_{2} \mathrm{O}$ and $\mathrm{CO}_{2}$ emissions from land use change (LUC), including $\mathrm{N}$ mineralisation and loss of soil organic carbon. Error bars indicate standard deviations of calculated total GHG emissions derived from Latin Hypercube Sampling (baseline) and sampling the minimum and maximum of the parameter ranges (scenarios). 


\section{The contribution of sectoral climate change mitigation to national targets}

\subsubsection{National targets and biophysical feasibility of scenarios}

Two scenarios met Kenya's NDC target, increased milk yields considerably associated with a marginal shortage of arable land throughout the study region (Figure 3.4). The FoCo scenarios at medium and high level of intensification increased total GHG emissions by 3.6 and $12.6 \%$ respectively. Taking into account the emission uncertainties, total emissions increased by 13.7 and $24.3 \%$ respectively at the upper $95 \%$ confidence limit. For the NDC, an increase of total emissions by $67.1 \%$ by 2030 relative to the base year 2010 would be tolerable. Only $0.5 \%$ (medium intensification) and $2.8 \%$ (high intensification) of the study region would not have enough arable land to implement these two scenarios. Through productivity increases in the same scenarios, the projected annual milk yield by 2030, as targeted in Kenya's dairy master plan was on average achieved by $38.3-40.5 \%$. Euclidean distances to the theoretical optimum were also shortest for the FoCo scenarios at medium and high level of intensification (Figure 3.4). 


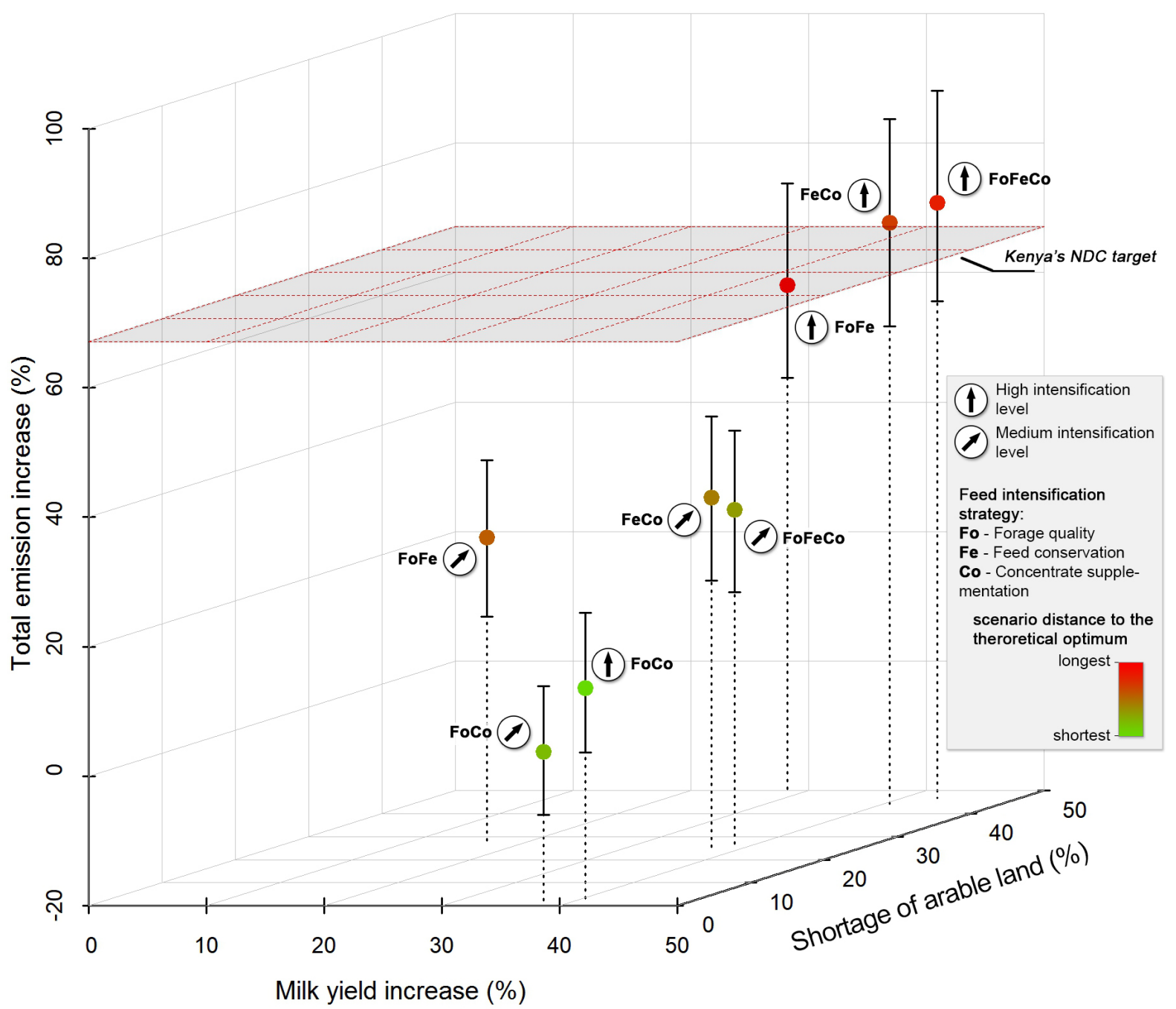

Figure 3.4: Scenarios (filled circles) are shown in 3-dimensional space marked by the increase in milk yield relative to the baseline and the milk yield target of Kenya's dairy master plan (xaxis), the increase of total GHG emissions in relation to the national BAU scenario of the NDC (y-axis), and the shortage of arable land (z-axis). Colours show the Euclidean distance of each scenario to the theoretical optimum (defined as $100 \%$ milk yield increase, $0 \%$ total emission increase and $0 \%$ shortage of arable land). The dark grey plane indicates the threshold of tolerable total emission increases according to the NDC target. X and z-axes are cut at $50 \%$ to improve visualisation. Error bars reflect the range of relative emission increases due to the overall uncertainty in emission parameters at $95 \%$ confidence levels.

\subsubsection{Baseline and mitigation scenarios at landscape level}

Three Kenyan counties (Nyandarua, Uasin Gishu, and Kisii) within the dairy production region show the highest total GHG emissions and milk production ranging between 1.3 
$\pm 0.5-1.6 \pm 1.2 \mathrm{t} \mathrm{CO}_{2} \mathrm{eq} \mathrm{ha}^{-1} \mathrm{yr}^{-1}$ and $0.6 \pm 0.2-0.7 \pm 0.5 \mathrm{t}_{\mathrm{FPCM}} \mathrm{ha}^{-1} \mathrm{yr}^{-1}$ respectively (Figure 3.5A - C). These counties have the highest densities of dairy cattle ranging from $0.7 \pm 0.5-0.9 \pm 0.6 \mathrm{TLU}^{\mathrm{h}} \mathrm{a}^{-1}$. Increases in total GHG emissions, milk production, and the availability of grazing land were mapped for the two scenarios that complied with Kenya's NDC target and showed a marginal shortage of arable land (Figure 3.4), namely FoCo at medium (Figure 3.5D - F) and high level of intensification (Figure 3.5G - I). The total emission increases ranged between $3.4 \pm 3.3-12.1 \pm 4.5 \%$. Milk production increases ranged between $47.6 \pm 7.2-50.2 \pm 5.6 \%$. 
Baseline
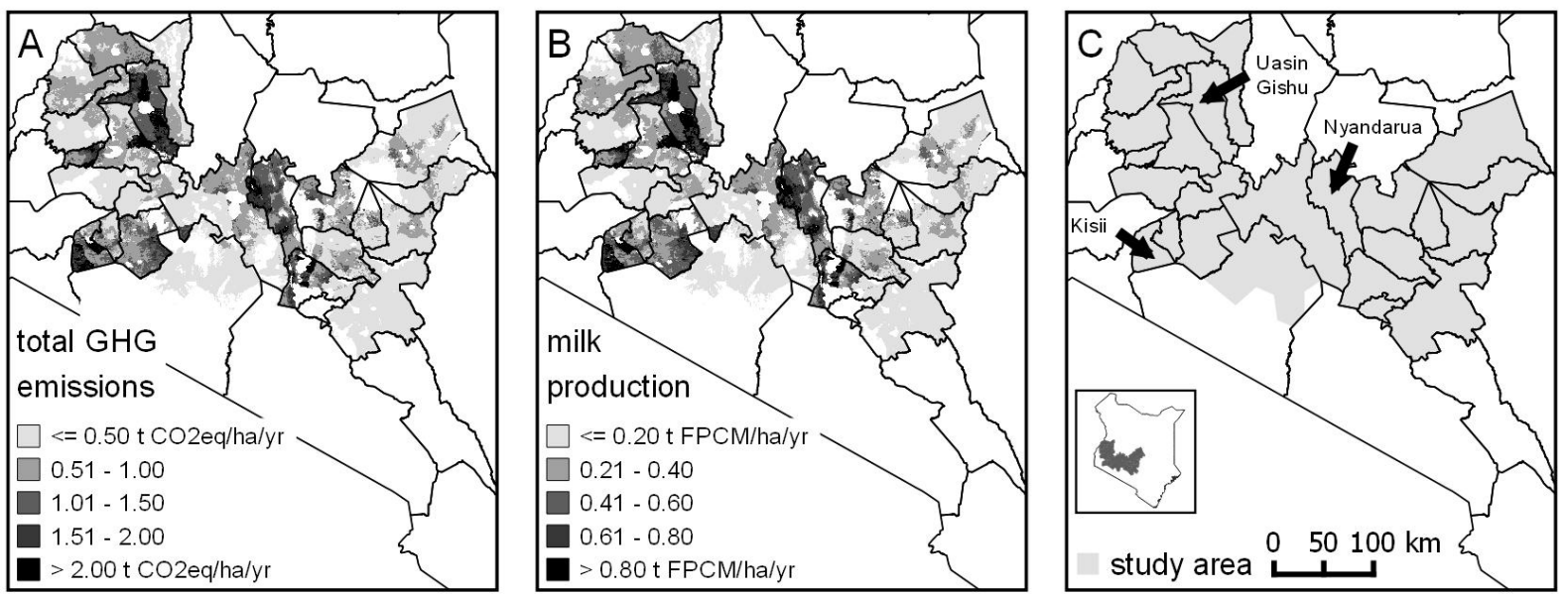

Scenario: Forage quality \& concentrate suppl. (FoCo) at medium intensification
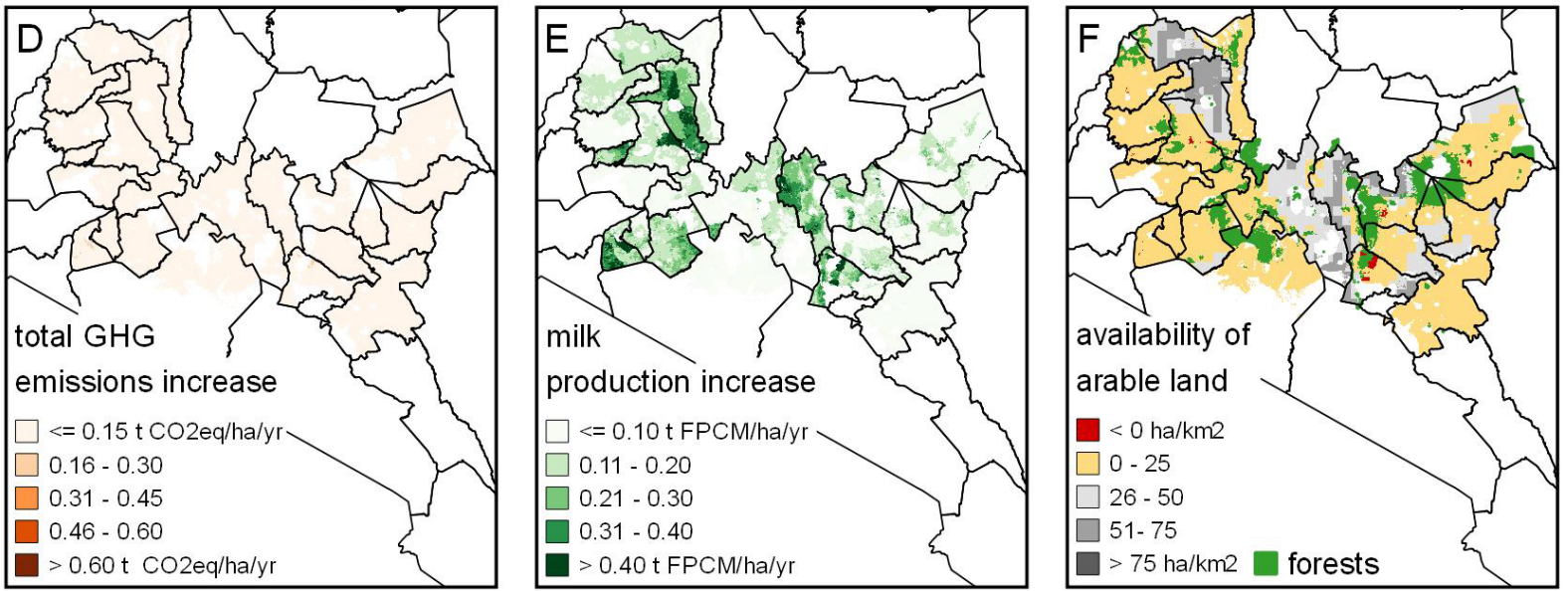

Scenario: Forage quality \& concentrate suppl. (FoCo) at high intensification level
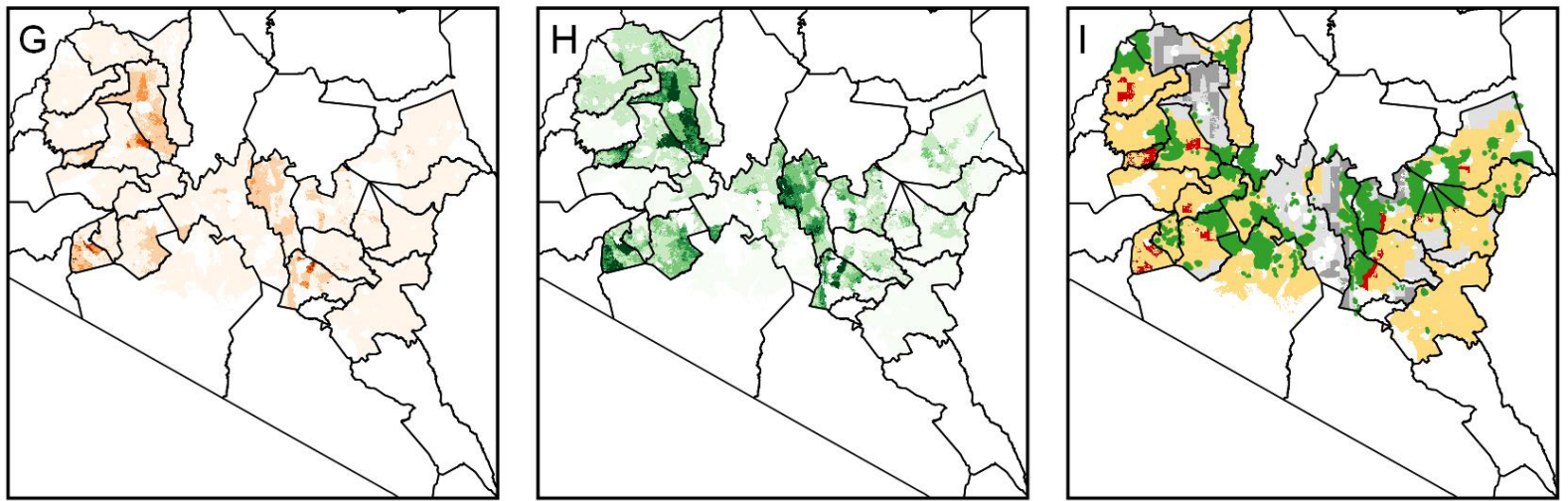

Figure 3.5: Baseline results were mapped for (A) total GHG emissions from dairy production and (B) milk production. Scenario changes relative to the baseline were mapped for increases in $(\mathrm{D}, \mathrm{G})$ total emissions and $(\mathrm{E}, \mathrm{H})$ milk production. Maps $(\mathrm{F}, \mathrm{I})$ illustrate the availability of arable land that could be converted to cropland required to grow additional maize and Napier grass (red $=$ shortage of arable land). Only the two scenarios that complied with Kenya's NDC target and showed the smallest shortage of arable land are indicated. 
The mean baseline emission intensity across LPS was $2.4 \pm 0.13 \mathrm{~kg} \mathrm{CO}_{2} \mathrm{eq} \mathrm{kg} \mathrm{FPCM}^{-1}$. Mean emission intensities decreased in relation to the baseline across LPS for the FoCo scenarios at medium $(30.6 \pm 1.7 \%)$ and high level of intensification $(25.7 \pm 1.6 \%)$ ranging from $1.7 \pm 0.03$ to $1.8 \pm 0.03 \mathrm{~kg} \mathrm{CO}_{2}$ eq $\mathrm{kg} \mathrm{FPCM}^{-1}$ respectively (Figure 3.6).

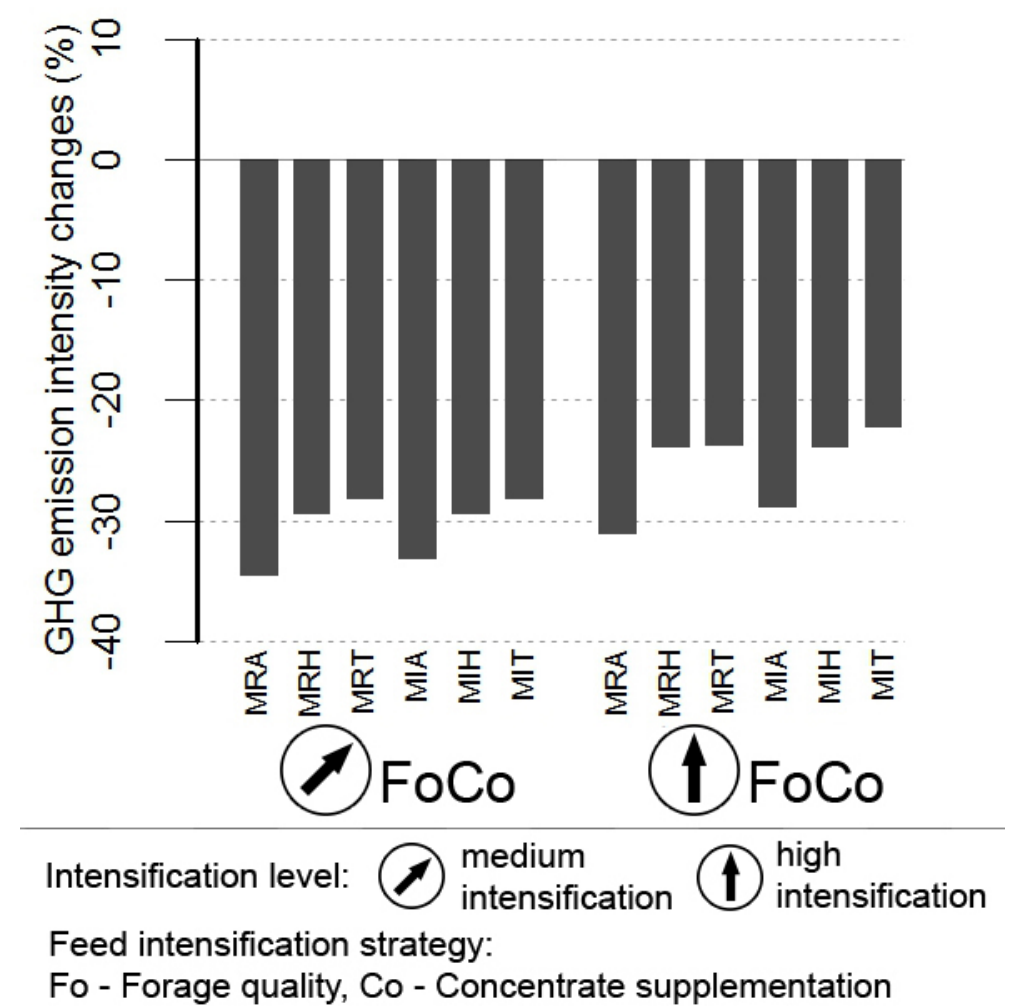

Figure 3.6: Mean GHG emission intensity changes, relative to baseline model, of the two scenarios that complied with Kenya's NDC target. Bars represent the different LPS (Appendix S3, Figure S3.2).

\subsubsection{Uncertainties}

Overall variability in total GHG emissions and emission intensities (pixel-based SD across LPS) due to uncertainties in emission parameters was smallest for the baseline $( \pm 1.9 \%)$ and highest for the FoFe scenario at high level of intensification $( \pm 7.8 \%)$ (Figure $3.3 \mathrm{~A}$ $\&$ B). The emission parameters used to quantify the baseline GHG emissions following the IPCC methodology had different impact on the variability of emissions. The methane conversion factor $\left(\mathrm{Y}_{\mathrm{m}}\right)$, with a range of $5.5-7.5 \%$ was the parameter that showed the strongest influence on the variation in baseline total GHG emissions with $\pm 7.2 \%$ relative to the mean total GHG emissions across LPS (Appendix S3, Figure S3.3). The SOC emission factor applied to calculate LUC emissions caused the largest uncertainty in total GHG emissions of the FoFe scenario at high intensification level. Total GHG emissions 
varied by $\pm 47.5 \%$ across LPS (Appendix S3, Figure S3.4). Uncertainty in livestock densities (expressed as mean SD across LPS) had the largest effect on $\mathrm{CH}_{4}$ emissions from enteric fermentation (Figure 3.5). The smallest effect was indicated for the baseline $( \pm 1.8 \%)$, whereas the largest was shown for the FoFe scenario at high intensification level $( \pm 4.4 \%)$. The mean SD of milk production was lowest for the baseline $( \pm 1.8 \%)$ and was highest for the FoFeCo scenario at high intensification level $( \pm 4.2 \%)$.

\subsection{Discussion}

\subsubsection{Baseline emission intensities and mitigation potential of scenarios}

In this study, the mean baseline emission intensity was $2.4 \pm 0.13 \mathrm{~kg} \mathrm{CO}_{2}$ eq $\mathrm{kg}_{\mathrm{FPCM}}{ }^{-1}$ per grid cell. Most recent estimates for smallholder dairy production in Kenya report similar emission intensities ranging from $2.4-3.1 \mathrm{~kg} \mathrm{CO}_{2}$ eq $\mathrm{kg} \mathrm{milk}^{-1}$ for semi-intensive and extensive production (Government of Kenya, 2017b). Emission intensities derived from life cycle assessments calculated for smallholder farms across the Kenyan highlands range from $1.8-2.0 \mathrm{~kg} \mathrm{CO}_{2} \mathrm{eq} \mathrm{kg} \mathrm{milk}^{-1}$ for free grazing farms (Weiler et al., 2014; Udo et al., 2016). Baseline emission intensities calculated in this study were within the range estimated in other studies for Kenya. Emission intensities can vary due to different feed quality values used to calculate $\mathrm{CH}_{4}$ emissions from enteric fermentation and manure management based on the IPCC tier 2 methodology (IPCC, 2006). For this study, these values were obtained from the East-African feed database and literature (Anindo et al., 1994; Rufino et al., 2009).

Total GHG emissions were higher for all scenarios in relation to the baseline, with the lowest increases of $3.4-12.1 \%$ for the FoCo scenarios at medium and high level of intensification respectively. However, the reduction of emission intensities by $30.6 \%$ (1.7 $\left.\pm 0.03 \mathrm{~kg} \mathrm{CO}_{2} \mathrm{eq} \mathrm{kg} \mathrm{FPCM}^{-1}\right)$ and $25.7 \%\left(1.8 \pm 0.03 \mathrm{~kg} \mathrm{CO}_{2} \mathrm{eq} \mathrm{kg} \mathrm{FPCM}^{-1}\right)$ was achieved through improvements in forage quality by increasing the proportion of Napier grass in the diet and through supplementing dairy concentrates during early lactation. In addition, emission intensities were reduced by covering manure heaps. The overall reduction of $\mathrm{N}_{2} \mathrm{O}$ emissions from manure management by $68 \%$ is in line with the reduction potential reported in the literature on management of cattle manure (Chadwick, 2005; Hou et al., 2015). Mottet et al. (2016) estimated the potential to reduce emission intensities by up to $14 \%$ through the improvement of feed quality alone in East Africa at a regional scale. Bryan et al. (2013) reported a potential to reduce emission intensities $\left(\mathrm{CH}_{4}\right.$ emissions only) by up to $60 \%$ through the increase of feed quality in a modelling study covering highland areas in Kenya, yet omitting likely emissions from LUC. With reductions of 26 - $31 \%$, this study ranks moderately compared to these findings, yet is more robust as detailed feed data and LUC emissions were included. 
The FoCo scenarios at medium and high intensification level led to relatively high achievement rates of the national dairy master plan target (Government of Kenya, 2010), increasing milk yields by 38.3 and $40.5 \%$ respectively. These scenarios led to the lowest increase in total GHG emissions by 3.4 and $12.1 \%$ respectively, complying with the NDC target (Government of Kenya, 2015a), while facing the smallest shortage of arable land across the dairy region (0.5 and $2.8 \%$ respectively) (Figure 3.4). Thus, these two scenarios present the lowest trade-offs between national level targets.

\subsubsection{Synergies from implementing the most beneficial mitigation sce- nario}

Average milk yield increases of the two FoCo scenarios were 47.6 - $50.2 \%$ higher than the baseline, which are modest increases compared to estimates by (Rufino et al., 2009) of $63-79 \%$ for single dairy cows fed with similar diets. Experimental studies conducted in Kenya estimated gains in milk yield of $37 \%$ and $63 \%$ supplementing $3 \mathrm{~kg} \mathrm{day}^{-1}$ and $7.8 \mathrm{~kg} \mathrm{day}^{-1}$ of dairy concentrates during lactation (Moran, 2005; Richards et al., 2016). Growing Napier grass can have further positive effects on farm productivity for instance as effective vegetative barriers preventing soil erosion and nutrient losses (Owino et al., 2006; Guto et al., 2011). In addition, Napier grass can be a lucrative feed alternative. Compared to diets of lower quality, Napier increased the net revenue for milk production in Central and Western Kenya most at medium intensification level (by $0.08-0.12$ USD 1 milk $^{-1}$ ) (Bryan et al., 2013). A medium level of intensification was also the most profitable choice (573 USD $\mathrm{yr}^{-1}$ ) for smallholder dairy farmers when compared to low and high intensification levels (473 and $360 \mathrm{USD} \mathrm{yr}^{-1}$ respectively) (Bebe et al., 2002). Dairy concentrates are relatively expensive for smallholders, which seems to be the reason for low adoption rates associated with fluctuations in milk prices (Lukuyu et al., 2011; Owen et al., 2012). Therefore, the FoCo scenario at medium intensification would be the most viable, with lower adoption barriers due to relatively high gains in milk yield, and lower financial risks for smallholders compared to the high intensification scenario.

\subsubsection{Supporting the development of sectoral and national mitigation plans}

As quantified in this study, the total land use based GHG emissions from dairy production in Kenya represent $12.9 \%$ of the total emissions from the agricultural sector. Agriculture is the largest contributor to GHG emissions in Kenya, totalling $30 \mathrm{Mt} \mathrm{CO}_{2} \mathrm{eq}$ in 2010 (Government of Kenya, 2015b), which emphasises the significance of sectoral mitigation actions. Kenya's national mitigation target defined in the NDC sets the scene for mitigation actions such as a dairy NAMA (Government of Kenya, 2017b). The findings of this study fill several knowledge gaps. First, it provides for the first time transparent quantifi- 
cations of baseline emissions and milk yields and changes in emissions and productivity resulting from intensification scenarios at a sectoral scale. Increases in productivity of smallholder dairy farms through feeding practices is one of the main objectives of Kenya's dairy NAMA (Government of Kenya, 2017b). This study identified promising mitigation practices such as the improvement of forage quality and supplementation of dairy concentrates at medium intensification level. Second, the mitigation potential of specific practices was assessed against the NDC, enabling an evaluation of their performances to contribute to national mitigation targets. Demonstrating the technical potential of certain practices to fulfil mitigation and productivity targets opens the door for climate financing schemes that require reliable estimates to monitor the achievement of targets (Government of Kenya, 2010, 2015a). Building a business case to finance climate mitigation, e.g. through NAMAs, requires quantitative information about the mitigation potential and productivity gains of specific practices in regions where these practices are feasible and an evaluation of inherent uncertainties (Grassi et al., 2017) as provided by this study. Third, considering changes in land availability and demand for land resulting from mitigation actions before their actual implementation is crucial to achieve effective mitigation. That is minimising the risk of negative spillover effects such as GHG emissions from indirect LUC. GHG emissions from the conversion of arable land required to grow additional high quality feeds can be substantial (Figure 3.3). Increasing the grain content in cattle diets, e.g. through ensiling maize can compromise the effective mitigation potential of feed intensification due to the relatively high demand for additional cropland.

Information provided by this study is required for 'Measurement, Reporting and Verification' (MRV) of agricultural mitigation actions and could guide the targeting of specific practices at the sub-national level (Lipper et al., 2011). For instance, the baseline emissions mapped in this study could aid in prioritising pilot projects in areas (e.g. counties) that show the highest total emissions (Figure 3.5).

\subsubsection{Climate-smart options that increase the mitigation potential for Kenya's dairy sector}

At herd level, emission intensities can be reduced through improved reproduction such as lowering the proportion of unproductive animals by artificial insemination (Hristov et al., 2013a; Knapp et al., 2014). Vaccination programmes ameliorate animal health, lower mortality rates and increase lifetime productivity of cattle (Mottet et al., 2016). De-stocking of animals with low productivity and replacement by breeds showing higher productivity would, in conjunction with improved feed management, decrease emissions and maintain or increase production (Herrero et al., 2016). Low productivity due to nutrient depleted soils is common in Kenya (Tittonell et al., 2009). Improving the retention and recycling of available nutrients through the management of manure and application to soils as organic fertiliser is important to sustain soil fertility and to increase crop yields 
(Rufino et al., 2007; Tittonell et al., 2010; Castellanos-Navarrete et al., 2015). Covering manure heaps, included in this study, is one option to minimise the loss of $\mathrm{N}$ during the manure storage phase (de Boer et al., 2011). In addition, the combination of organic and mineral fertiliser is proposed to compensate relatively small amounts of available animal manure in smallholder dominated production systems (Tittonell et al., 2010). A modelling exercise at global scale demonstrated that closing yield gaps could reduce LUC emissions, including deforestation, in Africa effectively outweighing potential increases in $\mathrm{N}_{2} \mathrm{O}$ emissions associated to fertiliser application (Valin et al., 2013).

\subsubsection{Uncertainty implication and data limitations}

In this study, the methane conversion factor $\left(\mathrm{Y}_{\mathrm{m}}\right)$ was the largest source of uncertainty for $\mathrm{CH}_{4}$ emissions from enteric fermentation in the baseline. Data from laboratory measurements on cattle breeds and feeds managed under conditions that represent tropical production systems, especially from SSA, are required to derive improved estimates. Feeding trials on native cattle breeds from Kenya, currently conducted by the International Livestock Research Institute (ILRI) to estimate $\mathrm{CH}_{4}$ emissions from enteric fermentation are promising efforts (Pelster et al., 2016). The loss of SOC due to the conversion of grazing land to cropland for additional feed crops influenced the uncertainty of scenario emissions most. High impact of LUC on total emissions due to the production of feeds by up to $877 \%$ were shown by van Middelaar et al. (2013). Dynamic land use models simulating soil-vegetation dynamics in response to LUC could reduce the uncertainty. However, a comprehensive parameterisation based on empirical data is required, which might prove difficult in data deficient regions such as SSA (Kim et al., 2016). Cattle density data were an additional source of uncertainty for upscaled emissions and milk production since the spatially-explicit dataset was derived from predictive modelling to match a very high resolution at sub-county level (Robinson et al., 2014). More detailed census data at sub-location level could reduce the related uncertainty in cattle densities. Feed intensification scenarios can be further improved by more comprehensive feed quality information, including empirical data on pastures and fodder trees. This would allow exploring alternative feed strategies and scenarios such as improved pasture and silvopastural management options.

\subsection{Conclusions}

This study demonstrated that specific farm-level practices focusing on feed intensification and manure management can improve the efficiency in smallholder dairy production by improving productivity significantly while increasing total GHG emissions only marginally. At the same time, these practices can contribute to national targets reducing the impact 
of the agricultural sector on the climate system and safeguarding food security through sustainable intensification in dairy production. Quantitative spatially-explicit estimates showing 'win-win' situations resulting from gains in agricultural productivity and climate change mitigation at sub-national level are crucial to implement climate change policies successfully. Assessing demand for land due to the intensification of feed production is essential to obtain realistic estimates of how effective certain mitigation practices are at landscape scale and to support tailor-made, location-specific mitigation planning at subnational level. Otherwise, mitigation planning could neglect the risk of GHG emissions from LUC triggered by feed intensification, outweighing potential gains from promising practices. Governments and the private sector could design financing instruments for farmers that seek to increase milk yields in compliance with mitigation targets through feed intensification and manure management using the findings of this study.

\section{Acknowledgments}

This study was funded by the CGIAR program on 'Climate Change, Agriculture and Food Security' (CCAFS) and the IFAD program on 'Greening livestock: Incentive-based interventions for reducing the climate impact of livestock production in East Africa'. Additionally, the research was supported by the 'Norwegian Agency for Development Cooperation' (NORAD) and Germany's 'International Climate Initiative' (IKI) through CIFOR's Global Comparative Study on REDD+, and the CGIAR Research Program on Forests, Trees and Agroforestry (CRP-FTA) with financial support from the CGIAR Fund. 



\section{Chapter 4}

\section{Sustainable intensification of dairy production can reduce forest disturbance in Kenyan montane forests}

Brandt, P., Hamunyela, E., Herold, M., de Bruin, S., Verbesselt, J., Rufino, M.C., 2018. Sustainable intensification of dairy production can reduce forest disturbance in Kenyan montane forests. Agriculture, Ecosystems \&f Environment 265, 307-319. 


\section{Abstract}

Increasing demand for food and the shortage of arable land call for sustainable intensification of farming, especially in Sub-Saharan Africa where food insecurity is still a major concern. Kenya needs to intensify its dairy production to meet the increasing demand for milk. At the same time, the country has set national climate mitigation targets and has to implement land use practices that reduce greenhouse gas (GHG) emissions from both agriculture and forests. This study analysed for the first time the drivers of forest disturbance and their relationship with dairy intensification across the largest montane forest of Kenya. To achieve this, a forest disturbance detection approach was applied by using Landsat time series and empirical data from forest disturbance surveys. Farm indicators and farm types derived from a household survey were used to test the effects of dairy intensification on forest disturbance for different farm neighbourhood sizes $(\mathrm{r}=2-5$ $\mathrm{km}$ ). About $18 \%$ of the forest area was disturbed over the period $2010-2016$. Livestock grazing and firewood extraction were the dominant drivers of forest disturbance at $75 \%$ of the forest disturbance spots sampled. Higher on-farm cattle stocking rates and firewood collection were associated with $1-10 \%$ increased risk of forest disturbance across farm neighbourhood sizes. In contrast, higher milk yields, increased supplementation with concentrated feeds and more farm area allocated to fodder production were associated with 1 $-7 \%$ reduced risk of forest disturbance across farm neighbourhood sizes. More intensified farms had a significantly lower impact on forest disturbance than small and resource-poor farms, and large and inefficient farms. The results show that intensification of smallholder dairy farming leads to both farm efficiency gains and reduced forest disturbance. These results can inform agriculture and forest mitigation policies which target options to reduce GHG emission intensities and the risk of carbon leakage. 


\subsection{Introduction}

Poor management of agricultural land and forests leads to deforestation and land degradation worldwide. The expansion of smallholder agriculture is one of the main drivers of deforestation in Sub-Saharan Africa (SSA) (Hosonuma et al., 2012). Such unsustainable land uses cause greenhouse gas (GHG) emissions and affect adversely ecosystem services such as soil carbon (C) sequestration and biodiversity (Barlow et al., 2016; Herrero et al., 2016; Grassi et al., 2017). Rising human population in many SSA countries has increased the demand for food and reduced the availability of arable land (Carter et al., 2018b). Thus, climate-smart practices are required to intensify production on smallholder farms sustainably, which improve food security and contribute to climate change mitigation.

Recently, an intensification trend of smallholder farming has been documented for the East African highland regions, particularly in Kenya (Herrero et al., 2014). However, in the past large parts of the Kenyan montane forests have been converted to agricultural land. Remaining forests are threatened by ongoing anthropogenic disturbance causing GHG emissions from forests. The 'land use, land use change and forestry' (LULUCF) sector contributes about 38 \% to total GHG emissions in Kenya (Government of Kenya, 2015b). Three quarters of forest-related GHG emissions result from small-scale forest disturbances such as fuelwood extraction, selective logging and wildfires (Pearson et al., 2017). Thus, mitigation efforts to effectively reduce these emissions are required. Kenya has committed to the United Nations framework convention on climate change (UNFCCC) defining mitigation targets in its nationally determined contribution (NDC) (Government of Kenya, 2015a). However, mitigation planning at national level is separated in land use sectors, i.e. agriculture and forests, which is likely to render the reduction of GHG emissions ineffective. Quantifying the relationship between agricultural land use practices and forest disturbance could be used to develop integrated mitigation approaches that minimise the risk of spillover effects such as C leakage (Minang \& van Noordwijk, 2013).

The Mau Forest located in the Kenyan highlands is the largest remaining montane forest complex in East Africa. The forest plays an important role as water tower for the whole region as it is the headwater area for 12 major rivers supplying freshwater to about five million people (Jacobs et al., 2017). The unsustainable use of the forest leads to disturbances that impair ecosystem services such as $\mathrm{C}$ storage, freshwater supply and biodiversity (Kinyanjui, 2011). To date, forest disturbance and its main drivers have not yet been quantified or characterised, neither for Kenya's forests nor for the Mau Forest, in particular.

The Mau region is dominated by smallholder crop-livestock production (Robinson et al., 2011). Smallholders throughout the highlands commonly engage in dairy farming contributing about $80 \%$ to Kenya's total milk production (Udo et al., 2016). Increasing the 
productivity of smallholder dairy farming throughout East Africa is promoted by several agricultural development programs to meet the demand for dairy products (Government of Kenya, 2010). Sustainable intensification of agricultural production is urgently required to improve the livelihood of smallholder farmers and is often reported as a promising measure to achieve climate mitigation targets (Campbell et al., 2014; Vanlauwe et al., 2014; Ortiz-Gonzalo et al., 2017). Human presence in landscapes that were formerly dominated by forests has been linked to changes in forest cover in SSA (Sassen et al., 2013; Ryan et al., 2017). However, an assessment of local human activities and their effects on adjacent forests is missing. A quantitative analysis of the relationship between specific practises of smallholder dairy farming and forest disturbance is needed to assess whether intensification is sustainable beyond individual farms. This analysis is also needed and highly relevant for other montane regions in East Africa that share comparable farming and forests systems and are exposed to similar pressures due to the increasing demand for food.

Intensification of smallholder dairy farming includes changes in cattle management e.g. feeds and breeds which have the potential to increase milk production (Rufino et al., 2009) and to reduce GHG emissions per unit of product (Herrero et al., 2016; Udo et al., 2016). To date, there are no comprehensive studies on the effects of intensification in smallholder dairy farming on adjacent forests, which can undermine the climate change mitigation effect of the farming practices promoted (Brandt et al., 2018b). This study aims to answer two questions. First, what are the dominant anthropogenic drivers of forest disturbance across the Mau Forest? Second, what is the intensification effect of smallholder dairy farming on forest disturbance? The approach applied to answer these questions involved i) the quantification of forest disturbance and the characterisation of the dominant drivers using a spatially-explicit framework to detect forest disturbance based on a Landsat time series and forest disturbance surveys and ii) the estimation of intensification effects of smallholder farms on forest disturbance based on empiricallyderived farm indicators and farm types.

\subsection{Material and methods}

\subsubsection{Study area}

The Mau Forest is located in the Western highlands of Kenya (Figure 4.1) and represents the largest remaining Afromontane forest in the country covering about 400,000 ha (Kinyanjui, 2011). It primarily consists of broadleaf tree species and bamboo forests, the latter in regions above $2400 \mathrm{~m}$ (Ng'Eno, 1996). Large parts of forest have been converted to agricultural land due to favourable biophysical conditions such as high annual precipitation and well drained soils. The region is characterised by high densities of human 
and livestock populations (Herrero et al., 2014; Robinson et al., 2014). Apart from smallholder crop-livestock production systems there are large-scale tea plantations (Baldyga et al., 2008; Jacobs et al., 2017). The Mau Forest is used for fuelwood, for livestock grazing and for timber production, which is mainly harvested from tree plantations (Government of Kenya, 2009b; Olang et al., 2011).

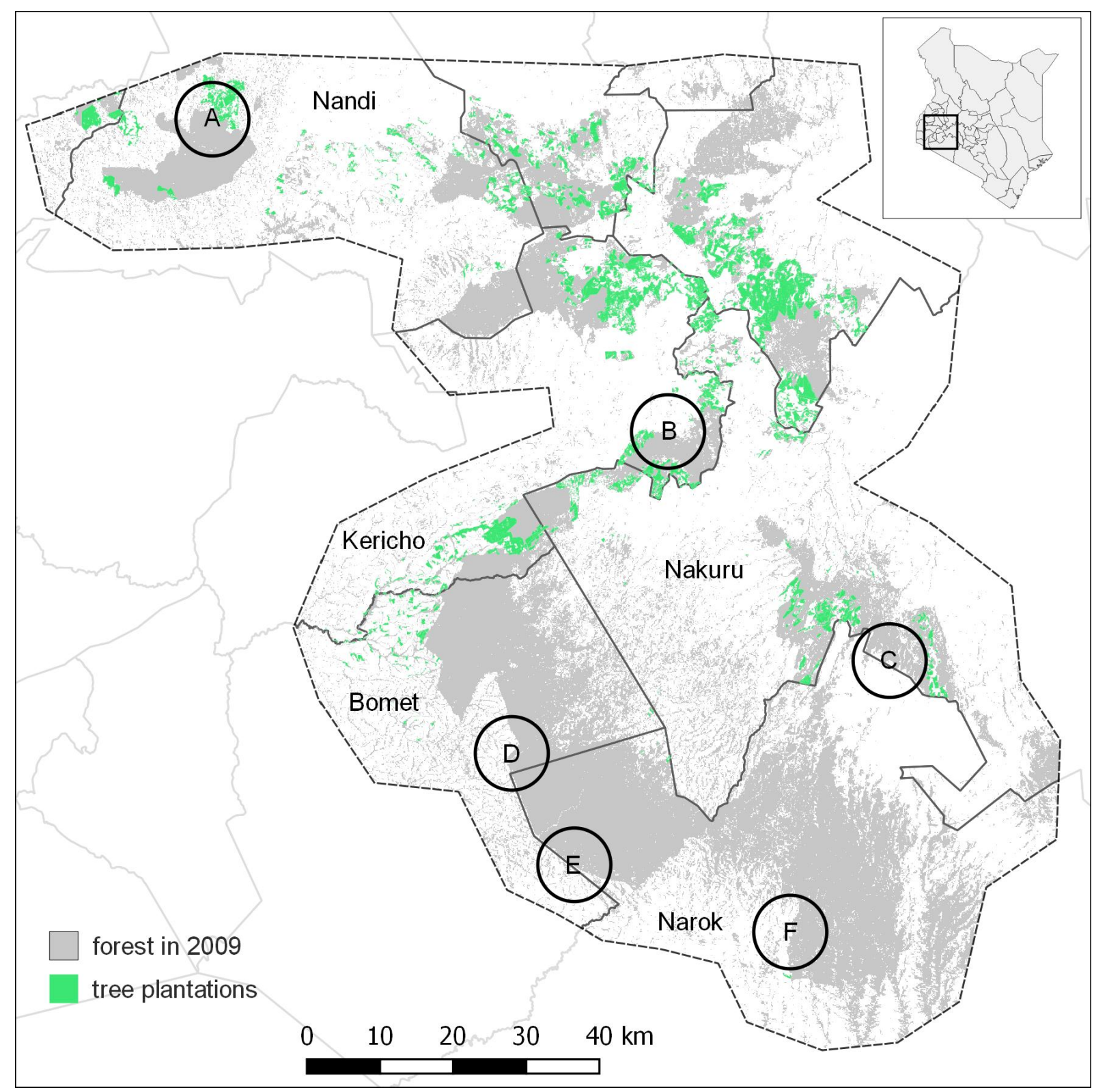

Figure 4.1: The study area of the Mau Forest complex in Kenya. Circles and letters indicate sampling sites selected to conduct farm and forest disturbance surveys: A) South Nandi Forest, B) Western Mau Forest, C) Eastern Mau Forest, D) South West Mau Forest, E) Transmara Mau Forest, and F) Maasai Mau Forest. 


\subsubsection{Analysis approach}

The approach followed in this study is shown in (Figure 4.2). First, remote sensing data were acquired and pre-processed. Data on farm practices and forest disturbance were obtained through field surveys (Section 4.2.3). Second, forest disturbance was detected from remote sensing data using the 'Space Time Extremes and Features' (STEF) algorithm (Hamunyela et al., 2017) (Section 4.2.4). Third, farm indicators and farm types were derived from farm survey data (Section 4.2.5). Fourth, the effects of farm indicators and farm types on forest disturbance intensity were modelled by using generalised linear mixed effect models (GLMMs) (Section 4.2.6). 


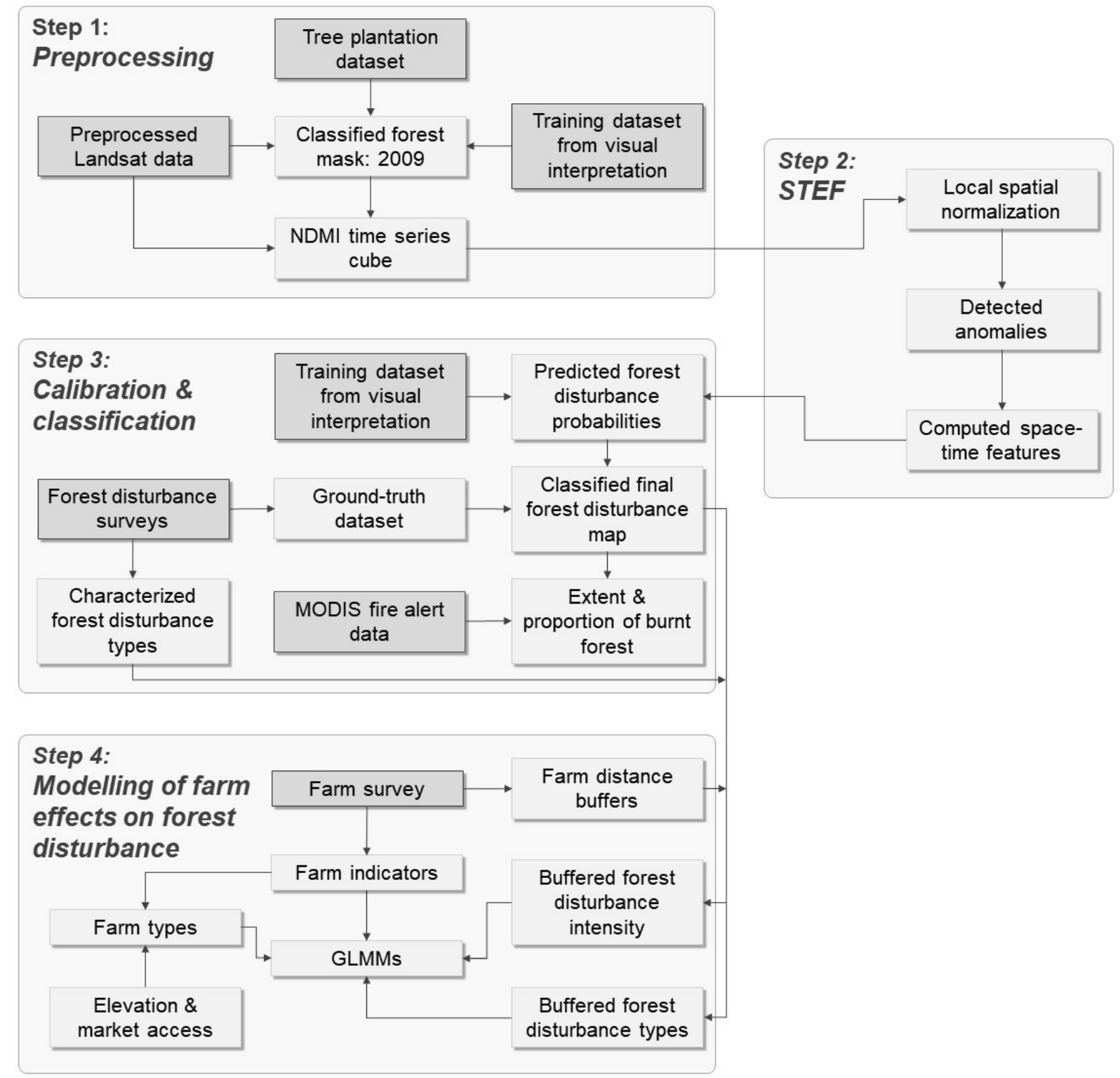

Figure 4.2: Flowchart of analysis steps followed in this study. Dark boxes represent data inputs from remote sensing and field observations. NDMI = Normalised Difference Moisture Index, STEF $=$ Space Time Extremes and Features approach, GLMMs = Generalised Linear Mixed Effect Models.

\subsubsection{Acquisition and pre-processing of data}

Remote sensing data

All available terrain-corrected (L1T) multi-spectral satellite images $(\mathrm{n}=639)$ acquired by Landsat 5-TM, Landsat 7-ETM+, and Landsat 8-OLI sensors (Figure 4.2, step 1) from 
January 2005 to December 2016 were downloaded from the United State of America's Geological Survey (USGS) Earth Explorer platform. The 'Normalised Difference Moisture Index' (NDMI) (Jin \& Sader, 2005) was computed from each image. NDMI is sensitive to changes in canopy moisture. It was chosen as it is known to discriminate well changes in tropical wet forests (DeVries et al., 2015a). NDMI was used to study small-scale disturbance in another Afromontane forest (DeVries et al., 2016). Clouds and cloud shadows were masked using the 'cmask' algorithm (Zhu et al., 2015).

A benchmark forest mask was created (Figure 4.2, step 1) to constrain the forest disturbance detection algorithm to forested areas. Clouds and cloud shadows were masked in the available Landsat spectral band images from 2009. Gaps were filled by mosaicking the images. A random forest model (Breiman, 2001) was trained to classify the study area into forest and non-forest regions using all Landsat spectral bands as predictors. The model was trained on randomly sampled polygons maintaining equal sample sizes $(\mathrm{n}=40)$ for both classes each containing at least 10000 Landsat pixels. This training dataset was obtained by visual interpretation of very high resolution Google Earth imagery. Forest patches smaller than 0.5 ha were excluded from the forest mask to satisfy the minimum forest area criterion of the 'Food and Agriculture Organisation' (FAO) of the UN forest definition (FRA, 2000).

A time series dataset of all pre-processed NDMI images was created. In addition, tree plantation data (Government of Kenya, 2015c; Jacobs et al., 2017) were used to exclude forest plantation areas from the forest disturbance analysis. Monthly fire alert data (Giglio, 2015) from the 'Moderate Resolution Imaging Spectroradiometer' (MODIS, MCD14ML) were used to determine the extent and proportion of burnt forests over the monitoring period.

Seasonal variability influences vegetation dynamics across the study area leading to fluctuating spectral signals which impair the accuracy of forest disturbance detection algorithms (Hamunyela et al., 2016b). A local spatial normalisation approach (Hamunyela et al., 2016a, 2017) was used to reduce the effect of seasonality in the NDMI time series (Figure 4.2, step 2). The normalisation procedure was applied on each NDMI image in the time series prior forest disturbance detection. The local neighbourhood was defined using a spatially-moving window with a size of $15 \times 15$ Landsat pixels. Each centre pixel within the window was divided by the 95 th percentile computed from pixel values within the window (Hamunyela et al., 2016b). A 15 x 15 pixel window was deemed sufficient because forest disturbances in the study area occur at small-scale.

\section{Field data}

Two field surveys were conducted between November and December 2016 to collect information about smallholder farms (farm survey) and forest disturbance (forest disturbance 
survey) in adjacent forests by using 'Open Data Kit' (ODK) questionnaires (Figure 4.2, step $3 \& 4$ ). Sampling sites for each survey were selected based on a stratified sampling design using spatially-explicit datasets on cattle density (Robinson et al., 2014) and forest loss (Hansen et al., 2013). Forest loss data were converted to forest disturbance density by using the kernel density tool in ArcGIS 10.3. Cattle and forest disturbance densities were reclassified based on quantile splits to derive six combinations of sampling strata ranging from low cattle and forest disturbance density to high cattle and disturbance density (Appendix S4, Figure S4.1). Circular sampling sites (radius $=5 \mathrm{~km}$ ) were placed into the sampling strata derived. Furthermore, by ensuring a forest cover of $50 \%$ in each site and by excluding tree plantations (Figure 4.1), the number of sampling sites was constrained, which led to the selection of the following areas: A) South Nandi Forest ( $\mathrm{n}=37$ farms and $\mathrm{m}=36$ disturbance spots sampled), B) Western Mau Forest $(\mathrm{n}=39, \mathrm{~m}=30), \mathrm{C})$ Eastern Mau Forest $(\mathrm{n}=34, \mathrm{~m}=32)$, D) South West Mau Forest $(\mathrm{n}=35, \mathrm{~m}=44)$, E) Transmara Mau Forest $(\mathrm{n}=39, \mathrm{~m}=45)$, and $\mathrm{F})$ Maasai Mau Forest $(\mathrm{n}=32, \mathrm{~m}=$ 34). A minimum sample size of 30 farms and 30 forest disturbance sports per site was targeted. Often, additional farm and forest disturbance data could be obtained.

The farm survey was conducted to gather information on cattle numbers, milk yields, feed types, farm area allocated to fodder production, farm size, and amount of firewood collected from the forest. Farms were sampled based on locations randomly selected within each sampling site $(\mathrm{n}=216)$. The forest disturbance survey characterised disturbance spots sampling randomly forest loss pixels derived from Hansen et al. (2013) that were still forest according to the forest mask created $(n=221)$ to avoid the sampling of deforested land. During this survey, information on disturbance types such as cattle grazing, firewood extraction, wildfires, and charcoal burning was collected. In this analysis, forest disturbance is defined as negative change in canopy cover over time directly or indirectly induced by anthropogenic activities. A detailed list of variables collected during the surveys is available in the supplementary information (Appendix S4, Table S4.1 \& S4.2). The field data gathered from this forest disturbance survey were used, in combination with additional forest disturbance data collected during a previous forest disturbance survey $(\mathrm{n}=127)$. The later survey was conducted in the Mau Forest between March and April 2016 (Bewernick, 2016), to validate an earlier forest disturbance detection in a sub-region of the study area.

\subsubsection{Forest disturbance detection, calibration and classification}

Forest disturbances were detected by using the STEF algorithm (Hamunyela et al., 2017). STEF detects forest disturbances as extreme events in local data cubes of satellite-derived time series (Figure 4.2, step 2). A local data cube was defined around each pixel containing both spatial and temporal extents which are user-defined (Hamunyela et al., 2017). The temporal extent corresponded to the full length of the NDMI time series. A moving 
spatial window of $9 \times 9$ Landsat pixels was used as the spatial extent of the local data cube. STEF takes the spatio-temporal context of an observation into account to reduce the sensitivity to data noise, e.g. introduced by cloud remnants increasing the algorithm's accuracy (Hamunyela et al., 2016b, 2017). Extreme events are identified as abnormally low observations in the monitoring period, by using an extreme value approach (Zscheischler et al., 2013). A pixel was considered abnormally low if its value was below the threshold computed from spatio-temporal observations in the history period of the local data cube. The history period of the time-series analysis was defined from 2005 - 2009 and the monitoring period was set to 2010 - 2016. Following an application of STEF on Afromontane forests in Ethiopia (Hamunyela et al., 2017), the $5^{\text {th }}$ percentile was chosen as the anomaly threshold. A pixel was flagged as potentially disturbed if the algorithm detected two consecutive anomalies in the monitoring period. Once consecutive anomalies are detected, STEF extracts 17 space-time features from the local data cube (Hamunyela et al., 2017). The features include information on the proximity of the extreme event to forest edges, existence and number of anomalies in the neighbourhood of the pixel where the extreme event is detected, and the spatial variability across the local data cube at the time step where a potential forest disturbance is detected (Hamunyela et al., 2017). These space-time features were subsequently used to confirm forest disturbances.

Forest disturbance was confirmed by first calculating the probability for forest disturbance by using the extracted space-time features as predictors of forest disturbances (Hamunyela et al., 2017). The probability of disturbance was calculated by using a trained random forest model. Random forest classifiers have the advantage to be of non-parametric nature and can handle many predictors without overfitting (Breiman, 2001). The random forest model was trained by using a calibration dataset $(\mathrm{n}=204)$ acquired through visual interpretation of multispectral Landsat images (Figure 4.2, step 3), complemented by very high resolution imagery available in the Google Earth, based on methodology proposed by Cohen et al. (2010). A stratified random sampling design was used to derive the calibration data. The magnitude of change, which is one of the features extracted by STEF indicating the deviation between detected anomaly and the $95^{\text {th }}$ percentile of the history distribution, was used to stratify the map of potential disturbances, produced from STEF. The magnitude of change was sampled randomly along the quantiles to derive four strata ranging from high to low magnitude.

Moreover, ground-truth data $(\mathrm{n}=348)$ from forest disturbance surveys (Section 4.2.3) were used to determine the optimal probability threshold (P) (Figure 4.2, step 3). A series of probability thresholds, ranging from 0 to 1 at an interval of 0.01 was created. Each probability threshold was used to classify the probability values derived for the groundtruth data into disturbed and undisturbed forest while calculating user's accuracy (UA = inverse of commission error) and producer's accuracy (PA = inverse of omission error). The probability threshold that indicated the lowest area bias, which is the minimum trade-off between commission and omission error was used to generate the final forest 
disturbance map (DeVries et al., 2015b; Hamunyela et al., 2017).

\subsubsection{Defining farm types}

Field data derived from the farm survey were used to cluster farms (Figure 4.2, step 4) into distinct types based on indicators that reflected differences in the degree of intensification and which were expected to influence the effect of dairy farming on the forest. Indicators chosen to cluster the farms were: number of cattle, milk yields, proportion of grass from on-farm pastures in the diet, farm area allocated to fodder production, quantity of feed concentrates supplemented, farm size, and amount of firewood collected. A correlation analysis was conducted prior to the clustering to exclude highly correlated variables (Spearman's rho $>=0.7$ ). The k-means partitioning algorithm was applied in $\mathrm{R}$ to cluster the farms, after farm indicators were standardised, by using the Euclidean distance measure ( $\mathrm{R}$ Core Team, 2016). The number of farm types was determined visually based on the drop in intra-cluster variation as a function of increasing numbers of clusters (Kassambara, 2017). In addition, farm types were tested regarding differences in elevation and market access by using an elevation dataset ('Shuttle Radar Topography Mission', SRTM) and a proxy dataset indicating travel time to cities with more than 50.000 inhabitants (Jarvis et al., 2008; Uchida \& Nelson, 2009). This analysis enabled an interpretation of how the remoteness of farms affects intensification of smallholder dairy production.

\subsubsection{Modelling the effects of farms on forest disturbances}

Using the 'raster' package in R (Hijmans, 2016), circular distance buffers with radiuses of $2,3,4$, and $5 \mathrm{~km}$ were created around recorded farm centroids, henceforth called farm neighbourhoods (Figure 4.2, step 4). The neighbourhood sizes were deemed to be appropriate to study the effects of local farm practices and characteristics on forest disturbance in forests adjacent to smallholder farms based on field observations and interviews with local forest rangers from the Kenyan Forest Service. The different neighbourhood sizes were chosen to assess the sensitivity of farm-related effects on forest disturbance over discrete changes of neighbourhood sizes through a sensitivity analysis. Two different response variables were generated. First, the proportion of forest disturbance pixels within each farm neighbourhood was calculated by dividing the number of these forest pixels by the total number of forest pixels. The proportion of forest disturbance pixels were used as a measure of 'disturbance intensity'. Second, forest disturbance sampled and characterised during the forest disturbance survey were counted within farm neighbourhoods to model farm effects on specific forest disturbance types.

GLMMs were used by applying the 'Ime4' package in R (Bates et al., 2015) to model the association between farm characteristics and forest disturbance intensities. The as- 
sociations were interpreted as driver-response relations, that is, farm characteristics were assumed to influence disturbance intensities. Farm indicators, farm types, and farm distances to the closest forest edge were included as fixed effects (explanatory variables). A categorical variable, which represented the sampling sites was included as a random effect. Binomial and Poisson GLMMs were run for the proportional disturbance intensity and the counted forest disturbance types derived from forest disturbance detection and survey data, respectively. Different GLMMs were run for each farm neighbourhood size separately (Figure 4.2, step 4). Model evaluation and selection was based on the Akaike information criterion (AIC) by applying likelihood ratio tests (Zuur et al., 2009). The model candidates that showed the lowest AICs were chosen.

To understand the effects of farm indicators on forest disturbance intensity derived from the binomial GLMMs, a relative risk measure was used. The relative risk quantifies the likelihood of an outcome (forest disturbance intensity), as a result of exposure to specific treatments such as farm practices and farm characteristic represented by chosen indicators (Akobeng, 2005). The effects of interactions between farm types and farm distances to the closest forest edges were explored to show potential differences of farm type effects along a farm distance to forest gradient on forest disturbance intensity. To characterise the influence of farm types on certain types of forest disturbance, modelled farm type effects on forest disturbance types observed during the survey are shown.

\subsection{Results}

\subsubsection{Forest disturbance across the Mau Forest}

A lowest area bias of $0.7 \%$ was achieved at $\mathrm{P}=0.39$ where the UA was $77.9 \%$ and the PA was $78.6 \%$ (Appendix S4, Figure S4.2). Hence, the threshold of 0.39 was chosen as the probability threshold to classify each forest pixel into disturbed and non-disturbed forest.

In total, $17.7 \%$ of the forested land was found to be disturbed between 2010 and 2016. The intensity of forest disturbance varied across the Mau Forest complex with the largest impacts in central and southern forest regions (Figure 4.3). Forest disturbance also strongly differed between sampling sites. The proportions of disturbed forest detected at the Western Mau Forest (42.4 \%) and the Maasai Mau Forest (17.0 \%) were the largest (inset Figure 4.3). With $3.9 \%$, the South Nandi Forest had the smallest proportion of disturbed forest. 


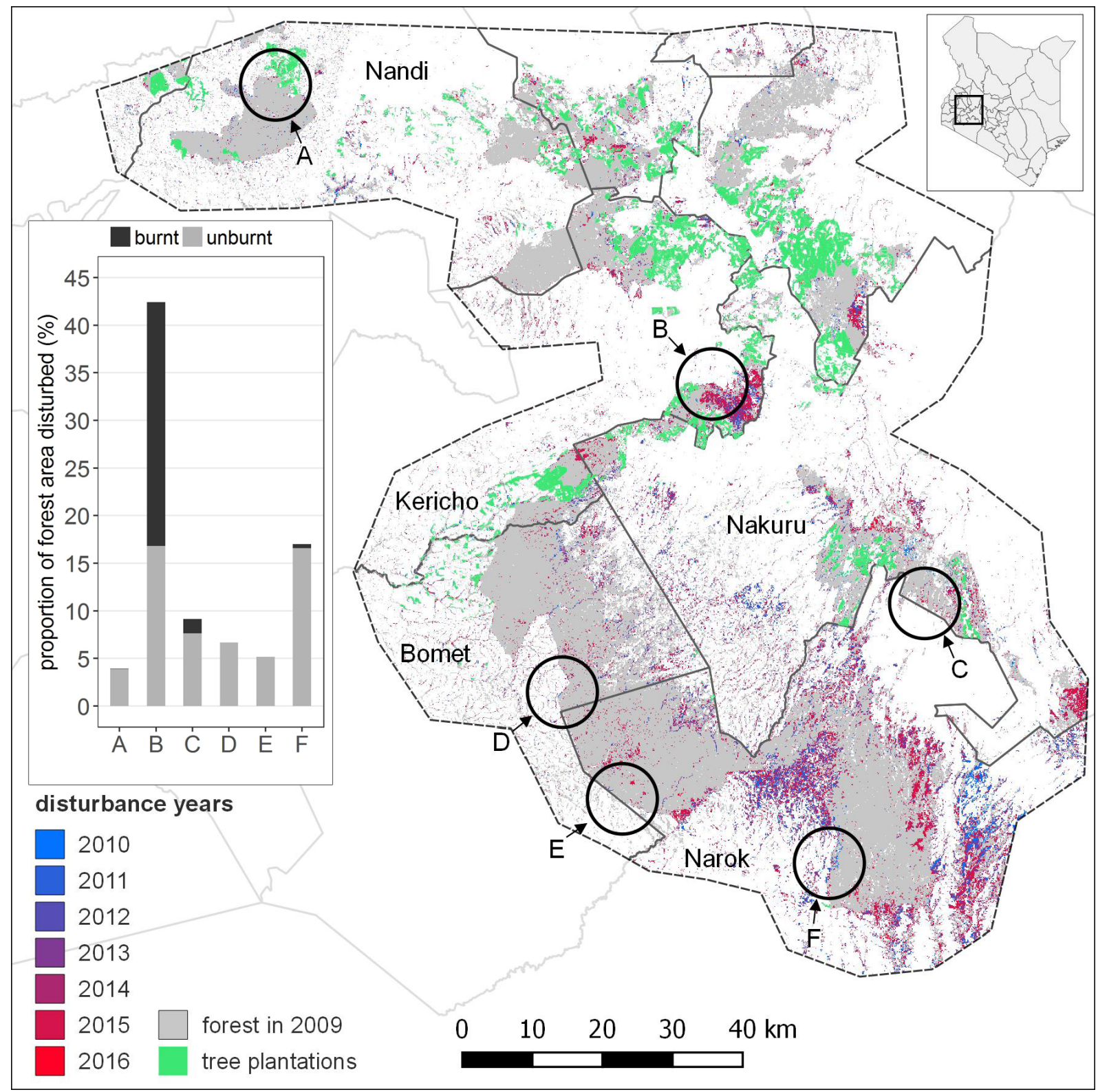

Figure 4.3: Forest disturbance mapped for 2010 to 2016 across the Mau forest. Circles indicate sampling sites for the field surveys: A) South Nandi Forest, B) Western Mau Forest, C) Eastern Mau Forest, D) South West Mau Forest, E) Transmara Mau Forest, and F) Maasai Mau Forest. Inset bar plot shows proportions of disturbed forest area that was burnt and unburnt for each sampling site.

\subsubsection{Dominant drivers of forest disturbance across sampling sites}

Firewood extraction and cattle grazing inside the forest were the most dominant drivers of forest disturbance at all six sampling sites. Firewood extraction was observed at $76 \%$ and cattle grazing at $75 \%$ of all disturbance spots visited. Burnt tree stems were observed 
on $31 \%$ of all spots sampled at four sampling sites, suggesting wildfires are an important driver of disturbance. Wildfire events observed on the ground were confirmed by MODIS fire alert data for three of the six sampling sites, detecting wildfires at the Western Mau Forest, Eastern Mau Forest, and Maasai Mau Forest at 25.6 \%, 1.5 \%, and $0.4 \%$ of the forested land respectively (inset Figure 4.3). The most common combination of drivers observed on $48 \%$ of all visited spots was firewood extraction and cattle grazing inside the forest (Figure 4.4). This co-occurrence of drivers was predominant across the sampling sites except for the Maasai Mau Forest site where forest grazing and wildfire were found to co-occur more often (Figure 4.4).

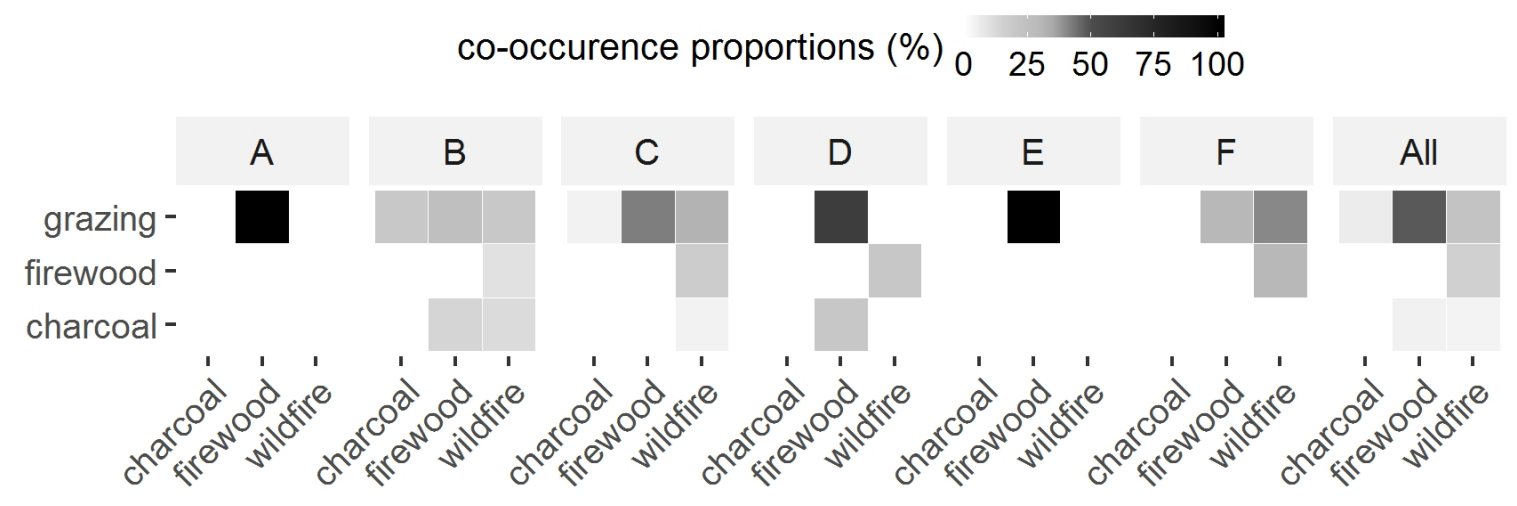

Figure 4.4: Co-occurrence proportions of forest disturbance drivers (\%). Forest disturbance spots were characterised during a forest survey at each sampling site: A) South Nandi Forest, B) Western Mau Forest, C) Eastern Mau Forest, D) South West Mau Forest, E) Transmara Mau Forest, F) Maasai Mau Forest, and All) all sampling sites.

\subsubsection{Effects of farm indicators on forest disturbance intensity}

Firewood collection rates, farm sizes, and cattle numbers were associated with a significantly increased risk of forest disturbance across farm neighbourhood sizes by $3-10 \%$, $1-5 \%$, and $1-5 \%$ respectively ( $\mathrm{p}<0.001$, Figure 4.5 ). In contrast, higher milk yields were related to a significantly lower risk of forest disturbance by $3-7 \%$ across farm neighbourhood sizes $(\mathrm{p}<0.001$, Figure 4.5). Larger farm area allocated to fodder production, increased supplementation of dairy concentrates and higher proportion of grass from on-farm pastures in the diet were associated with a significantly lower risk of forest disturbance by $2-5 \%, 1-2 \%$, and $1-2 \%$ in 3 (Figure 4.5B, C, D), 2 (Figure 4.5A, $\mathrm{D}$ ), and 2 (Figure $4.5 \mathrm{C}, \mathrm{D})$ of the farm neighbourhoods respectively $(\mathrm{p}<0.001)$. The risk of forest disturbance intensities decreased significantly by $8-15 \%$ across all farm neighbourhood sizes $(\mathrm{p}<0.001)$, when farms were located further away from the forest. In general, the effects of farm indicators to increase or reduce disturbance risks remained relatively constant over the different neighbourhood sizes. However, effects sizes of farm 
indicators became smaller with increasing size of farm neighbourhoods except for cattle numbers, which slightly increased the risk of forest disturbance in larger neighbourhoods (Figure 4.5). The variability around the effects shown by their $95 \%$ confidence intervals was low across farm neighbourhoods. For details on model selection see Appendix (S4, Table S4.3).

A
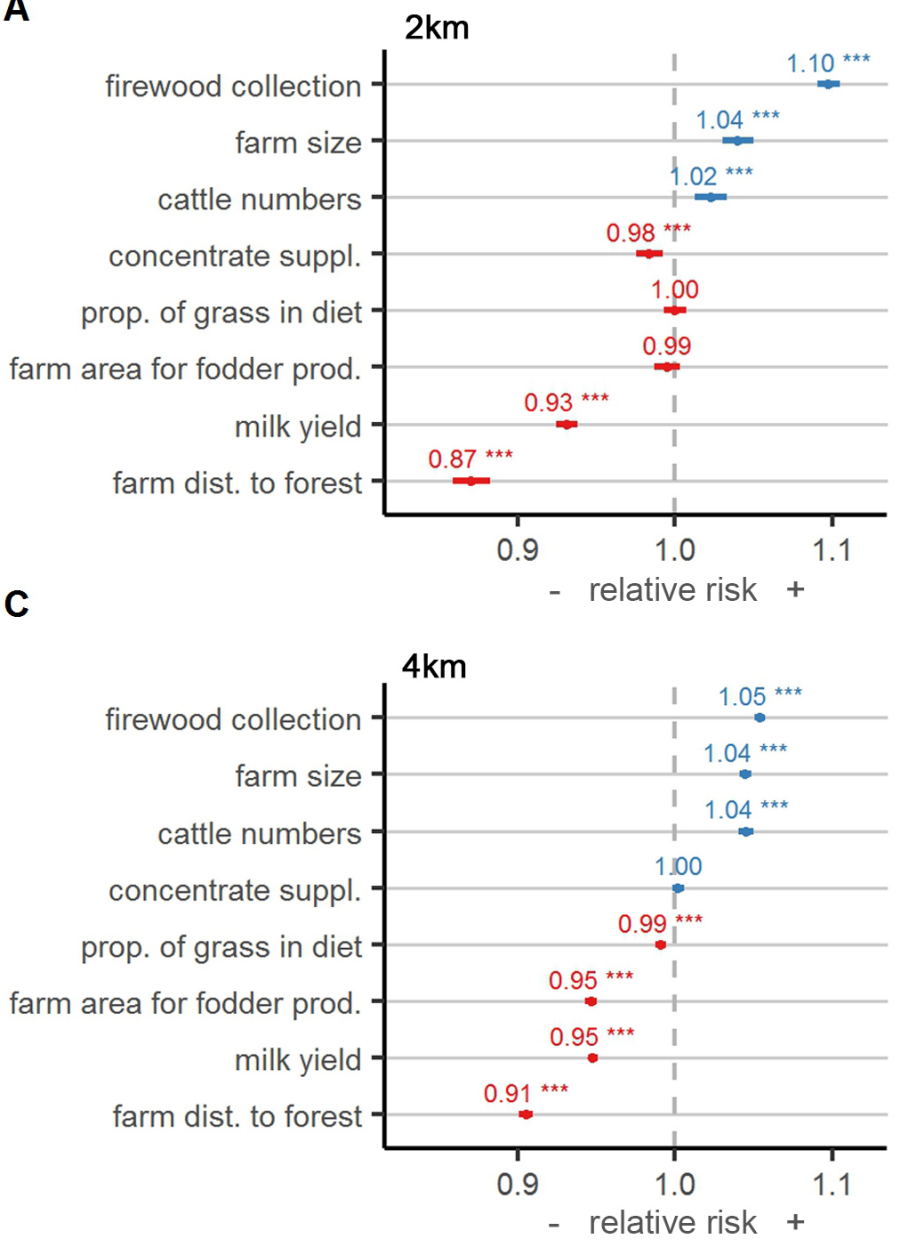

B
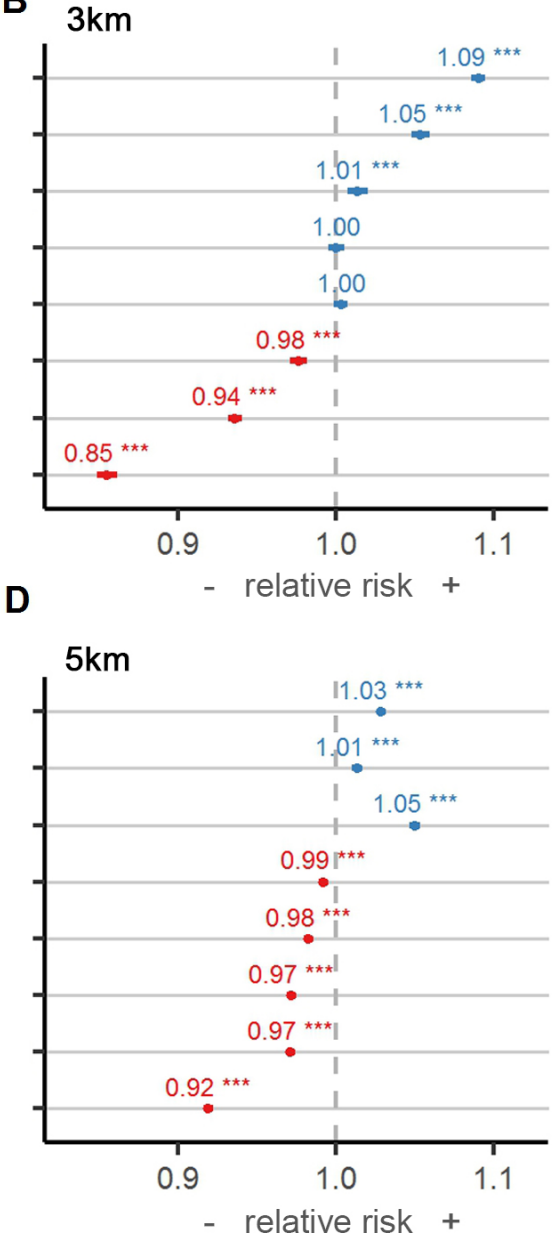

Figure 4.5: Relative risks of forest disturbance as response to farm indicators. Relative risks were derived from GLMMs for different farm neighbourhood sizes (buffer radiuses): A) $2 \mathrm{~km}$, B) $3 \mathrm{~km}$, C) $4 \mathrm{~km}$, and D) $5 \mathrm{~km}$. Horizontal bars show mean effect and $95 \%$ confidence intervals for each indicator. Stars show significance levels. Vertical dashed lines indicate no effect.

\subsubsection{Farm types}

Three farm types were inferred from the cluster analysis: 'small and resource-poor farms', 'large and inefficient farms' and 'intensified farms'. Small and resource-poor farms had the smallest mean sizes $(0.7 \pm 0.6$ ha, Figure $4.6 \mathrm{~A})$, the lowest total number of cattle herds 
(2.3 \pm 1.8 heads, Figure 4.6B) and the lowest number of dairy cattle ( $0.5 \pm 1.0$ heads $)$. The quality of cattle feed was low indicated by a relatively low proportion of native grass from pastures in the diet $(72.7 \pm 30.4 \%$, Figure $4.6 \mathrm{C})$, little farmland allocated to grow higher quality fodder $(0.03 \pm 0.04$ ha, Figure $4.6 \mathrm{D})$ and the smallest supplementation rate of concentrated feed $\left(0.08 \pm 0.11 \mathrm{~kg} \mathrm{cow}^{-1}\right.$ day $^{-1}$, Figure $\left.4.6 \mathrm{E}\right)$. Milk yields were the lowest $\left(1.2 \pm 1.4 \mathrm{~kg} \mathrm{cow}^{-1}\right.$ day $^{-1}$, Figure $\left.4.6 \mathrm{~F}\right)$. Firewood collection rates were intermediate $(36.5$ $\pm 79.3 \mathrm{~kg} \mathrm{week}^{-1}$, Figure $\left.4.6 \mathrm{G}\right)$. In addition, the farm survey data show for this farm type comparatively low proportions of farms with planted trees on on-farm pastures $(13 \%)$, cropland (5\%), farm boundaries (84\%), and in woodlots $(26 \%)$.

Large and inefficient farms had the largest mean sizes (4.9 \pm 5.5 ha) and cattle herds (14.0 \pm 16.7 heads) combined with a moderate number of dairy cattle $(2.5 \pm 11.4$ heads $)$. Feed quality was low shown by the highest proportion of native grass from pasture in the diet $(86.5 \pm 11.7 \%)$, little farmland allocated to grow high quality fodder ( $0.10 \pm 0.45 \mathrm{ha})$, and low supplementation rates of feed concentrates $\left(0.11 \pm 0.14 \mathrm{~kg} \mathrm{cow}^{-1}\right.$ day $\left.^{-1}\right)$. Milk yields were only slightly higher than those of the small and resource-poor farms $(1.8 \pm 1.2 \mathrm{~kg}$ $\mathrm{cow}^{-1}$ day $\left.^{-1}\right)$. Firewood collection rates for this farm type were the highest $(84.5 \pm 160.6$ $\mathrm{kg}$ week $\left.{ }^{-1}\right)$. The farm survey data indicate that the proportions of farms with planted trees on on-farm pastures $(16 \%)$ and cropland $(6 \%)$, farm boundaries $(78 \%)$, and in woodlots $(25 \%)$ were similar to those of the small and resource-poor farms.

Relatively more intensified farms had medium sizes (2.5 \pm 2.1 ha), moderate cattle head sizes ( $5.0 \pm 2.9$ heads) but the highest numbers of dairy cattle (3.0 \pm 3.5 heads). These farms had the best feed quality indicated by a moderate proportion of native grass from on-farm pastures in the diet $(78.3 \pm 16.4 \%)$, the largest farm area allocated to fodder production $(0.23 \pm 0.55 \mathrm{ha})$, and high rates of concentrated feed supplementation (0.9 $\pm 1.0 \mathrm{~kg} \mathrm{cow}^{-1}$ day $\left.^{-1}\right)$. Milk yields were the highest $\left(5.1 \pm 2.2 \mathrm{~kg} \mathrm{cow}^{-1}\right.$ day $\left.^{-1}\right)$. Firewood collection rates were the lowest $\left(31.2 \pm 81.6 \mathrm{~kg}\right.$ week $\left.^{-1}\right)$. This farm type had the highest proportions of farms with planted trees on on-farm pastures $(26 \%)$, cropland (14\%), farm boundaries $(90 \%)$, and in woodlots (40\%). 


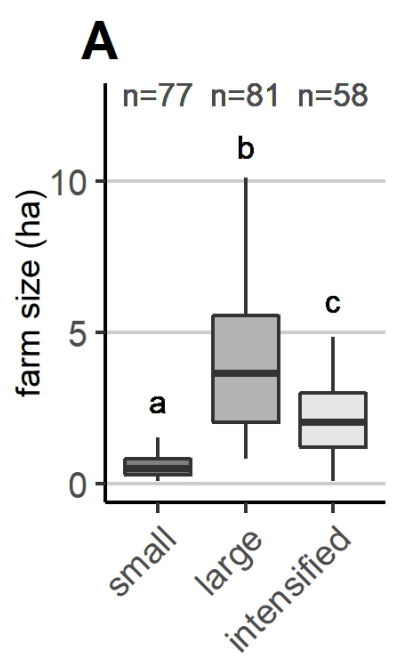

B

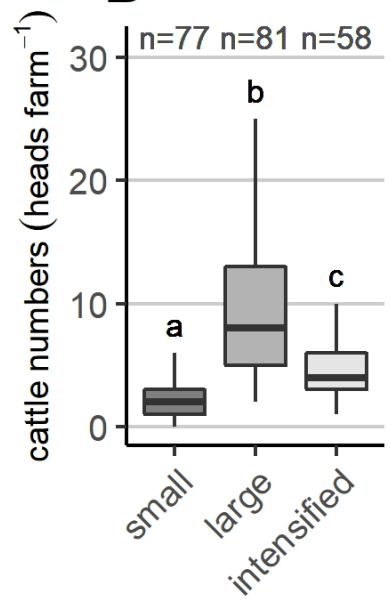

$\mathbf{F}$
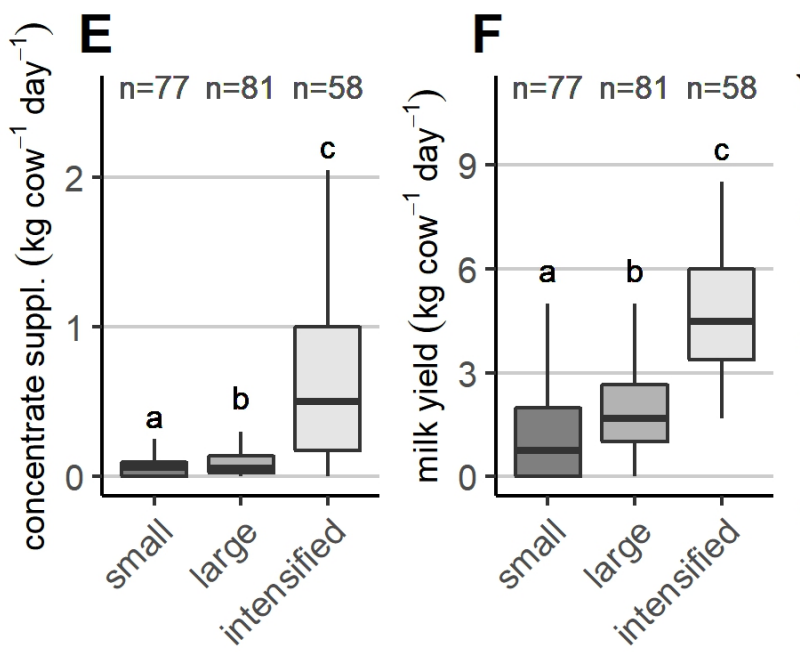

C
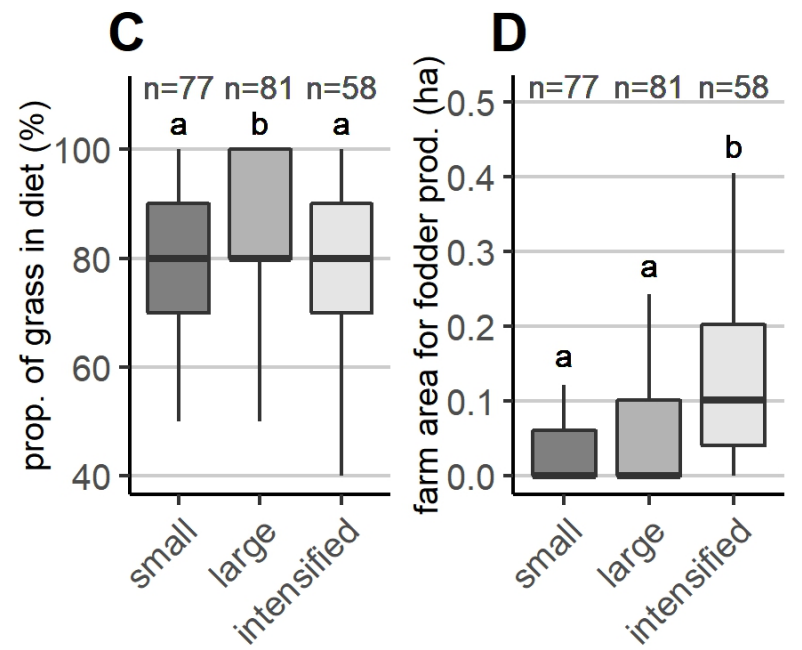

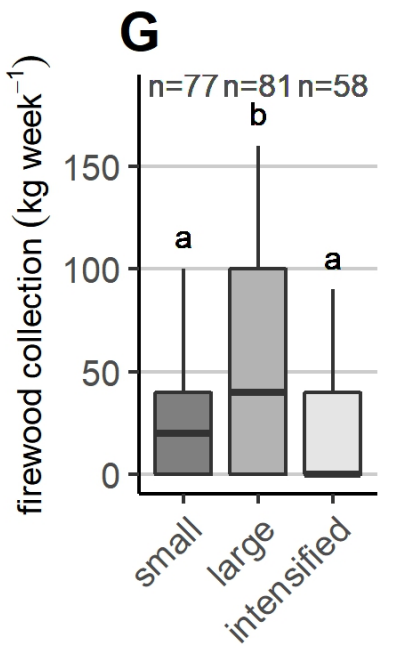

Figure 4.6: Farm indicators used to cluster farm types. Farm types were (x-axes): small $=$ small and resource-poor farms, large $=$ large and inefficient farms, intensified $=$ intensified farms. Included indicators were: A) cattle numbers, B) milk yields, C) proportion of grass from on-farm pastures in the diet, D) farm area allocated to fodder production, E) concentrate supplementation, F) farm size, and G) firewood collection. Different letters above whiskers indicate significant differences between farm types by using pairwise Wilcoxon rank sum tests (p-values were corrected for multiple testing).

Large and inefficient farms were located at higher elevation and show longer travel time to cities compared to small and resource-poor farms and intensified farms $(\mathrm{p}<0.001$, Figure 4.7A \& B). Therefore, large and inefficient farms were located more remotely and had less market access. 

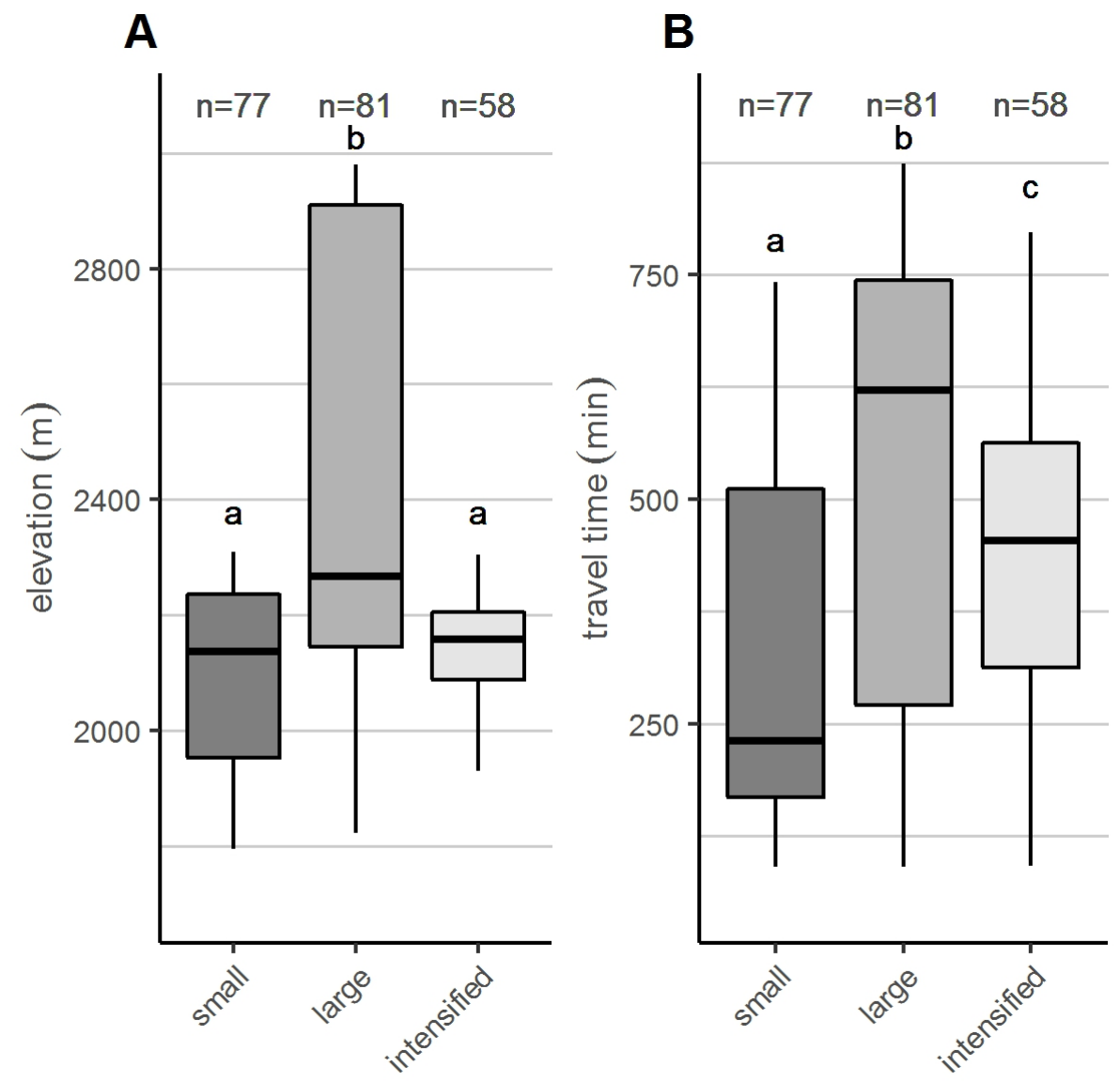

Figure 4.7: Elevation and remoteness of farm types. Boxplots show A) elevation and B) travel time to cities by farm type: small $=$ small and resource-poor farms, large $=$ large and inefficient farms, intensified $=$ intensified farms). Different letters above whiskers indicate significant differences between clusters farm types by using pairwise Wilcoxon rank sum tests (p-values were corrected for multiple testing).

\subsubsection{Farm types and forest disturbance intensity}

Farm types had a significant effect on forest disturbance intensity $(\mathrm{p}<0.05)$ for all farm neighbourhood sizes. Interactions between farm types and farm distance to forest edges show that more intensified farms had significantly smaller effects on the intensity of forest disturbance than the small and resource-poor farms and the large and inefficient farms for the different neighbourhood sizes $(\mathrm{p}<0.001$, Figure 4.8). However, differences in effects between large and small farms were not significant for the $4 \mathrm{~km}$ farm neighbourhood size (Figure 4.8C). In general, the effect of farm types on forest disturbance intensity became smaller with increasing farm distance to the forest edges. For the $5 \mathrm{~km}$ neighbourhood size, effects of farm types were less distinguishable and their slopes decreased (Figure $4.8 \mathrm{D})$, indicating that the influence of farm types on forest disturbance intensity are more 
difficult to disentangle from external effects. The $95 \%$ confidence intervals around the effects indicate an increased variability of the interaction effects of farm types along farm distance to forests across farm neighbourhoods. The lowest variability of effects was shown for intensified farms in all farm neighbourhood sizes. For details on model selection see Appendix (S4, Table S4.4). 
A

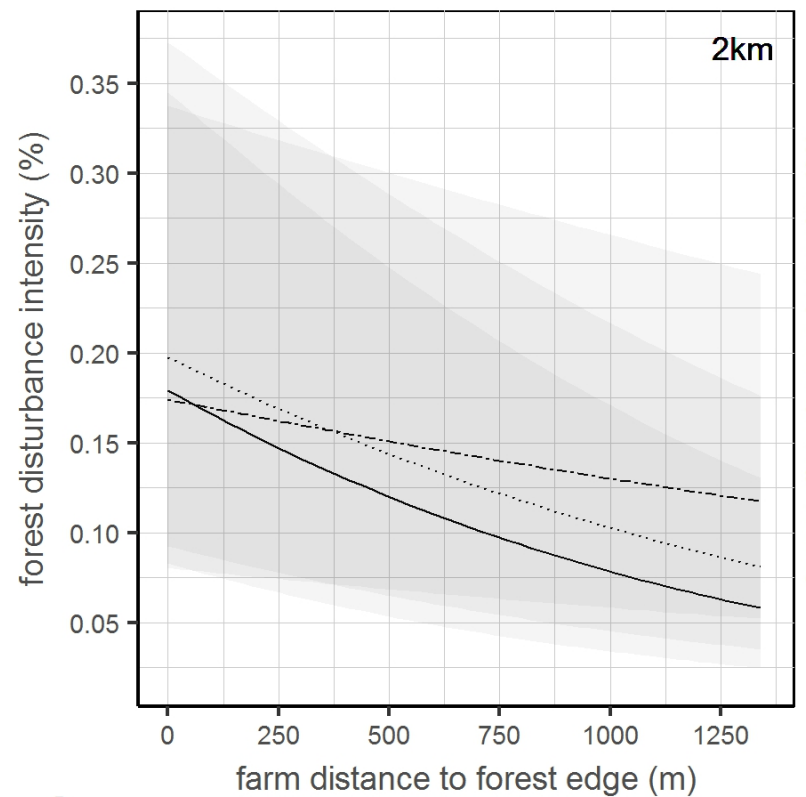

C

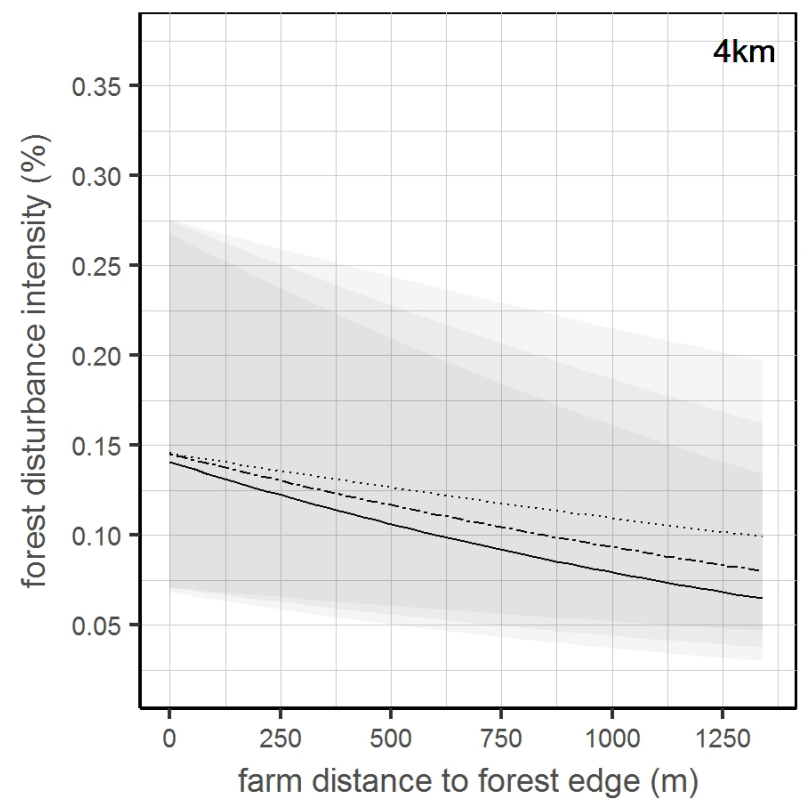

B

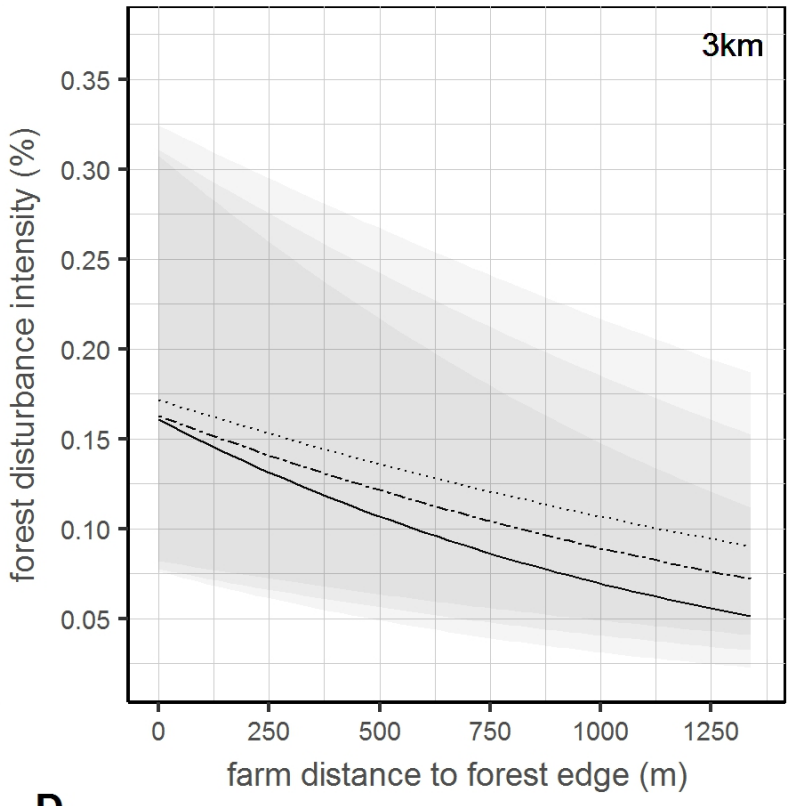

D

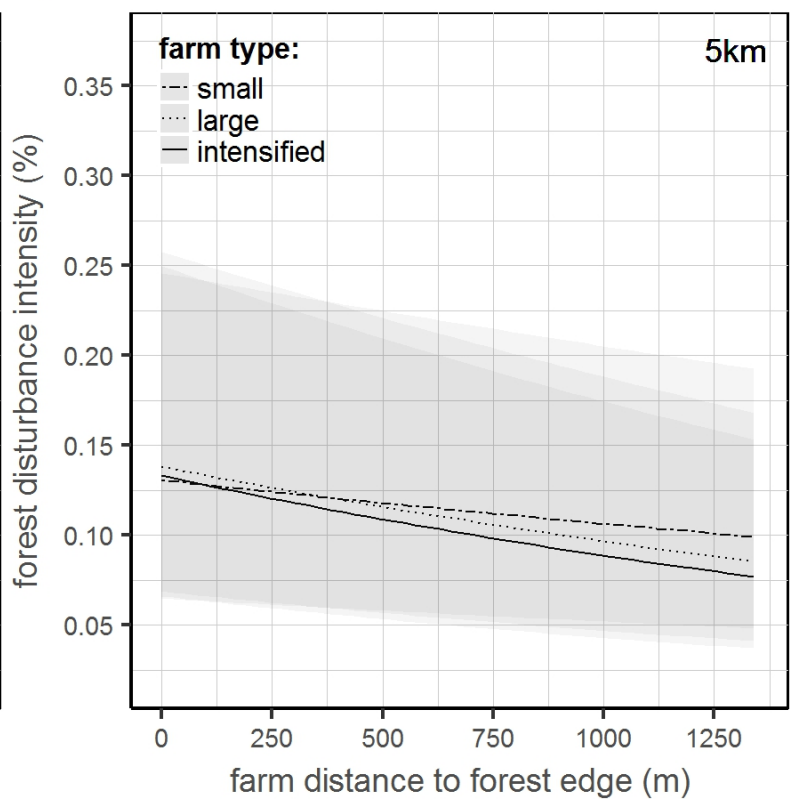

Figure 4.8: Effects of farm types on forest disturbance intensity. Effects of farm types interacting with farm distance to forest edges were derived from GLMMs for different farm neighbourhood sizes (buffer radiuses): A) $2 \mathrm{~km}$, B) $3 \mathrm{~km}$, C) $4 \mathrm{~km}$, and D) $5 \mathrm{~km}$. Shaded areas indicate $95 \%$ confidence intervals for each farm type (small $=$ small and resource-poor farms, large $=$ large and inefficient farms, intensified $=$ intensified farms).

Effects of farm types on the two most important forest disturbance types (i.e. disturbance drivers) observed during the survey (Figure 4.4) also differ (Figure 4.9). Intensified farms were associated with significantly lower intensities of forest disturbance $(\mathrm{p}<0.05)$ where firewood collection (Figure 4.9A, C) and cattle grazing (Figure 4.9D) were recorded, 
compared to small and resource-poor farms as well as large and inefficient farms. An exception is shown for forest grazing within the $2 \mathrm{~km}$ farm neighbourhood where large farms were associated with a significantly higher disturbance intensity $(\mathrm{p}<0.05)$ than small and resource-poor farms and intensified farms (Figure 4.9B). Results are only shown for the 2 and $3 \mathrm{~km}$ farm neighbourhoods due to few disturbance samples from the forest survey within the 4 and $5 \mathrm{~km}$ farm neighbourhoods (Figure 4.9D). The variability around the farm type effects was smallest for intensified farms shown by $95 \%$ confidence intervals. For details on model selection see Appendix (S4, Table S4.5). 
A

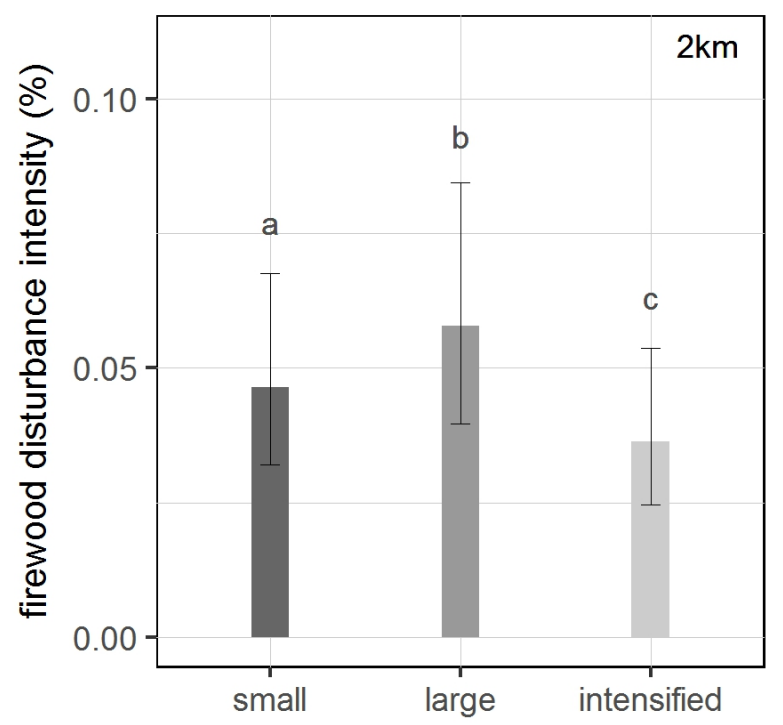

C

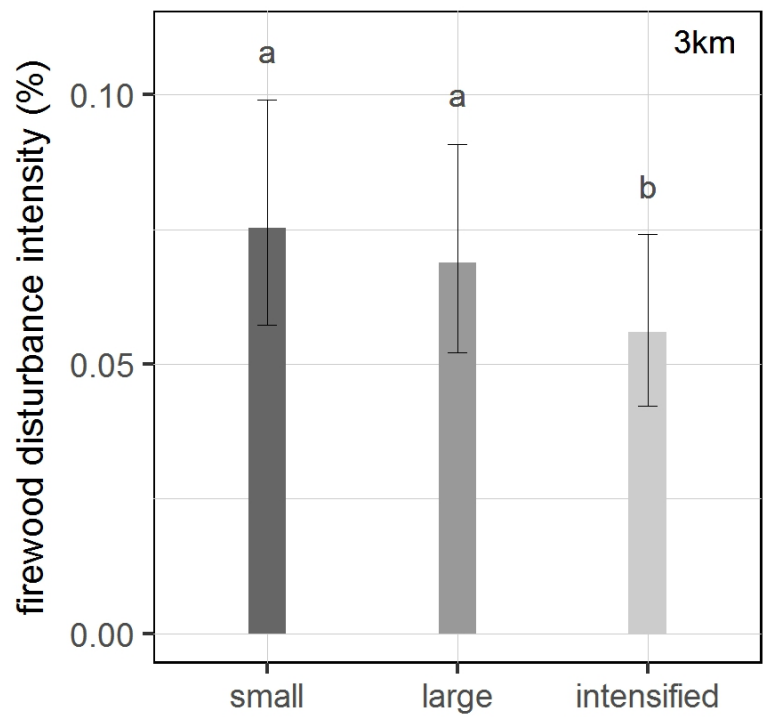

B

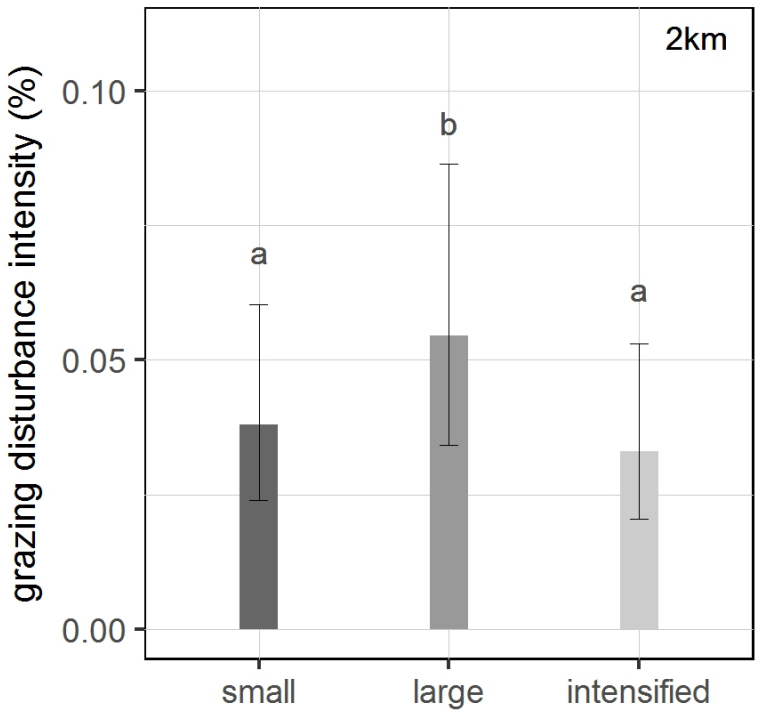

D

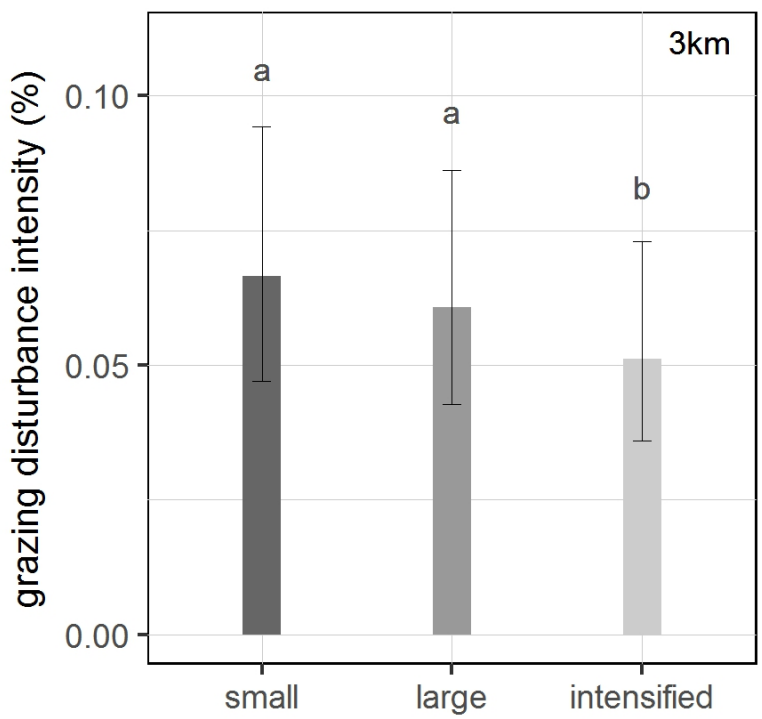

Figure 4.9: Farm types effects on forest disturbance types. Effects of farm types are shown for firewood collection (A, C) and cattle grazing in the forest (B, D) modelled for the 2 and $3 \mathrm{~km}$ farm neighbourhood sizes. Different letters above bars indicate significant differences between farm types (small $=$ small and resource-poor farms, large $=$ large and inefficient farms, intensified $=$ intensified farms). Vertical bars indicate $95 \%$ confidence intervals. 


\subsection{Discussion}

\subsubsection{Drivers of forest disturbance in context}

Forest disturbance across SSA is responsible for large parts of the land-based GHG emissions (Bailis et al., 2015; Pearson et al., 2017). In this study, the dominant drivers of forest disturbance were the extraction of firewood primarily used by local smallholder farmers living adjacent to the Mau Forest and cattle grazing inside the forest as opportunistic feed resource for cattle owned by local smallholders (Figure 4.4). Grazing happens mostly on forest land opened through fuelwood extraction or wildfires. Although grazing is not a primary driver of forest disturbance in the montane forests studied, it prevents the regrowth of woody vegetation, affects negatively $\mathrm{C}$ sequestration and, thus, reduces the $\mathrm{C}$ sink capacity of forests (Samojlik et al., 2016). Wildfires occur across the Mau Forest, often caused by human activities such as charcoal production or attempts to clear forested land, which increase the risk to spread fire during dry seasons.

Firewood extraction from forests partly covers the demand for fuelwood, which is the main driver of small-scale forest disturbance in SSA (Hosonuma et al., 2012). The high demand for fuelwood in East African countries such as Kenya exceeds the supply capacity of forest ecosystems (Mutoko et al., 2015). Therefore, Kenya is among the countries that show the most unsustainable fuelwood production across the tropics (Bailis et al., 2015). GHG emissions from fuelwood extraction and utilisation in tropical forests account with $0.62 \mathrm{Gt} \mathrm{CO}_{2}$ eq year ${ }^{-1}$ for about one third of the forest emissions, compared to timber production (1.09 Gt $\mathrm{CO}_{2}$ eq year ${ }^{-1}$ ) and wildfires (0.35 Gt $\mathrm{CO}_{2}$ eq year ${ }^{-1}$ ) as estimated by Pearson et al. (2017). Livestock grazing in forests is with $8 \%$ ranked as the third most important driver of disturbance as estimated by Hosonuma et al. (2012) after fuelwood extraction (58\%) and timber production (33\%) for SSA countries that are in their late forest transition phase such as Kenya. In this study, forest livestock grazing showed a more prominent role on forest disturbance, as it occurred at all six sampling sites at $75 \%$ of all spots visited (Section 4.3.2). Forest disturbance spots located deep inside the forest were not visited. It is likely that the intensity of forest grazing decreases further inside the forest with limited access. In addition to negative effects of $\mathrm{C}$ storage in forests, livestock grazing was shown to modify nutrient cycles and to reduce species richness in forests (Close et al., 2008; Denmead et al., 2015). 


\subsubsection{Mitigation potential on forested and agricultural land}

\section{Intensification may reduce the impact of smallholder farms on forests}

The increase in agricultural production in SSA has been mostly achieved through expansion of agriculture into natural ecosystems, including forests (Fisher, 2010). Increasing productivity without compromising environmental goals is required to meet future food demand and to contribute to climate change mitigation (Smith et al., 2013). This study shows that larger farms and higher cattle numbers increased the risk of forest disturbance by $1-5 \%$ (Figure 4.5). Higher firewood collection rates had an even stronger impact on the forest increasing the risk of disturbance by $3-10 \%$ (Figure 4.5 ). On the contrary, higher milk yields decreased these risks by $3-7 \%$ (Figure 4.5 ). The effects of indicators related to feed intensification such as larger farm area allocated to fodder production, supplementation of dairy concentrate and increased proportion of grass in the diet were less pronounced. These indicators reduced the risk of forest disturbance by 1 $5 \%$ (Figure 4.5). The results indicate that farms which own more cattle and collect more firewood are likely to cause more disturbance in the nearby forest than more intensified farms with high milk productivity and improved feed quality. The analysis of farm type effects on forest disturbance confirmed this pattern. More intensified farms had a lower impact on forests in general but also on disturbance caused by firewood extraction and livestock grazing in particular (Figure $4.8 \& 4.9$ ). Compared to small and resource poor farms and large but inefficient farms, intensified farms planted more trees on farmland (Section 4.3.4) e.g. in woodlots or on farm boundaries. These trees represent fuelwood sources available on-farm (Mbow et al., 2014), potentially translating into lower firewood extraction from the forest (Figure 4.6G). Small farms that lack resources such as land and access to higher quality feeds, and large but inefficient farms with many low productivity cattle (Figure 4.6A - F) increase the risk to remove biomass from local forests unsustainably by exceeding the regrowth rates. Yet, effect sizes of farm indicators and differences among the effects of farm type on forest disturbance were, despite significant, relatively small. The inefficiency of large farms is likely related to their location at higher elevation (Figure 4.7). Remoteness and lack of infrastructure result in reduced market access for these farms, rendering it more difficult for smallholders to buy higher quality feeds and feed supplements, and to sell the milk produced (Makoni et al., 2014).

The effects of dairy production and intensification on local forests can be quantified by relating farm practices and characteristics to forest disturbance patterns. Including farmrelated activities outside the farm boundaries that affect the broader landscape is relevant to assess the effectiveness and sustainability of policies that target climate change mitigation and food security (DeFries \& Rosenzweig, 2010). Potential spill over effects can be revealed, causes be identified and the risk of $\mathrm{C}$ leakage be minimised. 


\subsubsection{Increase of farm efficiency and on-farm tree cover}

Dairy production in SSA shows the highest GHG emission intensities compared to dairy production in other continents which points to low efficiency of smallholder dairy production (Gerssen-Gondelach et al., 2017). Mitigation and development policies seek for 'win-win' situations where increased farm production goes hand in hand with the avoidance of additional GHG emissions (Brandt et al., 2018b). Low quality feed from natural pastures and from opportunistic cattle grazing inside the forest result in low milk yields and high GHG emission intensities (Lukuyu et al., 2012). Increasing milk yields on smallholder farms can be achieved through feed intensification by improving the protein and energy density in feeds (Agle et al., 2010; Trupa et al., 2015). The intensified farm type showed the highest milk yields (Figure 4.6F). The quality of feed that is either grown on-farm such as fodder grasses or supplemented as concentrated feed such as dairy meals was also highest for intensified farms compared to the other two farm types (Figure 4.6D \& E). Perennial fodder grasses such as Napier grass show high potential for feed intensification as it has a higher quality than native grass from pastures and is widely accepted by smallholders across the Kenyan highlands (Katiku et al., 2011). Higher supplementation of concentrates during lactation periods was related to the increase in milk yields in this study (Figure 4.6E) and was also reported to improve milk yields in Kenya (Rufino et al., 2009; Richards et al., 2016).

However, C leakage emerging from intensification processes have to be considered. Feed imports from other regions or countries may raise due to feed intensification if the increased demand of higher quality feeds cannot be covered locally (Meyfroidt et al., 2014). GHG emissions from indirect land use changes due to agricultural expansion could be the consequence. Styles et al. (2018) conducted a life cycle assessment (LCA) of dairy intensification in the United Kingdom showing possible cascade effects of pasture-crop displacement and expansion of pastures that lead to deforestation in Brazil. Therefore, appropriate mitigation policies and funding schemes need to integrate measures (e.g. protocols on land use legacies, certification) that enable feed production which does not undermine effective climate change mitigation.

Depleted soils due to nutrient mining is a common reason for stagnating or falling crop yields in Kenya (Tittonell et al., 2010). Increasing the efficiency of nutrient cycling through improved manure management can increase soil fertility and crop yields as shown by Castellanos-Navarrete et al. (2015) for smallholder crop-livestock production systems in Kenya. Closing the yield gap is especially important for small farms that lack land to grow fodder. Furthermore, intensified farms had less cattle than large and inefficient farms (Figure 4.6B, F), and instead owned more improved breeds (Section 4.3.4). Reduced stocking rates with higher herd efficiency and the replacement of local cattle with improved breeds that produce more milk accompanied by better access to animal health services are additional factors to increase the efficiency of milk production and to reduce 
GHG emission intensities on smallholder dairy farms in Kenya (Bryan et al., 2013; Mottet et al., 2016). Adopting the dairy hub model, developed by the 'East African Dairy Development' (EADD) program, could facilitate the improvement of market access. This can be achieved by infrastructure funds and by linking the different actors throughout the dairy value chain such as dairy farmers, feed producers and dairy companies (EADD, 2014).

Agroforestry could increase the $\mathrm{C}$ sequestration potential of smallholder farms in the tropics and offset GHG emissions resulting from agricultural production (Mutuo et al., 2005; Abbas et al., 2017; Ortiz-Gonzalo et al., 2017). Kenya's target to increase the tree cover from about $6 \%$ in 2000 to $10 \%$ by 2030 is the policy frame to improve the tree cover on farm land (Government of Kenya, 2015b). However, between 2000 and 2010, the tree cover on farm land in Kenya on average increased by about 1 \% (Zomer et al., 2016). Thus, incentives such as climate financing schemes are required to encourage smallholder farmers to plant trees on their farms which could be used as fodder trees or as fuelwood source. Moreover, more efficient cooking stoves would reduce the demand of fuelwood and indoor air pollution translating into health improvements (Malla et al., 2011). Improved forest management that actively involves local communities could enable the sustainable use of forest resources e.g. by establishing regulated wood pastures located at the forest edges or tree plantations used for a certified fuelwood production (Börner \& Wunder, 2012; Chidumayo \& Gumbo, 2013; Mutoko et al., 2015).

\subsubsection{Limitation and benefits of the approach}

This is the first study that combines a remote sensing approach with an analysis of farm production to investigate the connection between dairy production and forest disturbance in Africa. It is also one of the first studies that applied a forest disturbance detection approach utilising the spatio-temporal information from Landsat time-series (Hamunyela et al., 2017). The approach was shown to outperform change detection based on temporal information only in terms of accuracy especially in environments where forest disturbances occur mainly at small-scale (Hamunyela et al., 2016b, 2017). The spatial accuracy achieved here $(\mathrm{UA}=77.9 \%, \mathrm{PA}=78.6 \%)$ is comparable to Hamunyela et al. (2017) who studied small-scale disturbances in the Ethiopian highlands (UA $=76.8 \%$, $\mathrm{PA}=78.3 \%$ ). By reducing false detections of small-scale disturbances, STEF could improve national forest monitoring capabilities especially in regions where these disturbance patterns are dominant such as in many SSA countries (DeVries et al., 2015b). The spatial resolution of Landsat sensors limits the detection of small-scale disturbances. However, new satellite systems such as the Sentinal platform bears high potential for forest monitoring applications due to increased spatial and temporal resolution (Mitchell et al., 2017). 
Training and validation data obtained from the ground are necessary to improve the detectability of forest disturbances even more so if they occur at small-scale and visual interpretation methods based on high resolution satellite imagery become unsuitable. Involving local experts into the monitoring can enhance the validity of detected changes and enable the characterisation of their drivers e.g. through community-based forest monitoring integrating remote-sensing and smart phone technologies (DeVries et al., 2016). Higher variability in the effects of farm type on forest disturbance reflected uncertainties that were introduced through the clustering of farm types by using farm survey data. Such uncertainties have to be reduced to improve the quantification of agricultural drivers and GHG emissions resulting from forest disturbance - e.g. through comprehensive measuring and reporting efforts.

\subsection{Conclusions}

This study revealed that the main anthropogenic drivers of forest disturbance across the Mau Forest are extraction of firewood and cattle grazing inside the forest. Both drivers are related to farm practices and characteristics of local smallholder farms. Intensification of smallholder dairy farming was associated to a lower risk of forest disturbance. Less forest disturbance translates eventually into reduced GHG emissions from forests. Thus, these results are informative for policy formulation and decision-making targeting mitigation options that increase farm efficiency and minimise negative effects on forests at the same time.

Incentive-based climate financing instruments are required for stakeholders such as farmers, cooperatives and the private sector involved in dairy production. These funds could be accessed once certain criteria are fulfilled such as the implementation of on-farm practices such as feed intensification that mitigate direct and indirect GHG emissions and increase farm productivity. A nationally appropriate mitigation action (NAMA) currently in development for the dairy sector in Kenya offers a promising policy framework to develop low emission dairy production, including capacity development and investment support targeting about two million smallholder households. However, assessments and criteria that minimise the risk for carbon leakage through indirect land use changes have to be integrated into policy development to achieve effective mitigation in the land use sector.

Based on the key results, policy recommendations are: i) reducing the emission source potential of agriculture through the increase of production efficiencies on dairy smallholder farms and through the improvement of their offsetting potential (i.e. the increase of tree cover on farmland) and ii) enhancing the $\mathrm{C}$ sink potential of forest systems by minimising forest disturbances through sustainable intensification of farming and improved forest management. 


\section{Acknowledgments}

This study was funded by the CGIAR program on 'Climate Change, Agriculture and Food Security' (CCAFS) and the IFAD project 'Greening livestock: Incentive-based interventions for reducing the climate impact of livestock production in East Africa'. The author thanks the forestry department of the 'Food and Agriculture Organization' (FAO) of the United Nations for technical support and courtesy to use the system for earth observations, data access, processing \& analysis for land monitoring (SEPAL). Additionally, the research was supported by the 'Norwegian Agency for Development Cooperation' (NORAD) and Germany's 'International Climate Initiative' (IKI) through CIFOR's Global Comparative Study on REDD+, and the CGIAR Research Program on Forests, Trees and Agroforestry (CRP-FTA) with financial support from the CGIAR Fund. 


\section{Chapter 5}

\section{Intensification of dairy feeds increases GHG mitigation potential across the land use sectors of agriculture and forestry in Kenya}

Brandt, P., Herold, M., Rufino, M., 2018. Intensification of dairy feeds increases GHG mitigation potential across the land use sectors of agriculture and forestry in Kenya. to be submitted. 


\section{Abstract}

Countries in Sub-Saharan Africa (SSA) need to produce more food to feed their fast growing populations. Agriculture drives forest disturbance in SSA through forest livestock grazing by preventing vegetation regrowth, which reduces the carbon (C) sink capacity of forests and causes greenhouse gas (GHG) emissions. Smallholder farming hast to be intensified sustainably by producing more food on agricultural land and by releasing the pressure on forests, which contributes to climate mitigation. Kenya aims for the lowemission development of its dairy sector to meet the growing demand for milk. This study assessed the potential of dairy feed improvements, including closing the yield gap of fodder maize, to mitigate agricultural GHG emissions and forest C loss linked to dairy cattle. The livestock production model LivSim was applied to estimate and upscale GHG emissions and milk yields for different feed improvement scenarios. Forest $\mathrm{C}$ loss due to dairy cattle was quantified by using remote-sensing data on aboveground $\mathrm{C}$ change. The shortage of grazing land potentially available to cultivate improved dairy feeds was analysed around forests to relate the scenarios and forest $\mathrm{C}$ loss due to dairy cattle. Scenarios that closed the maize yield gap could increase milk yields by up to $51 \%$ and lower GHG emission intensities by up to $19 \%$ due to reduced land requirements. The reduction of GHG emissions from land use change was up to 5 times higher than the increase of GHG emissions from additional fertilizer application. Forest $\mathrm{C}$ loss due to dairy cattle could be reduced by up $225 \%$, which turns forests into C sinks. However, only the scenario that improved forage quality based on Napier grass and increased concentrate supplementation would achieve a net reduction of combined total agricultural GHG emissions and forest $\mathrm{C}$ loss due to dairy cattle. The combined total emissions would be $2.5 \%$ lower than in the baseline, while the milk yield could be increased by $45 \%$. Thus, dairy feeds can realise productivity and effective mitigation benefits across land use sectors. The approach followed can aid the targeting and planning of interventions that improve the climate-smartness of smallholder livestock production. 


\subsection{Introduction}

Low agricultural productivity and rising human population in Sub-Saharan Africa (SSA) jeopardize food security and degrade natural ecosystems through unsustainable landuse practices (Herrero et al., 2016; Grassi et al., 2017). Agriculture is shown to drive forest disturbance in SSA, which causes the loss of forest carbon (C) and greenhouse gas (GHG) emissions (Carter et al., 2015). In addition to the conversion of forests into farm land, timber logging, and fuelwood extraction, cattle grazing causes forest disturbance by preventing the regrowth of vegetation (Hosonuma et al., 2012; Pearson et al., 2017; Brandt et al., 2018a). Forest disturbance reduces the sequestration of $\mathrm{C}$ and, thereby, decreases the $\mathrm{C}$ sink capacity of forests, and affects water and nutrient cycling, and biodiversity, which feedback negatively on agricultural production (Barlow et al., 2016; Arias-Navarro et al., 2017; Jacobs et al., 2017; Wanyama et al., 2018). Safeguarding and improving the supply of nutritious food is one of the 'Sustainable Development Goals' (SDG 2) of the 'United Nations' (UN) to achieve food security globally but especially in SSA (UN, 2017a). The majority of food in SSA is produced by smallholder farmers that are often affected by low livestock productivity, low and stagnating crop yields due to nutrient-depleted soils, and small farm sizes (Tittonell et al., 2009; Zhou et al., 2014; Brandt et al., 2018b). Food production on smallholder farms in SSA has to be intensified sustainably to reduce malnutrition and to reach SDG2. The concept of 'Climate-Smart Agriculture' (CSA) was brought forward to adapt agricultural systems to climate change, to mitigate anthropogenic impacts on the climate system and to safeguard food security (FAO, 2013).

Agriculture in East Africa is increasingly prone to erratic weather patterns and prolonged drought spells. To address these challenges, Kenya set up a national CSA strategy to transform the country's agricultural sector towards climate-smart food production systems. Agriculture is not only the country's economic backbone but also contributes with about $40 \%$ to its GHG emissions budget. About $90 \%$ of the agricultural emissions stem from livestock production (Government of Kenya, 2015b). As part of its ambitious economic development plan, Kenya seeks to develop its dairy sector to be able to meet the increasing demand for milk, which results from the fast growing human population (Government of Kenya, 2010). Dairy production engages approximately two million smallholder farmers, who contribute about $80 \%$ to the total milk production in Kenya (Udo et al., 2016). However, higher cattle numbers and the increasing demand for feeds will lead to higher GHG emissions from enteric fermentation, animal manure, the additional arable land allocated to feed production and pastures. Low yields of feed crops, small farm sizes and the shortage of agricultural land in Kenya increase the pressure on remaining natural forests and the risk of forest C loss due to forest cattle grazing (Kumar et al., 2009; O'Mara, 2011; Bosire et al., 2016; Brandt et al., 2018a). Therefore, sustainable intensification of the dairy sector is required, which increases milk yields by producing 
higher quality feeds more efficiently on available agricultural land without the need to expand into natural ecosystems.

Kenya defined targets in various national and sectoral mitigation and development policies such as the 'Nationally Determined Contribution' (NDC) and the national dairy master plan. The increase of total GHG emissions in Kenya has to be lowered by $30 \%$ relative to projected business as usual emissions between 2010 - 2030 (Government of Kenya, 2015a). Within the same time frame, milk yields of dairy cattle have to be increased by $150 \%$ (Government of Kenya, 2010). The 'Nationally Appropriate Mitigation Action' (NAMA) for the dairy sector in Kenya focuses on the low-emission development of smallholder dairy farming by increasing on-farm productivity through the improvement of dairy feeds (Government of Kenya, 2017b). To analyse weather these targets can be met effectively, the impact of feed improvements on dairy-related GHG emissions from the entire 'Agriculture, Forestry and Other Land Use' (AFOLU) sector have to be included into the assessments.

Brandt et al. (2018b) reported synergies between improving dairy feeds, milk yield increases, and GHG mitigation benefits on agricultural land. In addition, intensified smallholder dairy farms located close to forests are shown to reduce the risk of local forest disturbance (Brandt et al., 2018a). However, changes in cattle diet may require the conversion of potentially arable land such as grazing land to cultivate more nutritious feeds, which can cause GHG emissions from land use change (LUC) (van Middelaar et al., 2013), and ultimately render certain feed improvement options unfeasible (Brandt et al., 2018b). Promoting dairy production in a region with shortages of agricultural land for feed cultivation could, therefore, increase the risk of negative spillover effects such as $\mathrm{C}$ leakage as farmers may use close-by forests for grazing. Closing the yield gap of feed crops could reduce the demand for additional land and, thus, alleviate the disturbance pressure on forests. To date, there are no assessments that integrate the effects of agricultural intensification and GHG mitigation measures on forests in SSA, which are crucial for effective CSA targeting and planning, and to avoid negative spillover effects of mitigation interventions.

This study aimed to answer the questions: What is the potential of dairy feed improvements, including closing the yield gap of fodder maize, i) to reduce the direct total GHG emissions and emission intensities related to dairy production and ii) to decrease the $\mathrm{C}$ loss from forests due to the presence of dairy cattle? The livestock production model LivSim (Rufino et al., 2009) was used to calculate milk yields and GHG emissions for different feed improvement and intensification scenarios throughout the dairy production area in Kenya. Remote-sensing data were used to quantify forest $\mathrm{C}$ change and to approximate, for the first time, an estimation of forest $\mathrm{C}$ loss related to the presence of dairy cattle. The scenarios considered in this study are plausible and spatially-explicit 'what if' scenarios of dairy intensification and their potential effects on milk production, agricultural GHG 
emissions, and forest $\mathrm{C}$ loss.

\subsection{Material and methods}

\subsubsection{Study area}

The study area is located in the Central and Western highlands of Kenya. The area has a size of about $65000 \mathrm{~km}^{2}$ and is characterized by smallholder crop-livestock production systems. The region was defined previously in the analyses of Herrero et al. (2014) on smallholder dairy development pathways for the Kenyan highlands. The area shows the highest densities of human and livestock populations throughout Kenya (Imo, 2012). The majority of milk that is marketed in Kenya originates from this region and is mainly produced by dairy smallholders (Brandt et al., 2018b). Apart from agricultural land, the remaining Afromontane forests called 'water towers' are located in the area, namely the Aberdare range Forest, the Cherangani Hills Forest, the Mau Forest, the Mount Elgon Forest, and the Mount Kenya Forest. All of these forests experience ongoing forest degradation due to the unsustainable use of forest resources such as cattle grazing on forested land and fuelwood extraction (Imo, 2012; Drigo et al., 2015).

\subsubsection{Analytical framework}

The framework included a number of steps (Figure 5.1): First, spatially-explicit data on net forest $\mathrm{C}$ loss and gain were pre-processed and a dataset on forest $\mathrm{C}$ loss due to the presence of dairy cattle was created. Second, farm indicators and farm types derived from a farm survey were related to net forest $\mathrm{C}$ loss, gain and change to quantify the relationship between smallholder farming practices and forest $\mathrm{C}$ change. Third, a livestock simulation model was used to compute spatially-explicit data on dairy-related agricultural GHG emissions, milk production and the requirement of arable land to meet the demand of improved feeds. This analysis was conducted by applying a typical dairy diet and scenarios of feed improvements, including closing the yield gap of maize to quantify mitigation potentials for the agricultural land. Subsequently, the shortage of land was estimated, which is required land minus available land. Land shortage was related to forest $\mathrm{C}$ change associated to the presence of dairy cattle, which is $\mathrm{C}$ gain minus $\mathrm{C}$ loss due to dairy cattle for each feed improvement scenario to quantify the mitigation potentials for forests. 


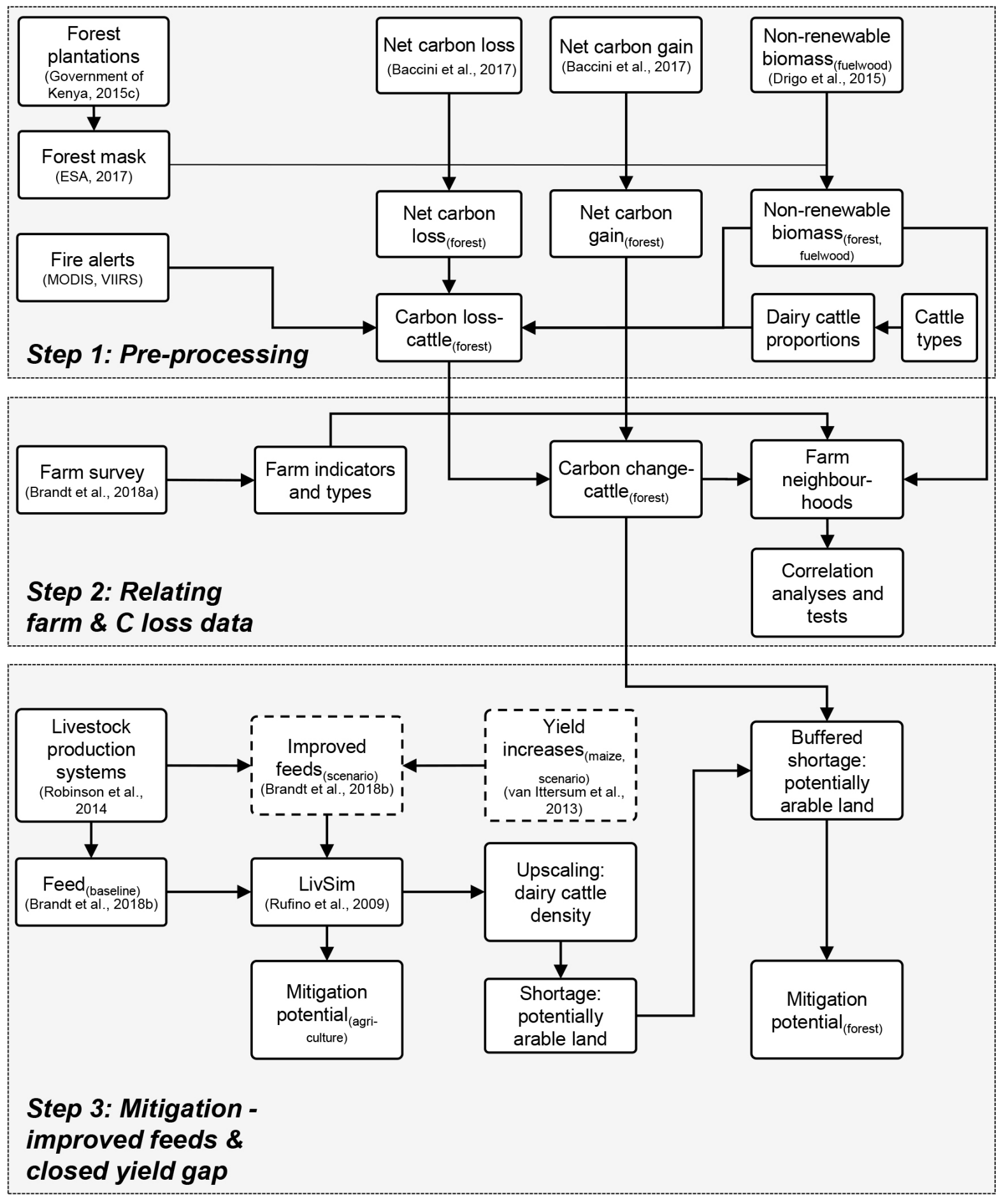

Figure 5.1: Flowchart of steps conducted to calculate mitigation potentials of feed improvement scenarios, including closing the yield gap of maize, on agricultural land and in forests. Carbon (C) loss-cattle ${ }_{\text {(forest) }}=\mathrm{C}$ loss related to the presence of dairy cattle in forests, Carbon change-cattle $_{(\text {forest })}=$ Forest $\mathrm{C}$ change, which includes the $\mathrm{C}$ loss fraction related to the presence of dairy cattle, LivSim = livestock simulation model. Dashed boxes represent scenarios of feed improvement and closing the yield gap of maize used to produce maize silage by realising water-limited yield potentials. 


\subsubsection{Pre-processing}

Spatially-explicit datasets, which indicate the changes in $\mathrm{C}$ density of aboveground biomass between 2003 - 2014 were obtained to quantify annual forest $\mathrm{C}$ changes (Baccini et al., 2017). These datasets include net gains (C gain) and losses of $\mathrm{C}$ (C loss) at a pixel resolution of $463 \times 463 \mathrm{~m}$ (Figure 5.1, step 1). A forest mask was applied to restrict the $\mathrm{C}$ change data to land that was forested in 2016 within the study area deriving net $\mathrm{C}$

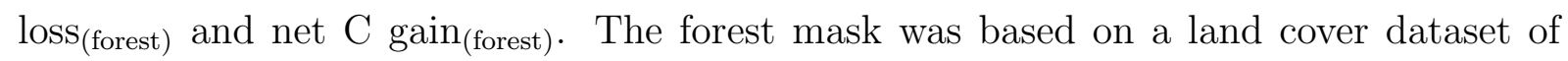
Africa at a pixel resolution of 20 x 20 m (ESA, 2017). Moreover, a dataset of tree plantations was used to limit the forest mask to natural forests (Government of Kenya, 2015c). The various spatial resolutions of input datasets applied in this study were resampled to a pixel resolution of $1 \times 1 \mathrm{~km}$ used consistently throughout the analyses.

Wildfires release substantial amounts of $\mathrm{C}$ from forests (Hurteau et al., 2008). Open forests in the aftermath of fire events represent land that is accessible for livestock and is frequently used as opportunistic grazing land. However, the $\mathrm{C}$ loss due to forest fires can neither be attributed to the presence of cattle in forests nor can this $\mathrm{C}$ loss be mitigated through improvements of cattle feeds. Therefore, pixels that indicate burnt forest between 2003 - 2014 were excluded from $C \operatorname{loss}_{\text {(forest) }}$ (Figure 5.1, step 1) by using daily fire alert data from the 'Moderate Resolution Imaging Spectroradiometer' (MODIS, MCD14ML) (Giglio, 2015) and the 'Visible Infrared Imaging Radiometer Suite' (VIIRS) (Schroeder et al., 2014).

Fuelwood harvest from forests causes about one third of the total forest emissions in Kenya (Pearson et al., 2017). Kenya is one of the countries that show highly unsustainable patterns of fuelwood consumption exceeding the capacity of natural ecosystems such as forests to regrow the biomass that is extracted as fuelwood (Bailis et al., 2015). Thus, this source of forest $\mathrm{C}$ loss was accounted to approximate the aboveground $\mathrm{C}$ loss related to cattle presence in forests $\left(\mathrm{C}\right.$ loss-cattle $\left._{(\text {forest }}\right)$. A spatially-explicit dataset of non-renewable biomass (NRB) harvested annually as fuelwood was obtained at a pixel resolution of $100 \times 100 \mathrm{~m}$ (Drigo et al., 2015). The NRB dataset was subtracted from the net $\mathrm{C} \operatorname{loss}_{\text {(forest) }}$ data after restricting it to forests $\left(\mathrm{NRB}_{\text {(forest) }}\right)$ by using the same forest

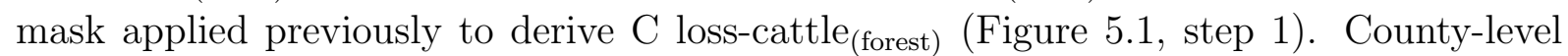
data on cattle types was used to calculate the proportion of dairy cattle by excluding cattle used for beef production (Government of Kenya, 2014). The C loss-cattle(forest) data was multiplied by proportions of dairy cattle to calculate forest $\mathrm{C}$ loss that could be attributed to the presence of dairy cattle. The estimate of $\mathrm{C}$ loss-cattle (forest) $_{\text {is a }}$ first approximation of $\mathrm{C}$ loss related to dairy cattle in forests and is based on previous empirical work with observations of cattle grazing in the forest (Brandt et al., 2018a). So far, there are no spatially-explicit data available that quantify the effects of livestock on carbon dynamics in Kenyan mountain forests. 
The uncertainty, which propagated into $\mathrm{C}$ loss-cattle(forest) due the uncertainties inherent to the input datasets net $\mathrm{C} \operatorname{loss}_{\text {(forest) }}$ and $\mathrm{NRB}_{\text {(forest) }}$ was quantified by applying equation (5.1) (Lee \& Forthofer, 2006):

$$
\begin{aligned}
\operatorname{var}\left(C \operatorname{loss}_{-} \operatorname{cattle}_{(\text {forest })}\right)= & \operatorname{var}\left(C \operatorname{loss}_{(\text {forest })}\right)+\operatorname{var}\left(N R B_{(\text {forest })}\right) \\
& -2 \times \operatorname{cov}\left(\text { net } C \operatorname{loss}_{(\text {forest })}, N R B_{(\text {forest })}\right)
\end{aligned}
$$

The reported values of relative standard deviations (SD) were used to quantify the input variances (Bailis et al., 2015; Baccini et al., 2017). The uncertainty values in this study are reported as relative SD.

\subsubsection{Relating smallholder farms and forest C loss, gain and change}

The effects of smallholder farms on forest $\mathrm{C}$ change were based on previous empirical analyses in the study area (Brandt et al., 2018a). These analyses related farming practices and characteristics obtained from a farm survey to forest disturbance derived from a remote-sensing based time-series analysis, which was validated by data from forest disturbance surveys (Brandt et al., 2018a). The farm survey was conducted in 2016 sampling 216 smallholder farms, located in close vicinity to forests. Information on total numbers of cattle, number of improved dairy cattle, milk yields, proportion of feed types in the cattle diet such as grass from on-farm pastures, fodder crops, and concentrated feed supplements, farm area allocated to fodder production such as fodder crops and on-farm pastures, and total farm size was collected, henceforth called 'farm indicators'. In addition, farms were clustered into farm types, which are henceforth called: 'small and resource-poor farms', 'large and inefficient farms', and 'intensified farms'. For details on the methodology see Brandt et al. (2018a). The results indicated stronger disturbance effects of farms that have higher total numbers of cattle and low milk yields. Farms that fed dairy cattle with improved diets showed smaller effects on forest disturbance.

To test whether similar farm effects are found when the same farm data are related to forest $\mathrm{C}$ changes, farm indicators and farm types were linked to forest $\mathrm{C}$ data within circular buffers created around farm centroids (Figure 5.1, step 2). A radius (r) of $5 \mathrm{~km}$ was selected for these buffers, which are henceforth called 'farm neighbourhoods'. This radius was chosen following Brandt et al. (2018a), who found that $\mathrm{r}=5 \mathrm{~km}$ created the maximum farm neighbourhood size in which farm indicators and farm types could be related significantly to forest disturbance. Forest $\mathrm{C}$ change that includes only the $\mathrm{C}$ loss fraction related to the presence of dairy cattle $(\mathrm{C}$ change-cattle (forest) $)=$ net $\mathrm{C}$ gain $_{(\text {forest })}$ - C loss-cattle(forest) was calculated within each farm neighbourhood (Figure 5.1, step 2). Farm indicators were correlated with net $\mathrm{C} \operatorname{loss}_{\text {(forest) }}$, net $\mathrm{C}$ gain(forest) $\mathrm{NRB}_{\text {(forest) }}$, $\mathrm{C}$

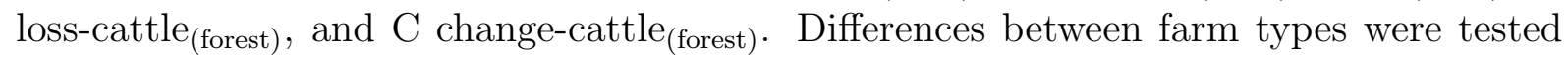
by using non-parametric pairwise Wilcoxon rank sum tests. 


\subsubsection{Mitigation potential of improving dairy feeds on agricultural land and in forests}

\section{Livestock production modelling and feed intensification}

The livestock production model LivSim (Rufino et al., 2009) was used following the methodology of Brandt et al. (2018b) to quantify and upscale milk production and agricultural GHG emissions from smallholder dairy production. GHG emissions were quantified based on IPCC tier 2 methodology (IPCC, 2006) and included methane $\left(\mathrm{CH}_{4}\right)$ emissions from enteric fermentation, $\mathrm{CH}_{4}$ emissions from manure management, direct and indirect nitrous oxide $\left(\mathrm{N}_{2} \mathrm{O}\right)$ emissions from manure management, direct and indirect $\mathrm{N}_{2} \mathrm{O}$ emissions from managed soils, including fertiliser application, and $\mathrm{N}_{2} \mathrm{O}$ and carbon dioxide $\left(\mathrm{CO}_{2}\right)$ emissions from LUC. The incorporation of LUC emissions is important since changes in the cattle diet require the cultivation of energy and protein-dense feeds with higher digestibility to increase milk yields (Hristov et al., 2013a; Brandt et al., 2018b). These feeds would be cultivated on potentially arable land such as grazing land that is converted to cropland. Milk yield and GHG emissions were computed by simulating dairy cows over a lifetime of 13 years. Model outputs were upscaled and mapped by using spatially-explicit data on livestock production systems (LPS), cattle density (Robinson et al., 2011, 2014), and dairy herd composition data (Bebe et al., 2002; Government of Kenya, 2014). For details on the modelling approach, input data, and scenarios see Brandt et al. (2018b).

Milk yields and GHG emissions were calculated for the baseline feed and several scenarios (Figure 5.1, step 3), which focused on three feed intensification strategies (Brandt et al., 2018b). The baseline represented a typical diet for smallholder dairy cattle in Kenya with a large proportion of low quality grass and crop residues. Scenarios included strategies such as the increase of forage quality (i.e. Napier grass, Pennisetum purpureum), feed conservation based on maize silage, and increased supplementation of dairy concentrates (i.e. dairy meal). The scenarios represent combinations of the three strategies and are henceforth called: 'forage quality and concentrate supplementation' (FoCo), 'feed conservation and concentrate supplementation' ( $\mathrm{FeCo}$ ), and 'forage quality, feed conservation and concentrate supplementation' (FoFeCo). Moreover, each scenario included medium and high intensification levels. The baseline feeds were replaced by $25 \%$ and $50 \%$ higher quality feeds representing the medium intensification and high intensification levels respectively. Rations of dairy meal were increased to $3 \mathrm{~kg}_{\text {day }}{ }^{-1}$ and $6 \mathrm{~kg} \mathrm{day}^{-1}$ during early lactation. The mitigation analyses in this study focused on three scenarios reported in Brandt et al. (2018b). The following scenarios were selected according to their mitigation potentials on agricultural land: i) FoFeCo with low potential at high intensification, ii) FeCo with medium potential at medium intensification and iii) FoCo with high potential at medium intensification level. 
The ranges of GHG emission parameters were sampled by using Latin hypercube sampling (LHS) (Xu et al., 2005) to estimate overall emission uncertainties of the baseline. Each parameter was sampled separately through LHS while all others were kept at their mean. Emission uncertainties of the scenarios were estimated one parameter at a time, sampling at the minimum and the maximum of the parameter ranges (Brandt et al., 2018b).

\section{Closing the yield gap of maize}

Each of the scenarios requires a certain amount of arable land to cultivate feeds such as Napier grass and maize. Brandt et al. (2018b) reported that the scenarios, which include feed conservation based on maize silage have a high demand for arable land. In addition to cropland used to cultivate maize for human consumption, cropland to grow maize exclusively as cattle feed was needed to prevent detrimental effects on food security. In Central and Western Kenya, the yield gap of maize ranges between 30 - $82 \%$ suggesting a high potential to intensify maize production (van Ittersum et al., 2013). Closing the yield gap of maize would increase the actual yield and could, therefore, help to reduce the land demand calculated in the scenarios. $\mathrm{CO}_{2}$ emissions from LUC would be lowered at the expense of $\mathrm{N}_{2} \mathrm{O}$ emissions from soils due to increased application rates of synthetic fertiliser.

The potential yield of crops is defined by several abiotic and biotic factors such as solar radiation, temperature, atmospheric $\mathrm{CO}_{2}$ concentration, and cultivar traits (van Ittersum et al., 2013). Maize cultivation in Kenya is rainfed. The water-limited yield potential $(\mathrm{Yw})$ is the most relevant benchmark indicator for rainfed crops as it further includes yield-limiting factors such as water supply, soil properties (e.g. water holding capacity), and topography (e.g. runoff). In this study, actual yields of maize in the baseline were increased by two levels realising $\mathrm{Yw}_{\text {(maize) }}$ at $50 \%$ and $80 \%$. Realising $\mathrm{Yw}$ at $80 \%$ is deemed to approach the maximum exploitable yield gap. Farm yields often reach a saddle point around $80 \%$ of $\mathrm{Yw}$ and are not feasible for farmers to increase further (van Ittersum et al., 2013). Actual yields (Ya) of maize cultivated in the Kenyan highlands were obtained from Monfreda et al. (2008), Weiler et al. (2014), and Castellanos-Navarrete et al. (2015). Data on $\mathrm{Yw}_{\text {(maize) }}$ and the minimum nitrogen $(\mathrm{N})$ input required to realise $\mathrm{Yw}$ (maize) at $50 \%$ and $80 \%$ in Kenya were obtained from the 'Global Yield Gap Atlas' (GYGA) and are based on agro-climatic zones used to upscale location-specific yield estimates derived from crop simulation models (van Wart et al., 2013a,b). Yw(maize) and minimum $\mathrm{N}$ input were linked to the LPS classification used in this study to upscale milk yield and GHG emissions. Each scenario that included maize silage was complemented by two versions, which closed the yield gap of maize: $\mathrm{Yw}_{\mathrm{w}}-50_{\text {(maize) }}$ and $\mathrm{Yw}-80_{\text {(maize) }}$ (Figure 5.1, step 3). 


\section{Analysing availability of potentially arable land and cattle grazing in forest}

The availability of potentially arable land was calculated for each scenario by comparing the extent of grazing land and demand for arable land per pixel using the $\mathrm{R}$ library 'raster' (v. 2.5) (Hijmans, 2016; R Core Team, 2016). Only existing grazing land was assumed to be available to cultivate additional Napier grass and maize (Brandt et al., 2018b). Scenario demands for additional cropland to cultivate feeds were quantified based on the yields $\left(\mathrm{Ya}_{(\text {maize })}, \mathrm{Yw}-50_{(\text {maize) }}\right.$ and $\left.\mathrm{Yw}-80_{\text {(maize) }}\right)$ per feed type, crop-specific feed intake per dairy cow (Rufino et al., 2009; Katiku et al., 2011; Herrero et al., 2013; Weiler et al., 2014; Castellanos-Navarrete et al., 2015), and the density of dairy cattle per 1 x $1 \mathrm{~km}$ pixel (Robinson et al., 2014). The availability of potentially arable land was quantified by using a spatially-explicit dataset on the density of grazing land, which had an original spatial resolution of $10 \times 10 \mathrm{~km}$ (van Velthuizen et al., 2007). All pixels that showed an excess of the demand for arable land in relation to the amount of grazing land available were labelled as pixels that have a shortage of potentially arable land. Spatially-explicit land shortage polygons were created for each scenario (Figure 5.1, step 3). For calculation details see Brandt et al. (2018b) and Appendix (S3, Table S3.3, equations S3.1 \& S3.2).

The pre-processed datasets on forest $\mathrm{C}$ change, which include the $\mathrm{C}$ loss fraction related to the presence of dairy cattle $\left(\mathrm{C}\right.$ loss-cattle $\left._{(\text {forest })}\right)$ and $\mathrm{C}$ gain $\left(\mathrm{C}\right.$ gain $\left._{\text {(forest })}\right)$, and the polygons of land shortage were used to link forest $\mathrm{C}$ change relate to the presence of dairy cattle to the management of dairy feeds on agricultural land. All C loss-cattle (forest) and $\mathrm{C}$ gain(forest) pixels were assumed to reflect the baseline forest $\mathrm{C}$ change ( $\mathrm{C}$ changecattle $\left._{(\text {forest })}\right)$ without any feed improvements. For the scenarios, it was assumed that the shortage of arable land and the resulting lack of available cattle feed on agricultural land, which surrounds forests forces smallholders to bring their dairy cattle into close-by forests to cover the daily feed requirements of cattle. Brandt et al. (2018a) reported significantly negative effects between indicators related to livestock management on smallholder dairy farms and forest disturbance for farm neighbourhoods that have a maximum $\mathrm{r}$ of $5 \mathrm{~km}$. Therefore, land shortage polygons were buffered with this distance. All C loss-cattle(forest) pixels that intersected with a buffered land shortage polygon were assumed to represent potential forest $\mathrm{C}$ losses related to the presence of dairy cattle that is likely to occur, if a certain scenario is implemented. Subsequently, the sum of $\mathrm{C}$ change-cattle (forest) $_{\text {pixel was }}$ calculated for each scenario and compared to the sum of baseline $\mathrm{C}$ change-cattle(forest) pixel to quantify the mitigation potential in forests (Figure 5.1, step 3). 


\subsection{Results}

\subsubsection{Effects of smallholder farms on $\mathrm{C}$ change in adjacent forests}

Correlation analyses of the empirical data on farm indicators and the quantified forest $\mathrm{C}$ change indicate that the total number of cattle on farm was positively correlated to $\mathrm{C}$ losscattle $_{\text {(forest) }}(\rho=0.15, \mathrm{p}<0.05)$ and negatively correlated to the $\mathrm{C}$ change-cattle (forest) $(\rho=-0.17, \mathrm{p}<0.05)$, which reflects $\mathrm{C}$ gain $_{(\text {forest })}$ minus $\mathrm{C}$ loss-cattle $_{(\text {forest })}$ (Figure 5.2). The number of improved dairy cattle per farm and milk yield were negatively correlated to $\mathrm{C}$ loss-cattle (forest) $(\rho=-0.37,-0.26, \mathrm{p}<0.001)$ and positively correlated to $\mathrm{C}$ changecattle $_{\text {(forest) }}(\rho=0.39,0.27, \mathrm{p}<0.001$, Figure 5.2$)$. The farm indicators, which reflect feed intensification such as the proportion of fodder crops in the cattle diet, the supplementation of concentrated feeds, and farm area allocated to the cultivation of fodder crops were negatively correlated to $\mathrm{C}$ loss-cattle $_{(\text {forest })}(\rho=-0.39,-0.21,-0.34, \mathrm{p}<0.001)$ and positively correlated to $\mathrm{C}$ change (forest) $_{(}(\rho=0.41,0.22,0.36, \mathrm{p}<0.001$, Figure 5.2). Farm level fuelwood extraction was positively correlated with non-renewable biomass due to fuelwood harvest from forests $\left(\mathrm{NRB}_{\text {(forest) }}, \rho=0.47, \mathrm{p}<0.001\right.$, Figure 5.2). 


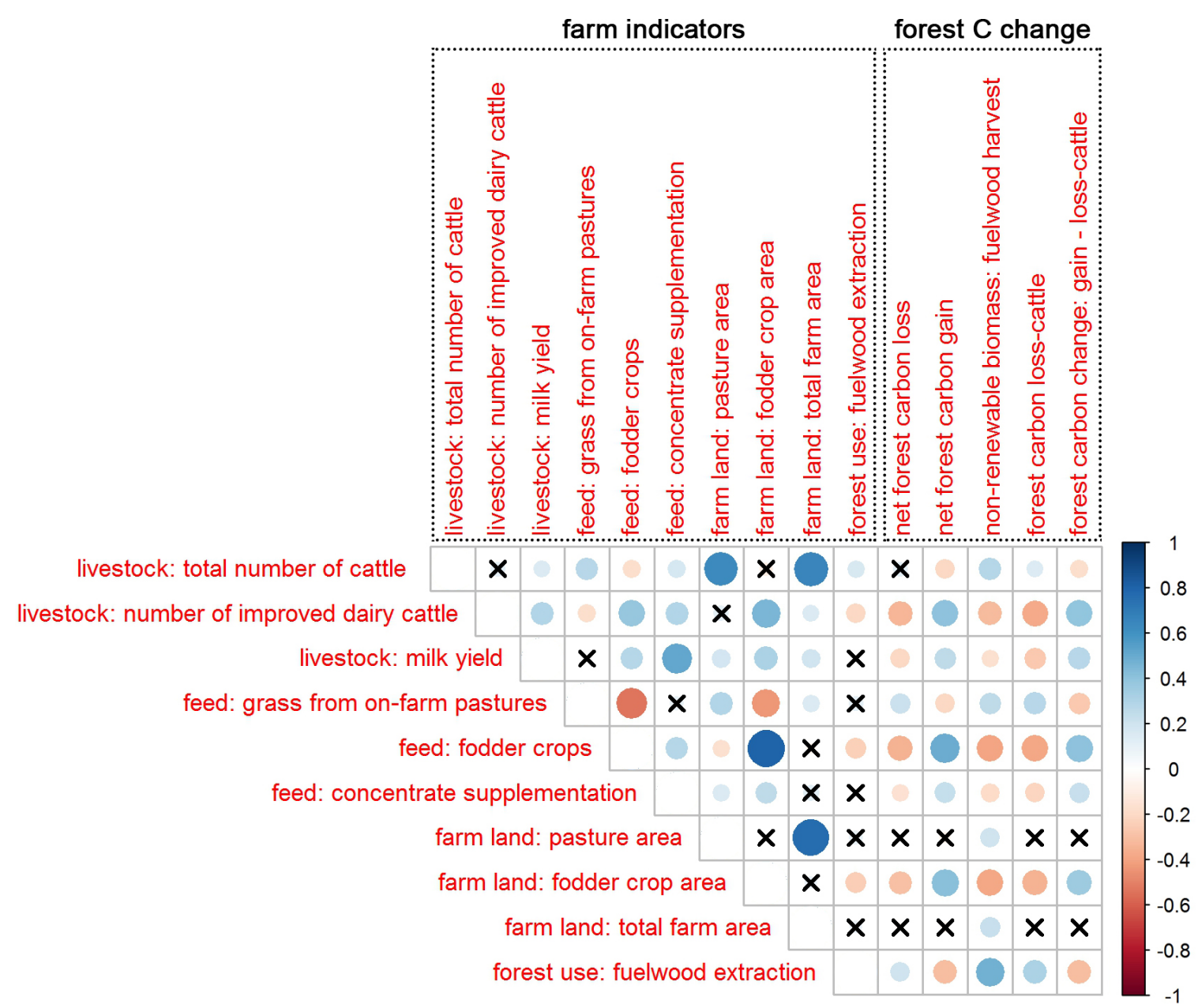

Figure 5.2: Correlation matrix of farm indicators derived from a farm survey and forest carbon $(\mathrm{C})$ change variables: net forest $\mathrm{C}$ loss $(\mathrm{C}$ loss $($ forest $)$, net forest $\mathrm{C}$ gain $(\mathrm{C}$ gain $($ forest $)$, non-renewable biomass due to fuelwood harvest in forests $\left(\mathrm{NRB}_{(\text {forest })}\right)$, forest $\mathrm{C}$ loss related to

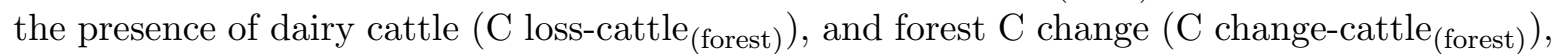
which includes $\mathrm{C}$ gain $_{\text {(forest) }}$ and the $\mathrm{C}$ loss fraction of dairy cattle $\left(\mathrm{C}\right.$ loss-cattle (forest) $\left._{\text {) }}\right)$. The forest $\mathrm{C}$ loss data were related to farms through farm neighbourhoods, which are distance buffers around farm centroids $(\mathrm{r}=5 \mathrm{~km})$. Crosses indicate non-significant correlations.

Farm types differed in the amount of net $\mathrm{C} \operatorname{loss}_{(\text {forest })}, \mathrm{NRB}_{\text {(forest) }}, \mathrm{C}$ loss-cattle $_{\text {(forest) }}$, and forest $\mathrm{C}$ change $(\mathrm{C}$ change-cattle (forest) $)$ within their neighbourhoods $(\mathrm{r}=5 \mathrm{~km}$, Figure 5.3). Intensified farms showed significantly less mean net $\mathrm{C} \operatorname{loss}_{(\text {forest })}, \mathrm{C}$ loss-cattle (forest) and $\mathrm{C}$ change-cattle (forest) $_{\text {(means }}=1676.4,512.0$, and $-54.6 \mathrm{~kg} \mathrm{C} \mathrm{ha}^{-1} \mathrm{yr}^{-1}$ respectively) than small and resource-pour farms (means $=2476.5,855.5$, and $-565.8 \mathrm{~kg} \mathrm{C} \mathrm{ha}^{-1} \mathrm{yr}^{-1}$ respectively) and large and inefficient farms (means $=2564.6,980.6$, and $-842.0 \mathrm{~kg} \mathrm{C}$ $\mathrm{ha}^{-1} \mathrm{yr}^{-1}$ respectively) ( $\mathrm{p}<0.05$, Figure 5.3A, C, D). Large and inefficient farms had significantly higher mean $\mathrm{NRB}_{\text {(forest) }}$ within their neighbourhoods (mean $=656.2 \mathrm{~kg} \mathrm{C}^{-1}$ $\mathrm{yr}^{-1}$ ) than small and resource-pour farms (mean $=501.0 \mathrm{~kg} \mathrm{C} \mathrm{ha}^{-1} \mathrm{yr}^{-1}$ ) and intensified 
farms $\left(\right.$ mean $\left.=463.1 \mathrm{~kg} \mathrm{C} \mathrm{ha}^{-1} \mathrm{yr}^{-1}\right)(\mathrm{p}<0.05$, Figure 5.3B).

A

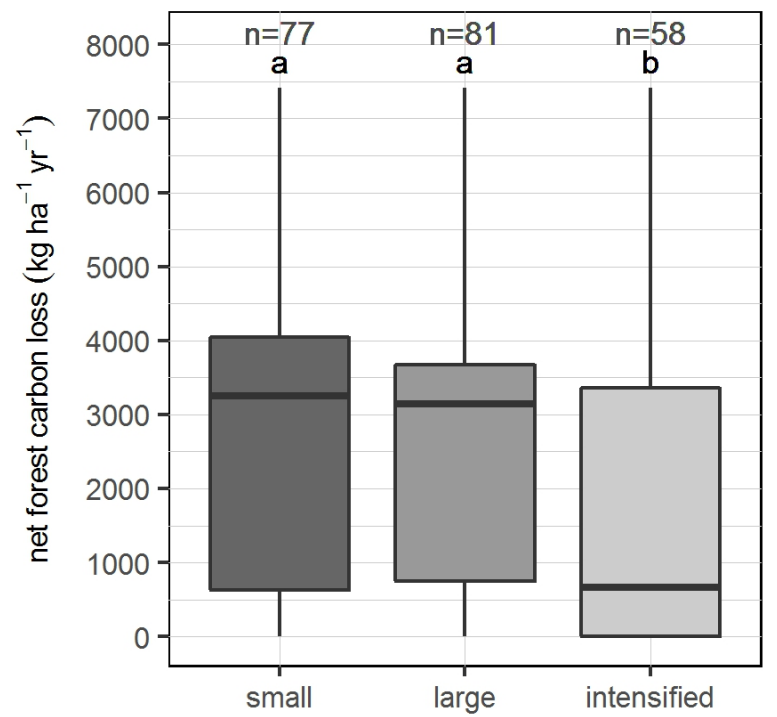

C

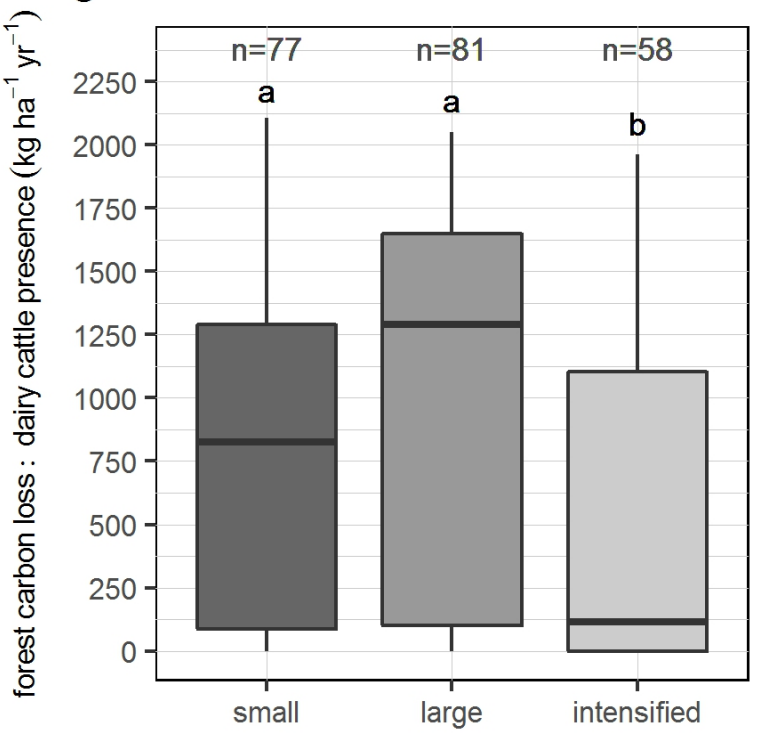

B
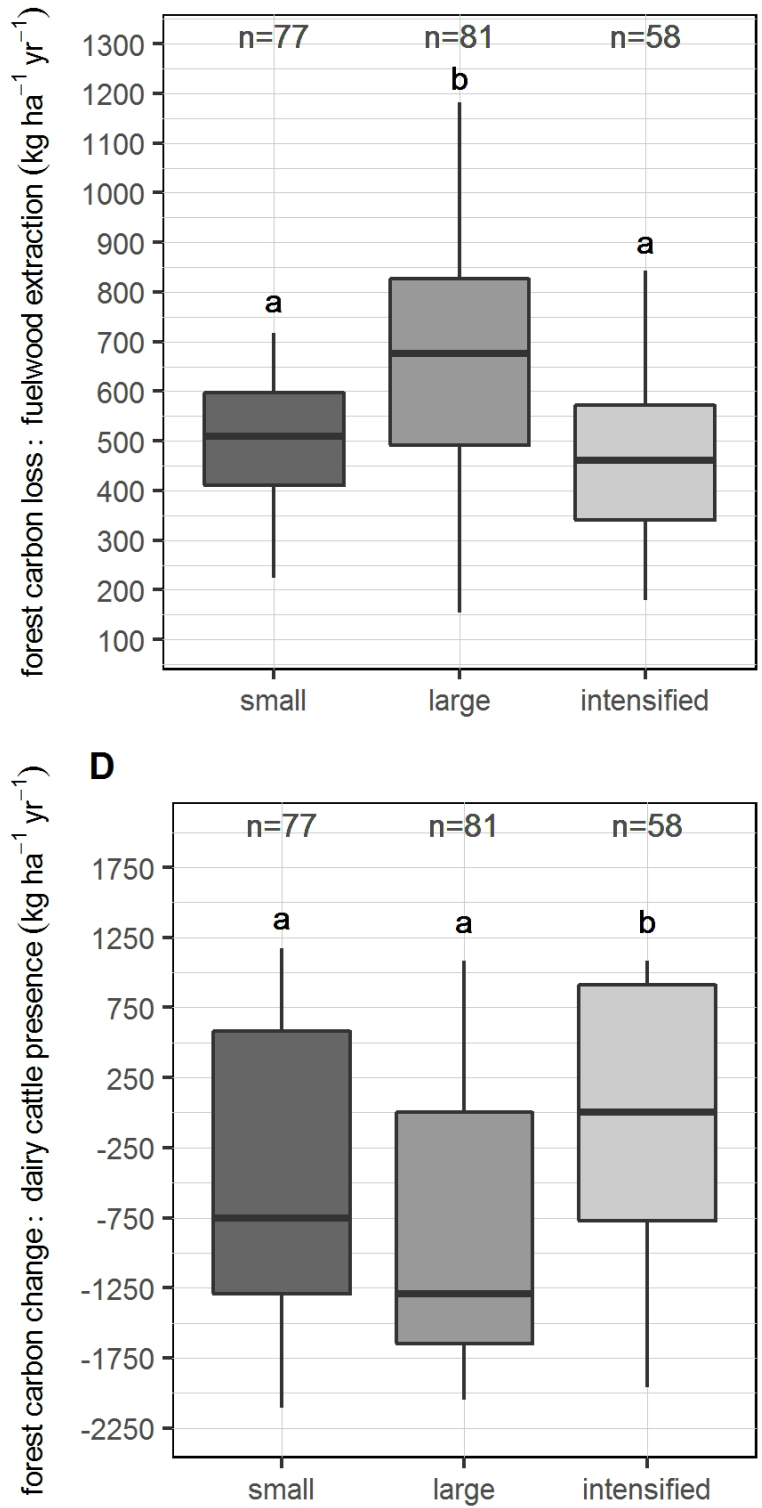

Figure 5.3: Boxplots of farm types and: A) net forest carbon (C) loss (C loss $($ forest $)$ ), B) forest $\mathrm{C}$ loss from firewood extraction $\left(\mathrm{NRB}_{(\text {forest })}\right)$, C) forest $\mathrm{C}$ loss due to the presence of dairy cattle $(\mathrm{C}$ loss-cattle $($ forest $)$, and $\mathrm{D})$ forest $\mathrm{C}$ change $\left(\mathrm{C}\right.$ change-cattle $\left.{ }_{(\text {forest }}\right)$, which is $\mathrm{C}$ gain $_{\text {(forest) }}$ minus the $\mathrm{C}$ loss fraction of dairy cattle $\left(\mathrm{C}\right.$ loss-cattle $\left._{(\text {forest }}\right)$. All $\mathrm{C}$ change variables were calculated for farm neighbourhoods with a radius of $5 \mathrm{~km}$. Farm types shown (X-axes) are: small $=$ small and resource-poor farms, large $=$ large and inefficient farms, intensified $=$ intensified farms. Different letters above whiskers indicate significant differences between farm types computed by using pairwise Wilcoxon rank sum tests ( $p$-values were corrected for multiple testing). 


\subsubsection{Agricultural and forest mitigation potentials of dairy feed improve- ments}

Reducing forest $C$ loss through closing the yield gap of maize: an example

The analyses show that all water tower forests were affected by $\mathrm{C}$ loss $(\mathrm{C}$ loss-cattle $($ forest) and gained $\mathrm{C}$ (C gain $_{\text {(forest) }}$ ) between 2003 - 2014. In total, forests across the study area lost $781,546.2 \mathrm{~kg} \mathrm{CO}_{2} \mathrm{eq} \mathrm{yr}^{-1}$ due to dairy cattle (Figure 5.4A, B). Feed improvements on agricultural land, including closing the yield gap of maize used for silage production could potentially reduce the amount of $\mathrm{C}$ loss-cattle $_{\text {(forest) }}$. This effect was shown for the feed improvement scenario FeCo, which combined feed conservation based on maize silage and concentrate supplementation at medium intensification level (Figure 5.4C). However, the shortage of potentially arable land in the vicinity of forests would lead to forest $\mathrm{C}$ loss due to dairy cattle (C loss-cattle (forest) $)$ because feed deficits would be met by forest grazing. Closing the yield gap of maize may reduce the amount of arable land required to grow additional maize and, therefore, can alleviate the land shortage as shown for the Maasai Mau Forest region (Figure 5.4C - E). Higher yields of maize in areas close to forests translate into a sufficient availability of improved feeds for dairy cattle, which would result in less $\mathrm{C}$ loss-cattle (forest) as forest grazing of dairy cattle is not required. 


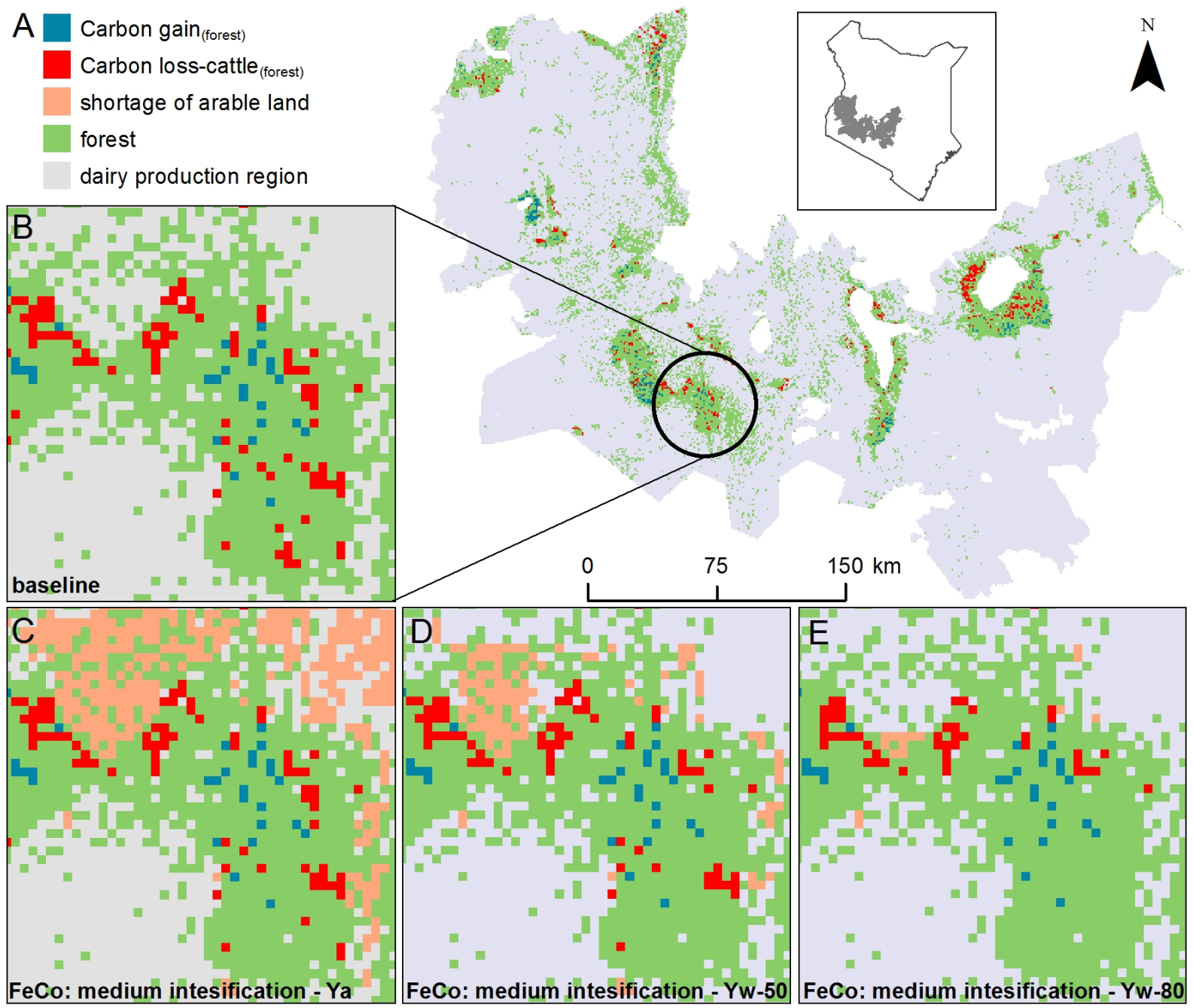

Figure 5.4: Forest carbon $(\mathrm{C})$ loss due to dairy cattle and forest $\mathrm{C}$ gain. Map A) shows the

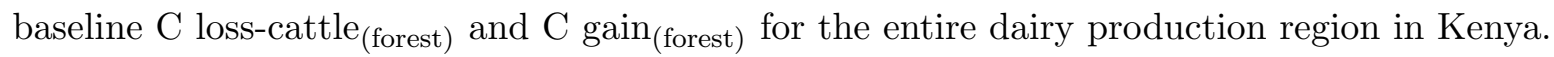

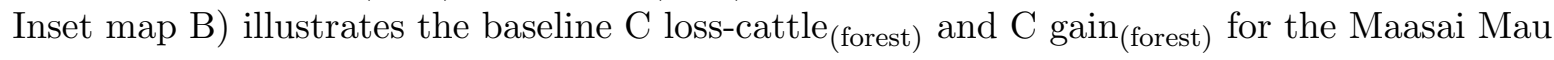
Forest region. For the same forest region, inset maps $\mathrm{C}-\mathrm{E}$ ) show the $\mathrm{C}$ loss-cattle $_{\text {(forest) }}$ due to the shortage of potentially arable land for the scenario FeCo, which combines feed conservation based on maize silage and concentrate supplementation at medium intensification level. Inset map D) indicates the shortage of potentially arable land and the potential C loss-cattle (forest) with actual maize yields (Ya). Realising the water-limited yield potential of maize $\left(\mathrm{Yw}_{(\text {maize) }}\right)$ at $50 \%$ (D) and $80 \%$ (E) may reduce the shortage of potentially arable land and C losscattle $_{\text {(forest) }}$ within a radius of $5 \mathrm{~km}$.

Total agricultural emissions, emission intensities and forest $C$ change

Across the study area, the feed improvement scenarios increased total agricultural GHG emissions in relation to the baseline by $3.2-69.4 \pm 2.8-6.5 \%$ (Figure 5.5A). The lowest increase of GHG emissions was indicated for the FoCo scenario at medium inten- 
sification level. The highest increase in emissions was shown for the FoFeCo scenario at high intensification level and with actual maize yields (baseline $\mathrm{Ya}_{(\text {maize) }}$ ), although GHG emissions from enteric fermentation were reduced by $1.9-21.1 \%$. The FoCo scenario at medium intensification level had the lowest effect on the reduction of emissions from enteric fermentation. In contrast, the FoFeCo scenarios at high intensification level, had the strongest effect on lowering enteric fermentation emissions. Emissions from manure management were increased by up to $100 \%$ through scenarios that included the feed intensification strategy of improving forage quality such as the FoFeCo scenarios at high intensification level. More $\mathrm{N}$ was excreted by cattle when the proportion of Napier grass in the cattle diet increased, which led to higher $\mathrm{N}_{2} \mathrm{O}$ emissions. GHG emissions from soils allocated to produce cattle feeds were increased by $48.3-266.5 \%$. The lowest increase of feed-related GHG emissions was shown for the FoCo scenario at medium intensification level. The highest increase was indicated for the FoFeCo scenario at high intensification level and with $\mathrm{Yw}$ realised at $80 \%\left(\mathrm{Yw}_{\mathrm{w}} 80_{\text {(maize) }}\right)$. The FoFeCo scenario, which included maize to produce silage at high intensification level and a water-limited yield potential of $\mathrm{Yw}_{\mathrm{w}} 80_{\text {(maize) }}$ led to highest increases in feed-related emissions due to high fertiliser $\mathrm{N}$ application rates of $108.2-167.9 \mathrm{~kg} \mathrm{~N} \mathrm{ha}{ }^{-1}$ required to realise this yield potential. The scenarios that included feed conservation such as FeCo and FoFeCo showed higher emissions from LUC than the FoCo scenario, which did not include silage. Maize required more land to convert pasture into cropland than Napier grass (Figure 5.5A). However, LUC emissions from FeCo and FoFeCo scenarios were reduced by $69.0-75.3 \%$ due to the increased yield of maize (from actual $\mathrm{Ya}_{\text {(maize) }}$ to $\mathrm{Yw}_{\mathrm{w}} 80_{\text {(maize) }}$ ). There was a reduction of GHG emissions from feed production and LUC by closing the maize yield gap throughout the scenarios that included maize silage (Figure 5.5A). The reduction of emissions from LUC was 2.6 - 4.9 times higher than the increase of emissions from additional fertiliser N. Despite the reduction of emissions from enteric fermentation and LUC by closing the yield gap of maize, none of the feed improvement scenarios could achieve a net reduction of total emissions on agricultural land (Figure 5.5A).

The GHG emission intensity of the baseline was $2.36 \pm 0.05 \mathrm{~kg} \mathrm{CO}_{2} \mathrm{eq} \mathrm{kg}$ fat and protein corrected milk (FPCM) $)^{-1}$ (Figure 5.5B). Milk production increased in all scenarios by 44.2 $-51.4 \pm 1.2-2.6 \%$ relative to the baseline. The feed improvement scenario FoFeCo at high intensification level, with actual maize yield did not reduce GHG emission intensity $\left(2.64 \pm 0.10 \mathrm{~kg} \mathrm{CO}_{2}\right.$ eq $\left.\mathrm{kg} \mathrm{FPCM}^{-1}\right)$. Realising $\mathrm{Yw}_{(\text {maize) }}$ at least at $50 \%$ reduced emission intensity compared to the baseline (Figure 5.5B). The lowest emission intensity was shown for the FoCo scenario at medium intensification level $\left(1.68 \pm 0.05 \mathrm{~kg} \mathrm{CO}_{2} \mathrm{eq} \mathrm{kg}\right.$ $\left.\mathrm{FPCM}^{-1}\right)$.

Forest $\mathrm{C}$ loss due to dairy cattle $\left(\mathrm{C}\right.$ loss-cattle $\left._{(\text {forest })}\right)$ was reduced in all scenarios by 47.9 $-270.4 \pm 7.4-4,935.1 \%$ relative to the baseline (Figure 5.5C). The scenarios with maize and actual maize yields $\mathrm{Ya}_{\text {(maize) }}$ showed the lowest reduction of $\mathrm{C}$ loss-cattle(forest) (by $47.9-93.5 \pm 121.1-789.3 \%$ ). Realising the yield potential $\mathrm{Yw}_{(\text {maize) }}$ at $50 \%$ and 
$80 \%$ lowered C loss-cattle $_{\text {(forest) }}$ (by $157.4-225.4 \pm 18.2-4,935.1 \%$ ) as the shortage of potentially arable land was reduced and the feed availability of maize silage on agricultural land in the vicinity of forests was increased throughout the study area. Hence, closing the yield gap of maize can turn forests into $\mathrm{C}$ sinks (Figure 5.5C). Nevertheless, the smallest shortage of potentially arable land, the lowest $\mathrm{C}$ loss-cattle (forest) and, therefore, the highest forest $\mathrm{C}$ sink potential was indicated for the FoCo scenario. This scenario showed the highest mitigation potential for the agricultural land and for forests due to the highest reduction of agricultural GHG emission intensities (by $28.8 \%$ ) and forest C loss (by $270.4 \%$ ) while increasing milk production by $45.4 \%$. For the FoFeCo scenario $\left(\mathrm{Yw}-80_{\text {(maize) }}\right)$, high uncertainties (relative $\mathrm{SD}=4,935.1 \%$ ) propagated into forest $\mathrm{C}$ change related to the presence of dairy cattle due to high variances in input datasets of $\mathrm{C}$ $\operatorname{loss}_{\text {(forest) }}, \mathrm{NRB}_{\text {(forest) }}$ and $\mathrm{C}$ gain(forest) that were used to estimate $\mathrm{C}$ change-cattle(forest), which is close to zero (Figure $5.5 \mathrm{C}$ ). 

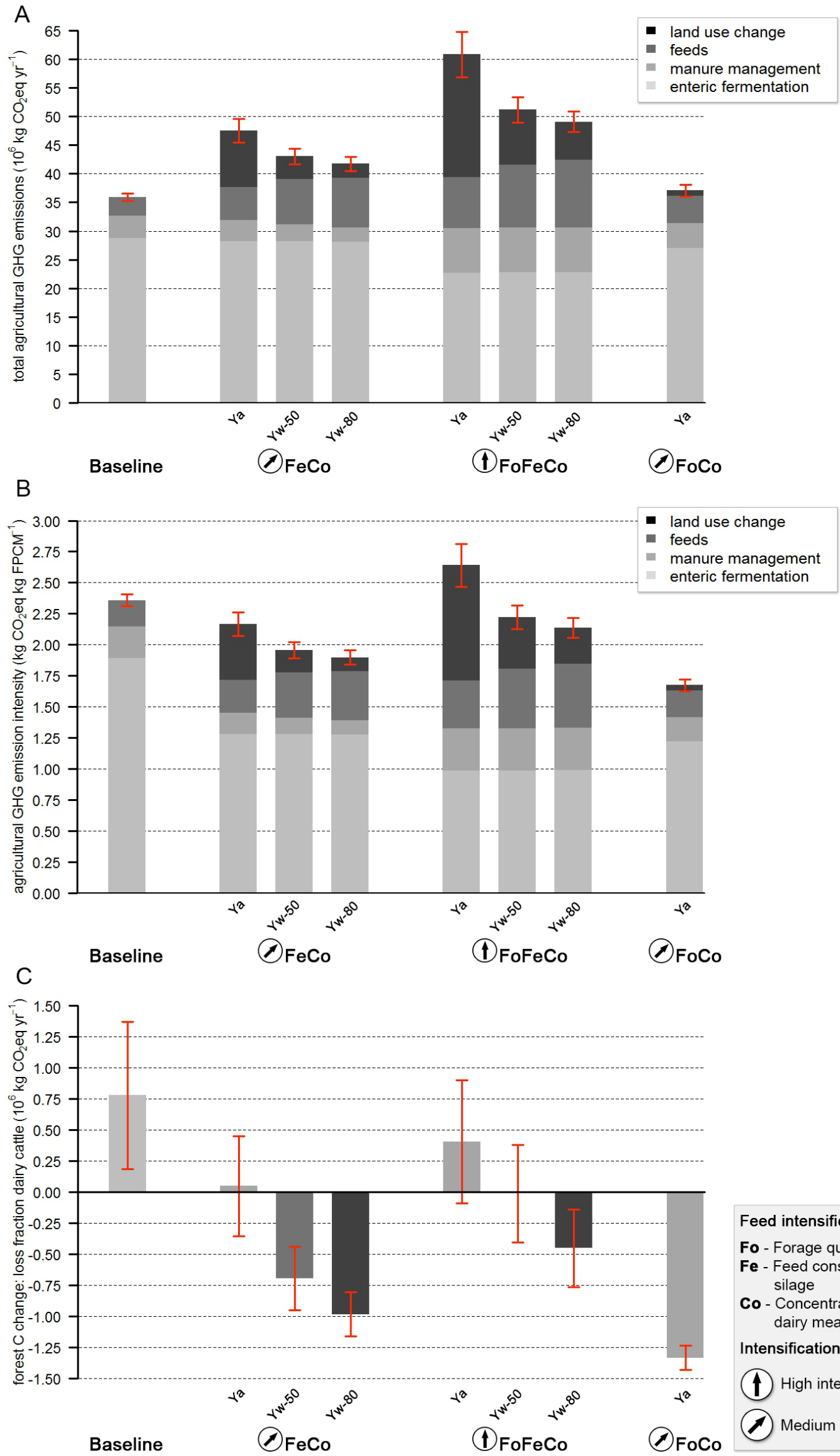

Feed intensification strategies: Fo - Forage quality: Napier grass Fe - Feed conservation: maize silage

Co - Concentrate supplementation: dairy meal

Intensification level:

(1) High intensification

Medium intensification

Figure 5.5: Caption follows on the next page. 
Figure 5.5: Agricultural GHG emissions and forest carbon (C) change related to smallholder dairy production. Plots show: A) aggregated total agricultural GHG emissions, B) agricultural GHG emission intensity per kg fat and protein corrected milk (FPCM), and C) aggregated forest $\mathrm{C}$ change due to dairy cattle $(\mathrm{C}$ change-cattle $($ forest $)$. Bars indicate baseline and three feed improvement scenarios, which represent combinations of three feed intensification strategies at medium or high intensification levels. The two scenarios that included maize silage use actual maize yields and two levels of water-limited yield potentials $\left(\mathrm{Yw}_{(\text {maize })}\right)$. Ya(maize) $=$ actual baseline yields, $\mathrm{Yw}_{\mathrm{w}} 50=\mathrm{Yw}_{(\text {maize) }}$ realised at $50 \%, \mathrm{Yw}_{\mathrm{w}} 80=\mathrm{Yw}_{(\text {maize) }}$ realised at $80 \%$. $\mathrm{CH}_{4}$, $\mathrm{N}_{2} \mathrm{O}$ emissions, and forest $\mathrm{C}$ change were converted to $\mathrm{kg} \mathrm{CO}_{2}$ eq. Agricultural GHG emission sources include i) $\mathrm{CH}_{4}$ emissions from enteric fermentation, ii) $\mathrm{CH}_{4}$ and $\mathrm{N}_{2} \mathrm{O}$ emissions from manure management, iii) $\mathrm{N}_{2} \mathrm{O}$ emissions from feed production, including manure deposition on pasture, manure application to fodder crops, crop residues from fodder crops and synthetic fertilizer application to fodder crops and emissions from concentrate supplementation, and iv) $\mathrm{N}_{2} \mathrm{O}$ and $\mathrm{CO}_{2}$ emissions from land use change, including $\mathrm{N}$ mineralization and loss of soil organic carbon. Error bars indicate relative standard deviations.

\subsection{Discussion}

\subsubsection{Intensification of smallholder dairy farms and forest $\mathrm{C}$ change}

Total number of cattle on smallholder farms in the dairy production region was positively linked to the loss of forest $\mathrm{C}$, which is related to the presence of dairy cattle in forests located within farm neighbourhoods (Figure 5.2). This is an important finding because there are no quantitative assessments of the impact of livestock production on tropical forest systems in SSA. Hosonuma et al. (2012) reported that 8 - $12 \%$ of the forest disturbance across SSA can be attributed to livestock grazing in forests. Brandt et al. (2018a) found that cattle grazing inside tropical mountain forests in Kenya is prevalent at $75 \%$ of the forest disturbance spots visited during a forest survey. The use of mountain forests by smallholder farmers to graze livestock is also reported for Ethiopia (Baudron et al., 2017; Duriaux Chavarría et al., 2018). Positive effects on dietary diversity and nutrient balances on farms located in the vicinity of the forests (distance $=5.5 \mathrm{~km}$ ) that are used for grazing were found. The authors argue that the amount of herbaceous biomass removed from the forest through grazing is likely to be lower than the regrowth rates. However, these studies did not quantify the impact of forest grazing on forest disturbance and the resulting $\mathrm{C}$ loss. In contrast, Brandt et al. (2018a) reported an increased risk of forest disturbance by up to $5 \%$ due to higher total numbers of cattle on smallholder farms within their farm neighbourhoods (maximum forest distance $=5$ $\mathrm{km}$ ). The results of this study show a net forest $\mathrm{C}$ loss due to dairy cattle within the neighbourhoods of smallholder farms ranging in average between $54.6-842.0 \mathrm{~kg} \mathrm{C} \mathrm{ha}^{-1}$ $\mathrm{yr}^{-1}$ (Figure 5.3D). 
Farm indicators of improved cattle feeds and intensified milk production on smallholder farms such as the proportion of fodder crops in cattle diet, concentrated feed supplements, farm area allocated to the cultivation of fodder crops, the number of improved dairy cattle and milk yield were negatively related to forest $\mathrm{C}$ loss that can be attributed to the presence of dairy cattle. The same set of indicators was positively related to forest $\mathrm{C}$ change, which is forest $\mathrm{C}$ gain minus forest $\mathrm{C}$ loss due to dairy cattle (Figure 5.2). Intensification of smallholder agriculture is in general postulated to reduce the pressure on forest ecosystems. Higher farm productivity is likely to reduce the demand for land (Campbell et al., 2014). Valin et al. (2013) showed in a modelling exercise that intensification of livestock production can lower GHG emissions from deforestation in SSA, through improved management practices such as intensified feeds. A modelling study conducted in Brazil reported that the intensification of dairy production can reduce the pressure on forests through pasture intensification (Caviglia-Harris, 2018). Brandt et al. (2018a) reported lower risks of forest disturbance by up to $7 \%$ within the neighbourhoods of farms that had improved dairy cattle, attained higher milk yields and fed improved cattle feeds. In addition, this study indicated that intensified farms have less C loss related to the presence of dairy cattle and gained more $\mathrm{C}$ in adjacent forests than non-intensified farms within their neighbourhoods of $\mathrm{r}=5 \mathrm{~km}$ (Figure 5.3C, D). Brandt et al. (2018a) showed that intensified farms affected forest disturbance less within their neighbourhoods than non-intensified farms.

The intensification of smallholder dairy production in Kenya based on more nutritious cattle feeds and improved dairy cattle appears to follow the general notion that an intensification of extensive production systems reduces the negative impact on local, natural ecosystems such as forests (Wollenberg et al., 2011). Thus, apart from the agricultural mitigation potential of intensification also quantified by Ortiz-Gonzalo et al. (2017) and Brandt et al. (2018b), smallholder dairy production in Kenya shows potential to mitigate GHG emissions from forests. However, the spatial distance of the relationship between farming practices and forest $\mathrm{C}$ loss $(5 \mathrm{~km})$ was determined empirically (Brandt et al., 2018a) and should be taken with caution when extrapolating to other regions. This distance depends on the region-specific land use dynamics and has to be assessed based on farming systems and landscape configurations.

\subsubsection{Mitigation of GHG emissions from smallholder dairy production across land use sectors}

This study showed that dairy feed improvements and the increase in feed productivity mitigates i) GHG emission intensities on agricultural land through higher milk yields and ii) the loss of $\mathrm{C}$ from forests related to the presence of dairy cattle through reduced grazing inside forests (Figure 5.5). The increase of livestock productivity through higher feed digestibility has been reported to benefit agricultural mitigation mainly through 
increased feed conversion efficiency and lower $\mathrm{CH}_{4}$ emissions from enteric fermentation (Hristov et al., 2013a; Knapp et al., 2014; Herrero et al., 2016). In addition, closing the yield gaps of feed crops can play a major role in avoiding $\mathrm{CO}_{2}$ emissions from LUC (Valin et al., 2013; Herrero et al., 2016; Weindl et al., 2017). The increased $\mathrm{N}_{2} \mathrm{O}$ emissions due to higher fertiliser $\mathrm{N}$ application rates to close the yield gap of maize could be offset by reduced $\mathrm{CO}_{2}$ emissions from $\mathrm{LUC}$ on agricultural land due to lower land requirements (Figure 5.5A). This finding is in line with other modelling exercises on the mitigation of livestock-related AFOLU emissions at a coarser continental scale for SSA (Valin et al., 2013; Havlík et al., 2014). The potential to close the yield gap of maize in Kenya is high (van Ittersum et al., 2013). Apart from being used as livestock feed, maize is a staple crop in Kenya and widely used for human consumption. However, the production of maize in Kenya does not meet the demand (van Ittersum et al., 2016). The country relies, therefore, on imported maize (USDA, 2017). Consequently, increasing maize yields is necessary to assure food security, especially if the livestock sector invests further into the promotion of grain-based livestock feeds. Opportunities of yield intensification increase the feasibility to implement feed improvement options, given the constraint of land availability, especially in regions that face shortages of arable land due to high densities of human and livestock populations (Gerssen-Gondelach et al., 2017; Brandt et al., 2018b). Smallholder farmers across the Kenyan highlands lack frequently the required land to grow sufficient amount of feeds with higher energy and protein density (Bebe, 2008), which leads to off-farm grazing on common land such as forests.

Throughout the study area, forest $\mathrm{C}$ loss related to the presence of dairy cattle could be reduced by feed improvement scenarios. For scenarios that included the strategy of feed conservation through maize silage, such as FeCo and FoFeCo, higher reductions of forest $\mathrm{C}$ loss were achieved by realising higher water-limited yield potentials for maize. Less shortage of potentially arable land due to the improved availability of higher quality feeds on agricultural land minimised the need to compensate the lack of feed through forest grazing (Figure $5.4 \&$ Figure 5.5C). Realising the water-limited yield potential for maize at least at $50 \%$, can turn forests into $\mathrm{C}$ sinks as the $\mathrm{C}$ gain fraction overweighed the $\mathrm{C}$ loss due to dairy cattle (Figure 5.5C). That the increase of feed and livestock productivity can result in land sparing effects, which reduce the pressure on natural ecosystems such as forests and lower GHG emissions from LUC has been shown by several modelling studies at a coarse continental scale for SSA (Valin et al., 2013; Havlík et al., 2014; Kreidenweis et al., 2018). However, these studies did neither include empirical bottom-up information on farm practices nor spatially-explicit data on forest $\mathrm{C}$ loss related to the presence of cattle, which are required to identify location-specific effects of certain feed improvement options on forests and to detect land constraints that limit the feasibility of mitigation interventions. 


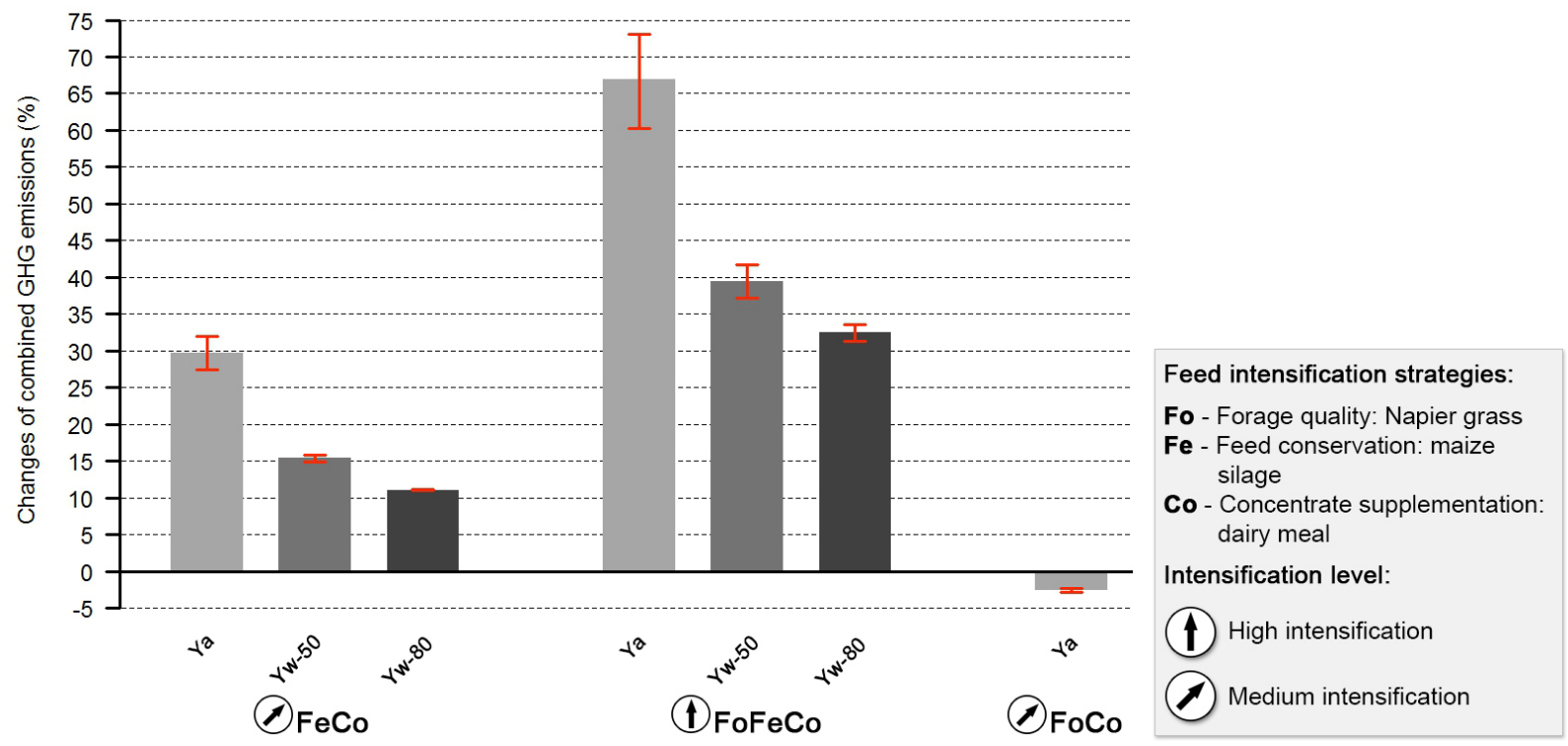

Figure 5.6: Changes of combined total agricultural GHG emissions and forest carbon (C) change, which is forest $\mathrm{C}$ gain minus the $\mathrm{C}$ loss fraction related to dairy cattle. Bars show changes of combined GHG emissions between feed improvement scenarios and the baseline. $\mathrm{Ya}_{(\text {maize })}=$ actual baseline yields, $\mathrm{Yw}_{\mathrm{w}}-50=\mathrm{Yw}_{(\text {maize })}$ realised at $50 \%, \mathrm{Yw}_{\mathrm{w}}-80=\mathrm{Yw}_{\text {(maize })}$ realised at $80 \%$.

Land requirements and the resulting shortage of potentially arable land were lowest for the FoCo scenario, which included the strategies of forage quality and concentrate supplementation. Almost no cattle grazing inside forests to compensate the lack of feed on agricultural land was needed for this scenario. The related forest $\mathrm{C}$ loss was reduced by $270 \%$, which led to the lowest forest $\mathrm{C}$ loss among all scenarios (Figure 5.5C). Consequently, the forest $\mathrm{C}$ sink potential was highest compared to all other scenarios. The FoCo scenario could result in a net benefit for AFOLU mitigation by reducing GHG emissions across the agricultural and forest sectors effectively, since total agricultural GHG emissions and forest $\mathrm{C}$ change combined were $2.5 \%$ lower than in the baseline (Figure 5.6). The national dairy master plan and the dairy NAMA seek for feed options that realise milk yield gains and mitigation benefits (Government of Kenya, 2010, 2017b). Therefore, this feed improvement option could represent a promising candidate to be targeted by the dairy sector.

\subsubsection{Policy relevance: targeting and financing the implementation of CSA practices}

The added value of this study emerges from the combined mitigation potential of smallholder intensification for the entire dairy production region in Kenya by linking agricultural production and the use of forests. The mitigation estimates were quantified across 
land use sectors based on empirical information from the ground (farm and forest surveys), using spatially-explicit input data on milk production, GHG emissions and forest C loss at high spatial resolution. The approach followed can shed light on the effectiveness of potential CSA practices to mitigate AFOLU emissions in the context of developing agricultural production such as dairy production in Kenya at sectoral level. Multi-objective modelling tools that aim to support decision-making processes on prioritising CSA practices based on evidence by integrating qualitative and quantitative information at various spatial and temporal scales have been developed recently (Brandt et al., 2017; Dunnett et al., 2018). This study provides input data for such tools to explore the feasibility of CSA practices in terms of land availability and their effectiveness to mitigate GHG emissions from agricultural land and forests.

Policy instruments that aim to enable the development of climate-smart food production sectors such as NAMAs have to rely on evidence, which shows the potential to realise 'win-win' situations that benefit smallholder farmers and contribute to climate mitigation goals (e.g. NDCs) (Lipper et al., 2014; Grassi et al., 2017). In addition, mitigation policies need to support the creation of economic incentives, which are required to foster the implementation of targeted CSA practices and to reduce potential adoption barriers (Lipper et al., 2014). Climate financing schemes could use quantitative information on productivity gains and mitigation potentials of specific feed improvement options to inform decisions on the investment into candidate practices that are targeted to be implemented at farm level, yet effect largely the broader landscape. Agricultural practices affect the use of tropical forests and their $\mathrm{C}$ dynamics, e.g. through the removal of biomass due to grazing or fuelwood harvest (Pearson et al., 2017; Brandt et al., 2018a). This study shows that intensified feed and livestock production helps to reduce GHG emissions from forests. This finding emphasises the alignment of climate mitigation policies and financing mechanisms across the land use sectors of agriculture and forestry to achieve effective mitigation outcomes, i.e. the net reduction of AFOLU emissions. Therefore, policy frameworks are required that integrate the CSA concept and policies on 'Reducing emissions from deforestation and forest degradation' (REDD+) (Carter et al., 2018a).

\subsubsection{Limitation and future research}

This is the first study that quantified the impact of livestock on forest $\mathrm{C}$ change by using spatially-explicit, remote-sensing data. Measurements obtained from grazing experiments for different forest and cattle types are required to estimate the direct impact of cattle on above and belowground carbon stocks in forests (e.g. Schulz et al., 2016). Animal movement patterns can be traced through telemetry analyses to gain knowledge about distances that cattle walk and the time they spend inside forests (Gao et al., 2016). Aggregated spatially and temporally, this ground-truth information could be used to calibrate and validate the estimates of forest $\mathrm{C}$ change related to cattle grazing derived 
from remote-sensing data. The approach to improve maize yields, chosen in this study, was to increase the $\mathrm{N}$ application from external inputs of synthetic fertiliser. Realising the water-limited yield potential of maize at $80 \%$ required high $\mathrm{N}$ inputs of up to $108-168 \mathrm{~kg}$ $\mathrm{N} \mathrm{ha}^{-1}$ (van Bussel et al., 2015). Fertiliser, transport and labour costs of high $\mathrm{N}$ application rates, however, may render the intensification of feed production economically unfeasible or simply uninteresting for smallholders, if economic returns from milk sales do not justify these investments. Consequently, moderate application rates of synthetic fertiliser of $60-$ $90 \mathrm{Kg} \mathrm{N} \mathrm{ha}{ }^{-1}$ could be more realistic from a farmer's point of view in the Kenyan highlands (Mucheru-Muna et al., 2007, 2014). Therefore, reliable market prices for milk, improved access to markets are required for smallholders to adopt practices that close the yield gap of feed crops such as maize. To increase the adoption of dairy feed improvements, assessments of agricultural productivity and climate change mitigation have to be coupled with cost-benefit analyses that take into account seasonal variation of costs and returns and farm distances to markets to find optimal cost-benefit ratios for smallholder farmers. Moreover, apart from abiotic and biotic factors, crop management practices influence the improvement and the stability of maize yields (Kiboi et al., 2017; Rattalino Edreira et al., 2018). Hence, the dissemination of knowledge about best practices through agricultural extension is crucial.

Greater efforts to intensify smallholder agriculture have to be undertaken to improve crop and livestock yields and to achieve food security goals in SSA (van Ittersum et al., 2016). More food produced from existing agricultural land will be required to feed the continent's fast growing population. Considering the shrinking of farm sizes and the increasing shortage of arable land in SSA (Vanlauwe et al., 2014), research at landscape level has to be strengthened to explore the boundaries within which smallholder agriculture can be intensified sustainably to safeguard food security. For instance, this study did not include international $\mathrm{C}$ leakage effects that potentially result from the displacement of GHG emissions due to the increased demand for feed imports, which could trigger cropland expansion into natural ecosystems outside the study area (Styles et al., 2018). The market-oriented stimulation of agricultural production sectors can lead to rebound effects due to reduced prices, higher demand and, therefore, further increasing production (Valin et al., 2013). Analyses of AFOLU mitigation need to integrate various scales ranging from farm, landscape to sectoral level and have to be coupled with economic models to further improve the estimates of effective mitigation potentials by incorporating feedbacks between markets and agricultural development.

\subsection{Conclusions}

Dairy feed improvements may have climate change mitigation benefits for agriculture and forests and can contribute to food security by increasing milk yields in Kenya. Closing 
the yield gap of maize used to produce silage could increase the feasibility to implement improved grain-based cattle feeds, and can reduce GHG emission intensities from milk production and the loss of $\mathrm{C}$ in local forests. However, the largest mitigation benefits across land use sectors could be achieved through the improvement of forage quality and the supplementation of concentrates. These findings emphasise the importance to assess the impact of specific CSA practices prior their targeting and prioritisation at high spatial resolution to identify mitigation potentials across land use sectors and to reveal implementation constraints such as land availability. General recommendations derived from top-down assessments conducted at coarse spatial scales risk to miss differences between candidate options identified by using bottom-up and high resolution data, which may render the implementation of targeted interventions unfeasible or may reduce the effectiveness of mitigation outcomes. Integrated mitigation and development policy frameworks and climate financing instruments could benefit from the approach followed and the information provided to prioritise the most effective CSA practices and to invest into bundles of options that show the most promising potentials for sectoral development and climate mitigation.

\section{Acknowledgments}

This study was funded by the CGIAR program on 'Climate Change, Agriculture and Food Security' (CCAFS) and the IFAD project 'Greening livestock: Incentive-based interventions for reducing the climate impact of livestock production in East Africa'. Additionally, the research was supported by the 'Norwegian Agency for Development Cooperation' (NORAD) and Germany's 'International Climate Initiative' (IKI) through CIFOR's Global Comparative Study on REDD+, and the CGIAR Research Program on Forests, Trees and Agroforestry (CRP-FTA) with financial support from the CGIAR Fund. 
Chapter 6

Synthesis 


\subsection{Main findings}

The objectives of this thesis were to i) improve the robust prioritisation and targeting of CSA practices at national level and to ii) shed light on the potential of intensified dairy feeds to reduce direct and indirect GHG emissions effectively. Four research questions were defined in Section 1.5 to address these objectives. The main findings for each question are summarised below, based on results from the previous chapters.

\subsubsection{How can 'multi-criteria decision-making' support national climate change adaptation and mitigation planning to target CSA practices? (RQ A)}

Adaptation and mitigation measures have to be prioritised and targeted robustly to transform agriculture into climate-smart food production systems at large scale. The multicriteria decision-making framework "targetCSA" was developed in Chapter 2 to explore targeting options for adaptation and mitigation practices based on spatially-explicit indices of climate change vulnerability and CSA suitability. The vulnerability index shows how urgent an implementation of CSA interventions would be at certain locations. CSA suitability indicates the technical feasibility of these interventions. The indices were derived from the integration of spatially-explicit data such as biophysical, social and economic indicators of climate change vulnerability and proxy data on CSA suitability (Table 2.1). An optimisation model was used to find combinations of stakeholder preferences regarding the prioritisation of certain CSA practices that approach the potential consensus achieved through minimising the disagreement between all stakeholder preferences. Vulnerability and suitability indices were weighed by the preferences of involved stakeholder groups and the aggregated consensual preferences to map and explore the potential effects of various decision-making outcomes based on group-specific preferences and the computed preference weights that approach the consensus of all stakeholder groups. Facing decision-makers with the effects decisions based on their 'point of view' may have and contrasting these with a consensus scenario can guide further negotiations to find agreed solutions in a decision-making process. The robustness of CSA-targeting outcomes can be increased by applying "targetCSA", as it helps to explore the potential of CSA-practices based on evidence (data-driven) and the minimised disagreement among stakeholders, which could lead to more informed and transparent decisions.

The applicability of "targetCSA" was demonstrated in Kenya. Stakeholders from various sectors such as the Kenyan government, NGOs, science and the private sector involved in the development of the national CSA strategy were interviewed about the importance they assign to sets of vulnerability indicators and CSA practices. The stakeholder groups weighed the importance of vulnerability indicators and CSA practices differently accord- 
ing to their agendas and interests (Figure 2.3). High dissent among stakeholders was shown for the biophysical vulnerability indicators 'annual precipitation' and 'soil organic matter' and for the CSA practices 'improvement of soil fertility and soil management' and 'identification and establishment of agroforestry practices'. Decision-making processes on complex issues such as climate change adaptation and mitigation are often characterised by disagreements among involved stakeholders. A disagreement among opinions on which CSA practices should be prioritised and targeted can slow down decision-making processes or may prevent legitimate decisions in cases that are highly conflict-prone. "targetCSA" can be used to make these differences explicit by mapping the resulting CSA-targeting scenarios and complement them with a scenario that reflects the minimised dissent among stakeholder opinions.

Furthermore, different consensus modes can be explored by minimising the dissent towards the majority of stakeholder preferences or towards the minority, which are preferences that are far apart from the majority. In this thesis, CSA potentials based on three different consensus scenarios were mapped (Figure 2.4). As a result, different regions in Northern and Eastern Kenya would be prioritised by decision-makers. Following the majority preferences, larger areas with high CSA potential concentrate in the Northwest, Northeast and Central Eastern parts of Kenya, whereas the minority would prioritise larger areas located in the North and Northeast of Kenya. A third consensus scenario that reflects the compromise between majority and minority (i.e. the most balanced tradeoff) highlights larger areas with high CSA potential where both consensus modes agree, which is the Northeast of Kenya. Mapping scenarios of CSA potentials based on different consensus modes allows to explore disagreement between opinions of the majority of stakeholders and a minority group. Visualising potential effects of disagreement between stakeholder groups or the majority and minority of stakeholders could, therefore, help to find solutions in a conflict-prone decision-making process, for instance in cases where marginalised groups are involved.

Stakeholder opinions may differ over time, as shown in Figure 2.5, due to changes in knowledge, interests and organisational agendas. Relying on 'snap-shot' opinions would fail to capture, illustrate and finally reduce the uncertainty that is introduced by varying stakeholder opinions. In this thesis, a change in importance was shown most drastically for the CSA practice 'improvement of soil fertility and soil management', which was ranked as fourth important CSA practice during the first expert survey and was ranked as most important during the second survey. "targetCSA" can be used iteratively to monitor and validate the importance that stakeholders assign to vulnerability indicators and CSA practices during the process of CSA prioritisation and targeting (Figure 2.1). Decisions to target certain CSA practices at specific locations can be assumed to be more robust and legitimate once stakeholder opinions are reflected by stabilised patterns of preferences. 
"targetCSA" was in general designed to structure complex decision-making processes by exploring preference scenarios derived from stakeholders based on quantitative and qualitative information to support the prioritisation and targeting of relevant CSA practices. To apply the framework in a livestock mitigation case, for instance to reduce GHG emissions from smallholder dairy production, input data should be adjusted to reflect this CSA-targeting context. Vulnerability indicators at high spatial resolution could include water and feed availability during dry seasons (e.g. mapped variability of vegetation and water indices based on remote-sensing time-series), animal health such as the occurrence of vector-borne diseases (e.g. mapped suitability of occurrence of vector species), yield gap of feed crops (e.g. mapped difference between actual yields and potentially attainable yields). Data that indicate the suitability of CSA practices could include the mapped density of local and improved dairy cattle, the mapped shortage of arable land, which shows the feasibility to implement certain livestock feed improvement practices (Chapter 3) and the mapped potential of certain feed improvement practices to reduce GHG emissions from agriculture and forests effectively (Chapter 5). The spatial extent of these input data can be constrained to the dairy production area in Kenya. Stakeholder involvement should include experts from dairy, feed and breeding companies, dairy cooperatives and farmer associations, livestock and nutritional scientists as well as agricultural and environmental ministries at county and national level.

\subsubsection{Which climate change mitigation options in the Kenyan dairy sector contribute to climate mitigation and food production targets defined at national level? (RQ B)}

In Chapter 3, the potential of livestock feed improvements to contribute to climate change mitigation and productivity targets at national scale was assessed. Feed alternatives that have higher protein and energy content are generally proposed to increase milk yields and to reduce GHG emission intensities in smallholder livestock production systems (Hristov et al., 2013a; Knapp et al., 2014). However, GHG emissions from LUC and the shortage of potentially arable land (e.g. grassland) required to cultivate feed crops may compromise mitigation efforts or render the implementation of promising practices unfeasible at certain locations. The analyses of feed improvement scenarios based on combinations of three feed intensification strategies (Figure 3.2) showed that feed conservation based on maize silage requires a high amount of land to be converted into cropland, which would lead to higher GHG emissions from LUC. LUC emissions from these scenarios were on average ten times higher than LUC emissions from scenarios, which included the strategy of forage quality improvement, by using Napier grass, instead of using maize to produce silage (Figure 3.3). Overall, scenarios that included the strategy of feed conservation did not reduce GHG emission intensities in regard to the baseline (Figure 3.3). In contrast, the improvement of forage quality and the supplementation of dairy concentrates reduced emission intensities 
by up to $31 \%$ (Figure 3.6). Implementing the improvement of forage quality would be more feasible in terms of available potentially arable land compared to scenarios that included maize silage used for feed conservation. Only $0.5-2.8 \%$ of the agricultural land throughout the study area lacked the amount of potentially arable land that would be required to implement forage-based feed improvements. On the contrary, $26-50 \%$ of the agricultural land across the study area would lack the potentially arable land required to implement scenarios that included maize silage (Figure 3.4). The shortage of potentially arable land shown for these scenarios resulted from their high demands for arable land due to additional maize that has to be cultivated in addition to existing maize, which was assumed to be grown to produce food and, therefore, was unavailable as cattle feed.

Moreover, the feed improvement scenarios were assessed to quantify their relative contribution to Kenya's climate change mitigation and milk yield targets defined in the country's NDC and in its national dairy master plan (Government of Kenya, 2010, 2015a). All scenarios increased the milk yields and contributed to the milk yield target by fulfilling it partially by $17-43 \%$ (Figure 3.4). Several scenarios that included the feed conservation strategy at high intensification level exceeded the tolerable GHG emissions increase of the NDC target due to high GHG emissions from LUC (Figure 3.4). The medium intensification variants of these scenarios partially achieved the milk yield target by 17 $39 \%$ and increased total GHG emissions at a tolerable level according to the NDC target, yet their implementation would be unfeasible on $24-26 \%$ of the agricultural land due the shortage of potentially arable land. The two scenarios that included the improvement of forage quality and the supplementation of dairy concentrates showed relatively high achievement rates in terms of the milk yield target $(38-40 \%)$ and increased only marginally total GHG emissions by $4-13 \%$. This increase ranged at the lower end of tolerable GHG emission increases as defined in the NDC. Based on these assessments, it can be inferred that alternative dairy feeds that are based on the improvement of forage quality and the supplementation of dairy concentrates are feasible to implement in the majority of areas across Kenya's dairy production region, are beneficial for smallholder farmers, and contribute to planning targets at national level. Increased milk yields result potentially in higher farm incomes (Bryan et al., 2013). However, the high intensification variant of these two scenarios requires farmers to invest more in dairy concentrates $(6 \mathrm{~kg}$ day $^{-1}$ ), which could render it economically less viable for smallholders in Kenya. The medium intensification scenario, however, achieved a relatively high gain of milk yield with moderate increases of concentrate supplementation rates $\left(3 \mathrm{~kg} \mathrm{day}^{-1}\right)$ and, therefore, shows a lower investment risk for smallholders (Bebe et al., 2002).

Uncertainties of emission parameters used to model GHG emissions influenced total GHG emissions and emission intensities (Figure 3.3). Emission parameters were inputs to the GHG emission module of the LivSim model. The ranges of emission parameters were sampled by using the LHS approach. The methane conversion factor showed the strongest effects on the variation of modelled baseline emissions, which varied by about $\pm 7 \%$. The 
SOC emission factor used to estimate GHG emissions from LUC, influenced the variation of scenario emissions most. For instance, the scenario that included the strategy of feed conservation and forage quality at high intensification level varied by about $\pm 48 \%$. LUC was reported to be a significant source of uncertainty for the estimation of GHG emissions from livestock production (van Middelaar et al., 2013). Since GHG emissions from LUC play an important role in environmental impact assessments of feed production, efforts in SSA must be strengthened to reduce the related uncertainty by measuring the effects of LUC (e.g. the conversion of grassland into cropland) on SOC and by using dynamic land use models that incorporate interactions between vegetation and soils. However, these models have to be parametrised comprehensively. The empirical data required are often missing in SSA.

Chapter 3 shows that ex-ante impact assessments of potential feed improvements are required for a successful mitigation of GHG emissions from livestock production. Mitigation planning based on general recommendations or top-down analyses at coarse spatial scales face the risk to neglect local realities, which can be uncovered by analyses that include bottom-up information. More detailed, spatially-explicit assessments that incorporate i) the effects of converting grassland to cultivate alternative feed crops with higher digestibility and ii) the availability of land (e.g. grassland) help to decide whether certain practices result in mitigation and productivity benefits and whether their implementation is feasible at specific locations. This is especially relevant for regions such as the Kenyan highlands, which are characterised by small farm sizes and high population density (Herrero et al., 2014). Relating the effects of CSA practices on climate change mitigation and agricultural production at sectoral level to national targets enables the performance monitoring of CSA practices in regard to integrated policies such as NAMAs, which focus on low-emissions development (LED) of economies, and international commitments such as UNFCCC. These assessments could also help to define realistic sectoral targets, e.g. for the agricultural sector in Kenya. Kenya has to comply with its NDC, yet misses quantitative targets that reflect sectoral responsibilities to contribute to the achievement of the target at national scale.

\subsubsection{How does the intensification of smallholder dairy farming affect forest disturbance? (RQ C)}

The intensification of smallholder farming has been proposed to increase food production on existing agricultural land while releasing the pressure on natural ecosystems (Garnett et al., 2013). The effects of smallholder dairy farm practices, characteristics and types on forest disturbance were analysed in Chapter 4 to determine whether an intensification on smallholder dairy farms could reduce the impact on the Mau Forest, the largest remaining montane forest complex in East Africa, located in the Kenyan highlands. The forest plays a critical role as 'water tower' for the entire region. It is the headwater area for 12 major 
rivers and provides freshwater to about five million people (Jacobs et al., 2017). Firewood extraction and cattle grazing inside forests were found to be the dominant drivers of forest disturbance present at about $75 \%$ of forest disturbance spots sampled during a forest survey. Only sparse information exists so far on the magnitude of forest disturbance related to fuelwood extraction and cattle grazing inside forests in SSA. According to Hosonuma et al. (2012), the relative contributions of fuelwood extraction and forest cattle grazing to forest disturbance are $58 \%$ and $8 \%$ respectively for countries in SSA, which are in their late forest transition phase such as Kenya. Pearson et al. (2017) estimated that fuelwood extraction contributes about $30 \%$ to the GHG emissions from tropical forests. However, none of these studies provides quantitative information about the impact of smallholder agriculture on forest disturbance based on observational data. From this thesis, the relative impact of farm-related practices such as firewood extraction and cattle grazing inside forests on forest disturbance and resulting GHG emissions can be assumed to be higher for montane forests located in the Kenyan highlands.

Farm practices and characteristics were used to calculate farm indicators for smallholder dairy farms located close to forests during a farm survey. Within farm neighbourhood sizes of $\mathrm{r}=2-5 \mathrm{~km}$, farm indicators such as total number of cattle, farm size and firewood collection rates were related to higher risks of forest disturbance. Risk increases ranged between $1-10 \%$ (Figure 4.5). On the contrary, higher milk yields, and indicators that reflected improved cattle feeds such as larger farm area allocated to fodder production and increased supplementation of dairy concentrates were related to lower risks of forest disturbance. Risk decreases ranged between $2-7 \%$ (Figure 4.5).

Moreover, different farm types were derived from the farm indicators in Chapter 4 such as small and resource-poor farms, large and inefficient farms, and intensified farms. These farm types differed in their effects on forest disturbance. Intensified farms showed in general a lower proportion of disturbed forest within their neighbourhoods $(\mathrm{r}=2-5$ $\mathrm{km}$ ) than the non-intensified farm types (Figure 4.8). The effects of farm types on forest disturbance that was specifically related to firewood extraction and cattle grazing inside forests, indicated a similar pattern. Intensified farms had a lower proportion of disturbed forest related to firewood extraction and cattle grazing in their farm neighbourhoods $(\mathrm{r}=2-3 \mathrm{~km}$ ) than the two non-intensified farm types (Figure 4.9). More improved dairy cattle, higher milk yields, higher proportions of improved cattle feeds, and more frequently planted on-farm trees were found on intensified farms than on non-intensified farms (Figure 4.6). Improved cattle, cattle feeds and more trees planted on farms, which are potentially available as fuelwood supply reduce the need to use forest resources and lower the risk to disturb forests located in close proximity to smallholder farms. However, a recent study conducted in a landscape characterised by smallholder agriculture and mountain forests in Ethiopia, reported positive effects between livestock grazing in forests and livestock productivity (Duriaux Chavarría et al., 2018). Farms located closer to forests $(5.5 \mathrm{~km})$ showed higher milk yields and more positive nutrient balances than farms 
located further away $(11 \mathrm{~km})$. Although quantitative estimates of forest disturbance were not included, the authors argue that the sustainable use of forest resources may increase the performance of adjacent smallholder farms.

Chapter 4 integrates empirical ground data and results from a forest change detection approach based on remote-sensing time series to relate smallholder farming and forest disturbance, which is a novel approach to assess agriculture-forest interactions. Forest disturbance and resulting GHG emissions caused by unsustainable land use practices can be alleviated by intensifying smallholder dairy farming, which is shown to realise 'winwin' potentials for smallholders through milk yield increases, and for the mitigation of agricultural GHG emissions (Chapter 3). The novel approach and the findings derived from Chapter 4 open new avenues to mitigate AFOLU emissions across the agricultural and forestry sectors (Chapter 5).

\subsubsection{What is the potential of livestock intensification options to reduce GHG emissions from agriculture and forests? (RQ D)}

The potential of dairy feed improvements to mitigate GHG emissions from agricultural land directly and from forests indirectly was assessed in Chapter 5 based on insights obtained from Chapter 3 and 4. Independent datasets of $\mathrm{C}$ change, including $\mathrm{C}$ gain and $\mathrm{C}$ loss (Baccini et al., 2017) were used to estimate the forest $\mathrm{C}$ loss related to the presence of dairy cattle (Figure 5.1). Farm indicators and types that were analysed in Chapter 4 were linked to forest $\mathrm{C}$ change variables to test whether the intensification of smallholder dairy farms can be associated with reduced forest $\mathrm{C}$ loss in their neighbourhoods. Farm indicators related to improved dairy cattle and cattle feeds such as the proportion of fodder crops in cattle diet, the supplementation of concentrated feeds, and farm area allocated to the cultivation of fodder crops and increased milk yields were negatively linked to forest $\mathrm{C}$ loss related to the presence of dairy cattle. The same set of indicators was positively linked to forest $\mathrm{C}$ change, which is forest $\mathrm{C}$ gain minus $\mathrm{C}$ loss related to the presence of dairy cattle (Figure 5.2). Lower forest $\mathrm{C}$ loss related to the presence of dairy cattle and higher forest $\mathrm{C}$ change (negative values closer to zero) were found in neighbourhoods of intensified farms compared to non-intensified farms (Figure 5.3). These results show that an intensification of smallholder dairy farming could reduce $\mathrm{C}$ loss from forests through the cultivation of improved cattle feeds on agricultural land, which lowers the need to use forests as grazing land for dairy cattle.

Using the methodology developed in Chapter 3 (Figure 3.1), three feed improvement scenarios were assessed regarding their potential to mitigate both GHG emissions from agricultural land and forest $\mathrm{C}$ loss. The latter one was analysed based on the scenario demand for land and the availability of potentially arable land required to cultivate additional maize (feed conservation strategy) and Napier grass (forage quality strategy). The 
shortage of grazing land that could be converted into cropland close to forests was assumed to cause cattle grazing in forests to meet the demand for feeds. In addition, the three feed improvement scenarios were complemented by variants that closed the yield gap of maize by realising the water-limited yield potential at $50 \%$ and $80 \%$. GHG emissions from higher application rates of synthetic fertiliser required to close the gap of maize yields increased by up to $267 \%$. In contrast, GHG emissions from LUC related to the conversion of grassland into cropland needed to cultivate additional feed crops was reduced by up to $75 \%$, which outbalanced the emission increase from soils due to higher fertiliser application rates (Figure 5.5). The effect of reduced GHG emissions from avoided LUC was up to five times higher than the increase of fertiliser-related emissions. Consequently, GHG emission intensities of scenarios that included the strategy of feed conservation by using maize silage were lowered by up to $20 \%$ and less arable land would be required to implement them. The lowered demand for arable land to cultivate alternative dairy feeds close to forests reduced forest $\mathrm{C}$ loss due to avoided grazing of dairy cattle inside forests by up to $94 \%$ (Figure 5.5). However, the scenario that included the strategies of improved forage quality and supplementation of dairy concentrates showed the highest reduction in emission intensity $(29 \%)$, the lowest demand for arable land and the highest reduction of forest $\mathrm{C}$ loss $(270 \%)$. This scenario was the only one modelled in this thesis that resulted in a net mitigation benefit once the effects of feed improvements on i) GHG emissions from agricultural and ii) on forest $\mathrm{C}$ loss were combined. Combined total GHG emissions were reduced by $2.5 \%$ in relation to the baseline (Figure 5.6).

Chapter 5 represents the first attempt to quantify the loss of $\mathrm{C}$ from tropical forests that is related to the presence of dairy cattle at a larger scale by using remote sensing data. The results emphasise the importance to incorporate the impact of agricultural practices on forests into assessments that quantify and evaluate the performance and effectiveness of CSA options in the livestock sector. Integrated policy instruments that aim to mitigate AFOLU emissions (e.g. NAMAs) can make use of the approach and the results provided in Chapter 5 to target CSA practices. Ex-ante information of land requirements and availability and the effectiveness to reduce GHG emissions across land use sectors can help to minimise the risk of negative spillover effects such as $\mathrm{C}$ leakage.

\subsection{Reflection and outlook}

The Paris agreement has set international efforts into motion to limit the global temperature rise below two degrees Celsius. Technical and financial capacity has to be built especially in SSA countries to achieve this ambitious target. AFOLU emission baselines and reduction potentials have to be quantified to fulfil national climate change mitigation targets expressed in NDCs. Methodological frameworks to target CSA practices based on quantified mitigation benefits are required to support this process. This thesis contributes 
to the development of i) frameworks that prioritise and target CSA practices and ii) approaches that assess the potential of livestock-related CSA practices to mitigate GHG emissions effectively while increasing agricultural productivity. These approaches allowed to study interactions between the agricultural and forestry sectors based on empirical data and enabled to identify trade-offs and synergies that were not known before. The following sections will reflect on the methodologies developed and applied by focusing on further research needed to increase their performance and scope through the inclusion of additional climate-smart livestock options, the integration of models and scales, as well as data improvements.

\subsubsection{Further options to increase climate-smartness of livestock produc- tion}

In this thesis, the potential to reduce GHG emissions from sustainably intensified livestock production was assessed by focusing on dairy feed improvements across the Kenyan highlands. The approach can be out-scaled to other regions that show comparable agricultural production systems and forest disturbance dynamics such as highland areas in Tanzania or Ethiopia (DeVries et al., 2016; Maleko et al., 2018). The need and interest to develop smallholder-driven dairy production in East Africa is marked by project activities of several international 'green' development programs such as the 'Smallholder Dairy Commercialization Programme' (SDCP) financed by the 'International Fund for Agricultural Development' (IFAD) and the 'East Africa Dairy Development' (EADD) program. These programs aim for market-oriented developments of smallholder dairy production in the region (EADD, 2014; Government of Kenya, 2017b). Apart from the feed intensification strategies considered in this thesis, other options have to be assessed concerning additional feed alternatives, animal health and herd structure as well as grazing and pasture management to increase livestock productivity and to reduce the pressure on natural ecosystems.

Further feed alternatives such as forage legumes and fodder trees should be explored to enrich the portfolio of feed improvement pathways viable for the various smallholder dairy production contexts in East Africa. Agricultural soils in SSA are often nutrient-depleted and, thus, highly N-limited, which puts legumes as protein-rich forage and their ability to fix atmospheric $\mathrm{N}_{2}$ on the spot (Giller, 2001). Leguminous forage species such as Desmodium, planted as sole crop or intercropped with grasses can improve soil fertility and have a higher protein content than, for instance, Napier grass (Lukuyu et al., 2012). Fodder trees grown on farmland improve the supply of nutritious livestock feeds and offer additional services such as erosion control and on-farm fuelwood (Franzel et al., 2014). Higher number of farms with trees on-farm were shown to contribute to reduced forest disturbance at landscape level (Chapter 4). About 500 Calliandra trees are required to feed a dairy cow. Therefore, small farms will not be able to feed dairy cattle based on 
fodder trees and have to rely on external feed inputs (Franzel et al., 2014). However, feed alternatives have to be selected carefully to avoid detrimental effects on feed and livestock productivity (e.g. through vulnerability to pest species or anti-nutritional properties). Additional work is required to improve the knowledge about nutrient quality and suitability of available legume, fodder tree and shrub species under different agro-climatic conditions in East Africa.

Apart from feeding higher quality diets, animal health has to be improved through access to vaccination services and the reduction of heat stress, which reduce mortality and increase lifetime productivity of dairy cows (Rufino et al., 2009; Mottet et al., 2016). Shorter calving intervals and an increase of the proportion of productive animals in dairy herds can improve the productivity at herd level, which further reduces GHG emission intensities per unit product (Rufino et al., 2009; Herrero et al., 2016). Based on the 'Global Livestock Environmental Assessment Model' (GLEAM), Mottet et al. (2016) estimated that the potential to mitigate GHG emissions in East Africa through an improved herd structure ranges between $4-10 \%$. The effects of animal health and herd management parameters on milk yields and resulting GHG emissions can also be explored by using models like the LivSim model, which was applied in Chapter 3 and 5.

Grass obtained from grazing on native, low-productivity pastures is one of the main feed sources in the Kenyan highlands (Chapter 3). Pastures in these areas are often overgrazed and degraded, which affects heavily the feed availability and quality especially during dry seasons (Lukuyu et al., 2012). The productivity of pastures should be improved in terms of weed control, timing and intensity of grazing, and fertility management through application of organic and inorganic fertiliser (Lukuyu et al., 2012; Mottet et al., 2016). The latter option will also contribute to the increase of GHG emissions from pasture soils, though (Wanyama et al., 2018). However, the extent of grazing land is low throughout the Kenyan highlands (Chapter 3) (Bosire et al., 2016). Therefore, improved pasture management for sustainably intensified smallholder dairy production in Kenya can be assumed to take on a supporting role.

\subsubsection{Integrated AFOLU mitigation policies require integrated ap- proaches}

Policies that aim to mitigate AFOLU emissions effectively require robust information about the potential of candidate interventions to reduce GHG emissions across land use sectors, prioritisation preferences of stakeholders, adoption constraints, and the economic viability of practices that are being targeted in a certain context. Various spatial scales have to be incorporated ranging from a single farm to the national or even international level to obtain this information (Dunnett et al., 2018). Smallholders are the decisionmakers at farm level on which and how agricultural goods are produced on their land. 
Their decisions are determined by biophysical and socio-economic constraints such as climate, soil fertility, financial capital, and education (van Wijk et al., 2009). The decisions of policy-makers on economic development pathways and investments into climate-smart production systems are made at (inter)national and sub-national scale such as the county level in Kenya. Integrated modelling tools are needed that enable the assessment of CSA-related policy interventions at the scale where farmers make decisions (i.e. the farm level), including their implications at landscape level while incorporating feedback dynamics between changes in productivity and market responses at the scale of production sectors.

Various farm household models exist to date (e.g. van Wijk et al., 2014). The 'NUANCESFARMSIM' model was developed specifically for smallholder systems in SSA and could be used to study the effects of changes in management practices at farm level over time (van Wijk et al., 2009). The model is able to simulate crop and livestock production on smallholder farms, including the interactions between farm components such as soils, crops and livestock. This enables the assessment of farmers' decisions on resource and nutrient flows, GHG emissions, and feed and livestock productivity in relation to constraints and changes in external systems such as climate and markets (Rusinamhodzi et al., 2015). The impacts, which would result from development pathways of farms that operate under certain biophysical and socio-economic constraints can be explored, including the opportunities and barriers to adopt certain CSA practices. Chapter 3 of this thesis used components of the FARMSIM model suite such as LivSim and HeapSim (Rufino et al., 2007, 2009). Thus, the proposed use of the FARMSIM model represents an extension of the methodology already applied and would require a broader range of input data to parameterise the model.

FARMSIM can be parametrised and run for different farm types based on a farm typology, which captures the various conditions of the landscapes and production regions that are potentially affected by climate mitigation and developmental policies. Such farm typology derived from farm censuses or farm surveys based on a stratified random sampling approach could improve the upscaling and mapping procedure applied in Chapter 3 and 5 of this thesis. So far, the simulation results from dairy cows were used for upscaling onto livestock production systems (Robinson et al., 2011). Farm type specific baseline data on agricultural production and GHG emissions as well as mitigation potentials obtained from the integrated crop-livestock production modelling based on ground data would reflect a more detailed picture on the potential benefits and trade-offs of targeted CSA practices at higher spatial scale such as the landscape or sectoral level. In addition, the effects of changes in agricultural practices and the use of forests have to be linked as demonstrated in Chapter 4. Therefore, the farm typology has to incorporate forest use variables to capture information on forest grazing and fuelwood collection.

The knowledge about temporal and spatial dynamics of forest disturbance has to be 
improved to differentiate more clearly between their drivers. For instance, the analyses conducted in Chapter 4 neither revealed the initial drivers of forest disturbance nor characterised post-disturbance trajectories. This information is crucial to quantify GHG emissions from forests and to allocate these emissions to certain drivers such as livestock grazing in forests or fuelwood harvest, which are related to agricultural practices and land uses. Moreover, this information is needed to monitor implemented CSA interventions and to evaluate their effectiveness to mitigate GHG emissions from agriculture and forests. Algorithms that detect forest changes based on remote-sensing data have to be developed further to track the changes in vegetation structure, including both disturbance and regrowth dynamics. Promising approaches have been brought forward recently (e.g. DeVries et al., 2015a; Hamunyela et al., 2017), yet need to be advanced to enable the characterisation of disturbance-regrowth dynamics at larger temporal and spatial scales. Cloud computing systems such as 'SEPAL' (developed by FAO), designed explicitly to process large earth observation data and to analyse and monitor changes of the land surface provide the necessary computational power for large-scale assessments. Based on forest disturbance dynamics that are characterised more clearly and differentiated into drivers, farm types and changes in farm management could be linked more closely to their impact on forests.

Further interdisciplinary research is necessary to answer the question; to which extent is the intensification of smallholder farming sustainable? This question cannot be answered at farm level alone and includes environmental, social and economic dimensions of agricultural production. In Chapter 4, it was shown that intensified farms were related to lower levels of local forest disturbance than non-intensified farms. This relationship was used in Chapter 5 to estimate the indirect mitigation benefits that could be achieved at landscape level throughout the dairy production region in Kenya. However, it is unknown at which point the farms, analysed in Chapter 4, are exactly on their intensification trajectory. Multi-dimensional and multi-scale assessments are required to explore the boundaries of sustainable intensification. For instance, rebound effects that are triggered by policy interventions to foster the intensification of smallholder dairy farming in a certain region could lead to higher cattle numbers, which consequently increase GHG emissions in this region or may result in negative spillover effects in other regions (e.g. countries) (Meyfroidt, 2018). The increased demand for feeds, which cannot be satisfied locally or regionally due to the shortage of resources such as arable land may lead to increasing feed imports and potentially causes C leakage from indirect land use changes (Meyfroidt et al., 2014). This interaction effect between remote regions was demonstrated for intensified production systems in industrial countries by using a consequential live cycle assessment approach (Styles et al., 2018). Rebound effects were shown for the export-oriented development of commodity goods (Jadin et al., 2016) and the intensification of livestock production in Latin America (Kaimowitz \& Angelsen, 2008), and were studied through modelling exercises at a coarse continental and global scale (e.g. Valin et al., 2013). Inte- 
grating interactions between the intensification of livestock production, market responses and their feedback effects is, therefore, highly important to inform policies that aim to mitigate AFOLU emissions effectively. The integration of changes in agricultural production and market response is commonly done by using partial equilibrium models such as 'GLOBIOM' or 'MAgPIE' (e.g. Valin et al., 2013; Kreidenweis et al., 2018). However, these models operate on a coarse spatial scale, i.e. grid cells have a size of roughly $55 \mathrm{x}$ $55 \mathrm{~km}$ at the equator. Future research would need to investigate opportunities to couple dynamically models of farm production (e.g. FARMSIM) with high resolution land use models and economic models at larger scale.

The outputs obtained from an integrated modelling approach to estimate ex-ante impacts of certain CSA practices represent potential inputs for multi-criteria decision-making frameworks such as "targetCSA" (Chapter 2). Up-scaled, bottom-up information is crucial for policy and decision-makers to prioritise and target mitigation interventions for livestock production at national and sub-national level. By using farm-level information, local conditions can be captured, which may reveal constraints and trade-offs that otherwise would have been missed. Therefore, relying on information from top-down approaches alone, could lead to low adoption rates or even negative impacts of targeted interventions. Decision-making on CSA, at large scale is likely to suffer from high complexity and is often characterised by conflicting stakeholder interests and objectives (Notenbaert et al., 2017). Thus, decision-making support frameworks would benefit from comprehensive information derived from integrated assessments to illustrate the potential effects of different stakeholder opinions on where to prioritise CSA interventions (Chapter 2). Visualising transparently various decision-making scenarios can aid eventually in building consensus among involved stakeholders and increases the legitimacy and robustness of decisions and their outcomes (Voinov \& Bousquet, 2010).

\subsubsection{Data improvements}

Quantitative information is needed urgently to estimate GHG emission baselines, to inform CSA policies and to implement interventions robustly based on ex-ante impact assessments. These assessments rely on i) data regarding crop and livestock management and productivity at farm level, ii) data on forest use and its impact on $\mathrm{C}$ dynamics, and iii) data from measurements of GHG emissions on smallholder farms.

Efforts have been strengthened recently to measure GHG emissions from smallholder farms in East Africa, including $\mathrm{CH}_{4}$ and $\mathrm{N}_{2} \mathrm{O}$ emissions from croplands and pastures, enteric fermentation and animal excreta (e.g. Pelster et al., 2016, 2017; Rosenstock et al., 2016; Goopy et al., 2018; Wanyama et al., 2018). More studies are needed, conducted systematically, considering the heterogeneity of soil, agro-climatic conditions and farming systems in SSA to estimate related emission factors and to reduce the uncertainty of 
GHG emissions such as quantified in Chapter 3. Especially improved estimates of GHG emissions from LUC, which result from the conversion of land used for livestock production are required to inform mitigation assessments about trade-offs of feed improvements. A promising initiative is the European-African 'SEACRIFOG' project, which aims to design a harmonised infrastructure to measure AFOLU emissions systematically based on a ground-based observation network across the African continent (López-Ballesteros et al., 2018). An improved data basis provides inputs for dynamic land use models that can be used to investigate the effects of LUC on interactions between vegetation, soils and resulting GHG emissions (e.g. Haas et al., 2013).

A standardised protocol for farm surveys that enables a consistent collection of crop and livestock production data at farm level is needed for assessments that quantify and upscale mitigation potentials and monitor the performance of implemented CSA practices (e.g. Rufino et al., 2016; Hammond et al., 2017). This protocol should further incorporate variables on feed trade to trace changes in demand and supply of livestock feeds triggered by policy interventions. Information on the use of local forests should also be included such as the collection of fuelwood and livestock grazing inside forests to assess whether changes in farm management reduce the pressure on forests. Such a protocol could be integrated into agricultural censuses conducted regularly. However, mistrust of farmers to reveal detailed information of their farm operations may compromise efforts to collect high quality farm-level data. Trust-building measures need to be implemented such as confidentiality agreements or the dissemination of information about the benefits of CSA practices through extension services.

The effects of forest disturbance drivers on above and belowground C dynamics and GHG emissions have to be studied more closely. Measurements based on grazing experiments are potentially helpful to estimate the effects of livestock grazing inside forests on vegetation structure and the loss of aboveground and belowground $\mathrm{C}$ for different forest types and livestock species. Telemetry analyses of livestock can be utilised to study animal movement patterns (e.g. Zampaligré \& Schlecht, 2018) such as distances covered and time spent inside forests. Based on daily nutrient and energy requirements and the resulting intake of biomass, the loss of $\mathrm{C}$ can be inferred and aggregated. This information is useful to calibrate and validate estimates of $\mathrm{C}$ change related to livestock presence in forests based on remote-sensing data (e.g. Baccini et al., 2017). Recently launched earth observation platforms such as the Sentinel-1 and Sentinel-2 satellites open new and promising avenues to improve the detection of small-scale disturbance patters (Reiche et al., 2018) and to study the effects of forest disturbance drivers on $\mathrm{C}$ loss due to higher spatial $(5-10 \mathrm{~m})$ and temporal resolution (revisiting time of approximately 5 days) than, for instance, the Landsat satellite platform. 


\subsection{Recommendations for climate mitigation policies and financing}

This $\mathrm{PhD}$ thesis provides useful approaches and information that can assist the targeting of CSA interventions based on:

1. the quantitative integration of climate change vulnerability, CSA feasibility, and stakeholder opinions to build consensus in decision-making processes on CSA prioritisation (Chapter 2).

2. quantified potentials of dairy feed improvements to mitigate GHG emissions and to increase milk yields, including the feasibility to implement these improvements due to land constraints (Chapter 3).

3. quantified potentials of dairy feed improvements to contribute to climate change mitigation and dairy productivity targets at national level (Chapter 3).

4. knowledge, which shows quantitatively that the intensification of smallholder dairy farming reduces the negative impact on natural forests ecosystems (Chapter 4).

5. quantified potentials of dairy feed improvements to mitigate direct and indirect GHG emissions effectively across land use sectors (Chapter 5).

The following key messages for policy makers can be deduced from this thesis. Contextspecific and detailed ex-ante impact assessments are essential to inform integrated CSA policies that target mitigation and agricultural development. Candidate interventions need to be assessed in terms of their direct and indirect mitigation benefits and productivity gains, which lead potentially to higher farm incomes. Concentrating on practices that realise these 'win-win' potentials is especially important in the context of smallholder farming in SSA, which is marked by low production efficiencies (Gerber et al., 2013; Descheemaeker et al., 2016). Analysing the demand of candidate interventions for arable land and land availability is imperative to answer the questions of how feasible and effective the implementation of the CSA practices at hand are at certain locations. Policy instruments such as the NAMA developed for the Kenyan dairy sector (Government of Kenya, 2017b) can target specific climate-smart feed practices based on ex-ante knowledge about their direct and indirect mitigation benefits and productivity gains that were quantified location-specific. Capacity and infrastructure development, including feed, fertiliser supply and trade, access to markets and extension services can be promoted more effectively.

Financial investment to stimulate the adoption of CSA can be channelled more closely along promoted practices that have been shown to realise mitigation and productivity benefits. The private sector has engaged recently to finance the implementation of CSA practices at farm level through micro-financing and crediting (e.g. www.f3-life.com). 
Accessing these services offers promising opportunities for individual farmers to adopt certain practices. Various international climate funds exist under the umbrella of the 'African Development Bank' (AfDB), e.g. the 'Climate Investment Funds' (CIF), the 'Green Climate Fund' (GCF), and the 'Africa Climate Change Fund' (ACCF) with a current total investment volume of about USD 12 billion (AfDB, 2018). These largescale financing schemes, which will include the reduction of GHG emissions from forests through REDD+ components, fund projects and initiatives across SSA that target and implement CSA measures on the ground. Both, small and large-scale financing schemes require evidence that indicates the effectiveness and feasibility of these practices across the agricultural and forestry land use sectors.

Kenya pledged to reduce total GHG emission increases by $30 \%$ between 2010 - 2030, as defined in its NDC (Government of Kenya, 2015a). Linking CSA practices, implemented at farm level, to sectoral and national scales enables the assessment of the extent at which targeted practices contribute to the achievement of national mitigation targets. Up-scaling mitigation potentials, as done in this thesis (Chapter $3 \& 5$ ), could, therefore, be useful to monitor the mitigation performance and to report the status of target fulfilment (e.g. through MRVs) to the UNFCCC. 



\section{References}

Abbas, F., Hammad, H., Fahad, S., Cerdà, A., Rizwan, M., Farhad, W., Ehsan, S., \& Bakhat, H. (2017). Agroforestry: A sustainable environmental practice for carbon sequestration under the climate change scenarios - a review. Environmental Science and Pollution Research, 24, 11177-11191. doi: 10.1007/s11356-017-8687-0.

Abson, D. J., Dougill, A. J., \& Stringer, L. C. (2012). Using Principal Component Analysis for information-rich socio-ecological vulnerability mapping in Southern Africa. Applied Geography, 35, 515-524. doi: 10.1016/j.apgeog.2012.08.004.

Agle, M., Hristov, A., Zaman, S., Schneider, C., Ndegwa, P., \& Vaddella, V. (2010). Effect of dietary concentrate on rumen fermentation, digestibility, and nitrogen losses in dairy cows. Journal of Dairy Science, 93, 4211-4222. doi: 10.3168/jds.2009-2977.

Akobeng, A. (2005). Understanding systematic reviews and meta-analysis. Archives of Disease in Childhood, 90, 845-848. doi: 10.1136/adc.2004.058230.

Allen, V., Baker, M., Segarra, E., \& Brown, C. (2007). Integrated irrigated crop-livestock systems in dry climates. Agronomy Journal, 99, 346-360. doi: 10.2134/agronj2006.0148.

Anindo, D., Said, A., \& Lahlou-Kassi, A. (1994). Chemical Composition and Nutritive Value of Feedstuffs for Ruminant Livestock in Sub-Saharan Africa. Technical Report International Livestock Centre for Africa Addis Ababa (Ethiopia). URL: http://192.156.137.110/ssafeed/ [Accessed: 2017-01-26].

Arias-Navarro, C., Díaz-Pinés, E., Zuazo, P., Rufino, M. C., Verchot, L. V., \& ButterbachBahl, K. (2017). Quantifying the contribution of land use to N2O, NO and CO2 fluxes in a montane forest ecosystem of Kenya. Biogeochemistry, 134, 95-114. doi: 10.1007/s10533-017-0348-3.

Atela, J., Quinn, C., \& Minang, P. (2014). Are REDD projects pro-poor in their spatial targeting? Evidence from Kenya. Applied Geography, 52, 14-24. doi: 10.1016/j.apgeog.2014.04.009.

Baccini, A., Goetz, S. J., Walker, W. S., Laporte, N. T., Sun, M., Sulla-Menashe, D., Hackler, J., Beck, P. S. A., Dubayah, R., Friedl, M. A., Samanta, S., \& Houghton, R. A. (2012). Estimated carbon dioxide emissions from tropical deforestation improved by 
carbon-density maps. Nature Climate Change, 2, 182-185. doi: 10.1038/nclimate1354.

Baccini, A., Walker, W., Carvalho, L., Farina, M., Sulla-Menashe, D., \& Houghton, R. (2017). Tropical forests are a net carbon source based on aboveground measurements of gain and loss. Science, 358, 230-234. doi: 10.1126/science.aam5962.

Bailis, R., Drigo, R., Ghilardi, A., \& Masera, O. (2015). The carbon footprint of traditional woodfuels. Nature Climate Change, 5, 266-272. doi: 10.1038/nclimate2491.

Baldyga, T., Miller, S., Driese, K., \& Gichaba, C. (2008). Assessing land cover change in Kenya's Mau Forest region using remotely sensed data. African Journal of Ecology, 46, 46-54. doi: 10.1111/j.1365-2028.2007.00806.x.

Barlow, J., Lennox, G., Ferreira, J., Berenguer, E., Lees, A., Nally, R., Thomson, J., Ferraz, S., Louzada, J., Oliveira, V., Parry, L., Ribeiro, D. C. S., Vieira, I., Aragaõ, L., Begotti, R., Braga, R., Cardoso, T., Jr, R., Souza, C., Jr., Moura, N., Nunes, S., Siqueira, J., Pardini, R., Silveira, J., Vaz-De-Mello, F., Veiga, R., Venturieri, A., \& Gardner, T. (2016). Anthropogenic disturbance in tropical forests can double biodiversity loss from deforestation. Nature, 535, 144-147. doi: 10.1038/nature18326.

Bates, D., Mächler, M., Bolker, B., \& Walker, S. (2015). Fitting linear mixed-effects models using lme4. Journal of Statistical Software, 67, 1-48. doi: 10.18637/jss.v067.i01.

Baudron, F., Duriaux Chavarría, J.-Y., Remans, R., Yang, K., \& Sunderland, T. (2017). Indirect contributions of forests to dietary diversity in Southern Ethiopia. Ecology and Society, 22. doi: 10.5751/ES-09267-220228.

Beauchemin, K., Kreuzer, M., O’Mara, F., \& McAllister, T. (2008). Nutritional management for enteric methane abatement: A review. Australian Journal of Experimental Agriculture, 48, 21-27. doi: 10.1071/EA07199.

Bebe, B. (2008). Dairy heifer rearing under increasing intensification of smallholder dairy systems in the Kenya highlands. Livestock Research for Rural Development, 20. URL: https://www. lrrd.cipav.org.co/lrrd20/2/bebea20022.htm.

Bebe, B., Udo, H., \& Thorpe, W. (2002). Development of smallholder dairy systems in the Kenya highlands. Outlook on Agriculture, 31, 113-120. doi: $10.5367 / 000000002101293958$.

Beuchelt, T., \& Badstue, L. (2013). Gender, nutrition- and climate-smart food production: Opportunities and trade-offs. Food Security, 5, 709-721. doi: 10.1007/s12571-013-02908.

Bewernick, T. (2016). Mapping Forest Degradation in the Mau Forest Complex Using NDFI Time Series. Master's Thesis Report Wageningen University \& Research Wageningen (The Netherlands). URL: http://library . wur.nl/WebQuery/theses/2199331 [Accessed: 2017-10-09].

Boadi, D., Benchaar, C., Chiquette, J., \& Massé, D. (2004). Mitigation strategies to 
reduce enteric methane emissions from dairy cows: Update review. Canadian Journal of Animal Science, 84, 319-335. doi: 10.4141/A03-109.

Börner, J., \& Wunder, S. (2012). The scope for reducing emissions from forestry and agriculture in the Brazilian Amazon. Forests, 3, 546-572. doi: 10.3390/f3030546.

Boroushaki, S., \& Malczewski, J. (2008). Implementing an extension of the analytical hierarchy process using ordered weighted averaging operators with fuzzy quantifiers in ArcGIS. Computers and Geosciences, 34, 399-410. doi: 10.1016/j.cageo.2007.04.003.

Bosire, C. K., Krol, M. S., Mekonnen, M. M., Ogutu, J. O., de Leeuw, J., Lannerstad, M., \& Hoekstra, A. Y. (2016). Meat and milk production scenarios and the associated land footprint in Kenya. Agricultural Systems, 145, 64-75. doi: 10.1016/j.agsy.2016.03.003.

Bousquet, F., \& Le Page, C. (2004). Multi-agent simulations and ecosystem management: A review. Ecological Modelling, 176, 313-332. doi: 10.1016/j.ecolmodel.2004.01.011.

Brandt, P., Hamunyela, E., Herold, M., de Bruin, S., Verbesselt, J., \& Rufino, M. (2018a). Sustainable intensification of dairy production can reduce forest disturbance in Kenyan montane forests. Agriculture, Ecosystems \&5 Environment, 265, 307-319. doi: $10.1016 /$ j.agee.2018.06.011.

Brandt, P., Herold, M., \& Rufino, M. (2018b). The contribution of sectoral climate change mitigation options to national targets: A quantitative assessment of dairy production in Kenya. Environmental Research Letters, 13, 034016. doi: 10.1088/1748-9326/aaac84.

Brandt, P., Kvakić, M., Butterbach-Bahl, K., \& Rufino, M. (2017). How to target climate-smart agriculture? Concept and application of the consensus-driven decision support framework "targetCSA". Agricultural Systems, 151, 234-245. doi: 10.1016/j.agsy.2015.12.011.

Brask, M., Lund, P., Hellwing, A., Poulsen, M., \& Weisbjerg, M. (2013). Enteric methane production, digestibility and rumen fermentation in dairy cows fed different forages with and without rapeseed fat supplementation. Animal Feed Science and Technology, 184, 67-79. doi: 10.1016/j.anifeedsci.2013.06.006.

Breiman, L. (2001). Random forests. Machine Learning, 45, 5-32. doi: 10.1023/A:1010933404324.

Bressen, T. (2007). Consensus Decision Making. In P. Holman, T. Devane, \& S. Cady (Eds.), The Change Handbook: Group Methods for Shaping the Future: The Definitive Resource to Today's Best Methods for Engaging Whole Systems. San Francisco (USA): Berrett-Koehler Publishers. (2nd ed.).

Bryan, E., Ringler, C., Okoba, B., Koo, J., Herrero, M., \& Silvestri, S. (2013). Can agriculture support climate change adaptation, greenhouse gas mitigation and rural livelihoods? insights from Kenya. Climatic Change, 118, 151-165. doi: 10.1007/s10584012-0640-0. 
Campbell, B. M., Thornton, P., Zougmoré, R., van Asten, P., \& Lipper, L. (2014). Sustainable intensification: What is its role in climate smart agriculture? Current Opinion in Environmental Sustainability, 8, 39-43. doi: 10.1016/j.cosust.2014.07.002.

Carter, S., Arts, B., Giller, K., Soto, G., Kok, K., de Koning, J., van Noordwijk, M., Reisdma, P., Rufino, M., Salvini, G., Verchot, L., Wollenberg, E., \& Herold, M. (2018a). Climate-smart land use requires local solutions, transdisciplinary research, policy coherence and transparency. Carbon Management, (pp. 1-11). doi: 10.1080/17583004.2018.1457907.

Carter, S., Herold, M., Avitabile, V., de Bruin, S., Sy, V. D., Kooistra, L., \& Rufino, M. C. (2018b). Agriculture-driven deforestation in the tropics from 1990 to-2015: Emissions, trends and uncertainties. Environmental Research Letters, 13, 014002. doi: 10.1088/1748-9326/aa9ea4.

Carter, S., Herold, M., Rufino, M., Neumann, K., Kooistra, L., \& Verchot, L. (2015). Mitigation of agricultural emissions in the tropics: Comparing forest land-sparing options at the national level. Biogeosciences, 12, 4809-4825. doi: 10.5194/bg-12-4809-2015.

Castellanos-Navarrete, A., Tittonell, P., Rufino, M., \& Giller, K. (2015). Feeding, crop residue and manure management for integrated soil fertility management - A case study from Kenya. Agricultural Systems, 134, 24-35. doi: 10.1016/j.agsy.2014.03.001.

Caviglia-Harris, J. L. (2018). Agricultural innovation and climate change policy in the Brazilian Amazon: Intensification practices and the derived demand for pasture. Journal of Environmental Economics and Management, 90, 232-248. doi: 10.1016/j.jeem.2018.06.006.

Chadwick, D. (2005). Emissions of ammonia, nitrous oxide and methane from cattle manure heaps: Effect of compaction and covering. Atmospheric Environment, 39, 787-799. doi: 10.1016/j.atmosenv.2004.10.012.

Chagunda, M., Flockhart, J., \& Roberts, D. (2010). The effect of forage quality on predicted enteric methane production from dairy cows. International Journal of Agricultural Sustainability, 8, 250-256. doi: 10.3763/ijas.2010.0490.

Challinor, A., Wheeler, T., Garforth, C., Craufurd, P., \& Kassam, A. (2007). Assessing the vulnerability of food crop systems in Africa to climate change. Climatic Change, 83, 381-399. doi: 10.1007/s10584-007-9249-0.

Chaudhury, A. S., Helfgott, A., Thornton, T. F., \& Sova, C. (2014). Participatory adaptation planning and costing. Applications in agricultural adaptation in western Kenya. Mitigation and Adaptation Strategies for Global Change, . doi: 10.1007/s11027-0149600-5.

Chidumayo, E., \& Gumbo, D. (2013). The environmental impacts of charcoal production in tropical ecosystems of the world: A synthesis. Energy for Sustainable Development, 17, 86-94. doi: 10.1016/j.esd.2012.07.004. 
Chung, E.-S., Won, K., Kim, Y., \& Lee, H. (2014). Water resource vulnerability characteristics by district's population size in a changing climate using subjective and objective weights. Sustainability (Switzerland), 6, 6141-6157. doi: 10.3390/su6096141.

Close, D., Davidson, N., \& Watson, T. (2008). Health of remnant woodlands in fragments under distinct grazing regimes. Biological Conservation, 141, 2395-2402. doi: 10.1016/j.biocon.2008.07.006.

Cohen, W., Yang, Z., \& Kennedy, R. (2010). Detecting trends in forest disturbance and recovery using yearly Landsat time series: 2. TimeSync - Tools for calibration and validation. Remote Sensing of Environment, 114, 2911-2924. doi: 10.1016/j.rse.2010.07.010.

Conway, D., \& Mustelin, J. (2014). Strategies for improving adaptation practice in developing countries. Nature Climate Change, 4, 339-342. doi: 10.1038/nclimate2199.

Crawley, M. (2007). The $R$ Book. The R Book. West Sussex (UK): Whiley. doi: 10.1002/9780470515075.

de Boer, I., Cederberg, C., Eady, S., Gollnow, S., Kristensen, T., Macleod, M., Meul, M., Nemecek, T., Phong, L., Thoma, G., van der Werf, H., Williams, A., \& ZonderlandThomassen, M. (2011). Greenhouse gas mitigation in animal production: Towards an integrated life cycle sustainability assessment. Current Opinion in Environmental Sustainability, 3, 423-431. doi: 10.1016/j.cosust.2011.08.007.

DeFries, R., \& Rosenzweig, C. (2010). Toward a whole-landscape approach for sustainable land use in the tropics. Proceedings of the National Academy of Sciences of the United States of America, 107, 19627-19632. doi: 10.1073/pnas.1011163107.

Delgado, M., \& Sendra, J. (2004). Sensitivity analysis in multicriteria spatial decisionmaking: A review. Human and Ecological Risk Assessment, 10, 1173-1187. doi: 10.1080/10807030490887221.

Denmead, L., Barker, G., Standish, R., \& Didham, R. (2015). Experimental evidence that even minor livestock trampling has severe effects on land snail communities in forest remnants. Journal of Applied Ecology, 52, 161-170. doi: 10.1111/1365-2664.12370.

Descheemaeker, K., Oosting, S. J., Tui, S. H.-K., Masikati, P., Falconnier, G. N., \& Giller, K. E. (2016). Climate change adaptation and mitigation in smallholder crop-livestock systems in sub-Saharan Africa: A call for integrated impact assessments. Regional Environmental Change, 16, 2331-2343. doi: 10.1007/s10113-016-0957-8.

DeVries, B., Decuyper, M., Verbesselt, J., Zeileis, A., Herold, M., \& Joseph, S. (2015a). Tracking disturbance-regrowth dynamics in tropical forests using structural change detection and Landsat time series. Remote Sensing of Environment, 169, 320-334. doi: 10.1016/j.rse.2015.08.020.

DeVries, B., Pratihast, A., Verbesselt, J., Kooistra, L., \& Herold, M. (2016). Characterizing forest change using community-based monitoring data and landsat time series. 
PLoS ONE, 11, 1-25. doi: 10.1371/journal.pone.0147121.

DeVries, B., Verbesselt, J., Kooistra, L., \& Herold, M. (2015b). Robust monitoring of small-scale forest disturbances in a tropical montane forest using Landsat time series. Remote Sensing of Environment, 161, 107-121. doi: 10.1016/j.rse.2015.02.012.

Diaz-Balteiro, L., Gonzalez-Pachon, J., \& Romero, C. (2009). Forest management with multiple criteria and multiple stakeholders: An application to two public forests in Spain. Scandinavian Journal of Forest Research, 24, 87-93. doi: 10.1080/02827580802687440.

Dijkstra, J., Oenema, O., \& Bannink, A. (2011). Dietary strategies to reducing N excretion from cattle: Implications for methane emissions. Current Opinion in Environmental Sustainability, 3, 414-422. doi: 10.1016/j.cosust.2011.07.008.

Don, A., Schumacher, J., \& Freibauer, A. (2011). Impact of tropical land-use change on soil organic carbon stocks - a meta-analysis. Global Change Biology, 17, 1658-1670. doi: 10.1111/j.1365-2486.2010.02336.x.

Drigo, R., Bailis, R., Ghilardi, A., \& Masera, O. (2015). WISDOM Kenya - Analysis of Woodfuel Supply, Demand and Sustainability in Kenya. Tier 2 Report. URL: https://cleancookstoves .org/binary-data/RESOURCE/file/000/000/426-1.pdf [Accessed: 2017-07-02].

Dunnett, A., Shirsath, P. B., Aggarwal, P. K., Thornton, P., Joshi, P. K., Pal, B. D., Khatri-Chhetri, A., \& Ghosh, J. (2018). Multi-objective land use allocation modelling for prioritizing climate-smart agricultural interventions. Ecological Modelling, 381, 2335. doi: 10.1016/j.ecolmodel.2018.04.008.

Duriaux Chavarría, J.-Y., Baudron, F., \& Sunderland, T. (2018). Retaining forests within agricultural landscapes as a pathway to sustainable intensification: Evidence from Southern Ethiopia. Agriculture, Ecosystems \& Environment, 263, 41-52. doi: 10.1016/j.agee.2018.04.020.

EADD (2014). East Africa Dairy Development Phase II. Annual Report xc1904 Heifer International Little Rock (USA). URL: https://www . heifer .org/ending-hunger/our-work/programs/eadd/index.html [Accessed: 2016-02-21].

Eastman, J., Weigen Jin, Kyem, P., \& Toledano, J. (1995). Raster procedures for multicriteria/multi-objective decisions. Photogrammetric Engineering $\&$ Remote Sensing, $61,539-547$.

Eaton, J., Bateman, D., Hauberg, S., \& Wehbring, S. (2015). GNU Octave: A high-level interactive language for numerical computations. URL: http://www .gnu.org/software/octave/doc/interpreter/ [Accessed: 2015-06-02].

Eckard, R., Grainger, C., \& de, K. (2010). Options for the abatement of methane and 
nitrous oxide from ruminant production: A review. Livestock Science, 130, 47-56. doi: 10.1016/j.livsci.2010.02.010.

Eriksen, S., \& O'Brien, K. (2007). Vulnerability, poverty and the need for sustainable adaptation measures. Climate Policy, 7, 337-352. doi: 10.1080/14693062.2007.9685660.

ESA (2017). CCI LAND COVER - S2 Prototype Land Cover 20m Map of Africa 2016. Technical Report European Space Agency. URL: http://2016africalandcover20m.esrin.esa.int/ [Accessed: 2018-02-05].

FAO (2013). Climate-Smart Agriculture Sourcebook. Technical Report Food and Agriculture Organization of the United Nations Rome (Italy). URL: http://www.fao.org/docrep/018/i3325e/i3325e.pdf [Accessed: 2014-11-02].

FAO, IFAD, UNICEF, WFP, \& WHO (2017). The State of Food Security and Nutrition in the World 2017. Technical Report Rome (Italy). URL: http://www.fao.org/state-of-food-security-nutrition/en/ [Accessed: 2018-06$23]$.

Fellmann, T. (2012). The assessment of climate change-related vulnerability in the agricultural sector: Reviewing conceptual frameworks. In A. Meybeck, J. Lankoski, S. Redfern, N. Azzu, \& V. Gitz (Eds.), Building Resilience for Adaptation to Climate Change in the Agriculture Sector Proceedings of a Joint FAO/OECD Workshop (pp. 37-61). Rome (Italy): FAO/OECD.

Ferretti, V., \& Pomarico, S. (2013). Ecological land suitability analysis through spatial indicators: An application of the Analytic Network Process technique and Ordered Weighted Average approach. Ecological Indicators, 34, 507-519. doi: 10.1016/j.ecolind.2013.06.005.

Fisher, B. (2010). African exception to drivers of deforestation. Nature Geoscience, 3, 375-376. doi: 10.1038/ngeo873.

Foley, J. A., DeFries, R., Asner, G. P., Barford, C., Bonan, G., Carpenter, S. R., Chapin, F. S., Coe, M. T., Daily, G. C., Gibbs, H. K., Helkowski, J. H., Holloway, T., Howard, E. A., Kucharik, C. J., Monfreda, C., Patz, J. A., Prentice, I. C., Ramankutty, N., \& Snyder, P. K. (2005). Global Consequences of Land Use. Science, 309, 570-574. doi: 10.1126/science.1111772.

Foley, J. A., Ramankutty, N., Brauman, K. A., Cassidy, E. S., Gerber, J. S., Johnston, M., Mueller, N. D., O’Connell, C., Ray, D. K., West, P. C., Balzer, C., Bennett, E. M., Carpenter, S. R., Hill, J., Monfreda, C., Polasky, S., Rockström, J., Sheehan, J., Siebert, S., Tilman, D., \& Zaks, D. P. M. (2011). Solutions for a cultivated planet. Nature, 478, 337-342. doi: 10.1038/nature10452.

FRA (2000). On Definitions of Forest and Forest Change. Technical Report Working Paper 33 Forestry Department, Food and Agriculture Organization of the United Nations (FAO) Rome (Italy). URL: http://www.fao.org/docrep/006/ad665e/ad665e00.htm 
[Accessed: 2017-07-01].

Franzel, S., Carsan, S., Lukuyu, B., Sinja, J., \& Wambugu, C. (2014). Fodder trees for improving livestock productivity and smallholder livelihoods in Africa. Current Opinion in Environmental Sustainability, 6, 98-103. doi: 10.1016/j.cosust.2013.11.008.

Fritz, S., See, L., McCallum, I., You, L., Bun, A., Moltchanova, E., Duerauer, M., Albrecht, F., Schill, C., Perger, C., Havlik, P., Mosnier, A., Thornton, P., Wood-Sichra, U., Herrero, M., Becker-Reshef, I., Justice, C., Hansen, M., Gong, P., Abdel Aziz, S., Cipriani, A., Cumani, R., Cecchi, G., Conchedda, G., Ferreira, S., Gomez, A., Haffani, M., Kayitakire, F., Malanding, J., Mueller, R., Newby, T., Nonguierma, A., Olusegun, A., Ortner, S., Rajak, D. R., Rocha, J., Schepaschenko, D., Schepaschenko, M., Terekhov, A., Tiangwa, A., Vancutsem, C., Vintrou, E., Wenbin, W., van der Velde, M., Dunwoody, A., Kraxner, F., \& Obersteiner, M. (2015). Mapping global cropland and field size. Global Change Biology, (pp. n/a-n/a). doi: 10.1111/gcb.12838.

Gachathi, F., \& Eriksen, S. (2011). Gums and resins: The potential for supporting sustainable adaptation in Kenya's drylands. Climate and Development, 3, 59-70. doi: 10.3763/cdev.2010.0066.

Gao, P., Kupfer, J., Zhu, X., \& Guo, D. (2016). Quantifying Animal Trajectories Using Spatial Aggregation and Sequence Analysis: A Case Study of Differentiating Trajectories of Multiple Species. Geographical Analysis, 48, 275-291. doi: 10.1111/gean.12098.

Garnett, T., Appleby, M., Balmford, A., Bateman, I., Benton, T., Bloomer, P., Burlingame, B., Dawkins, M., Dolan, L., Fraser, D., Herrero, M., Hoffmann, I., Smith, P., Thornton, P., Toulmin, C., Vermeulen, S., \& Godfray, H. (2013). Sustainable intensification in agriculture: Premises and policies. Science, 341, 33-34. doi: 10.1126/science. 1234485 .

Gebrezgabher, S., Meuwissen, M., \& Oude Lansink, A. (2014). A multiple criteria decision making approach to manure management systems in the Netherlands. European Journal of Operational Research, 232, 643-653. doi: 10.1016/j.ejor.2013.08.006.

Gerber, P., Steinfeld, H., Henderson, B., Mottet, A., Opio, C., Dijkman, J., Falcucci, A., \& Tempio, G. (2013). Tackling Climate Change through Livestock - A Global Assessment of Emissions and Mitigation Opportunities. Technical Report Food and Agriculture Organization of the United Nations (FAO) Rome (Italy). URL: www.fao.org/3/a-i3437e.pdf [Accessed: 2016-04-10].

Gerber, P., Vellinga, T., Opio, C., Henderson, B., \& Steinfeld, H. (2010). Greenhouse Gas Emissions from the Dairy Sector. A Life Cycle Assessment. Technical Report Food and Agriculture Organization of the United Nations. Animal Production and Health Division Rome, Italy. URL: www. fao.org/docrep/012/k7930e/k7930e00 .pdf [Accessed: 2016-04-10].

Gerssen-Gondelach, S., Lauwerijssen, R., Havlík, P., Herrero, M., Valin, H., Faaij, A., 
\& Wicke, B. (2017). Intensification pathways for beef and dairy cattle production systems: Impacts on GHG emissions, land occupation and land use change. Agriculture, Ecosystems and Environment, 240, 135-147. doi: 10.1016/j.agee.2017.02.012.

Giglio, L. (2015). MODIS Collection 6 Active Fire Product User's Guide Revision A. Technical Report Department of Geographical Sciences, University of Maryland Maryland (USA). URL: http://modis-fire.umd.edu/pages/manuals .php [Accessed: 2017-09$17]$.

Giller, K. E. (Ed.) (2001). Nitrogen Fixation in Tropical Cropping Systems. (2nd ed.). Wallingford: CABI. URL: http://www.cabi.org/cabebooks/ebook/20013118217 [Accessed: 2018-07-13].

González-Pachón, J., Rodriguez-Galiano, M., \& Romero, C. (2003). Transitive approximation to pairwise comparison matrices by using interval goal programming. Journal of the Operational Research Society, 54, 532-538. doi: 10.1057/palgrave.jors.2601542.

González-Pachón, J., \& Romero, C. (2007). Inferring consensus weights from pairwise comparison matrices without suitable properties. Annals of Operations Research, 154, 123-132. doi: 10.1007/s10479-007-0182-4.

González-Pachón, J., \& Romero, C. (2011). The design of socially optimal decisions in a consensus scenario. Omega, 39, 179-185. doi: 10.1016/j.omega.2010.06.004.

Goopy, J. P., Onyango, A. A., Dickhoefer, U., \& Butterbach-Bahl, K. (2018). A new approach for improving emission factors for enteric methane emissions of cattle in smallholder systems of East Africa - Results for Nyando, Western Kenya. Agricultural Systems, 161, 72-80. doi: 10.1016/j.agsy.2017.12.004.

Government of Kenya (2007). Kenya Vision 2030. Technical Report Ministry of Planning and National Development Nairobi (Kenya). URL: http://vision2030.go.ke/ [Accessed: 2016-03-13].

Government of Kenya (2009a). Kenya Population and Housing Census. Technical Report Kenya National Bureau of Statistics Nairobi (Kenya).

Government of Kenya (2009b). Rehabilitation of the Mau Forest Ecosystem (A Project Concept Prepared by the Interim Coordinating Secretariat, Office of the Prime Minister. Technical Report Office of the Prime Minister, on behalf of the Government of Kenya) Nairobi (Kenya). URL: http://www.kws.go.ke/file/1446/download?token=S8zEP3q1 [Accessed: 2017-08$28]$.

Government of Kenya (2010). Kenya National Dairy Master Plan. Technical Report Ministry of Livestock Development Nairobi (Kenya). URL: http://kdb.co.ke/press/publications/reports [Accessed: 2016-05-18].

Government of Kenya (2012). National Climate Change Action Plan. Technical 
Report Ministry of Environment and Mineral Resources Nairobi (Kenya). URL: http://www.kccap.info/ [Accessed: 2014-05-25].

Government of Kenya (2013). County Development Profiles. Technical Report Ministry of Devolution and Planning Nairobi (Kenya).

Government of Kenya (2014). Livestock Numbers and Production Dataset. Technical Report Ministry of Agriculture, Livestock and Fisheries Nairobi (Kenya). [Accessed: 2016-02-26].

Government of Kenya (2015a). Kenya's Intended Nationally Determined Contribution (INDC). Technical Report Ministry of Environment and Natural Resources Nairobi (Kenya). URL: http://www4. unfccc. int/ndcregistry/Pages/Party. aspx?party=KEN [Accessed: 2016-09-03].

Government of Kenya (2015b). Second National Communication to the United Nations Framework Convention On Climate Change. Technical Report National Environment Management Authority Nairobi (Kenya). URL: http://unfccc.int/resource/docs/natc/phlnc2.pdf [Accessed: 2016-11-07].

Government of Kenya (2015c). Spatially-Explicit Tree Plantation Dataset. Technical Report Kenya Forest Service (KFS) Nairobi, Kenya.

Government of Kenya (2017a). Kenya Climate Smart Agriculture Strategy 2017-2026. Technical Report Ministry of Agriculture, Livestock and Fisheries Nairobi (Kenya). URL: http://projects.worldbank.org/P154784?lang=en [Accessed: 2018-06-12].

Government of Kenya (2017b). Kenya's Dairy Nationally Appropriate Mitigation Action (NAMA). Concept Note Ministry of Agriculture, Livestock and Fisheries Nairobi (Kenya). URL: http://www. nama-database.org [Accessed: 2018-01-20].

Grace, K., Husak, G., \& Bogle, S. (2014). Estimating agricultural production in marginal and food insecure areas in Kenya using very high resolution remotely sensed imagery. Applied Geography, 55, 257-265. doi: 10.1016/j.apgeog.2014.08.014.

Grassi, G., House, J., Dentener, F., Federici, S., Den, E., \& Penman, J. (2017). The key role of forests in meeting climate targets requires science for credible mitigation. Nature Climate Change, 7, 220-226. doi: 10.1038/nclimate3227.

Greene, R., Devillers, R., Luther, J. E., \& Eddy, B. G. (2011). GIS-Based MultipleCriteria Decision Analysis. Geography Compass, 5, 412-432. doi: 10.1111/j.17498198.2011.00431.x.

Guto, S., Pypers, P., Vanlauwe, B., de, R., \& Giller, K. (2011). Tillage and vegetative barrier effects on soil conservation and short-term economic benefits in the Central Kenya highlands. Field Crops Research, 122, 85-94. doi: 10.1016/j.fcr.2011.03.002.

Haas, E., Klatt, S., Fröhlich, A., Kraft, P., Werner, C., Kiese, R., Grote, R., Breuer, 
L., \& Butterbach-Bahl, K. (2013). LandscapeDNDC: A process model for simulation of biosphere-atmosphere-hydrosphere exchange processes at site and regional scale. Landscape Ecology, 28, 615-636. doi: 10.1007/s10980-012-9772-x.

Hammond, J., Fraval, S., van Etten, J., Suchini, J. G., Mercado, L., Pagella, T., Frelat, R., Lannerstad, M., Douxchamps, S., Teufel, N., Valbuena, D., \& van Wijk, M. T. (2017). The Rural Household Multi-Indicator Survey (RHoMIS) for rapid characterisation of households to inform climate smart agriculture interventions: Description and applications in East Africa and Central America. Agricultural Systems, 151, 225-233. doi: 10.1016/j.agsy.2016.05.003.

Hamunyela, E., Reiche, J., Verbesselt, J., \& Herold, M. (2017). Using space-time features to improve detection of forest disturbances from Landsat time series. Remote Sensing, 9, 1-17. doi: 10.3390/rs9060515.

Hamunyela, E., Verbesselt, J., Bruin, S., \& Herold, M. (2016a). Monitoring deforestation at sub-annual scales as extreme events in landsat data cubes. Remote Sensing, 8, 1-16. doi: $10.3390 /$ rs8080651.

Hamunyela, E., Verbesselt, J., \& Herold, M. (2016b). Using spatial context to improve early detection of deforestation from Landsat time series. Remote Sensing of Environment, 172, 126-138. doi: 10.1016/j.rse.2015.11.006.

Hansen, M., Potapov, P., Moore, R., Hancher, M., Turubanova, S., Tyukavina, A., Thau, D., Stehman, S., Goetz, S., Loveland, T., Kommareddy, A., Egorov, A., Chini, L., Justice, C., \& Townshend, J. (2013). High-resolution global maps of 21st-century forest cover change. Science, 342, 850-853. doi: 10.1126/science.1244693.

Harvey, C., Chacón, M., Donatti, C., Garen, E., Hannah, L., Andrade, A., Bede, L., Brown, D., Calle, A., Chará, J., Clement, C., Gray, E., Hoang, M., Minang, P., Rodríguez, A., Seeberg-Elverfeldt, C., Semroc, B., Shames, S., Smukler, S., Somarriba, E., Torquebiau, E., van Etten, J., \& Wollenberg, E. (2014a). Climate-Smart Landscapes: Opportunities and Challenges for Integrating Adaptation and Mitigation in Tropical Agriculture. Conservation Letters, 7, 77-90. doi: 10.1111/conl.12066.

Harvey, C., Rakotobe, Z., Rao, N., Dave, R., Razafimahatratra, H., Rabarijohn, R., Rajaofara, H., \& MacKinnon, J. (2014b). Extreme vulnerability of smallholder farmers to agricultural risks and climate change in Madagascar. Philosophical Transactions of the Royal Society B: Biological Sciences, 369. doi: 10.1098/rstb.2013.0089.

Havlík, P., Valin, H., Herrero, M., Obersteiner, M., Schmid, E., Rufino, M., Mosnier, A., Thornton, P., Böttcher, H., Conant, R., Frank, S., Fritz, S., Fuss, S., Kraxner, F., \& Notenbaert, A. (2014). Climate change mitigation through livestock system transitions. Proceedings of the National Academy of Sciences of the United States of America, 111, 3709-3714. doi: 10.1073/pnas.1308044111.

Hengl, T., Heuvelink, G., Kempen, B., Leenaars, J., Walsh, M., Shepherd, K., Sila, A., 
MacMillan, R., De, J., Tamene, L., \& Tondoh, J. (2015). Mapping soil properties of Africa at $250 \mathrm{~m}$ resolution: Random forests significantly improve current predictions. PLoS ONE, 10. doi: 10.1371/journal.pone.0125814.

Herrero, M., Havlík, P., Valin, H., Notenbaert, A., Rufino, M., Thornton, P., Blümmel, M., Weiss, F., Grace, D., \& Obersteiner, M. (2013). Biomass use, production, feed efficiencies, and greenhouse gas emissions from global livestock systems. Proceedings of the National Academy of Sciences of the United States of America, 110, 20888-20893. doi: $10.1073 /$ pnas.1308149110.

Herrero, M., Henderson, B., Havlík, P., Thornton, P., Conant, R., Smith, P., Wirsenius, S., Hristov, A., Gerber, P., Gill, M., Butterbach-Bahl, K., Valin, H., Garnett, T., \& Stehfest, E. (2016). Greenhouse gas mitigation potentials in the livestock sector. Nature Climate Change, 6, 452-461. doi: 10.1038/nclimate2925.

Herrero, M., Thornton, P., Bernués, A., Baltenweck, I., Vervoort, J., van de Steeg, J., Makokha, S., van Wijk, M., Karanja, S., Rufino, M., \& Staal, S. (2014). Exploring future changes in smallholder farming systems by linking socio-economic scenarios with regional and household models. Global Environmental Change, 24, 165-182. doi: 10.1016/j.gloenvcha.2013.12.008.

Hijmans, R. (2016). Raster: Geographic Data Analysis and Modeling. URL: https : //CRAN.R-project.org/package=raster [Accessed: 2016-08-27].

Hijmans, R., Cameron, S., Parra, J., Jones, P., \& Jarvis, A. (2005). Very high resolution interpolated climate surfaces for global land areas. International Journal of Climatology, 25, 1965-1978. doi: 10.1002/joc.1276.

Hillocks, R. (2014). Addressing the Yield Gap in Sub-Saharan Africa. Outlook on Agriculture, 43, 85-90. doi: 10.5367/oa.2014.0163.

Hosonuma, N., Herold, M., De Sy, V., De Fries, R., Brockhaus, M., Verchot, L., Angelsen, A., \& Romijn, E. (2012). An assessment of deforestation and forest degradation drivers in developing countries. Environmental Research Letters, 7, 044009. doi: 10.1088/17489326/7/4/044009.

Hou, Y., Velthof, G., \& Oenema, O. (2015). Mitigation of ammonia, nitrous oxide and methane emissions from manure management chains: A meta-analysis and integrated assessment. Global Change Biology, 21, 1293-1312. doi: 10.1111/gcb.12767.

Hristov, A., Oh, J., Firkins, J., Dijkstra, J., Kebreab, E., Waghorn, G., Makkar, H., Adesogan, A., Yang, W., Lee, C., Gerber, P., Henderson, B., \& Tricarico, J. (2013a). SPECIAL TOPICS-Mitigation of methane and nitrous oxide emissions from animal operations: I. A review of enteric methane mitigation options. Journal of Animal Science, 91, 5045-5069. doi: 10.2527/jas2013-6583.

Hristov, A., Ott, T., Tricarico, J., Rotz, A., Waghorn, G., Adesogan, A., Dijkstra, J., Montes, F., Oh, J., Kebreab, E., Oosting, S., Gerber, P., Henderson, B., Makkar, H., 
\& Firkins, J. (2013b). SPECIAL TOPICS-Mitigation of methane and nitrous oxide emissions from animal operations: III. A review of animal management mitigation options. Journal of Animal Science, 91, 5095-5113. doi: 10.2527/jas.2013-6585.

Hurteau, M. D., Koch, G. W., \& Hungate, B. A. (2008). Carbon protection and fire risk reduction: Toward a full accounting of forest carbon offsets. Frontiers in Ecology and the Environment, 6, 493-498. doi: 10.1890/070187.

Imo, M. (2012). Forest Degradation in Kenya: Impacts of Social, Economic and Political Transitions. In J. Adoyo, \& I. Cole (Eds.), Kenya: Political, Social and Environmental Issues (pp. 1-38). New York, NY (USA): Nova Science Publishers, Inc.

IPCC (2006). IPCC Guidelines for National Greenhouse Gas Inventories, Prepared by the National Greenhouse Gas Inventories Programme. Japan: The Intergovernmental Panel on Climate Change. URL: https://www.ipcc-nggip.iges.or.jp/public/2006gl/ [Accessed: 2016-04-27].

IPCC (2014). Climate Change 2014 - Impacts, Adaptation and Vulnerability: Part A: Global and Sectoral Aspects: Working Group II Contribution to the IPCC Fifth Assessment Report. New York, NY (USA). URL: http://www.ipcc.ch/report/ar5/wg2/ [Accessed: 2016-02-21].

Ishizaka, A., \& Labib, A. (2011). Review of the main developments in the analytic hierarchy process. Expert Systems with Applications, 38, 14336-14345. doi: 10.1016/j.eswa.2011.04.143.

Jacobs, S., Breuer, L., Butterbach-Bahl, K., Pelster, D., \& Rufino, M. (2017). Land use affects total dissolved nitrogen and nitrate concentrations in tropical montane streams in Kenya. Science of the Total Environment, 603-604, 519-532. doi: 10.1016/j.scitotenv.2017.06.100.

Jadin, I., Meyfroidt, P., \& Lambin, E. F. (2016). International trade, and land use intensification and spatial reorganization explain Costa Rica's forest transition. Environmental Research Letters, 11, 035005. doi: 10.1088/1748-9326/11/3/035005.

Jarvis, A., Reuter, H., Nelson, E., \& Guevara, E. (2008). Hole-Filled SRTM for the Globe Version 4. Technical Report. URL: mfkp.org/INRMM/article/14258097 [Accessed: 2016-09-14].

Jin, S., \& Sader, S. (2005). Comparison of time series tasseled cap wetness and the normalized difference moisture index in detecting forest disturbances. Remote Sensing of Environment, 94, 364-372. doi: 10.1016/j.rse.2004.10.012.

Kaimowitz, D., \& Angelsen, A. (2008). Will Livestock Intensification Help Save Latin America's Tropical Forests? Journal of Sustainable Forestry, 27, 6-24. doi: $10.1080 / 10549810802225168$.

Kangas, A., Saarinen, N., Saarikoski, H., Leskinen, L., Hujala, T., \& Tikkanen, J. (2010). 
Stakeholder perspectives about proper participation for Regional Forest Programmes in Finland. Forest Policy and Economics, 12, 213-222. doi: 10.1016/j.forpol.2009.10.006.

Kariuki, J., Gitau, G., Gachuiri, C., Tamminga, S., \& Muia, J. (1999). Effect of supplementing napier grass with desmodium and lucerne on DM, CP and NDF intake and weight gains in dairy heifers. Livestock Production Science, 60, 81-88. doi: 10.1016/S0301-6226(99)00035-4.

Kassambara, A. (2017). Practical Guide to Cluster Analysis in R: Unsupervised Machine Learning. (1st ed.). STHDA.

Kategile, J., Said, A., \& Dzowela, B. (1987). Animal Feed Resources for Small-Scale Livestock Producers. Technical Report International Laboratory for Research on Animal Diseases, International Development Research Centre Nairobi (Kenya). URL: https://cgspace.cgiar.org/bitstream/handle/10568/49993/x5548e.pdf [Accessed: 2016-04-06].

Katiku, P., Gachuiri, C., \& Mbugua, P. (2011). Characterization of Dairy Cattle Farming in Mbeere District of Eastern Kenya. Livestock Research for Rural Development, 23. URL: http://www. lrrd.org/lrrd23/11/kati23236.htm.

Keeney, R. L. (2002). Common Mistakes in Making Value Trade-Offs. Operations Research, 50, 935-945. doi: 10.1287/opre.50.6.935.357.

Kiboi, M., Ngetich, K., Diels, J., Mucheru-Muna, M., Mugwe, J., \& Mugendi, D. (2017). Minimum tillage, tied ridging and mulching for better maize yield and yield stability in the Central Highlands of Kenya. Soil and Tillage Research, 170, 157-166. doi: 10.1016/j.still.2017.04.001.

Kim, D.-G., Thomas, A. D., Pelster, D., Rosenstock, T. S., \& Sanz-Cobena, A. (2016). Greenhouse gas emissions from natural ecosystems and agricultural lands in subSaharan Africa: Synthesis of available data and suggestions for further research. Biogeosciences, 13, 4789-4809. doi: 10.5194/bg-13-4789-2016.

Kinyanjui, M. (2011). NDVI-based vegetation monitoring in Mau forest complex, Kenya. African Journal of Ecology, 49, 165-174. doi: 10.1111/j.1365-2028.2010.01251.x.

Knapp, J., Laur, G., Vadas, P., Weiss, W., \& Tricarico, J. (2014). Invited review: Enteric methane in dairy cattle production: Quantifying the opportunities and impact of reducing emissions. Journal of Dairy Science, 97, 3231-3261. doi: 10.3168/jds.2013-7234.

Kreidenweis, U., Humpenöder, F., Kehoe, L., Kuemmerle, T., Bodirsky, B., LotzeCampen, H., \& Popp, A. (2018). Pasture intensification is insufficient to relieve pressure on conservation priority areas in open agricultural markets. Global Change Biology, 24, 3199-3213. doi: 10.1111/gcb.14272.

Krellenberg, K., \& Barth, K. (2014). Inter- and transdisciplinary research for planning climate change adaptation responses: The example of Santiago de Chile. Interdisciplinary 
Science Reviews, 39, 360-375. doi: 10.1179/0308018814Z.00000000097.

Kumar, S., Puniya, A., Puniya, M., Dagar, S., Sirohi, S., Singh, K., \& Griffith, G. (2009). Factors affecting rumen methanogens and methane mitigation strategies. World Journal of Microbiology and Biotechnology, 25, 1557-1566. doi: 10.1007/s11274-009-0041-3.

Lal, R., Delgado, J., Groffman, P., Millar, N., Dell, C., \& Rotz, A. (2011). Management to mitigate and adapt to climate change. Journal of Soil and Water Conservation, 66, 276-282. doi: 10.2489/jswc.66.4.276.

Lee, E., \& Forthofer, R. (2006). Strategies for Variance Estimation. In Analyzing Complex Survey Data. Thousand Oaks (USA): Sage Publications volume Second Edition of Quantitative Applications in the Social Sciences.

Lin, L., Sills, E., \& Cheshire, H. (2014). Targeting areas for Reducing Emissions from Deforestation and forest Degradation (REDD+) projects in Tanzania. Global Environmental Change, 24, 277-286. doi: 10.1016/j.gloenvcha.2013.12.003.

Linares, P., \& Romero, C. (2002). Aggregation of preferences in an environmental economics context: A goal-programming approach. Omega, 30, 89-95. doi: 10.1016/S03050483(01)00059-7.

Lipper, L., Neves, B., Wilkes, A., Tennigkeit, T., Gerber, P., Henderson, B., Branca, G., \& Mann, W. (2011). Climate Change Mitigation Finance for Smallholder Agriculture. A Guide Book to Harvesting Soil Carbon Sequestration Benefits. Technical Report Food and Agriculture Organization of the United Nations (FAO) Rome (Italy). URL: https://searchworks.stanford.edu/view/10776009 [Accessed: 2015-10-29].

Lipper, L., Thornton, P., Campbell, B., Baedeker, T., Braimoh, A., Bwalya, M., Caron, P., Cattaneo, A., Garrity, D., Henry, K., Hottle, R., Jackson, L., Jarvis, A., Kossam, F., Mann, W., McCarthy, N., Meybeck, A., Neufeldt, H., Remington, T., Sen, P., Sessa, R., Shula, R., Tibu, A., \& Torquebiau, E. (2014). Climate-smart agriculture for food security. Nature Climate Change, 4, 1068-1072. doi: 10.1038/nclimate2437.

López-Ballesteros, A., Beck, J., Bombelli, A., Grieco, E., Lorencová, E. K., Merbold, L., Brümmer, C., Hugo, W., Scholes, R. B., Vačkář, D., Vermeulen, A., Acosta, M., Butterbach-Bahl, K., Helmschrot, J., Kim, D.-G., Jones, M., Jorch, V., Pavelka, M., Skjelvan, I., \& Saunders, M. (2018). Towards a feasible and representative pan-African Research Infrastructure network for GHG observations. Environmental Research Letters, . doi: 10.1088/1748-9326/aad66c.

Lowder, S., Skoet, J., \& Sing, S. (2014). What Do We Really Know about the Number and Distribution of Farms and Family Farms in the World? Background Paper for The State of Food and Agriculture 2014. Technical Report ESA Working Paper No. 14-02 Food and Agriculture Organization of the United Nations (FAO) Rome (Italy). URL: http://www.fao.org/docrep/019/i3729e/i3729e.pdf [Accessed: 2017-04-21].

Lukuyu, B., Franzel, S., Ongadi, P., \& Duncan, A. (2011). Livestock feed re- 
sources: Current production and management practices in central and northern rift valley provinces of Kenya. Livestock Research for Rural Development, 23. URL: http://www.lrrd.org/lrrd23/5/luku23112.htm.

Lukuyu, B. A., Gachuiri, C. K., Lukuyu, M. N., Lusweti, C., \& Mwendia, S. (2012). Feeding Dairy Cattle in East Africa. East Africa Dairy Development Project. URL: https://cgspace.cgiar.org/handle/10568/16873 [Accessed: 2016-10-07].

Makoni, N., Mwai, R., Redda, T., van der Zijpp, A., \& van der Lee, J. (2014). White Gold : Opportunities for Dairy Sector Development Collaboration in East Africa. Technical Report Centre for Development Innovation Wageningen (The Netherlands). URL: https://edepot.wur.nl/307878 [Accessed: 2016-03-09].

Maleko, D., Msalya, G., Mwilawa, A., Pasape, L., \& Mtei, K. (2018). Smallholder dairy cattle feeding technologies and practices in Tanzania: Failures, successes, challenges and prospects for sustainability. International Journal of Agricultural Sustainability, 16, 201-213. doi: 10.1080/14735903.2018.1440474.

Malla, M., Bruce, N., Bates, E., \& Rehfuess, E. (2011). Applying global costbenefit analysis methods to indoor air pollution mitigation interventions in Nepal, Kenya and Sudan: Insights and challenges. Energy Policy, 39, 7518-7529. doi: 10.1016/j.enpol.2011.06.031.

Mbow, C., Smith, P., Skole, D., Duguma, L., \& Bustamante, M. (2014). Achieving mitigation and adaptation to climate change through sustainable agroforestry practices in africa. Current Opinion in Environmental Sustainability, 6, 8-14. doi: 10.1016/j.cosust.2013.09.002.

McDermott, J., Staal, S., Freeman, H., Herrero, M., \& Van, d. S. (2010). Sustaining intensification of smallholder livestock systems in the tropics. Livestock Science, 130, 95-109. doi: 10.1016/j.livsci.2010.02.014.

Meyfroidt, P. (2018). Trade-offs between environment and livelihoods: Bridging the global land use and food security discussions. Global Food Security, 16, 9-16. doi: 10.1016/j.gfs.2017.08.001.

Meyfroidt, P., Carlson, K., Fagan, M., Gutiérrez-Vélez, V., Macedo, M., Curran, L., Defries, R., Dyer, G., Gibbs, H., Lambin, E., Morton, D., \& Robiglio, V. (2014). Multiple pathways of commodity crop expansion in tropical forest landscapes. Environmental Research Letters, 9. doi: 10.1088/1748-9326/9/7/074012.

Minang, P., \& van Noordwijk, M. (2013). Design challenges for achieving reduced emissions from deforestation and forest degradation through conservation: Leveraging multiple paradigms at the tropical forest margins. Land Use Policy, 31, 61-70. doi: 10.1016/j.landusepol.2012.04.025.

Mitchell, A., Rosenqvist, A., \& Mora, B. (2017). Current remote sensing approaches to monitoring forest degradation in support of countries measurement, reporting and 
verification (MRV) systems for REDD+. Carbon Balance and Management, 12, 1-22. doi: 10.1186/s13021-017-0078-9.

Molua, E., Benhin, J., Kabubo-Mariara, J., Ouedraogo, M., \& El-Marsafawy, S. (2010). Global climate change and vulnerability of African agriculture: Implications for resilience and sustained productive capacity. Quarterly Journal of International Agriculture, 49, 183-211.

Monfreda, C., Ramankutty, N., \& Foley, J. (2008). Farming the planet: 2. Geographic distribution of crop areas, yields, physiological types, and net primary production in the year 2000. Global Biogeochemical Cycles, 22, 1-19. doi: 10.1029/2007GB002947.

Montes, F., Meinen, R., Dell, C., Rotz, A., Hristov, A., Oh, J., Waghorn, G., Gerber, P., Henderson, B., Makkar, H., \& Dijkstra, J. (2014). SPECIAL TOPICS-Mitigation of methane and nitrous oxide emissions from animal operations: II. A review of manure management mitigation options. Journal of Animal Science, 91, 5070-5094. doi: 10.2527/jas.2013-6584.

Moran, J. (2005). Tropical Dairy Farming: Feeding Management for Small Holder Dairy Farmers in the Humid Tropics. Landlinks Press.

Mosadeghi, R., Warnken, J., Mirfenderesk, H., \& Tomlinson, R. (2013). Spatial uncertainty analysis in coastal land use planning: A case study at Gold Coast, Australia. Journal of Coastal Research, (pp. 1003-1008). doi: 10.2112/SI65-170.

Mottet, A., Henderson, B., Opio, C., Falcucci, A., Tempio, G., Silvestri, S., Chesterman, S., \& Gerber, P. (2016). Climate change mitigation and productivity gains in livestock supply chains: Insights from regional case studies. Regional Environmental Change, (pp. 1-13). doi: 10.1007/s10113-016-0986-3.

Mucheru-Muna, M., Mugendi, D., Kung'u, J., Mugwe, J., \& Bationo, A. (2007). Effects of organic and mineral fertilizer inputs on maize yield and soil chemical properties in a maize cropping system in Meru South District, Kenya. Agroforestry Systems, 69, 189-197. doi: 10.1007/s10457-006-9027-4.

Mucheru-Muna, M., Mugendi, D., Pypers, P., Mugwe, J., Kung'u, J., Vanlauwe, B., \& Merckx, R. (2014). Enhancing maize productivity and profitability using organic inputs and mineral fertilizer in central Kenya small-hold farms. Experimental Agriculture, 50, 250-269. doi: 10.1017/S0014479713000525.

Mueller, N. D., Gerber, J. S., Johnston, M., Ray, D. K., Ramankutty, N., \& Foley, J. A. (2012). Closing yield gaps through nutrient and water management. Nature, 490, 254-257. doi: 10.1038/nature11420.

Muia, J., Tamminga, S., Mbugua, P., \& Kariuki, J. (2001). Effect of supplementing napier grass (Pennisetum purpureum) with poultry litter and sunflower meal based concentrates on feed intake and rumen fermentation in Friesian steers. Animal Feed Science and Technology, 92, 113-126. doi: 10.1016/S0377-8401(01)00221-8. 
Muriuki, H. (2011). Dairy Development in Kenya. Technical Report Food and Agriculture Organization of the United Nations Rome, Italy. URL: www.fao.org/3/a-al745e.pdf [Accessed: 2016-06-14].

Mutoko, M., Hein, L., \& Shisanya, C. (2015). Tropical forest conservation versus conversion trade-offs: Insights from analysis of ecosystem services provided by Kakamega rainforest in Kenya. Ecosystem Services, 14, 1-11. doi: 10.1016/j.ecoser.2015.03.003.

Mutuo, P., Cadisch, G., Albrecht, A., Palm, C., \& Verchot, L. (2005). Potential of agroforestry for carbon sequestration and mitigation of greenhouse gas emissions from soils in the tropics. Nutrient Cycling in Agroecosystems, 71, 43-54. doi: 10.1007/s10705004-5285-6.

Nachtergaele, F., van Velthuizen, H. T., Verelst, L., Wiberg, D., Batjes, N., Dijkshoorn, J. A., van Engelen, V., Fischer, G., Jones, A., Montanarella, L., Petri, M., Prieler, S., Teixeira, E., \& Shi, X. (2012). Harmonized World Soil Database (Version 1.2). Technical Report FAO, IIASA, ISRIC, ISSCAS, JRC Rome (Italy), Laxenburg (Austria). URL: http://www.fao.org/soils-portal/en/ [Accessed: 2014-06-11].

Ng'Eno, J. K. (1996). Kenya: Country Report to the FAO International Technical Conference on Plant Genetic Resources. Technical Report Food and Agriculture Organization of the United Nations (FAO) Leipzig (Germany). URL: www.fao.org/pgrfa-gpa-archive/ken/kenya.pdf [Accessed: 2016-08-16].

Niles, M. T., \& Salerno, J. D. (2018). A cross-country analysis of climate shocks and smallholder food insecurity. PLOS ONE, 13, e0192928. doi: 10.1371/journal.pone.0192928.

Njarui, D., Gatheru, M., Wambua, J., Nguluu, S., Mwangi, D., \& Keya, G. (2011). Feeding management for dairy cattle in smallholder farming systems of semi-arid tropical Kenya. Livestock Research for Rural Development, 23. URL: http://www . Irrd.org/lrrd23/5/njar23111.htm.

Nordström, E.-M., Eriksson, L., \& Öhman, K. (2010). Integrating multiple criteria decision analysis in participatory forest planning: Experience from a case study in northern Sweden. Forest Policy and Economics, 12, 562-574. doi: 10.1016/j.forpol.2010.07.006.

Nordström, E.-M., Öhman, K., \& Eriksson, L. (2012). Approaches for Aggregating Preferences in Participatory Forest Planning - An Experimental Study. The Open Forest Science Journal, 5, 23-32. doi: 10.2174/1874398601205010023.

Notenbaert, A., Pfeifer, C., Silvestri, S., \& Herrero, M. (2017). Targeting, out-scaling and prioritising climate-smart interventions in agricultural systems: Lessons from applying a generic framework to the livestock sector in sub-Saharan Africa. Agricultural Systems, 151, 153-162. doi: 10.1016/j.agsy.2016.05.017.

Odera, M., M., Thomas, T. S., Waithaka, M., \& Kyotalimye, M. (2013). Kenya. In M. Waithaka, G. C. Nelson, T. S. Thomas, \& M. Kyotalimye (Eds.), East African Agriculture and Climate Change: A Comprehensive Analysis (pp. 183-212). Washing- 
ton, DC (USA): International Food Policy Research Institute.

Olang, L., Kundu, P., Bauer, T., \& Fürst, J. (2011). Analysis of spatio-temporal land cover changes for hydrological impact assessment within the Nyando River Basin of Kenya. Environmental Monitoring and Assessment, 179, 389-401. doi: 10.1007/s10661-0101743-6.

O'Mara, F. (2011). The significance of livestock as a contributor to global greenhouse gas emissions today and in the near future. Animal Feed Science and Technology, 166-167, 7-15. doi: 10.1016/j.anifeedsci.2011.04.074.

Ortiz-Gonzalo, D., Vaast, P., Oelofse, M., de, N., Albrecht, A., \& Rosenstock, T. (2017). Farm-scale greenhouse gas balances, hotspots and uncertainties in smallholder croplivestock systems in Central Kenya. Agriculture, Ecosystems and Environment, 248, 58-70. doi: 10.1016/j.agee.2017.06.002.

Owen, E., Smith, T., \& Makkar, H. (2012). Successes and failures with animal nutrition practices and technologies in developing countries: A synthesis of an FAO e-conference. Animal Feed Science and Technology, 174, 211-226. doi: 10.1016/j.anifeedsci.2012.03.010.

Owino, J., Owido, S., \& Chemelil, M. (2006). Nutrients in runoff from a clay loam soil protected by narrow grass strips. Soil and Tillage Research, 88, 116-122. doi: 10.1016/j.still.2005.05.007.

Patt, A., Tadross, M., Nussbaumer, P., Asante, K., Metzger, M., Rafael, J., Goujon, A., \& Brundrit, G. (2010). Estimating least-developed countries' vulnerability to climate-related extreme events over the next 50 years. Proceedings of the $\mathrm{Na}$ tional Academy of Sciences of the United States of America, 10\%, 1333-1337. doi: 10.1073/pnas.0910253107.

Pearson, T., Brown, S., Murray, L., \& Sidman, G. (2017). Greenhouse gas emissions from tropical forest degradation: An underestimated source. Carbon Balance and Management, 12, 1-11. doi: 10.1186/s13021-017-0072-2.

Pelster, D., Gisore, B., Koske, J., Goopy, J., Korir, D., Rufino, M., \& ButterbachBahl, K. (2016). Methane and nitrous oxide emissions from cattle excreta on an East African grassland. Journal of Environmental Quality, 45, 1531-1539. doi: 10.2134/jeq2016.02.0050.

Pelster, D., Rufino, M., Rosenstock, T., Mango, J., Saiz, G., Diaz-Pines, E., Baldi, G., \& Butterbach-Bahl, K. (2017). Smallholder farms in eastern African tropical highlands have low soil greenhouse gas fluxes. Biogeosciences, 14, 187-202. doi: 10.5194/bg-14$187-2017$.

Podsakoff, P., MacKenzie, S., Lee, J.-Y., \& Podsakoff, N. (2003). Common Method Biases in Behavioral Research: A Critical Review of the Literature and Recommended Remedies. Journal of Applied Psychology, 88, 879-903. doi: 10.1037/0021-9010.88.5.879. 
Potter, P., Ramankutty, N., Bennett, E., \& Donner, S. (2010). Characterizing the spatial patterns of global fertilizer application and manure production. Earth Interactions, 14 . doi: $10.1175 / 2009 \mathrm{EI} 288.1$.

Preston, B., Westaway, R., \& Yuen, E. (2011). Climate adaptation planning in practice: An evaluation of adaptation plans from three developed nations. Mitigation and Adaptation Strategies for Global Change, 16, 407-438. doi: 10.1007/s11027-010-9270-x.

R Core Team (2016). R: A language and environment for statistical computing. R Foundation for Statistical Computing. URL: https://www.R-project .org/ [Accessed: 2016-10-15].

Rattalino Edreira, J. I., Guilpart, N., Sadras, V., Cassman, K. G., van Ittersum, M. K., Schils, R. L. M., \& Grassini, P. (2018). Water productivity of rainfed maize and wheat: A local to global perspective. Agricultural and Forest Meteorology, 259, 364-373. doi: 10.1016/j.agrformet.2018.05.019.

Reed, J., Vianen, J. V., Deakin, E. L., Barlow, J., \& Sunderland, T. (2016). Integrated landscape approaches to managing social and environmental issues in the tropics: Learning from the past to guide the future. Global Change Biology, 22, 2540-2554. doi: $10.1111 /$ gcb.13284.

Reiche, J., Verhoeven, R., Verbesselt, J., Hamunyela, E., Wielaard, N., \& Herold, M. (2018). Characterizing Tropical Forest Cover Loss Using Dense Sentinel-1 Data and Active Fire Alerts. Remote Sensing, 10, 1-18. doi: 10.3390/rs10050777.

Richards, S., VanLeeuwen, J., Shepelo, G., Gitau, G., Wichtel, J., Kamunde, C., \& Uehlinger, F. (2016). Randomized controlled trial on impacts of dairy meal feeding interventions on early lactation milk production in smallholder dairy farms of Central Kenya. Preventive Veterinary Medicine, 125, 46-53. doi: 10.1016/j.prevetmed.2016.01.006.

Robinson, T., Thornton, P., Franceschini, G., Kruska, R., Chiozza, F., Notenbaert, A., Cecchi, G., Herrero, M., Epprecht, M., Fritz, S., You, L., Conchedda, G., \& See, L. (2011). Global Livestock Production Systems. Technical Report Food and Agriculture Organization of the United Nations, International Livestock Research Institute Rome, Italy. URL: http://www.fao.org/docrep/014/i2414e/i2414e.pdf [Accessed: 201405-25].

Robinson, T., William Wint, G., Conchedda, G., Van Boeckel, T., Ercoli, V., Palamara, E., Cinardi, G., D'Aietti, L., Hay, S., \& Gilbert, M. (2014). Mapping the global distribution of livestock. PLOS ONE, 9. doi: 10.1371/journal.pone.0096084.

Romero, C., \& Rehman, T. (Eds.) (2003). Multiple Criteria Analysis for Agricultural Decisions volume 11 of Developments in Agricultural Economics. Amsterdam (the Netherlands): Elsevier.

Rosenstock, T., Mpanda, M., Pelster, D., Butterbach-Bahl, K., Rufino, M., Thiong'o, M., Mutuo, P., Abwanda, S., Rioux, J., Kimaro, A., \& Neufeldt, H. (2016). Greenhouse gas 
fluxes from agricultural soils of Kenya and Tanzania. Journal of Geophysical Research G: Biogeosciences, 121, 1568-1580. doi: 10.1002/2016JG003341.

Rosenstock, T., Mpanda, M., Rioux, J., Aynekulu, E., Kimaro, A., Neufeldt, H., Shepherd, K., \& Luedeling, E. (2014). Targeting conservation agriculture in the context of livelihoods and landscapes. Agriculture, Ecosystems and Environment, 187, 47-51. doi: 10.1016/j.agee.2013.11.011.

Rufino, M., Atzberger, C., Baldi, G., Butterbach-Bahl, K., Rosenstock, T., \& Stern, D. (2016). Targeting landscapes to identify mitigation options in smallholder agriculture. In T. Rosenstock, M. Rufino, K. Butterbach-Bahl, E. Wollenberg, \& M. Richards (Eds.), Methods for Measuring Greenhouse Gas Balances and Evaluating Mitigation Options in Smallholder Agriculture. Springer.

Rufino, M., Brandt, P., Herrero, M., \& Butterbach-Bahl, K. (2014). Reducing uncertainty in nitrogen budgets for African livestock systems. Environmental Research Letters, 9. doi: 10.1088/1748-9326/9/10/105008.

Rufino, M., Herrero, M., Van Wijk, M., Hemerik, L., De Ridder, N., \& Giller, K. (2009). Lifetime productivity of dairy cows in smallholder farming systems of the central highlands of Kenya. Animal, 3, 1044-1056. doi: 10.1017/S1751731109004248.

Rufino, M., Thornton, P., Ng'ang'a, S., Mutie, I., Jones, P., van, W., \& Herrero, M. (2013). Transitions in agro-pastoralist systems of East Africa: Impacts on food security and poverty. Agriculture, Ecosystems and Environment, 179, 215-230. doi: 10.1016/j.agee.2013.08.019.

Rufino, M., Tittonell, P., van, W., Castellanos-Navarrete, A., Delve, R., de, R., \& Giller, K. (2007). Manure as a key resource within smallholder farming systems: Analysing farm-scale nutrient cycling efficiencies with the NUANCES framework. Livestock Science, 112, 273-287. doi: 10.1016/j.livsci.2007.09.011.

Rusinamhodzi, L., van, W., Corbeels, M., Rufino, M., \& Giller, K. (2015). Maize crop residue uses and trade-offs on smallholder crop-livestock farms in Zimbabwe: Economic implications of intensification. Agriculture, Ecosystems and Environment, 214, 31-45. doi: $10.1016 /$ j.agee.2015.08.012.

Ryan, S., Palace, M., Hartter, J., Diem, J., Chapman, C., \& Southworth, J. (2017). Population pressure and global markets drive a decade of forest cover change in Africa's Albertine Rift. Applied Geography, 81, 52-59. doi: 10.1016/j.apgeog.2017.02.009.

Saaty, T. (1977). A scaling method for priorities in hierarchical structures. Journal of Mathematical Psychology, 15, 234-281. doi: 10.1016/0022-2496(77)90033-5.

Saaty, T. (1994). Highlights and critical points in the theory and application of the Analytic Hierarchy Process. European Journal of Operational Research, 74, 426-447. doi: 10.1016/0377-2217(94)90222-4. 
Sae-Lim, P., Komen, H., Kause, A., van Arendonk, J., Barfoot, A., Martin, K., \& Parsons, J. (2012). Defining desired genetic gains for rainbow trout breeding objective using analytic hierarchy process. Journal of Animal Science, 90, 1766-1776. doi: $10.2527 /$ jas.2011-4267.

Samojlik, T., Fedotova, A., \& Kuijper, D. (2016). Transition from traditional to modern forest management shaped the spatial extent of cattle pasturing in Białowieża Primeval Forest in the nineteenth and twentieth centuries. Ambio, 45, 904-918. doi: 10.1007/s13280-016-0795-4.

Sanchez, P., Palm, C., \& Buol, S. (2003). Fertility capability soil classification: A tool to help assess soil quality in the tropics. Geoderma, 114, 157-185. doi: 10.1016/S00167061(03)00040-5.

Sassen, M., Sheil, D., Giller, K., \& ter, B. (2013). Complex contexts and dynamic drivers: Understanding four decades of forest loss and recovery in an East African protected area. Biological Conservation, 159, 257-268. doi: 10.1016/j.biocon.2012.12.003.

Scherr, S. J., Shames, S., \& Friedman, R. (2012). From climate-smart agriculture to climate-smart landscapes. Agriculture \& Food Security, 1, 12. doi: 10.1186/2048-7010$1-12$.

Schroeder, W., Oliva, P., Giglio, L., \& Csiszar, I. A. (2014). The New VIIRS 375m active fire detection data product: Algorithm description and initial assessment. Remote Sensing of Environment, 143, 85-96. doi: 10.1016/j.rse.2013.12.008.

Schulz, K., Voigt, K., Beusch, C., Almeida-Cortez, J. S., Kowarik, I., Walz, A., \& Cierjacks, A. (2016). Grazing deteriorates the soil carbon stocks of Caatinga forest ecosystems in Brazil. Forest Ecology and Management, 367, 62-70. doi: 10.1016/j.foreco.2016.02.011.

Smith, P., Clark, H., Dong, H., Elsiddig, E. A., Haberl, H., Harper, R., House, J., Jafari, M., Masera, O., Mbow, C., Ravindranath, N. H., Rice, C. W., do Abad, C. R., Romanovskaya, A., Sperling, F., \& Tubiello, F. (2014). Chapter 11 - Agriculture, forestry and other land use (AFOLU). In Climate Change 2014: Mitigation of Climate Change. IPCC Working Group III Contribution to AR5. Cambridge University Press.

Smith, P., Haberl, H., Popp, A., Erb, K.-H., Lauk, C., Harper, R., Tubiello, F., De Siqueira Pinto, A., Jafari, M., Sohi, S., Masera, O., Böttcher, H., Berndes, G., Bustamante, M., Ahammad, H., Clark, H., Dong, H., Elsiddig, E., Mbow, C., Ravindranath, N., Rice, C., Robledo Abad, C., Romanovskaya, A., Sperling, F., Herrero, M., House, J., \& Rose, S. (2013). How much land-based greenhouse gas mitigation can be achieved without compromising food security and environmental goals? Global Change Biology, 19, 2285-2302. doi: 10.1111/gcb.12160.

Soren, N., Sejian, V., \& Malik, P. (2015). Enteric Methane emission under different feeding systems. In V. Sejian, J. Gaughan, L. Baumgard, \& Prasad (Eds.), Climate 
Change Impact on Livestock: Adaptation and Mitigation. New Delhi, Heidelberg, New York, Dordrecht, London: Springer.

Stares, J., Said, A., \& Kategile, J. (1991). The Complementarity of Feed Resources for Animal Production in Africa. Technical Report ILCA (International Livestock Centre for Africa) Addis Ababa (Ethiopia). URL: https://cgspace.cgiar.org/handle/10568/49683 [Accessed: 2016-09-17].

Styles, D., Gonzalez-Mejia, A., Moorby, J., Foskolos, A., \& Gibbons, J. (2018). Climate mitigation by dairy intensification depends on intensive use of spared grassland. Global Change Biology, 24, 681-693. doi: 10.1111/gcb.13868.

Tammi, I., \& Kalliola, R. (2014). Spatial MCDA in marine planning: Experiences from the Mediterranean and Baltic Seas. Marine Policy, 48, 73-83. doi: 10.1016/j.marpol.2014.03.015.

ten Broeke, G., van Voorn, G., \& Ligtenberg, A. (2016). Which sensitivity analysis method should i use for my agent-based model? Journal of Artificial Societies and Social Simulation, 19. doi: 10.18564/jasss.2857.

Thornton, P., Ericksen, P., Herrero, M., \& Challinor, A. (2014). Climate variability and vulnerability to climate change: A review. Global Change Biology, 20, 3313-3328. doi: $10.1111 /$ gcb.12581.

Thornton, P., \& Herrero, M. (2010). Potential for reduced methane and carbon dioxide emissions from livestock and pasture management in the tropics. Proceedings of the National Academy of Sciences of the United States of America, 107, 19667-19672. doi: 10.1073/pnas.0912890107.

Tittonell, P., Rufino, M., Janssen, B., \& Giller, K. (2010). Carbon and nutrient losses during manure storage under traditional and improved practices in smallholder crop-livestock systems-evidence from Kenya. Plant and Soil, 328, 253-269. doi: 10.1007/s11104-009-0107-x.

Tittonell, P., van Wijk, M., Herrero, M., Rufino, M., de Ridder, N., \& Giller, K. (2009). Beyond resource constraints - Exploring the biophysical feasibility of options for the intensification of smallholder crop-livestock systems in Vihiga district, Kenya. Agricultural Systems, 101, 1-19. doi: 10.1016/j.agsy.2009.02.003.

Trupa, A., Aplocina, E., \& Degola, L. (2015). Forage quality and feed intake effect on methane emissions from dairy farming. (pp. 601-605). volume 14.

Uchida, H., \& Nelson, A. (2009). Agglomeration Index: Towards a New Measure of Urban Concentration. Background Paper for the World Bank's World Development Report. URL: https: //openknowledge.worldbank.org/handle/10986/9039 [Accessed: 2014-06-03].

Udo, H., Weiler, V., Modupeore, O., Viets, T., \& Oosting, S. (2016). Intensification to 
reduce the carbon footprint of smallholder milk production: Fact or fiction? Outlook on Agriculture, 45, 33-38. doi: 10.5367/oa.2016.0229.

UN (2015). Paris Agreement. Technical Report United Nations Framework Convention on Climate Change (UNFCCC) Paris (France). URL: http://unfccc.int/resource/docs/2015/cop21/eng/109r01.pdf [Accessed: 201806-10].

UN (2017a). The Sustainable Development Goals Report 2017. Technical Report United Nations New York, NY (USA). URL: https://unstats.un.org/sdgs/report/2017/ [Accessed: 2018-04-24].

UN (2017b). World Population Prospects: The 2017 Revision, Key Findings and Advance Tables. Technical Report ESA/P/WP/248 United Nations, Department of Economic and Social Affairs, Population Devision New York, NY (USA). URL: https://esa.un.org/unpd/wpp [Accessed: 2018-06-13].

UNFCCC (2011). Report of the Conference of the Parties on Its Sixteenth Session, Held in Cancun from 29 November to 10 December 2010. Part Two: Action Taken by the Conference of the Parties at Its Sixteenth Session. Technical Report United Nations Framework Convention on Climate Change. URL: https://unfccc.int/resource/docs/2010/cop16/eng/07a01.pdf [Accessed: 201507-28].

USDA (2017). Kenya Grain and Feed Annual 2017 Kenya Corn, Wheat and Rice Report. Technical Report USDA Foreign Agricultural Service Nairobi (Kenya). URL: https://www.fas.usda.gov/data/kenya-grain-and-feed-annual-3 [Accessed: 2018-05-26].

Valin, H., Havlík, P., Mosnier, A., Herrero, M., Schmid, E., \& Obersteiner, M. (2013). Agricultural productivity and greenhouse gas emissions: Trade-offs or synergies between mitigation and food security? Environmental Research Letters, 8, 035019. doi: 10.1088/1748-9326/8/3/035019.

van Bussel, L. G. J., Grassini, P., Van Wart, J., Wolf, J., Claessens, L., Yang, H., Boogaard, H., de Groot, H., Saito, K., Cassman, K. G., \& van Ittersum, M. K. (2015). From field to atlas: Upscaling of location-specific yield gap estimates. Field Crops Research, 177, 98-108. doi: 10.1016/j.fcr.2015.03.005.

van Ittersum, M. K., Cassman, K. G., Grassini, P., Wolf, J., Tittonell, P., \& Hochman, Z. (2013). Yield gap analysis with local to global relevance-A review. Field Crops Research, 143, 4-17. doi: 10.1016/j.fcr.2012.09.009.

van Ittersum, M. K., van Bussel, L. G. J., Wolf, J., Grassini, P., van Wart, J., Guilpart, N., Claessens, L., de Groot, H., Wiebe, K., Mason-D'Croz, D., Yang, H., Boogaard, H., van Oort, P. A. J., van Loon, M. P., Saito, K., Adimo, O., Adjei-Nsiah, S., Agali, A., Bala, A., Chikowo, R., Kaizzi, K., Kouressy, M., Makoi, J. H. J. R., Ouattara, K., 
Tesfaye, K., \& Cassman, K. G. (2016). Can sub-Saharan Africa feed itself? Proceedings of the National Academy of Sciences, 113, 14964-14969. doi: 10.1073/pnas.1610359113.

van Middelaar, Cederberg, C., Vellinga, T., Van, D. W., \& De, B. (2013). Exploring variability in methods and data sensitivity in carbon footprints of feed ingredients. International Journal of Life Cycle Assessment, 18, 768-782. doi: 10.1007/s11367012-0521-9.

van Wart, J., Kersebaum, K. C., Peng, S., Milner, M., \& Cassman, K. G. (2013a). Estimating crop yield potential at regional to national scales. Field Crops Research, 143, 34-43. doi: 10.1016/j.fcr.2012.11.018.

van Wart, J., van Bussel, L. G. J., Wolf, J., Licker, R., Grassini, P., Nelson, A., Boogaard, H., Gerber, J., Mueller, N. D., Claessens, L., van Ittersum, M. K., \& Cassman, K. G. (2013b). Use of agro-climatic zones to upscale simulated crop yield potential. Field Crops Research, 143, 44-55. doi: 10.1016/j.fcr.2012.11.023.

van Wijk, M., Tittonell, P., Rufino, M., Herrero, M., Pacini, C., Ridder, N., \& Giller, K. (2009). Identifying key entry-points for strategic management of smallholder farming systems in sub-Saharan Africa using the dynamic farm-scale simulation model NUANCES-FARMSIM. Agricultural Systems, 102, 89-101. doi: 10.1016/j.agsy.2009.07.004.

van Wijk, M. T., Rufino, M. C., Enahoro, D., Parsons, D., Silvestri, S., Valdivia, R. O., \& Herrero, M. (2014). Farm household models to analyse food security in a changing climate: A review. Global Food Security, 3, 77-84. doi: 10.1016/j.gfs.2014.05.001.

Vanlauwe, B., Coyne, D., Gockowski, J., Hauser, S., Huising, J., Masso, C., Nziguheba, G., Schut, M., \& Van, A. (2014). Sustainable intensification and the African smallholder farmer. Current Opinion in Environmental Sustainability, 8, 15-22. doi: 10.1016/j.cosust.2014.06.001.

van Velthuizen, H., Huddleston, B., Fischer, G., Salvatore, M., Ataman, E., Nachtergaele, F. O., Zanetti, M., \& Bloise, M. (2007). Mapping Biophysical Factors That Influence Agricultural Production and Rural Vulnerability. Technical Report Food and Agriculture Organization of the United Nations Rome (Italy). URL: http://www.fao.org/docrep/pdf/010/a1075e/a1075e00.pdf [Accessed: 2014-0521].

Voinov, A., \& Bousquet, F. (2010). Modelling with stakeholders. Environmental Modelling E Software, 25, 1268-1281. doi: 10.1016/j.envsoft.2010.03.007.

Vrieling, A., Meroni, M., Shee, A., Mude, A., Woodard, J., de Bie, C., \& Rembold, F. (2014). Historical extension of operational NDVI products for livestock insurance in Kenya. International Journal of Applied Earth Observation and Geoinformation, 28, 238-251. doi: 10.1016/j.jag.2013.12.010.

Wanyama, I., Pelster, D., Arias-Navarro, C., Butterbach-Bahl, K., Verchot, L., \& Rufino, 
M. (2018). Management intensity controls soil N2O fluxes in an Afromontane ecosystem. Science of the Total Environment, 624, 769-780. doi: 10.1016/j.scitotenv.2017.12.081.

Weiler, V., Udo, H., Viets, T., Crane, T., \& De, B. (2014). Handling multi-functionality of livestock in a life cycle assessment: The case of smallholder dairying in Kenya. Current Opinion in Environmental Sustainability, 8, 29-38. doi: 10.1016/j.cosust.2014.07.009.

Weindl, I., Popp, A., Bodirsky, B., Rolinski, S., Lotze-Campen, H., Biewald, A., Humpenöder, F., Dietrich, J., \& Stevanović, M. (2017). Livestock and human use of land: Productivity trends and dietary choices as drivers of future land and carbon dynamics. Global and Planetary Change, 159, 1-10. doi: 10.1016/j.gloplacha.2017.10.002.

Westhoek, H., Rood, T., van den Berg, M., Janse, J., Nijdam, D., Reudink, M., \& Stehfest, E. (2011). The Protein Puzzle: The Consumption and Production of Meat, Dairy and Fish in the European Union. Rationale Reference Netherlands Environmental Assessment Agency, European Environment Agency (EEA) The Hague, Netherlands. URL: http://library . wur.nl/WebQuery/wurpubs/406619 [Accessed: 2016-05-15].

Wheeler, T., \& von Braun, J. (2013). Climate Change Impacts on Global Food Security. Science, 341, 508-513. doi: 10.1126/science.1239402.

Wiesmann, U., Kiteme, B., \& Mwangi, Z. (Eds.) (2014). Socio-Economic Atlas of Kenya: Depicting the National Population Census by County and Sub-Location. Nairobi, Nanyuki (Kenya), Bern (Switzerland): KNBS, CETRAD, CDE.

Wind, Y., \& Saaty, T. L. (1980). Marketing applications of the analytic hierarchy process. Management Science, 26, 641-658.

Wollenberg, E. K., Campbell, B. M., Holmgren, P., F, S., Sibanda, L. M., \& von Braun, J. (2011). Actions needed to halt deforestation and promote climate-smart agriculture. Policy brief, 4, 1-11. URL: https://cgspace.cgiar.org/handle/10568/10233.

$\mathrm{Xu}$, C., He, H., Hu, Y., Chang, Y., Li, X., \& Bu, R. (2005). Latin hypercube sampling and geostatistical modeling of spatial uncertainty in a spatially explicit forest landscape model simulation. Ecological Modelling, 185, 255-269. doi: 10.1016/j.ecolmodel.2004.12.009.

Xu, E., \& Zhang, H. (2013). Spatially-explicit sensitivity analysis for land suitability evaluation. Applied Geography, 45, 1-9. doi: 10.1016/j.apgeog.2013.08.005.

Zampaligré, N., \& Schlecht, E. (2018). Livestock foraging behaviour on different land use classes along the semi-arid to sub-humid agro-ecological gradient in West Africa. Environment, Development and Sustainability, 20, 731-748. doi: 10.1007/s10668-0179907-y.

Zhou, M., Brandt, P., Pelster, D., Rufino, M., Robinson, T., \& Butterbach-Bahl, K. (2014). Regional nitrogen budget of the Lake Victoria Basin, East Africa: Syntheses, uncertainties and perspectives. Environmental Research Letters, 9, 105009. doi: 
10.1088/1748-9326/9/10/105009.

Zhu, Z., Wang, S., \& Woodcock, C. E. (2015). Improvement and expansion of the Fmask algorithm: Cloud, cloud shadow, and snow detection for Landsats 4-7, 8, and Sentinel 2 images. Remote Sensing of Environment, 159, 269-277. doi: 10.1016/j.rse.2014.12.014.

Zomer, R., Neufeldt, H., Xu, J., Ahrends, A., Bossio, D., Trabucco, A., van Noordwijk, M., \& Wang, M. (2016). Global Tree Cover and Biomass Carbon on Agricultural Land: The contribution of agroforestry to global and national carbon budgets. Scientific Reports, 6, 1-12. doi: 10.1038/srep29987.

Zomer, R., Trabucco, A., Bossio, D., \& Verchot, L. (2008). Climate change mitigation: A spatial analysis of global land suitability for clean development mechanism afforestation and reforestation. Agriculture, Ecosystems and Environment, 126, 67-80. doi: 10.1016/j.agee.2008.01.014.

Zscheischler, J., Mahecha, M., Harmeling, S., \& Reichstein, M. (2013). Detection and attribution of large spatiotemporal extreme events in Earth observation data. Ecological Informatics, 15, 66-73. doi: 10.1016/j.ecoinf.2013.03.004.

Zuur, A., Ieno, E., Walker, N., Saveliev, A., \& Smith, G. (2009). Mixed Effects Models and Extensions in Ecology with $R$ - Alain Zuur - Springer. Statistics for Biology and Health (1st ed.). New York, NY (USA): Springer-Verlag New York. 

Appendices 


\section{Appendix S1 belonging to Chapter 2 of this thesis}

\section{Computing a consensus matrix based on input PC matrices}

The aim is to search a consensus matrix (c) that shows minimised differences to the input PC matrices $(\mathrm{m})$ obtained from individual stakeholders $(\mathrm{k})$. The distance minimisation function is translated into a linear goal programming model (S1.1) (González-Pachón \& Romero, 2007).

Achievement function:

$$
\operatorname{Min}(1-\lambda) D+\lambda\left[\sum_{k=1}^{m} \sum_{i=1}^{n} \sum_{\substack{j=1 \\ j \neq i}}^{n}\left(n_{i j}^{k}+p_{i j}^{k}\right)\right]
$$

$i, j$ refer to the elements of a matrix, subjected to the following constraints:

$$
\begin{aligned}
& m_{i j}^{c}-m_{i j}^{k}+n_{i j}^{k}-p_{i j}^{k}=0, \quad i, j \in\{1, \ldots, n\}, \quad k \in\{1, \ldots, m\} \\
& \sum_{i=1}^{n} \sum_{\substack{j=1 \\
j \neq i}}^{n}\left(n_{i j}^{k}+p_{i j}^{k}\right)-D \leq 0, \quad k \in\{1, \ldots, m\} \\
& 1 / 9 \leq m_{i j}^{c} \leq 9, \quad i, j \in\{1, \ldots, n\} \\
& n \geq 0, \quad p \geq 0 \\
& \lambda \in[0,1] \text { (control parameter) }
\end{aligned}
$$

The control parameter $\lambda$ is used to explore possible solutions as well as trade-offs between the consensus towards the majority $(\lambda=1)$ and the minority $(\lambda=0)$. The metric $\mathrm{D}$ indicates the deviation between the stakeholder matrix that is furthest from the obtained consensus matrix. The variables $n_{i j}^{k}$ and $p_{i j}^{k}$ measure the degree of under and over-achievement between single matrix preferences $\left(m_{i j}^{k}\right)$ and calculated preferences of the consensus matrix $\left(m_{i j}^{c}\right)$. They can be accumulated to the measure A, which indicates the overall deviation between the computed consensus matrix and all individual stakeholder preferences (González-Pachón \& Romero, 2007). The resulting consensus matrix has the same structure as the input PC matrices.

\section{Inferring preference weights from a single PC matrix}

The preference vector $(\mathrm{w})$ for $\mathrm{i}=1, \ldots, \mathrm{n}$ criteria is calculated through the following optimisation model (S1.2) (González-Pachón \& Romero, 2007). 
Achievement function:

$$
\operatorname{Min}(1-\lambda) D+\lambda\left[\sum_{i=1}^{n} \sum_{\substack{j=1 \\ j \neq i}}^{n}\left(n_{i j}+p_{i j}\right)\right]
$$

subjected to the following constraints:

$$
\begin{aligned}
& m_{i j} w_{j}-w_{i}+n_{i j}-p_{i j}=0, \quad i, j \in\{1, \ldots, n\} \\
& n_{i j}+p_{i j} \leq D, \quad i, j \in\{1, \ldots, n\} \\
& \sum_{i=1}^{n} w_{i}=1, w_{i}>0, \quad \forall i \\
& n \geq 0, \quad p \geq 0 \\
& \lambda \in[0,1] \text { (control parameter) }
\end{aligned}
$$

The meaning of variables $\lambda, \mathrm{D}, n_{i j}$ and $p_{i j}$ is congruent with model (S1.1).

\section{Inferring preference weights from several PC matrices}

The following optimisation model (S1.3) is an extension of model (S1.2) applicable to (k) stakeholders. A scenario that might be interesting in a case where stakeholders are kept as individuals and do not form one consensus oriented group (González-Pachón \& Romero, 2007).

Achievement function:

$$
\operatorname{Min}(1-\lambda) D+\lambda\left[\sum_{k=1}^{m} \sum_{i=1}^{n} \sum_{\substack{j=1 \\ j \neq i}}^{n}\left(n_{i j}^{k}+p_{i j}^{k}\right)\right]
$$

subjected to the following constraints:

$$
\begin{aligned}
& m_{i j}^{k} w_{j}-w_{i}+n_{i j}^{k}-p_{i j}^{k}=0, \quad i, j \in\{1, \ldots, n\}, \quad k \in\{1, \ldots, m\} \\
& \sum_{i=1}^{n} \sum_{\substack{j=1 \\
j \neq i}}^{n}\left(n_{i j}^{k}+p_{i j}^{k}\right)-D \leq 0, \quad k \in\{1, \ldots, m\} \\
& \sum_{i=1}^{n} w_{i}=1, w_{i}>0, \quad \forall i \\
& n \geq 0, \quad p \geq 0 \\
& \lambda \in[0,1] \text { (control parameter) }
\end{aligned}
$$


Determining the consensus matrix that shows the most balanced trade-off between majority and minority consensuses

An additive maximisation function was utilised based on standardised indices of majority (A) and minority (D) deviation by using equations (S1.4), (S1.5) and (S1.6) developed by González-Pachón \& Romero (2011).

$$
I_{A_{\lambda}}=\frac{\left(A_{0}-A_{\lambda}\right)}{\left(A_{0}-A_{1}\right)}, \quad \lambda \in[0,1]
$$

$I_{A_{\lambda}}=$ index of majority consensus, $A_{1}=$ closed point towards majority, $A_{0}=$ most distant point from majority, $A_{\lambda}=\mathrm{A}$ for a certain $\lambda$ value

$$
I_{D_{\lambda}}=\frac{\left(D_{1}-D_{\lambda}\right)}{\left(D_{1}-D_{0}\right)}, \quad \lambda \in[0,1]
$$

$I_{D_{\lambda}}=$ index of minority consensus, $D_{0}=$ closed point towards majority, $D_{1}=$ most distant point from majority, $D_{\lambda}=\mathrm{D}$ for a certain $\lambda$ value

The applied utility function maximises the sum of both indices for a certain consensus matrix for $\lambda=0-1$ :

$$
I_{A *}+I_{D *}=\operatorname{Max}\left(I_{A_{\lambda}}+I_{D_{\lambda}}\right)
$$

The highest value is selected representing the most balanced trade-off (i.e. compromise) between majority and minority consensus (González-Pachón \& Romero, 2011).

Combination and aggregation of spatial datasets and stakeholder preferences using the weighed linear combination rule (WLC)

Prior to the spatial aggregation, all single datasets have to be standardised and consistently rescaled to range from $0-1(0=$ low, $1=$ high vulnerability and CSA suitability $)$ by applying equation (S1.7).

$$
x_{i}=\frac{\left(R_{i}-R_{i_{\min }}\right)}{\left(R_{i_{\max }}-R_{i_{\min }}\right)}
$$

$x_{i}=$ standardised dataset i, $R_{i}=$ original dataset $\mathrm{i}, R_{i_{\min }}=$ minimum grid cell value of dataset i, $R_{i_{\max }}=$ maximum grid cell value of dataset $\mathrm{i}$

Subsequently, the products of standardised datasets $x_{i}$ and related preference weights $w_{i}$ are summed up as shown in equation (S1.8). Finally, the summed products are combined with boolean constraints $c_{j}$ (e.g. areas that have to be excluded) deriving the composite index S (Eastman et al., 1995).

$$
S=\sum\left(w_{i} x_{i}\right) \times \Pi c_{j}
$$

$\mathrm{S}=$ weighted composite index, $w_{i}=$ preference weight relating to dataset $\mathrm{i}, x_{i}=$ standardised dataset $\mathrm{i}, c_{i}=$ boolean constraint $\mathrm{j}$ 


\section{Appendix S2 belonging to Chapter 2 of this thesis}

Table S2.1: Overview of involved stakeholder groups and related organisations.

\begin{tabular}{|c|c|}
\hline Group & Organisation \\
\hline Governmental organisations (GOs) & $\begin{array}{l}\text { Ministry of Agriculture Livestock and Fish- } \\
\text { eries (MoALF) } \\
\text { Ministry of Environment and Mineral Re- } \\
\text { sources (MEWNR) } \\
\text { Ministry of Water \& Irrigation } \\
\text { State Department of Livestock } \\
\text { Kenya Forest Service (KFS) } \\
\text { National Environment Management Author- } \\
\text { ity (NEMA) } \\
\text { National Treasury } \\
\text { National Agricultural Research Laboratories } \\
\text { (NARL) }\end{array}$ \\
\hline Non-governmental organisations (NGOs) & $\begin{array}{l}\text { African Centre for Technology Studies } \\
\text { (ACTS) } \\
\text { SNV-Netherlands Development Organisation } \\
\text { Kenya Community Development Foundation } \\
\text { (KCDF) } \\
\text { Consumer Unity \& Trust Society Africa Re- } \\
\text { source Centre (CUTS ARC) } \\
\text { Vi Agroforestry } \\
\text { Kenya Climate Justice Women Champions } \\
\text { (KCJWC) } \\
\text { Wetlands International } \\
\text { Kenya National Farmers' Federation (KE- } \\
\text { NAFF) }\end{array}$ \\
\hline Scientific institutions & $\begin{array}{l}\text { South Eastern Kenya University (SEKU) } \\
\text { Kenya Institute for Public Policy Research } \\
\text { and Analysis (KIPPRA) } \\
\text { IGAD Climate Prediction And Applications } \\
\text { Center (ICPAC) } \\
\text { University of Nairobi (CASELAP) } \\
\text { University of Reading } \\
\text { Kenya Meteorological Department (KMS) } \\
\text { World Agroforestry Centre (ICRAF) }\end{array}$ \\
\hline
\end{tabular}


Table S2.1: continued

International Livestock Research Institute (ILRI)

Private Sector

Kenya Private Sector Alliance (KEPSA)

Price Water House Coopers $(\mathrm{PwC})$

Kenya Association of Manufacturers (KAM)

GrainPro

African Seed Trade Association (AFSTA)

Coffee Board Of Kenya

Geo-EnviAgro Solutions International

Kenya Tea Development Agency (KTDA) 

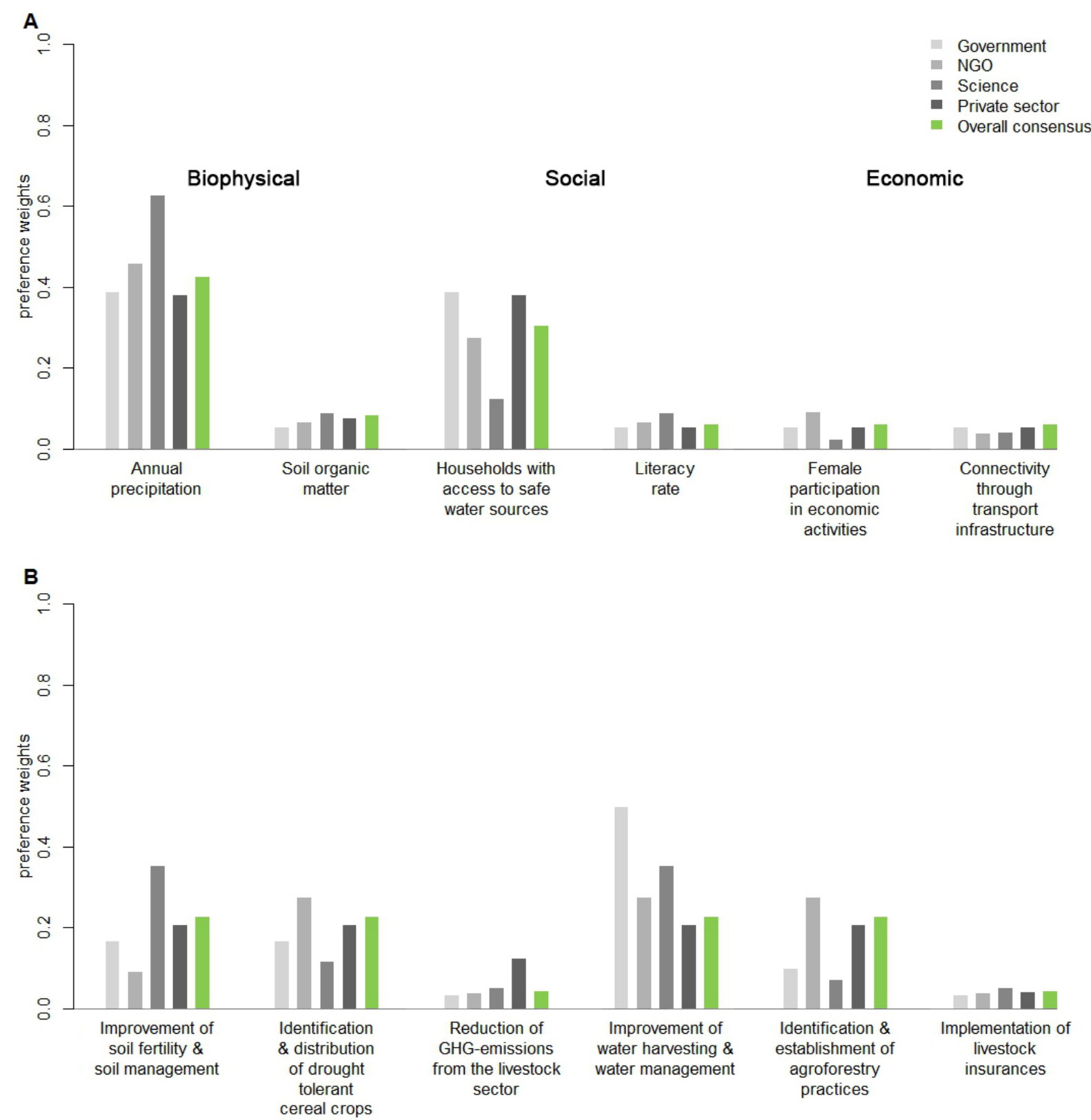

Figure S2.1: Preference weights for each stakeholder group and the overall consensus (including all experts) resulting from the majority consensus scenario for (A) vulnerability indicators and (B) CSA practices. 

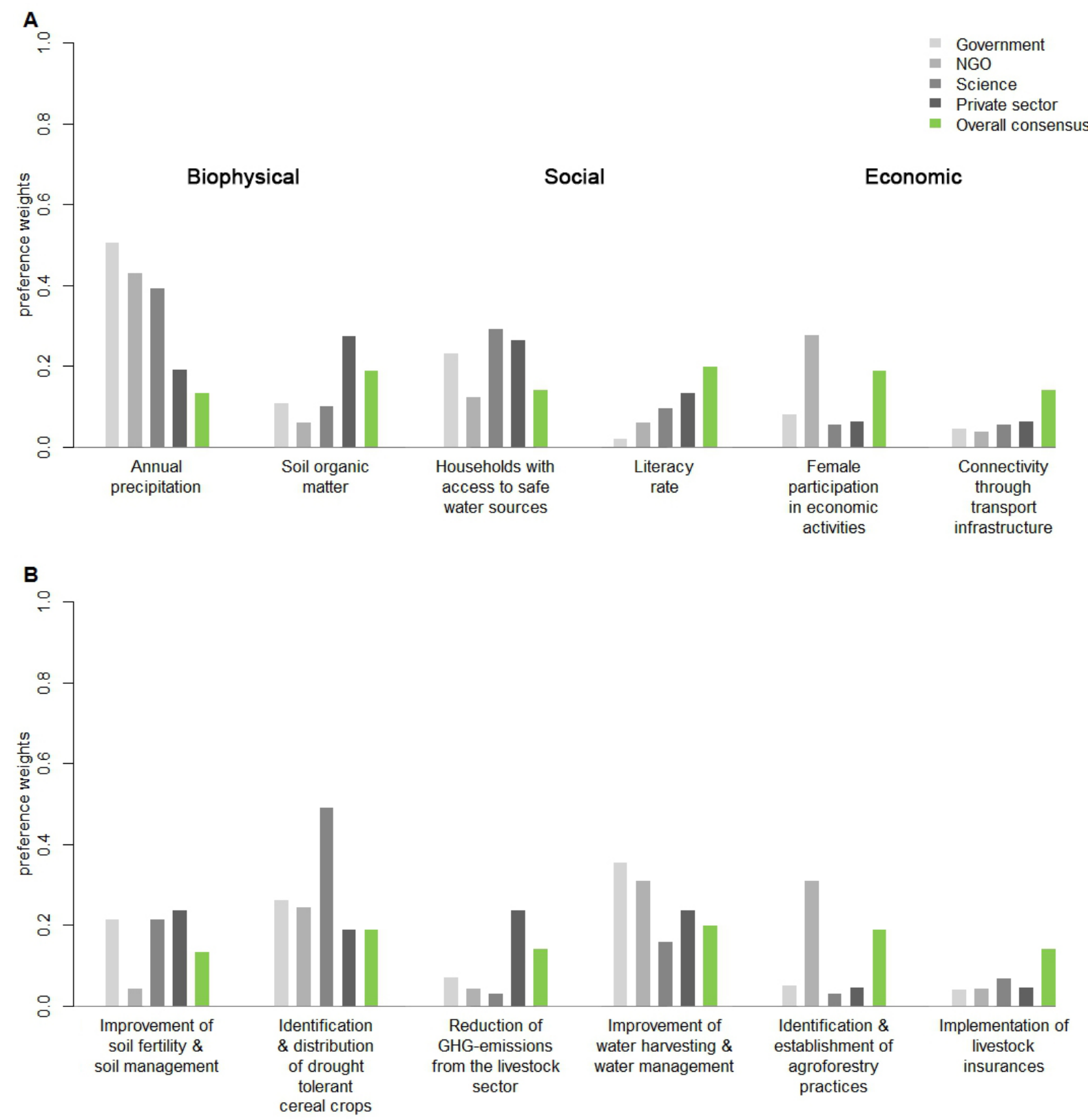

Figure S2.2: Preference weights for each stakeholder group and the overall consensus (including all experts) resulting from the minority consensus scenario for (A) vulnerability indicators and (B) CSA practices. 


\section{Appendix S3 belonging to Chapter 3 of this thesis}

\section{Study Area}

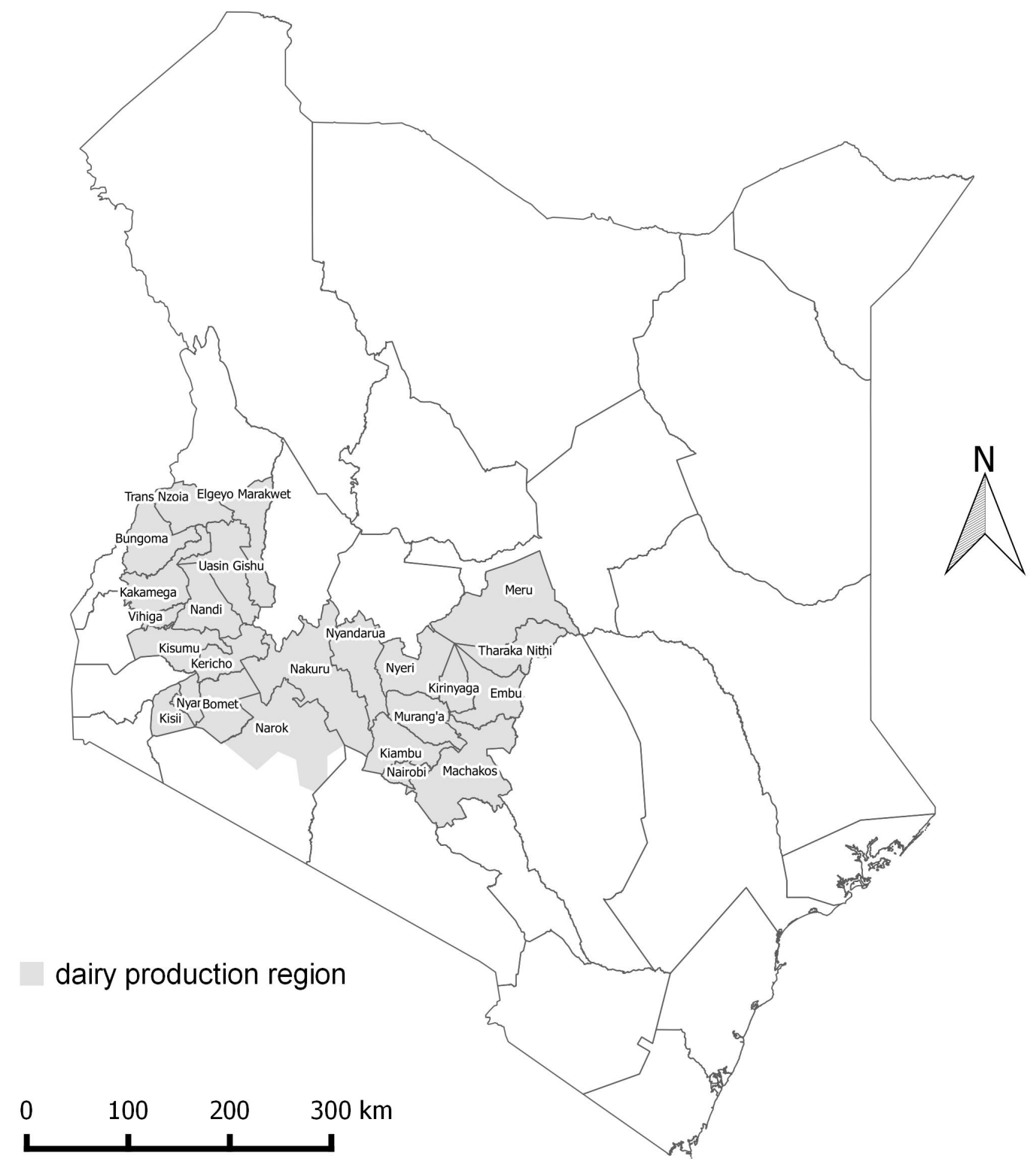

Figure S3.1: Dairy production region in Kenya, adapted based on Herrero et al. (2014). 


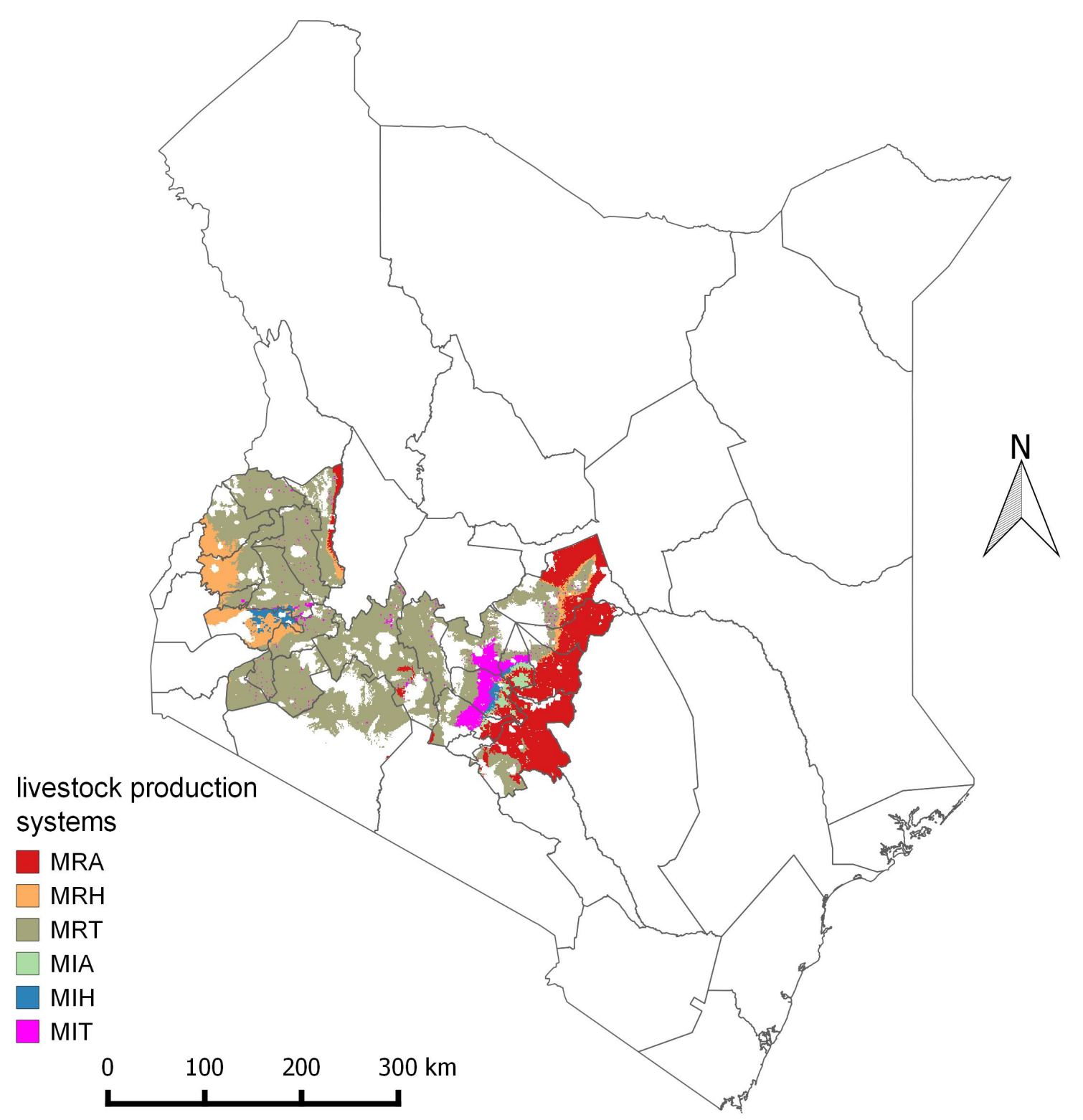

Figure S3.2: Spatial distribution of livestock production systems (LPS) within the study area: mixed rainfed system in arid areas (MRA), mixed rainfed system in humid areas (MRH), mixed rainfed system in tropical highlands (MRT), mixed irrigated system in arid areas (MIA), mixed irrigated system in humid areas $(\mathrm{MIH})$ and the mixed irrigated system in tropical highlands (MIT).

\section{The Livestock Simulator}

\section{LivSim}

LivSim is an individual-based livestock production model used to simulate animal production such as milk and excreta as well as maintenance requirements (Rufino et al., 2009). 
Different livestock units can be taken into account each characterised by animal species and breeds such as a specific dairy cattle breeds (e.g. Frisians). The state variables of the model are the age, weight and reproductive status of the animal. Conception, sex of the calves and mortality (involuntary disposal) are prompted stochastically. Changes in age, weight and mortality due to undernourishment are described deterministically. Intake is determined by feed quality and quantity, and animal characteristics. Each time step in a simulation represents a month. Animal production is calculated on a monthly basis.

\section{HeapSim}

The dynamics of nutrients through manure collection, storage and use as well as changes in quality due to management are simulated by HeapSim (Rufino et al., 2007). This model is able to consider the transfer efficiencies for the different processes under different livestock production systems and types of storage. HeapSim is coupled with LivSim. Manure inputs are obtained from the LivSim model dynamically during simulations on a monthly basis.

\section{Calculation of GHG emissions from dairy production}

Table S3.1: Descriptions of parameters, their values and uncertainty ranges ( $\min -\max$ ), used to compute $\mathrm{CH}_{4}, \mathrm{~N}_{2} \mathrm{O}$ and $\mathrm{CO}_{2}$ emissions from enteric fermentation (EF), manure management (MM), managed soils (MS), including land use changes, and dairy concentrate supplementation.

\begin{tabular}{|c|c|c|c|}
\hline Parameter & $\begin{array}{l}\text { Applied } \\
\text { IPCC- } \\
\text { equation }\end{array}$ & Value / range & Reference \\
\hline $\begin{array}{l}\text { Net energy mainte- } \\
\text { nance (EF) }\end{array}$ & Eq. 10.3 & $\begin{array}{l}\mathrm{Cf}=0.386 \text { for lactating } \\
\text { cow; } \mathrm{Cf}=0.322 \text { for non- } \\
\text { lactating cow }\end{array}$ & $\begin{array}{l}\text { IPCC } \quad(2006, \text { table } \\
10.4)\end{array}$ \\
\hline $\begin{array}{l}\text { Net energy activity } \\
(\mathrm{EF})\end{array}$ & Eq. 10.4 & $\begin{array}{l}\mathrm{Ca}=0.17 \text { for grazing; Ca } \\
=0 \text { for non-grazing }\end{array}$ & $\begin{array}{l}\text { IPCC } \quad(2006, \text { table } \\
10.5)\end{array}$ \\
\hline $\begin{array}{l}\text { Net energy growth } \\
(\mathrm{EF})\end{array}$ & Eq. 10.6 & $\begin{array}{l}\mathrm{BW}=\text { calculated by } \\
\text { LivSim; } \mathrm{C}=1 ; \mathrm{WG}= \\
\text { calculated by LivSim }\end{array}$ & $\begin{array}{l}\text { IPCC (2006), Rufino } \\
\text { et al. (2009) }\end{array}$ \\
\hline $\begin{array}{l}\text { Net energy lactation } \\
(\mathrm{EF})\end{array}$ & Eq. 10.8 & $\begin{array}{l}\text { Milk yield = calculated by } \\
\text { LivSim; Fat = calculated } \\
\text { by LivSim }(2.7 \%-4.2 \%) \text {; } \\
\text { Lactation state = calcu- } \\
\text { lated by LivSim }\end{array}$ & Rufino et al. (2009) \\
\hline
\end{tabular}


Table S3.1: continued

\begin{tabular}{|c|c|c|c|}
\hline $\begin{array}{l}\text { Net energy preg- } \\
\text { nancy (EF) }\end{array}$ & Eq. 10.13 & $\begin{array}{l}\text { Cpregnancy }=0.1 ; \text { Preg- } \\
\text { nancy state }=\text { calculated } \\
\text { by LivSim }\end{array}$ & $\begin{array}{l}\text { IPCC }(2006, \text { table } \\
10.7) \text {, Rufino et al. } \\
(2009)\end{array}$ \\
\hline $\begin{array}{l}\text { Ratio net energy } \\
\text { available for mainte- } \\
\text { nance to digestible } \\
\text { energy consumed } \\
(\mathrm{EF}, \mathrm{MM})\end{array}$ & Eq. 10.14 & $\begin{array}{l}\mathrm{DE}=\text { feed type specific } \\
(\%): \\
\text { - Grazing land: } 45- \\
55 \\
\text { - Napier grass: } 50-60 \\
\text { - Maize stover: } 45-55 \\
\text { - Maize silage: } 50-60 \\
\text { - Dairy concentrate: } \\
75-85\end{array}$ & $\begin{array}{ll}\text { IPCC } & (2006), \\
\text { Anindo et al. } & (1994), \\
\text { Rufino et al. } & (2009)\end{array}$ \\
\hline $\begin{array}{l}\text { Ratio net energy } \\
\text { available for growth } \\
\text { to digestible energy } \\
\text { consumed (EF, MM) }\end{array}$ & Eq. 10.15 & $\mathrm{DE}=$ see above & IPCC (2006) \\
\hline $\begin{array}{l}\text { Gross Energy (EF, } \\
\text { MM) }\end{array}$ & Eq. 10.16 & $\mathrm{DE}=$ see above & $\operatorname{IPCC}(2006)$ \\
\hline $\mathrm{CH}_{4}$ emissions $(\mathrm{EF})$ & Eq. 10.21 & $\mathrm{Ym}=5.5 \%-7.5 \%$ & $\begin{array}{l}\text { IPCC }(2006, \text { table } \\
10.12)\end{array}$ \\
\hline $\begin{array}{l}\text { Volatile solid excre- } \\
\text { tion }(\mathrm{MM})\end{array}$ & Eq. 10.24 & $\begin{array}{l}\mathrm{DE}=\text { see above; } \mathrm{UE}^{*} \mathrm{GE}= \\
0.04 ; \mathrm{ASH}=0.08\end{array}$ & IPCC (2006) \\
\hline $\mathrm{CH}_{4}$ emissions (MM) & Eq. 10.23 & $\begin{array}{l}\mathrm{Bo}(\mathrm{T})=0.11-0.15 ; \mathrm{MCF} \\
\text { storage }(\%)=1.5-2 \text { (dry } \\
\text { lot) and } 4-5 \text { (solid stor- } \\
\text { age); MCF grazing (\%) } \\
=1.5-2 ; \mathrm{MCF} \text { appli- } \\
\text { cation }(\%)=0.5-1 ; \\
\mathrm{MS}=\text { proportion of ma- } \\
\text { nure stored based on ra- } \\
\text { tio between grazing land } \\
\text { (not managed) and crop- } \\
\text { land under feed production } \\
\text { (managed) }\end{array}$ & $\begin{array}{l}\text { IPCC }(2006, \text { table } \\
10.17 \text { and } 10 \mathrm{~A}-4)\end{array}$ \\
\hline $\mathrm{N}$ excretion $(\mathrm{MM})$ & & $\begin{array}{l}\mathrm{N} \text { content of urine and fae- } \\
\text { ces = calculated by LivSim }\end{array}$ & Rufino et al. (2009) \\
\hline
\end{tabular}


Table S3.1: continued

\begin{tabular}{|c|c|c|c|}
\hline $\begin{array}{l}\text { Direct } \mathrm{N}_{2} \mathrm{O} \text { emis- } \\
\text { sions }(\mathrm{MM})\end{array}$ & 10.25 & $\begin{array}{l}\text { EF3 }=0.01-0.02(\text { dry lot }) \\
\text { and } 0.0025-0.0075 \text { (solid } \\
\text { storage) }\end{array}$ & $\begin{array}{l}\text { IPCC }(2006, \text { table } \\
10.21) \text {, Herrero et al. } \\
(2013)\end{array}$ \\
\hline $\begin{array}{l}\mathrm{N} \text { volatilisation as } \\
\mathrm{NH}_{3} \text { and } \mathrm{NO}_{\mathrm{x}}(\mathrm{MM})\end{array}$ & Eq. 10.26 & $\begin{array}{l}\mathrm{MS}=\text { see above; Frac- } \\
\text { GasMS }(\%)=30-50 \text { (dry } \\
\text { lot), } 30-40 \text { (solid storage) }\end{array}$ & $\begin{array}{l}\text { IPCC }(2006, \text { table } \\
10.22) \text {, Herrero et al. } \\
(2013)\end{array}$ \\
\hline $\begin{array}{l}\text { N losses due to leach- } \\
\text { ing (MM) }\end{array}$ & Eq. 10.28 & $\begin{array}{l}\text { MS = see above; Fra- } \\
\text { cleachMS }(\%)=0-20 \\
\text { (dry lot) and } 5-15 \text { (solid } \\
\text { storage) }\end{array}$ & $\begin{array}{l}\text { IPCC }(2006, \text { table } \\
10.23), \text { Herrero et al. } \\
(2013)\end{array}$ \\
\hline $\begin{array}{l}\text { Indirect } \mathrm{N}_{2} \mathrm{O} \text { emis- } \\
\text { sions }(\mathrm{MM})\end{array}$ & $\begin{array}{l}\text { Eq. } 10.27 \text { and } \\
10.29\end{array}$ & $\begin{array}{l}\mathrm{EF} 4=0.02-0.01 ; \mathrm{EF} 5= \\
0.0005-0.0075 ; \mathrm{N}_{2} \mathrm{O}=\mathrm{N} \\
* 44 / 28\end{array}$ & $\begin{array}{l}\text { IPCC }(2006, \text { table } \\
11.3) \text {, Herrero et al. } \\
(2013)\end{array}$ \\
\hline $\begin{array}{l}\mathrm{N} \text { from animal ma- } \\
\text { nure applied to soils } \\
\text { used for feed produc- } \\
\text { tion (MS) }\end{array}$ & Eq. 11.4 & $\begin{array}{l}\text { FracFEED }=1-\text { MSO } \\
(\%) \text { (fraction of manure for } \\
\text { other uses) } 0.1-0.2\end{array}$ & $\begin{array}{l}\text { IPCC }(2006), \text { Her- } \\
\text { rero et al. }(2013)\end{array}$ \\
\hline $\begin{array}{l}\mathrm{N} \text { in urine and dung } \\
\text { deposited on pasture } \\
(\mathrm{MS})\end{array}$ & Eq. 11.5 & $\begin{array}{l}1-\mathrm{MS}=\text { fraction of ma- } \\
\text { nure dropped on grazing } \\
\text { land }\end{array}$ & IPCC (2006) \\
\hline $\begin{array}{l}\text { Direct } \mathrm{N}_{2} \mathrm{O} \text { emis- } \\
\text { sions from manure } \\
\text { deposited on pas- } \\
\text { tures (MS) }\end{array}$ & Eq. 11.1 & $\mathrm{EF} 3 \mathrm{PRP}=0.007-0.06$ & $\begin{array}{l}\text { IPCC (2006, table } \\
11.3) \text {, Herrero et al. } \\
\text { (2013), Rosenstock } \\
\text { et al. (2016) }\end{array}$ \\
\hline $\begin{array}{l}\mathrm{N} \text { in synthetic fer- } \\
\text { tiliser }(\mathrm{MS})\end{array}$ & Eq. 11.1 & $\begin{array}{l}\text { FSN }(\mathrm{kg} \text { ha- }-1)=\text { spatially } \\
\text { explicit dataset }\end{array}$ & Potter et al. (2010) \\
\hline $\begin{array}{l}\mathrm{N} \text { in crop residues } \\
\text { (above and below } \\
\text { ground) (MS) }\end{array}$ & $\begin{array}{l}\text { Eq. } 11.7 \text { and } \\
11.7 \mathrm{~A}\end{array}$ & $\begin{array}{l}\text { Fcr }=\text { calculated per } \\
\text { crop (Napier grass and } \\
\text { maize); Yields }(\mathrm{kg} \mathrm{ha-1):}\end{array}$ & $\begin{array}{lr}\text { IPCC } & (2006, \text { table } \\
11.2), & \text { Monfreda } \\
\text { et al. } & (2008),\end{array}$ \\
\hline & & Napier grass $=12000$ & Katiku \\
\hline & & $(\mathrm{MRA}, \quad \mathrm{MIA})-16000$ & (2011), Weiler et al. \\
\hline & & $\begin{array}{l}(\mathrm{MRH}, \mathrm{MIH}), \text { Maize }= \\
2335 \text { (MRA, MIA })-4747 \\
(\mathrm{MRH}, \mathrm{MIH}) \text { FracRemove } \\
=0.75 ; \text { Area burnt }=0 ; \\
\text { Other values taken from } \\
\text { table } 11.2, \text { for Napier grass } \\
=\text { perennial grasses }\end{array}$ & $\begin{array}{l}(2014) \text {, Castellanos- } \\
\text { Navarrete et al. } \\
(2015)\end{array}$ \\
\hline
\end{tabular}


Table S3.1: continued

\begin{tabular}{|c|c|c|c|}
\hline $\begin{array}{l}\text { Mineralised } \mathrm{N} \text { in } \\
\text { mineral soils due to } \\
\text { loss of soil carbon } \\
\text { through land use } \\
\text { change }\end{array}$ & Eq. 11.8 & $\begin{array}{l}\mathrm{R}(\mathrm{C}: \mathrm{N} \text { ratio })=\text { spatially } \\
\text { explicit dataset; Area }= \\
\text { see equation }(\mathrm{S} 3.1) \text { below }\end{array}$ & Hengl et al. (2015) \\
\hline $\begin{array}{l}\text { Direct } \mathrm{N}_{2} \mathrm{O} \text { emis- } \\
\text { sions (MS) }\end{array}$ & Eq. 11.1 & $\begin{array}{l}\mathrm{EF} 1=0.003-0.005 \\
(\mathrm{MRA}, \mathrm{MIA}), 0.003-0.02 \\
(\mathrm{MRH}, \mathrm{MIH}), 0.003-0.01 \\
(\mathrm{MRT}) \text { and } 0.0004-0.036 \\
(\mathrm{MIT})\end{array}$ & $\begin{array}{l}\text { IPCC }(2006, \text { table } \\
11.1 \text { and } 11.2) \text {, Her- } \\
\text { rero et al. (2013), } \\
\text { Hickmann et al. } \\
(2017)\end{array}$ \\
\hline $\begin{array}{l}\mathrm{N}_{2} \mathrm{O}-\mathrm{N} \text { from atmo- } \\
\text { spheric deposition } \\
(\mathrm{MS})\end{array}$ & Eq. 11.9 & $\begin{array}{l}\text { FracGASM }=0.05-0.3 \\
\text { (dry lot) and } 0.05-0.2 \\
\text { (solid storage); FacGASF } \\
=0.03-0.3 ; \mathrm{EF} 4=0.002 \\
-0.01\end{array}$ & $\begin{array}{l}\text { IPCC } \quad(2006, \text { table } \\
11.3) \text {, Herrero et al. } \\
(2013)\end{array}$ \\
\hline $\begin{array}{l}\mathrm{N}_{2} \mathrm{O}-\mathrm{N} \text { from leach- } \\
\text { ing/runoff }(\mathrm{MS})\end{array}$ & Eq. 11.10 & $\begin{array}{l}\text { FracLEACH-H }=0.1-0.3 \\
\text { EF5 }=0.005-0.0075\end{array}$ & $\begin{array}{l}\text { IPCC }(2006, \text { table } \\
11.3), \text { Herrero et al. } \\
(2013)\end{array}$ \\
\hline $\begin{array}{l}\text { Indirect } \mathrm{N}_{2} \mathrm{O} \text { emis- } \\
\text { sions }(\mathrm{MS})\end{array}$ & $\begin{array}{l}\text { Eq. } 11.9 \text { and } \\
11.10\end{array}$ & $\begin{array}{l}\mathrm{Fcr}=\text { calculated per crop } \\
\text { (Napier grass and maize); } \\
\mathrm{N}_{2} \mathrm{O}=\mathrm{N}_{2} \mathrm{O}-\mathrm{N} * 44 / 28\end{array}$ & $\begin{array}{l}\text { IPCC }(2006, \text { table } \\
11.2 \text { and } 11.3), \text { Her- } \\
\text { rero et al. }(2013)\end{array}$ \\
\hline $\begin{array}{l}\mathrm{CO}_{2} \text { emissions from } \\
\text { land use change } \\
\text { (only grazing land to } \\
\text { cropland) }\end{array}$ & & $\begin{array}{l}\text { Soil carbon loss }(\mathrm{kg} \mathrm{C} \mathrm{ha-1} \\
\left.\mathrm{yr}^{-1}\right)=11.1-688.2 ; \text { Area } \\
=\text { see formula }(1) \text { below; } \\
\mathrm{CO}_{2}=\text { Soil carbon loss } * \\
44 / 12\end{array}$ & Don et al. (2011) \\
\hline $\begin{array}{l}\mathrm{CO}_{2} \mathrm{eq} \text { emissions } \\
\text { from dairy concen- } \\
\text { trate }\end{array}$ & & $\begin{array}{l}\text { Emission factor }(\mathrm{kg} \mathrm{CO} 2 \mathrm{eq} \\
\left.\mathrm{kg} \text { concentrate }{ }^{-1}\right)=1.36\end{array}$ & Weiler et al. (2014) \\
\hline Cattle densities & & $\begin{array}{l}\text { Spatially explicit dataset } \\
\left(\text { heads } \mathrm{km}^{-2} \text { ) used to up- }\right. \\
\text { scale GHG emissions and } \\
\text { milk production. Grid cell } \\
\text { wise uncertainty ranges } \\
\text { are calculated based on: } \\
\text { RMSE of } 0.42=\log (\mathrm{x}+ \\
\text { 1) }\end{array}$ & $\begin{array}{l}\text { Robinson et al. } \\
(2014)\end{array}$ \\
\hline
\end{tabular}


Table S3.2: Ingredients of the baseline diet and their proportions in relation to the annual dry matter intake (DMI) per tropical livestock unit (TLU) as lifetime average. Grazing refers to native grass species from natural pastures.

\begin{tabular}{|c|c|c|c|c|c|}
\hline LPS & $\begin{array}{l}\text { DMI } \\
\left(\mathrm{kg} \mathrm{TLU}^{-1}\right. \\
\left.\mathrm{yr}^{-1}\right)\end{array}$ & $\begin{array}{l}\text { Grazing } \\
(\%)\end{array}$ & $\begin{array}{l}\text { Napier } \\
\text { grass (\%) }\end{array}$ & $\begin{array}{l}\text { Maize } \\
\text { stover (\%) }\end{array}$ & $\begin{array}{l}\text { Dairy con- } \\
\text { centrate } \\
(\%)\end{array}$ \\
\hline MRA & 2470 & 52 & 24 & 23 & 1 \\
\hline $\mathrm{MRH}$ & 2474 & 34 & 38 & 27 & 1 \\
\hline MRT & 2414 & 36 & 42 & 21 & 1 \\
\hline MIA & 2466 & 52 & 24 & 23 & 1 \\
\hline MIH & 2475 & 34 & 38 & 27 & 1 \\
\hline MIT & 2417 & 36 & 42 & 21 & 1 \\
\hline
\end{tabular}

\section{Calculation of the NDC target}

Steps $(1-5)$ were applied to calculate the tolerable relative GHG emission increase according to the Kenya NDC target (Government of Kenya, 2015a):

(1) National baseline 2010: $73 \mathrm{Mt} \mathrm{CO}_{2} \mathrm{eq}$

(2) National BAU scenario 2030: $143 \mathrm{Mt} \mathrm{CO}_{2} \mathrm{eq}=95.9 \%$ increase relative to the baseline

(3) Expected BAU increase: $143 \mathrm{Mt} \mathrm{CO}_{2} \mathrm{eq}-73 \mathrm{Mt} \mathrm{CO}_{2} \mathrm{eq}=70 \mathrm{Mt} \mathrm{CO}_{2} \mathrm{eq}$

(4) NDC target to reduce emission increase by $30 \%$ : $70 \mathrm{Mt} \mathrm{CO}_{2} \mathrm{eq} * 0.3=21 \mathrm{Mt}$ $\mathrm{CO}_{2} \mathrm{eq}$

(5) Tolerable emission increase (according to the NDC) relative to the national baseline:

$\left(21 \mathrm{Mt} \mathrm{CO}_{2} \mathrm{eq}+73 \mathrm{Mt} \mathrm{CO}_{2} \mathrm{eq}\right) / 73 \mathrm{Mt} \mathrm{CO} \mathrm{CO}_{2} \mathrm{eq}=67.1 \%$

\section{Calculation of land demand and availability}

Table S3.3: Data used to analyse land demand and availability.

\begin{tabular}{lll}
\hline Data & Type & Reference \\
\hline Maize yields & $\begin{array}{l}\text { Spatially explicit dataset } \\
\text { with a grid cell resolution of }\end{array}$ & Monfreda et al. (2008) \\
$10 \times 10 \mathrm{~km}\left(\mathrm{~kg} \mathrm{ha}^{-1} \mathrm{yr}^{-1}\right)$ & \\
Napier yields & Katiku et al. (2011), Weiler \\
& & $\begin{array}{l}\text { et al. (2014), Castellanos- } \\
\text { Navarrete et al. (2015) }\end{array}$
\end{tabular}


Table S3.3: continued

Feed intake literature $\left(\mathrm{kg}^{\mathrm{TLU}} \mathrm{TL}^{-1} \mathrm{yr}^{-1}\right)$

Rufino et al. (2009), Katiku et al. (2011), Herrero et al. (2013), Weiler et al. (2014), Castellanos-Navarrete et al. (2015)

Dairy cattle density

Grazing land tabular data at county level (\%), spatially explicit dataset with a grid cell resolution of $1 \times 1 \mathrm{~km}\left(\right.$ TLU km$\left.{ }^{-2}\right)$

Spatially explicit dataset Velthuizen et al. (2007)
Government of Kenya (2014), Robinson et al. (2014) with a grid cell resolution of $10 \times 10 \mathrm{~km}\left(\mathrm{ha} \mathrm{km}^{-2}\right)$

Equations (S3.1) and (S3.2) were applied to calculate land availability and the scenariospecific demand for land for each grid cell across the study area (Figure S3.1) based on data of feed intake per tropical livestock unit (TLU), fodder crop yields, and spatially explicit data on cattle density and grazing land (Table, S3.3).

$$
\text { land demand }\left(\text { ha } T L U^{-1}\right)=\sum_{i=1}^{n} \frac{\text { feed intake }_{\text {crop }_{i}}\left(k g T L U^{-1}\right)}{\text { crop yield }_{\text {crop }_{i}}\left(k g h a^{-1}\right)}
$$

land availability $\left(\right.$ ha $\left.\mathrm{km}^{-2}\right)=$ available grazing land $\left(\mathrm{ha} \mathrm{km}^{-2}\right)$

- land demand $\left(\right.$ ha $\left.T L U^{-1}\right) \times$ dairy cattle density $\left(T L U \mathrm{~km}^{-2}\right)$ 


\section{Sources of Uncertainties}

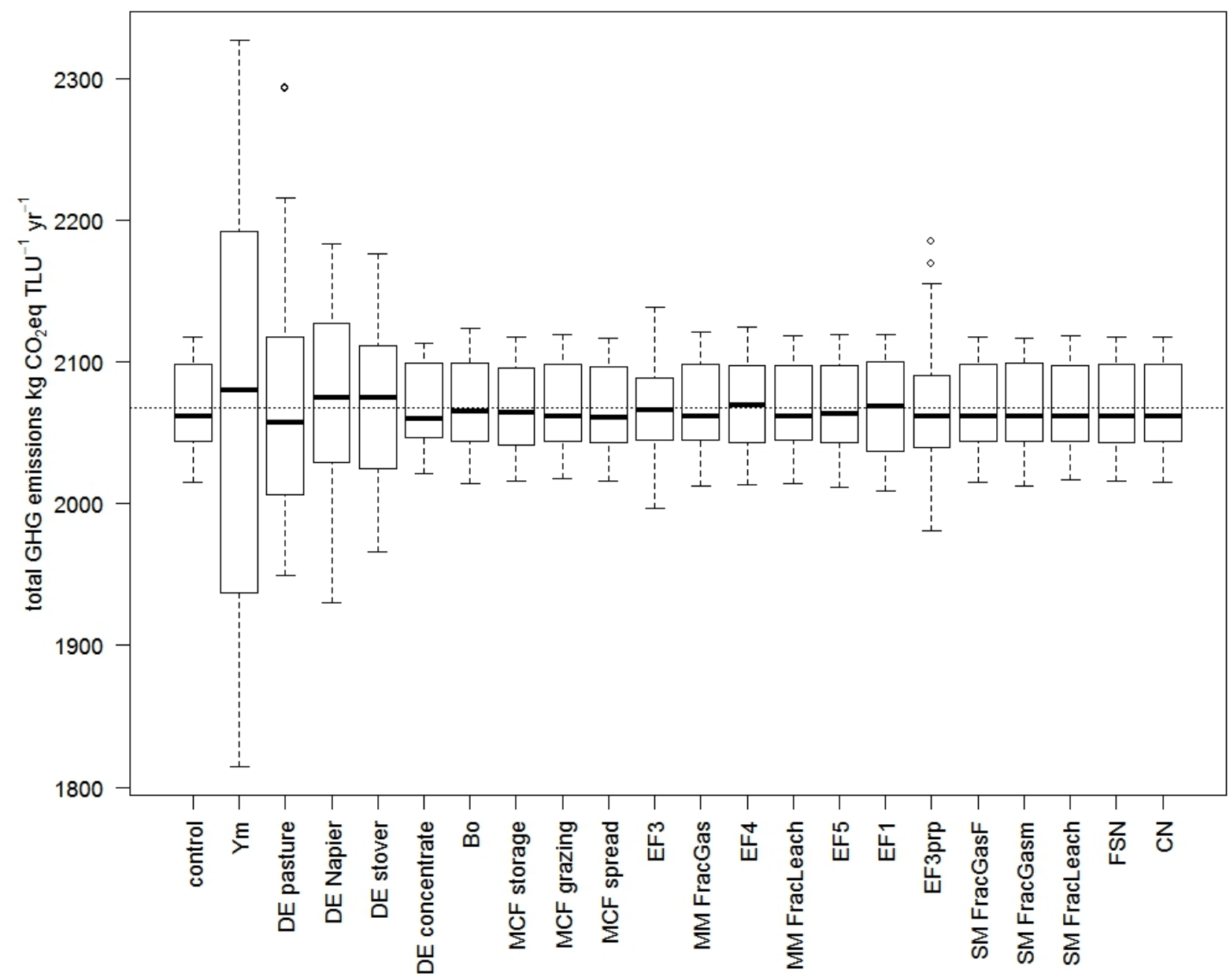

Figure S3.3: Variation in baseline total GHG emissions due to the uncertainty in applied emission parameters calculated through latin hypercube sampling derived from baseline LivSim simulations, one parameter at a time while all others were fixed at the mean of their range. Control $=$ all parameters were fixed at the mean of their range. Dashed horizontal line represents the control mean. 


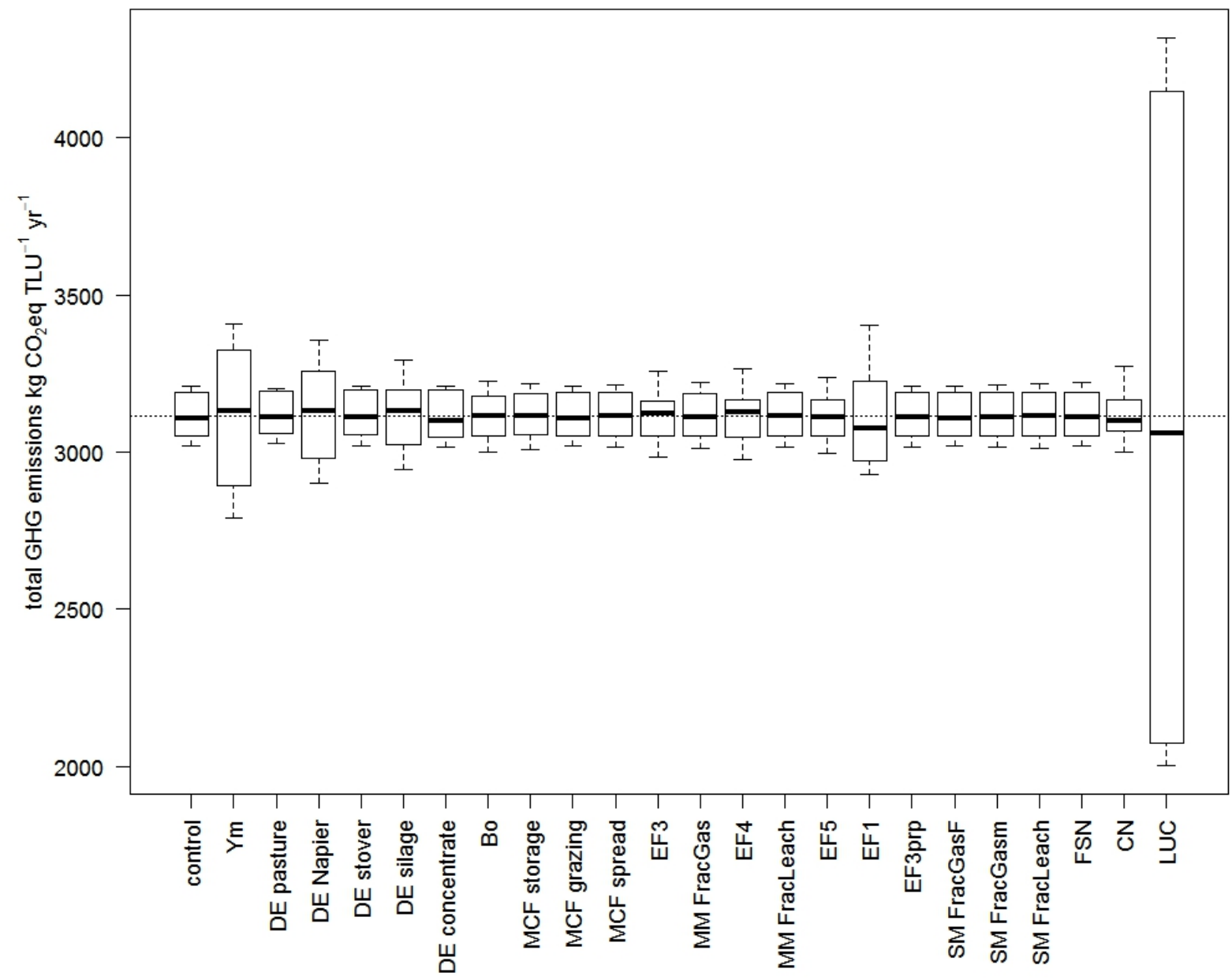

Figure S3.4: Variation of total GHG emissions shown for the scenario 'forage quality and feed conservation (FoFe)' at high level of intensification derived from LivSim simulations. The variation was caused by uncertainties in applied emission parameters calculated through sampling the minimum and maximum of each parameter range, one parameter at a time while all others were fixed at the mean of their range. Control $=$ all parameters were fixed at the mean of their range. Dashed horizontal line represents the control mean. 


\section{Appendix S4 belonging to Chapter 4 of this thesis}

\section{Data collection}

Sampling design

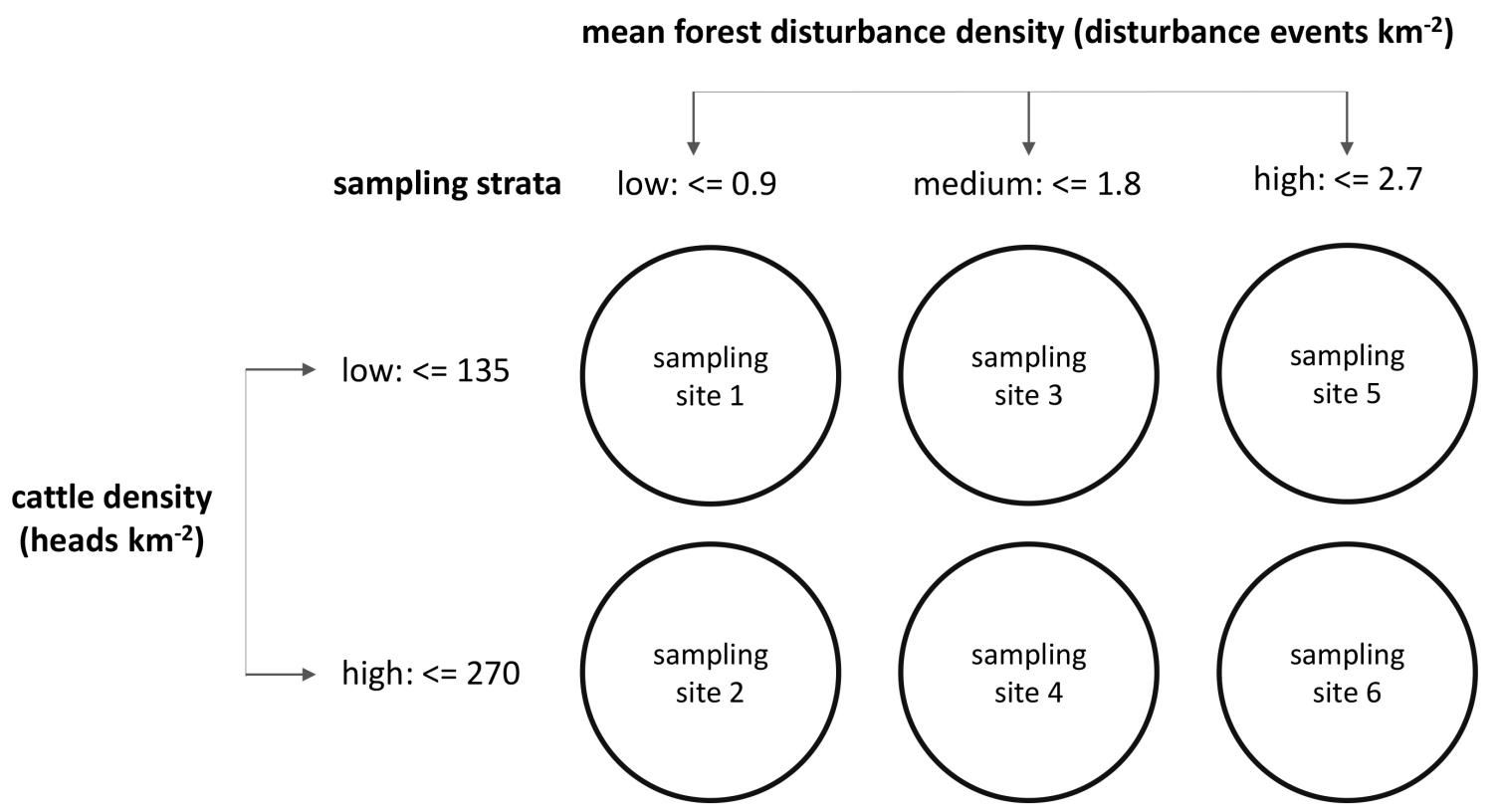

Figure S4.1: Schematic of applied stratified sampling design to collect field data through farm and forest disturbance surveys.

Collection of field data

Table S4.1: List of variables queried in the farm survey.

Category Variables

Farm animals

cattle numbers (heads)

breeds (categorical)

small ruminant numbers (heads)

Dairy production

milk yield $\left(\mathrm{kg} \mathrm{cow}^{-1}\right.$ day $\left.^{-1}\right)$

proportion of milk sold (\%)

milk buyer type (categorical)

dairy herd size (heads) 
Table S4.1: continued

Feeding

Grazing

Fodder crops

Food crops

Cash crops

Farm in general given feed type (categorical) given feed type proportions (\%) concentrate type (categorical) concentrate quantity $\left(\mathrm{kg} \mathrm{cow}^{-1}\right.$ day $\left.^{-1}\right)$ feed conservation (categorical) external feed source (categorical) external feed type (categorical)

on-farm pasture area (ha) off-farm grazing on community land (categorical)

on-farm pasture leased (categorical)

crop type (categorical)

farm area under fodder crops (ha)

feed crop sold (categorical)

fertiliser use (categorical)

crop type (categorical)

farm area under food crops (ha)

feed crop sold (categorical)

fertiliser use (categorical)

crop type (categorical)

farm area under cash crops (ha)

feed crop sold (categorical)

fertiliser use (categorical)

household size (persons)

total farm area (ha)

tress on farm (categorical) 
Table S4.2: List of variables queried in the forest disturbance survey.

\begin{tabular}{|c|c|}
\hline Variable & Value categories \\
\hline Disturbance class & $\begin{array}{l}\text { logging } \\
\text { charcoal } \\
\text { grazing } \\
\text { burned } \\
\text { windfall } \\
\text { other } \\
\text { none }\end{array}$ \\
\hline Surrounding forest type & $\begin{array}{l}\text { pristine primary forest } \\
\text { secondary successional forest } \\
\text { heavily disturbed forest } \\
\text { other } \\
\text { none }\end{array}$ \\
\hline Grazing signs & $\begin{array}{l}\text { livestock presence } \\
\text { paw prints } \\
\text { dung } \\
\text { other } \\
\text { none }\end{array}$ \\
\hline Succession type & $\begin{array}{l}\text { bare soil } \\
\text { herb layer only } \\
\text { heterogeneous shrub and herb layers } \\
\text { trees with closing canopies } \\
\text { other } \\
\text { none }\end{array}$ \\
\hline
\end{tabular}




\section{Results}

Spatial accuracy assessment

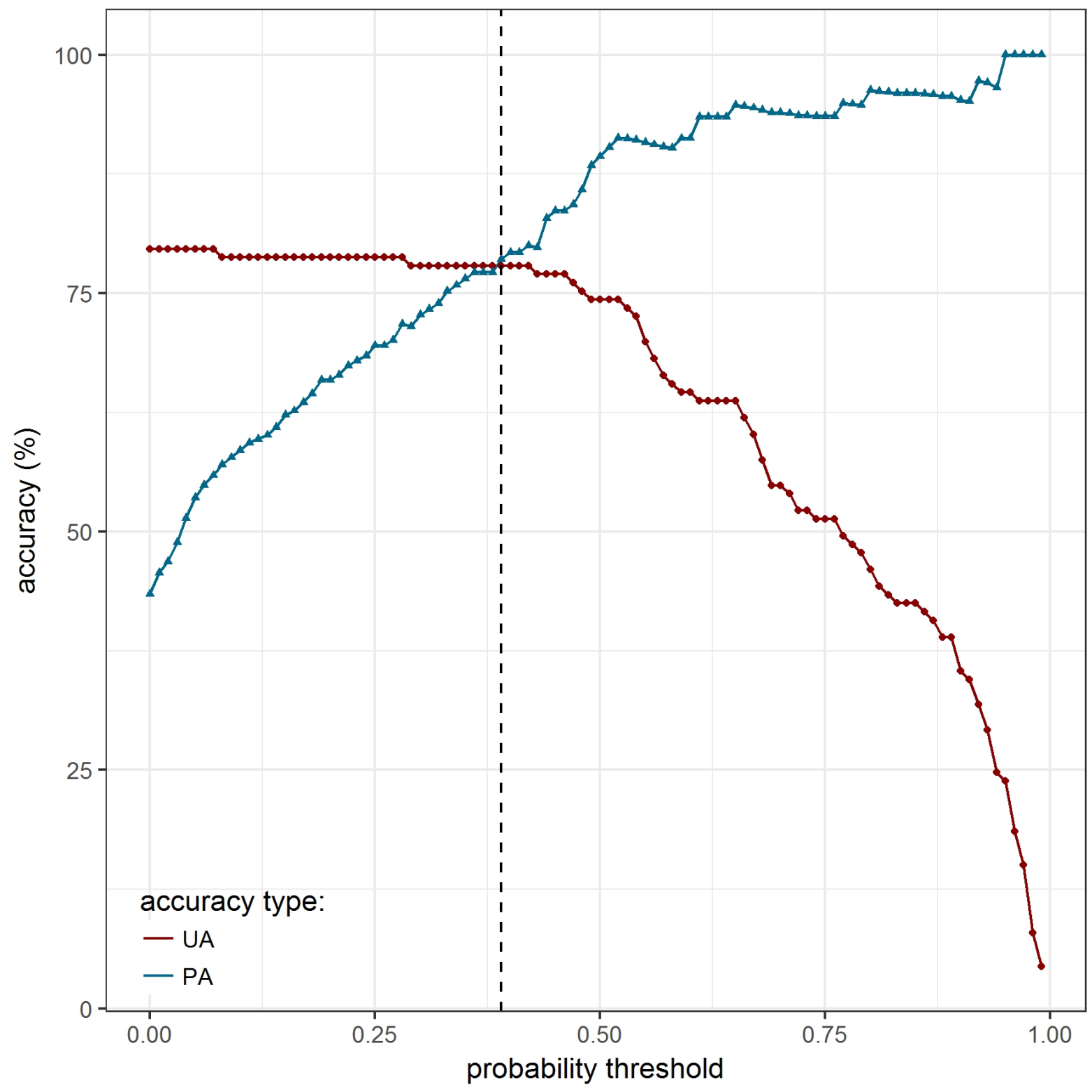

Figure S4.2: User's accuracy (UA) and producer's accuracy (PA) for disturbances detected in the Mau Forest between 2010 and 2016 across probability thresholds ranging from $0-1$. Vertical dashed line shows optimal threshold chosen based on the crossover point between UA and PA. 
Model selection

Table S4.3: Overview of GLMMs established by including farm indicators. The differences in Akaike's information criterion $(\Delta \mathrm{AIC})$ are shown in relation to final models. Indicated significance levels were derived from likelihood ratio tests of model candidates against Null models.

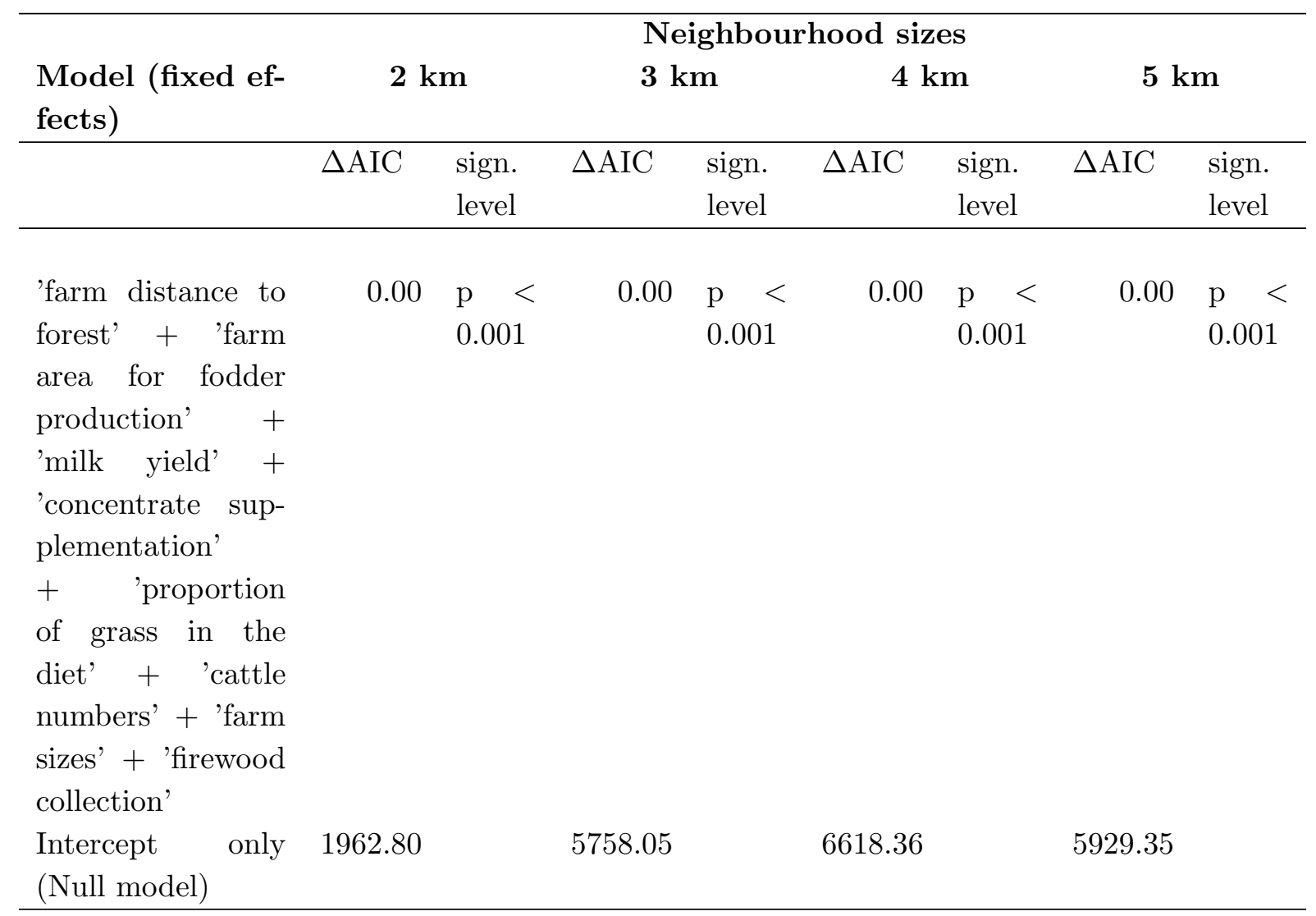


Table S4.4: Overview of GLMM selection results, including final, intermediate model candidates, and the Null models in descending order. The differences in Akaike's information criterion $(\triangle \mathrm{AIC})$ are shown in relation to final models. Indicated significance levels were derived from likelihood ratio tests of model candidates against Null models.

\begin{tabular}{|c|c|c|c|c|c|c|c|c|}
\hline \multirow{3}{*}{$\begin{array}{l}\text { Model (fixed ef- } \\
\text { fects) }\end{array}$} & \multicolumn{8}{|c|}{ Neighbourhood sizes } \\
\hline & \multicolumn{2}{|c|}{$2 \mathrm{~km}$} & \multicolumn{2}{|c|}{$3 \mathrm{~km}$} & \multicolumn{2}{|c|}{$4 \mathrm{~km}$} & \multicolumn{2}{|c|}{$5 \mathrm{~km}$} \\
\hline & $\Delta \mathrm{AIC}$ & $\begin{array}{l}\text { sign. } \\
\text { level }\end{array}$ & $\Delta \mathrm{AIC}$ & $\begin{array}{l}\text { sign. } \\
\text { level }\end{array}$ & $\Delta \mathrm{AIC}$ & $\begin{array}{l}\text { sign. } \\
\text { level }\end{array}$ & $\Delta \mathrm{AIC}$ & $\begin{array}{l}\text { sign. } \\
\text { level }\end{array}$ \\
\hline 'farm type' + & 0.00 & $\mathrm{p}<$ & 0.00 & $\mathrm{p}<$ & 0.00 & $\mathrm{p}<$ & 0.00 & $\mathrm{p}<$ \\
\hline $\begin{array}{l}\text { 'farm distance to } \\
\text { forest' }+ \text { 'farm } \\
\text { type' } \mathrm{x} \text { 'farm } \\
\text { distance to forest' }\end{array}$ & & 0.001 & & 0.001 & & 0.001 & & 0.001 \\
\hline $\begin{array}{l}\text { 'farm type' }+ \\
\text { 'farm distance to } \\
\text { forest' }\end{array}$ & 125.04 & $\begin{array}{l}\mathrm{p}< \\
0.001\end{array}$ & 124.22 & $\begin{array}{l}\mathrm{p}< \\
0.001\end{array}$ & 224.65 & $\begin{array}{l}\mathrm{p} \quad< \\
0.001\end{array}$ & 280.07 & $\begin{array}{l}\mathrm{p} \quad< \\
0.001\end{array}$ \\
\hline 'farm type' & 824.84 & $\begin{array}{l}\mathrm{p}< \\
0.001\end{array}$ & 2794.87 & $\begin{array}{l}\mathrm{p}< \\
0.001\end{array}$ & 2960.12 & $\begin{array}{l}\mathrm{p}< \\
0.001\end{array}$ & 3402.49 & $\begin{array}{l}\mathrm{p}< \\
0.001\end{array}$ \\
\hline $\begin{array}{l}\text { Intercept only } \\
\text { (Null model) }\end{array}$ & 1200.82 & & 3860.39 & & 3844.11 & & 3816.37 & \\
\hline
\end{tabular}

Table S4.5: Overview of GLMM selection results, including final models and Null models in descending order. The differences in Akaike's information criterion ( $\triangle \mathrm{AIC})$ are shown in relation to final models. Indicated significance levels were derived from likelihood ratio tests of model candidates against Null models.

\begin{tabular}{|c|c|c|c|c|c|c|c|c|}
\hline \multirow{3}{*}{ Model (fixed effects) } & \multicolumn{8}{|c|}{ Neighbourhood sizes } \\
\hline & \multicolumn{2}{|c|}{$2 \mathrm{~km}$} & \multicolumn{2}{|c|}{$3 \mathrm{~km}$} & \multicolumn{2}{|c|}{$4 \mathrm{~km}$} & \multicolumn{2}{|c|}{$5 \mathrm{~km}$} \\
\hline & $\Delta \mathrm{AIC}$ & $\begin{array}{l}\text { sign. } \\
\text { level }\end{array}$ & $\Delta \mathrm{AIC}$ & $\begin{array}{l}\text { sign. } \\
\text { level }\end{array}$ & $\Delta \mathrm{AIC}$ & $\begin{array}{l}\text { sign. } \\
\text { level }\end{array}$ & $\Delta \mathrm{AIC}$ & $\begin{array}{l}\text { sign. } \\
\text { level }\end{array}$ \\
\hline 'farm type' & 0.00 & $\begin{array}{l}\mathrm{p}< \\
0.01\end{array}$ & 0.00 & $\begin{array}{l}\mathrm{p}< \\
0.001\end{array}$ & 0.00 & $\begin{array}{l}\mathrm{p}< \\
0.001\end{array}$ & 0.00 & $\begin{array}{l}\mathrm{p}< \\
0.001\end{array}$ \\
\hline $\begin{array}{l}\text { Intercept only (Null } \\
\text { model) }\end{array}$ & 9.75 & & 17.30 & & 12.13 & & 11.90 & \\
\hline
\end{tabular}




\section{Acknowledgements}

Doing a PhD was not only a big step in my life but also brought me many valuable experiences. I am very grateful to all the people that I met during this time, who contributed to this achievement.

In particular, I would like to thank wholeheartedly my promotor Martin Herold and copromotors Mariana Rufino and Jan Verbesselt. Mariana gave me the chance to work on a very interesting topic of high societal relevance. During the time of the $\mathrm{PhD}$, I got the opportunity to work in various, excellent research environments in different countries, which extended my intellectual horizon and brought me numerous, precious insights. She always provided excellent and inspiring inputs during the many discussions we had and supported my work tremendously. I would like to deeply thank Martin, who took me on board of his GIS and remote sensing lab, which has been a stimulating place to exchange ideas and to collaborate with as well as learn from, extremely nice, scientists. He provided a great deal of illuminating ideas, guidance and support, which helped me to shape the $\mathrm{PhD}$ further. I would like to express my gratitude to Jan for his valuable support of my work and the helpful discussions we had.

A big thanks, I would like to express to my past and present $\mathrm{PhD}$ fellows, including Agnieszka, Alvaro, Anne, Astrid, Ben, Beni, Dainius, Diego, Eliakim, Eskender, Gustavo, Jalal, Jose, Kalkidan, Konstantin, Lieneke, Marian, Marston, Mathieu, Michi, Nandika, Niki, Peter, Qijun, Sabina, Samantha, Sarah, Shivangi, Simon and Yang for the fun time during the PhD. You are a nice bunch of people, folks! I am very grateful to my two paranymphs Daniela and Meckie. My thanks also goes to the former and present staff of the research group, including Aldo, Antoinette, Arend, Arnold, Arun, Brice, Christelle, Corne, Danaë, Devis, Erika R, Erika S, Harm, Jan C, Joao, Johannes, John, Lammert, Lukasz, Marcello, Ron, Sylvain, Sytze, Truus, Valerio and Willy for the valuable support during the time in Wageningen.

Moreover, I'd like to thank the CIFOR staff, including Christopher, Esther, George, Paolo and Rosa for their crucial support and the interesting discussions, the Kenyan field staff, namely Edmund, Edwin and Victorine for the great work during the field surveys. I am especially thankful to Cristina, James, Suzanne and Victoria for the nice time in Kenya. 
A special thanks goes to my family: Christoph, Frank, Hanna, Heike, Inge, Karsten and Mandy for providing a great deal of support during this special time.

I'd like to thank Larisa for truly being a jewel of a soul and the time we spent together. It felt very sweet to get some distraction from the $\mathrm{PhD}$ life.

I would like to give my thanks to my long and good friends Anna and Steven for being there when I needed them. Thank you so much! 


\section{About the author}

Patric Brandt was born in Salzwedel, Germany on September 24, 1980. Between 1997 and 2005, he worked as a land surveyor and IT specialist. Patric graduated in 2008 with a Bachelor of Science in Environmental Sciences at Leuphana University (Lüneburg, Germany). In 2010, he completed his Master of Science in Sustainability Sciences at Leuphana University (Lüneburg, Germany).

Patric worked on various research projects between 2011 and 2013 at Leuphana University (Lüneburg, Germany). His main projects dealt with ecological impacts of the Chernobyl nuclear accident and the use of transdisciplinary research approaches in sustainability science. He was engaged in the 'Rapid Assessment of the Yale framework and Adaptation Blueprint' for the North American Pacific Coastal Rainforest to integrate climate adaptation and landscape conservation planning (coordinated by the Yale School of Forestry \& Environmental Studies) and assessed linkage patterns between ecosystem services and biodiversity across temperate rainforests of the Pacific Northwest region (USA). Moreover, he participated in several ecological modelling studies during this time.

In 2014, Patric started his $\mathrm{PhD}$ thesis entitled 'Climate-smart livestock production at landscape level in Kenya' funded by the CGIAR program on 'Climate Change, Agriculture and Food Security' (CCAFS) and the IFAD project 'Greening livestock: Incentive-based interventions for reducing the climate impact of livestock production in East Africa'. During his $\mathrm{PhD}$, he has been working with various research and development organisations such as the Institute of Meteorology and Climate Research - Atmospheric Environmental Research (IMK-IFU) in Garmisch-Partenkirchen (Germany), which is part of the Karlsruhe Institute of Technology (KIT), the International Livestock Research Institute (ILRI) and the Center for International Forestry Research (CIFOR) in Nairobi (Kenya). In 2016, he came to the Netherlands to continue his PhD at the Laboratory of Geo-information Science and Remote Sensing (Wageningen University \& Research).

Patric's current research interests include the impact of climate change on biodiversity and ecosystems services, climate change adaptation and mitigation, interactions between land use practices and forest ecosystems, and sustainable land use patters. 


\section{Peer-reviewed journal publications}

Brandt, P., Hamunyela, E., Herold, M., de Bruin, S., Verbesselt, J., Rufino, M.C., 2018. Sustainable intensification of dairy production can reduce forest disturbance in Kenyan montane forests. Agriculture, Ecosystems \& Environment 265, 307-319. https://doi.org/10.1016/j.agee.2018.06.011

Brandt, P., Herold, M., Rufino, M.C., 2018. The contribution of sectoral climate change mitigation options to national targets: a quantitative assessment of dairy production in Kenya. Environmental Research Letters 13, 034016. https://doi.org/10.1088/1748$9326 /$ aaac 84

Brandt, P., Kvakić, M., Butterbach-Bahl, K., Rufino, M.C., 2017. How to target climate-smart agriculture? Concept and application of the consensusdriven decision support framework "targetCSA." Agricultural Systems 151, 234-245. https://doi.org/10.1016/j.agsy.2015.12.011

Arias-Navarro, C., Díaz-Pinés, E., Klatt, S., Brandt, P., Rufino, M.C., ButterbachBahl, K., Verchot, L.V., 2017. Spatial variability of soil N2O and CO2 fluxes in different topographic positions in a tropical montane forest in Kenya. Journal of Geophysical Research: Biogeosciences 122, 514-527. https://doi.org/10.1002/2016JG003667

Plath, M., Moser, C., Bailis, R., Brandt, P., Hirsch, H., Klein, A.-M., Walmsley, D., von Wehrden, H., 2016. A novel bioenergy feedstock in Latin America? Cultivation potential of Acrocomia aculeata under current and future climate conditions. Biomass and Bioenergy 91, 186-195. https://doi.org/10.1016/j.biombioe.2016.04.009

Drees, C., Husemann, M., Homburg, K., Brandt, P., Dieker, P., Habel, J.C., von Wehrden, H., Zumstein, P., Assmann, T., 2016. Molecular analyses and species distribution models indicate cryptic northern mountain refugia for a forest-dwelling ground beetle. Journal of Biogeography 43, 2223-2236. https://doi.org/10.1111/jbi.12828

Brandt, P., Abson, D.J., DellaSala, D.A., Feller, R., von Wehrden, H., 2014. Multifunctionality and biodiversity: Ecosystem services in temperate rainforests of the Pacific Northwest, USA. Biological Conservation 169, 362-371. https://doi.org/10.1016/j.biocon.2013.12.003

Rufino, M.C., Brandt, P., Herrero, M., Butterbach-Bahl, K., 2014. Reducing uncertainty in nitrogen budgets for African livestock systems. Environmental Research Letters 9. https://doi.org/10.1088/1748-9326/9/10/105008

Zhou, M., Brandt, P., Pelster, D., Rufino, M.C., Robinson, T., Butterbach-Bahl, K., 2014. Regional nitrogen budget of the Lake Victoria Basin, East Africa: Syntheses, uncertainties and perspectives. Environmental Research Letters 9, 105009. https://doi.org/10.1088/1748-9326/9/10/105009 
Homburg, K., Brandt, P., Drees, C., Assmann, T., 2014. Evolutionarily significant units in a flightless ground beetle show different climate niches and high extinction risk due to climate change. Journal of Insect Conservation 18, 781-790. https://doi.org/10.1007/s10841-014-9685-x

Zimmermann, H., Brandt, P., Fischer, J., Welk, E., von Wehrden, H., 2014. The Human Release Hypothesis for biological invasions: Human activity as a determinant of the abundance of invasive plant species [version 2; referees: 2 approved]. F1000Research 3, 1-13. https://doi.org/10.12688/f1000research.3740.1

Brandt, P., Ernst, A., Gralla, F., Luederitz, C., Lang, D.J., Newig, J., Reinert, F., Abson, D.J., Von Wehrden, H., 2013. A review of transdisciplinary research in sustainability science. Ecological Economics 92, 1-15. https://doi.org/10.1016/j.ecolecon.2013.04.008

DellaSala, D.A., Brandt, P., Koopman, M., Leonard, J., Meisch, C., Herzog, P., Alaback, P., Goldstein, M.I., Jovan, S., MacKinnon, A., von Wehrden, H., 2013. Climate Change May Trigger Broad Shifts in North America's Pacific Coastal Rainforests. Reference Module in Earth Systems and Environmental Sciences 2, 233-244. https://doi.org/10.1016/B978-0-12-809665-9.09367-8

von Wehrden, H., Fischer, J., Brandt, P., Wagner, V., Kümmerer, K., Kuemmerle, T., Nagel, A., Olsson, O., Hostert, P., 2012. Consequences of nuclear accidents for biodiversity and ecosystem services. Conservation Letters 5, 81-89. https://doi.org/10.1111/j.1755263X.2011.00217.x 



\section{PE\&RC Training and Education Statement}

With the training and education activities listed below the $\mathrm{PhD}$ candidate has complied with the requirements set by the C.T. de Wit Graduate School for Production Ecology and Resource Conservation (PE\&RC) which comprises of a minimum total of 32 ECTS (= 22 weeks of activities)

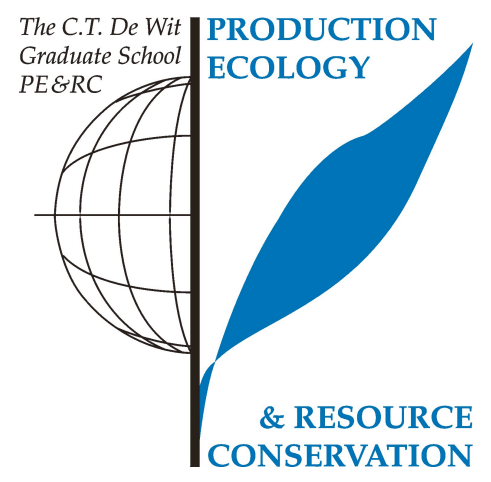

Review of literature (6 ECTS)

- Targeting climate-smart agricultural (CSA) practices

\section{Writing of project proposal (4.5 ECTS)}

- Development of targeting and planning approaches for climate-smart landscapes linking agriculture and forests in Kenya

\section{Post-graduate courses (4.9 ECTS)}

- Summer school - climate-smart agriculture: from fundamentals to application; PE\&RC (2016)

- R and Big Data; PE\&RC (2017)

- Multivariate analysis; Biometris (2017)

- Design of experiments; WIAS/PE\&RC (2018)

\section{Laboratory training and working visits (5 ECTS)}

- Developing a decision support framework to target climate-smart agriculture; International Livestock Research Institute - ILRI, Nairobi, Kenya (2014-2015)

- Modelling of GHG emissions from smallholder dairy production in Kenya, including mitigation options; Karlsruhe Institute of Technology - KIT, GarmischPartenkirchen, Germany (2015-2016) 


\section{Invited review of (unpublished) journal manuscript (2 ECTS)}

- Agriculture, Ecosystems \& Environment: climate change mitigation in smallholder agriculture (2017)

- Agricultural systems: priority setting in research for climate-smart research (2018)

Deficiency, refresh, brush-up courses (1.5 ECTS)

- Spatial modelling and statistics; Laboratory of GIS \& remote-sensing (2016)

Competence strengthening / skills courses (2.1 ECTS)

- Ethics of science course; Leuphana University Lüneburg, Germany (2010-2011)

- Scientific writing; Wageningen in'to Languages (2018)

- Research data management; Wageningen University \& Research Library (2018)

PE\&RC Annual meetings, seminars and the PE\&RC weekend

\section{(1.2 ECTS)}

- PE\&RC PhD Weekend (2016)

- PE\&RC Day (2017)

Discussion groups / local seminars / other scientific meetings (4.6 ECTS)

- CSA Webinar with CGIAR scientists and other national and international research organisations; oral presentation (2015)

- CSA Workshops in Nairobi with CGIAR scientists and other national and international research organisations; oral presentations (2015-2016)

- Meetings and discussions with CGIAR scientists and other national and international research organisations; oral presentations (2015-2017)

- REDD+/CSA Discussion group at WUR; oral presentation (2016-2018)

International symposia, workshops and conferences (5 ECTS)

- International conference on global food security; oral presentation; Cape town, South Africa (2017)

- International conference on remote sensing and geoinformation of the environment; oral presentation; Paphos, Cyprus (2018)

Supervision of MSc student (1 ECTS)

- GHG emissions of smallholder dairy production in Tanzania 

The research conducted for this $\mathrm{PhD}$ thesis received funding from the CGIAR program on 'Climate Change, Agriculture and Food Security' (CCAFS) and the IFAD project 'Greening livestock: Incentive-based interventions for reducing the climate impact of livestock production in East Africa'. The financial support from Wageningen University \& Research for printing this PhD thesis is gratefully acknowledged.

Cover image: Google, Landsat / Copernicus

Printed by ProefschriftMaken, www.proefschriftmaken.nl 